FORM FOLLOWS FOOD

\title{
An Examination of Architecture's Role in Urban Farming
}

by OLIVIA FONG 



\title{
FOR M FOLLOWS FOOD
}

\section{AN EXAMINATION OF ARCHITECTURE'S ROLE IN URBAN FARMING}

\author{
BY
}

OLIVIA FONG
A 120-point thesis submitted to the Victoria University of Wellington in partial fulfilment of the requirements for the degree in
Master of Architecture (Professional)

Victoria University of Wellington 


\section{ABSTRACT}

With rising global urban populations, existing food infrastructure systems are rapidly becoming unsustainable. Increasing distances between rural food production and urban residents extends to a conceptual divide and misguided understanding of what activities ought to be classed as 'rural' versus 'urban'. Some of those looking for alternative solutions note food's potential to act as an organiser of urban systems and catalyst for sustainable living. However the concept of sustainability is often sidelined in photorealistic renders where designs are decorated with organic matter, designs that are unlikely to be viable. Tapping into food's potential and with the readily available space of urban rooftops, the thesis explores rooftop urban farming to speculate the opportunities it presents in the city of Wellington, New Zealand. In relation to this important social, economic and ecological infrastructure, the thesis investigates how the potential for urban farming, from production to trading and consumption contributes to a sense of place through architectural interpretation. While widening the discussions of food and the city, architecture provides the built accommodation for both plants and people, so that the 'urban future' can be reevaluated. 


\section{ACKNOWLEGEMENTS}

Thank you to everyone who has supported me not only during the production of this thesis but throughout my five years of study at Victoria University. The completion of this work would not have been possible without your invaluable guidance. A special mention to the following people:

To my parents - words cannot express my gratitude for the sacrifices you have made for your children. It is because of your desire for us to have a better quality of life that we are able to undertake tertiary study as the first generation in our family, you have always put our needs before yours. I sincerely thank you for your continual love and support during my 26 years on this earth.

To my friends Hana and Loren - you two have contributed to some of the happiest memories of my time at university, and in life. Needless to say, it wouldn't have been the same without you. Thank you for your friendship, love and encouragement.

To my friend Takeshi, thank you for the architecture/ thesis rants that I clearly needed throughout the year. I'm looking forward to joining you in the 'grown-up-architect' working life.

Lastly, to my thesis supervisor Morten Gjerde - thank you for your insightful advice and utmost positivity. You have provided fantastic direction whenever it was sought but have methodically allowed this thesis to be my own work. 
CONTENTS

$\begin{array}{ll}\text { ABSTRACT } & 05\end{array}$

$\begin{array}{ll}\text { ACKNOWLEDGEMENTS } & 07\end{array}$

$\begin{array}{ll}\text { [1.0] INTRODUCTION } & 11\end{array}$

[2.0] RESEARCH METHODOLOGY 15

[3.0] LITERATURE REVIEW 17

[4.0] PRECEDENT STUDIES 31

4.1 Urban Agriculture 32

4.2 Rooftop Additions $\quad 40$

4.3 Elevated Landscapes 42

4.4 Production as Performance 44

[5.0] SITE 47

5.1 Macro 48

5.2 Intermediate 52

$\begin{array}{lll}5.3 & \text { Micro } & 62\end{array}$

$\begin{array}{ll}\text { [6.0] DESIGN } & 67\end{array}$

6.1 Design Criteria 68

6.2 Preliminary 70

$\begin{array}{lll}6.3 & \text { Developed } & 100\end{array}$

$\begin{array}{lll}6.4 & \text { Final } & 120\end{array}$

[7.0] CONCLUSION 145

LIST OF FIGURES 148

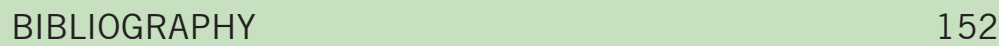




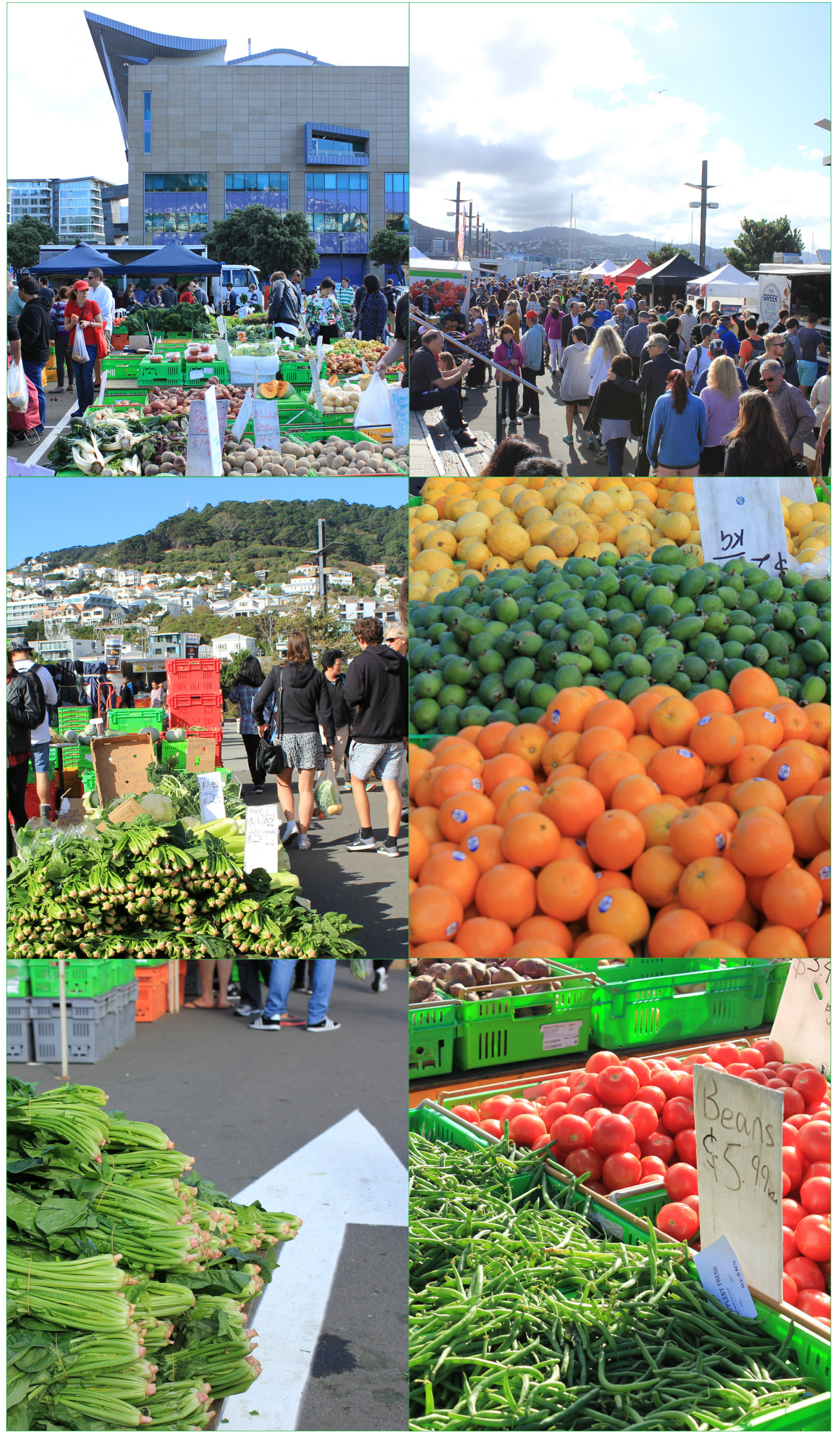




\section{[1.0] \\ INTRODUCTION}

On any given day, the discussion of food for most urban residents predominantly centres around the consumption of it - an unsurprising revelation, given that urban 'food spaces' are largely attributed to the increasing array of cafes and restaurants in city centres. Undoubtedly, this is important in fostering urban life, but does little in raising awareness of impending concerns that are primarily associated with the beginning and the end of the food cycle - that is, its production and waste stages. In the past century, rapid urbanization came with it an increased travelling distance between city centres and rural farmland, along with the amount of food that goes to the wasteland. This extends to a conceptual divide between what activities ought to be classed as rural versus urban as reflected in attidudes toward food among urban dwellers. Due to the complexities within each phase of the food cycle, this thesis principally addresses its production phase through the design and urban integration of a commercial vegetable farm in the heart of Wellington City, New Zealand.

The rationale behind urban farming has its merits, but the practice of it has met a fair level of criticism - of its viability concerning economic value, energy use, produce quality and quantity along with other concerns that altogether question its sustainable advantages. Though there are a number of steadily thriving urban farms in developed countries, its overall contribution seems to be outweighed by the many problems it faces.

Architecture's response to the topic often depicts blue-sky proposals to address the issue, though this approach is often the limitation as visionary designs are unlikely viable due to real-world constraints. On the contrary, examples of urban farms that do exist tend to give very little attention to architecture, the low priority being somewhat justified as spaces are optimized for plants, not people. But with the introduction of farming in developed cities, this demands a reinterpretation of the farm - as well as what it means to be 'urban' in the search for a sustainable future. Urban residents need to recognise their responsibility in the food cycle and and architecture could have a role in supporting this. This prompts the following research question for the investigation:

How can architecture help diversify food space through the introduction of urban farming, breaking down the conceptual divide between urban versus rural?

Like many urban centres, Wellington boasts a number of underutilized rooftops. Of particular focus in this investigation are larger scale rooftops, being a logical starting point in that they can accommodate more growing space. For this investigation, a greenhouse will be proposed as a rooftop addition to house the urban farm. Figure 1.1 shows potential rooftops in Wellington's inner city suburb of Te Aro, based on a visual inspection of an ariel map.

\section{Aim}

The implications of accomodating an urban farm in an already compact city suggests it will not only impact the physicalities of the immediate site, but also the wider context concerning its social, cultural, economic and environmental dimensions. The comprehension of this is fundamental and provides direction for research into literature, precedent and site studies. Ultimately, the design outcome should not solely amount to an 'architectural masterpiece' of an urban farm, but ensure it is thoughtfully integrated within the immediate and wider context of Wellington to communicate the inherent connection between food and place. 


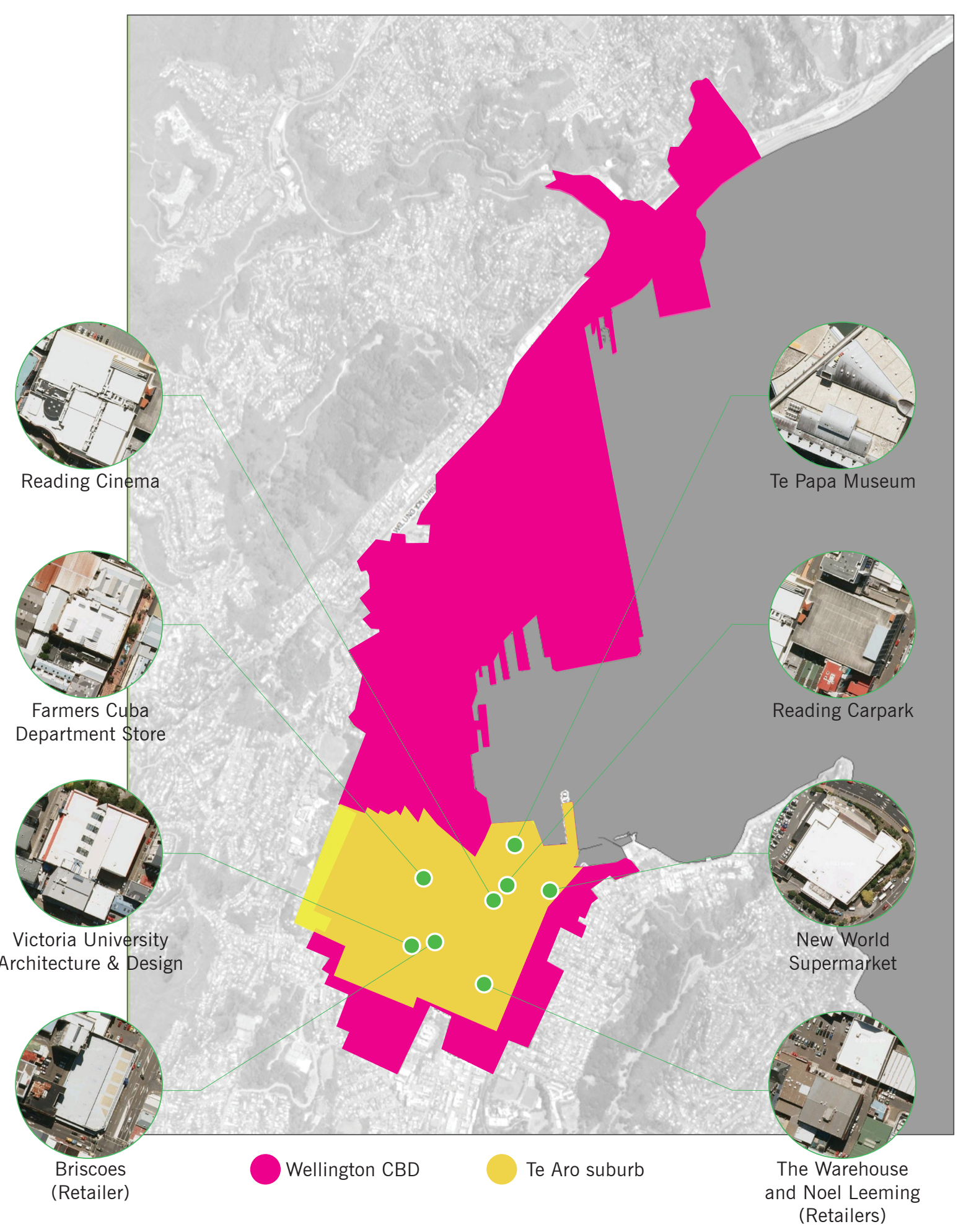

Fig. 1.1: Large scale rooftops in Wellington's inner city suburb Te Aro. 


\section{Scope}

The thesis will undertake research through design of an urban rooftop farm and of its contextual integration towards the formation of an architectural proposal. The thesis acknowledges that in the current day, the realities of such a project would face limitations in being architecturally realized and in truth urban farming is a broad topic consisting numerous areas of study. The design chapter therefore takes the form of a case study where there is a fine balance between the 'real' and the 'visionary'. The 'real' is informed by the practice of existing urban farms while the 'visionary' draws inspiration from academic works emerging from the architectural discourse.

\section{Thesis Outline}

The thesis totals seven chapters. Following is chapter two, the Research Methodology shown diagrammatically to illustrate the rationale behind the investigative process. Chapter three is a Literature Review where key themes are explored to reinforce understanding of the research. Following this, chapter four's Precedent Studies analyzes a broad range of projects under a variety of themes considered important for the case study. Chapter five covers analyses of the Site from a macro to micro level. This is then followed by chapter six's Design, separated into three phases and constituting a large portion of the thesis. Finally the Conclusion chapter consists of an exegesis, further development and summary of the overall investigation. Further details can be seen in the following chapter. 


\section{RESEARCH QUESTION}

How can architecture help diversify food space through the introduction of urban farming, breaking down the conceptual divide between urban vs. rural?

(And what does this mean for a place-making opportunity?)

\section{LITERATURE REVIEW}

\begin{tabular}{l}
\multicolumn{1}{c|}{ Food Space } \\
- media's portrayal \\
- consequences \\
of obsession with \\
consumption \\
- visibility of the food \\
system
\end{tabular}

\section{KEY THEMES}

Urb. Farming + Architecture
- historical and current
practices
- technology
- architectural interpretation
- rooftops as site opportunity

\begin{tabular}{|l|}
\hline \multicolumn{1}{c|}{ Food + Identity } \\
- supermarket critique \\
- markets as identifying \\
with local produce \\
- spectacle in the \\
preparation of food \\
- ethnic food enclaves
\end{tabular}

Urban Farm as Place - urban place theory - image / form / activity "good" place-making to design for urban quality

\section{PRECEDENT STUDIES}

\section{Urban Agriculture} - commercial farms - technologies involved - speculative architectural proposals

\section{INFORMING DESIGN FRAMEWORK}

Rooftop Additions
- shape + form
- relationship to existing
building

\begin{tabular}{|l|} 
Elevated Landscapes \\
- contextual design \\
- mixed use \\
- place
\end{tabular}

Production as Performance - business objectives - enhanced consumer experience - architecture's role to support this

\section{SITE STUDIES}

Macro
- urban scale analysis
- urban form
- city topography
- urban connections
- site history

\section{DESIGN}

Design Framework - set out by literature, precedent and site studies - used as reference for measure / evaluation

\section{CONCLUSION}

\section{CONTEXTUAL CONSIDERATIONS}

Intermediate
- areas surrounding
rooftop site
- access
- view corridors
- culture
- businesses

- Micro
- rooftop selection: the
host building itself
- structure / materials
(building archives)
- form / orientation
- lighting

\section{THE PROPOSAL}

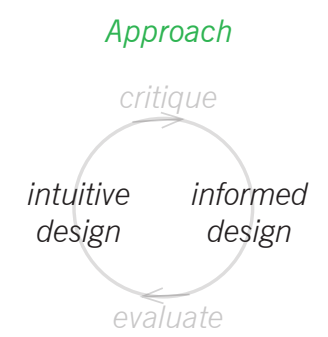

1. preliminary
2. developed
final

\section{CLOSING THOUGHTS}

Reflection \& Summary
- findings / has the research question been answered?
- limitations of project / future development - "where to?" from here
- design process - how was it?
- final summary




\title{
[2.0]
}

RESEARCH METHODOLOGY

\begin{abstract}
The research methodology as set out will be an essential guideline for the investigation. Nevertheless, it allows room for unexpected findings that may steer the research onto a different (yet valuable) path, prompting further questioning. This ensures the investigation not only addresses the research question but considers its implications, being open to a wider discussion if necessary.
\end{abstract}

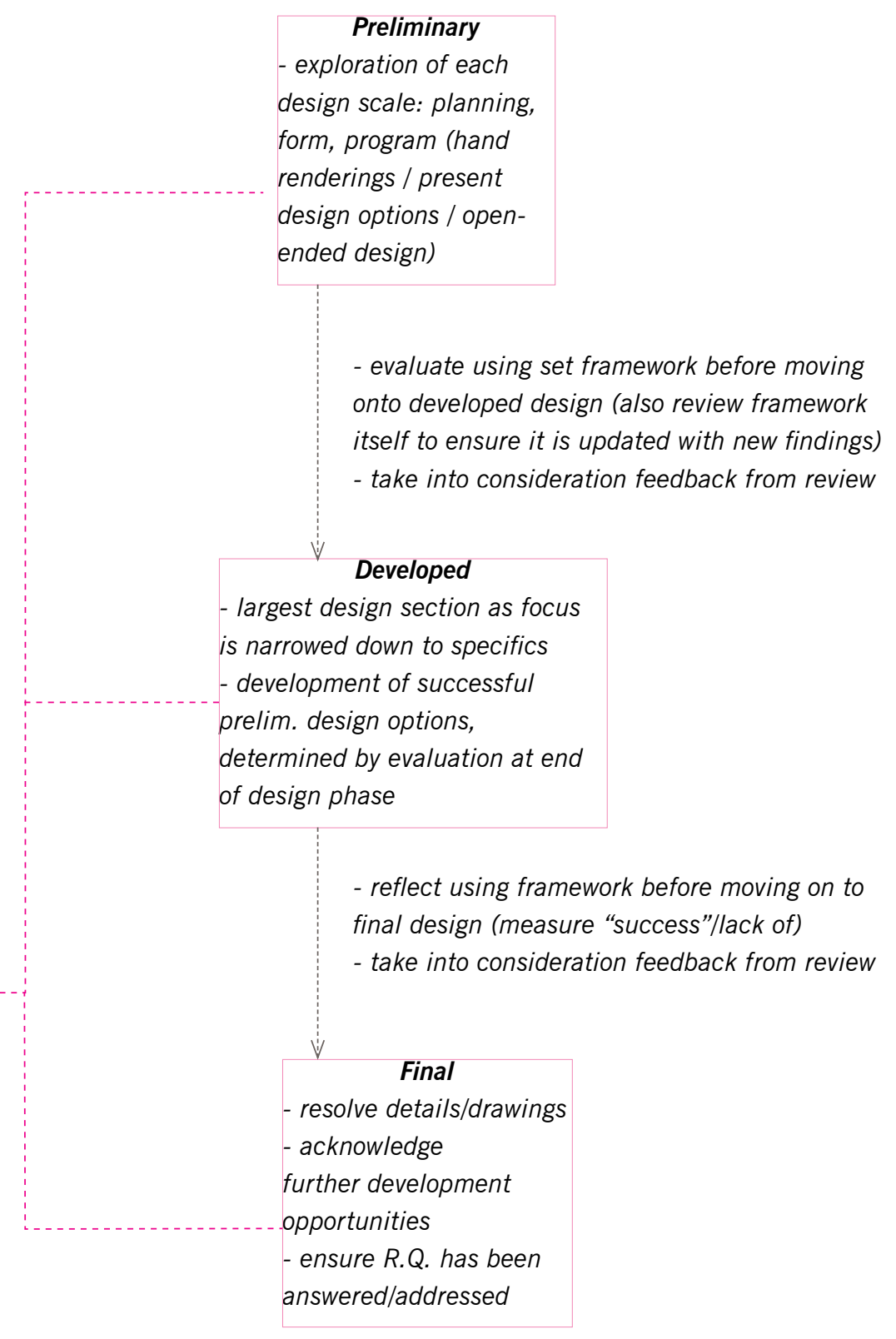




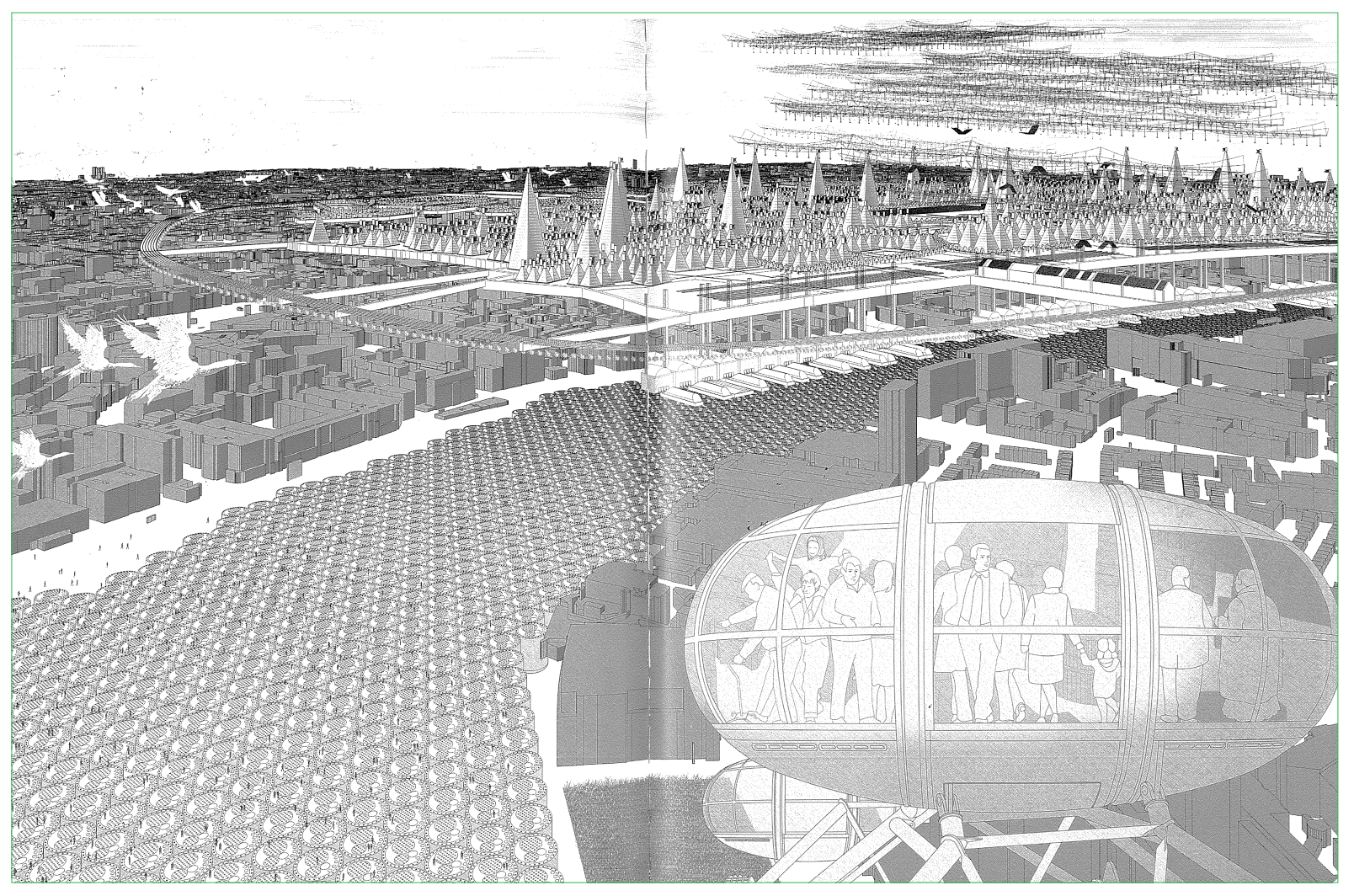

Fig. 3.0: Rendering of Lim's visionary proposal for The Food

Parliament of London 2080. 
Food can be considered a universal language, a form of dialogue. But the full cycle of food is not always understood or accepted in urbanised areas because of preconceptions around those activities considered either rural and urban. Steel's Hungry City speaks of an 'urban paradox' in drawing attention to the failure of cities to recognize that they remain reliant on the land for their sustenance. Conversations around food and the city often centre on consumption - the buying and eating of food at tempting new stores, along with the fashionable 'foodie' culture that has emerged. Seldom discussed are the production or waste stages of the food cycle. On the one hand, food is glamourized and celebrated as it is being consumed while on the other, its full cycle is discussed in some kind of "shock horror exposé" (Steel 4). The framing of contemporary urban food culture suggests that some activities are less worthy for discussion, possibly because of the near invisibility of a sustainable food system in the urban environment altogether.

Dining out can be a pleasurable experience, evidence in most cultures of a prosperous lifestyle and helping to foster streetlife. The presence of food can often generate a feeling of intimacy between people (Franck, The Space of Food 5) and helping link people to public spaces. Public eateries are important urban 'third' places; semi-public places of refreshment where one can visit regularly to linger and socialize (Oldenburg). It seems that public eateries have grown to become expected in all urban settings, whether for gathering socially or for convenience.

The idea of bringing a complete food system into cities - from its production to the way it is ultimately disposed - has begun to emerge as a common theme across multiple disciplines. In architecture for example, the design and planning of urban systems has begun to see food as a potent element. Urban farming is often seen as the foundation for such design constructs, though many projects remain speculative due to lack of financial feasibility. On the other hand, urban farming that has been established is often utilitarian in nature, placing little emphasis on architectural design. Examples include commercial rooftop greenhouses, which are designed to create optimal growing conditions but which generally contribute little to the surrounding cityscape. The relationship between urban farms and urban centres is consequently undervalued, a missed opportunity to enrich cities with an identity of a local sustainable food culture.

This literature review explores the potential for farming activities to enrich our experience of urban places. It examines the economic and psychological gaps that currently exist between producer and consumer. In addressing this, the current and speculative practices of urban farming are examined. Finally, the development of place identity through food in the city is discussed. The scope for a solution springs from architecture's role in assimilating urban farms into the city fabric. The functional programmes of farm + market + building is laid out for ongoing investigation. The thesis acknowledges that the topic is extremely broad but the scope is narrowed by the research question: how can architecture help diversify food space through the introduction of urban farms, breaking down the conceptual divide between urban versus rural?

\section{Food Space}

While consumption is critical for a city's social and local economic viability, what is often reflected in mainstream 'food + architecture' publications are designs confined to eating venues as 'spaces of food' (fig. 3.1). That is, coffee-table books featuring the trendiest restaurant/café designs of the season (Castle 4). These are often seen to promote a self- 

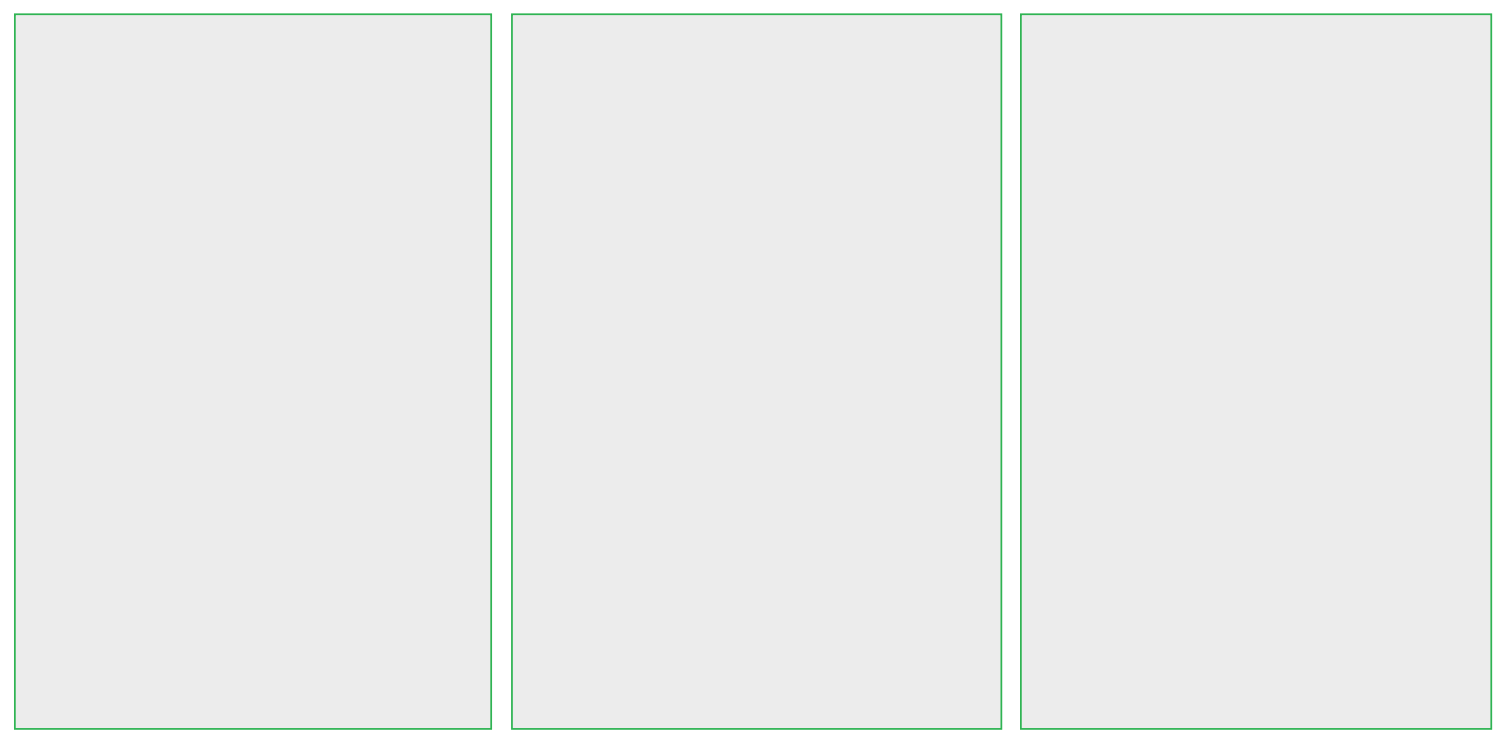

Fig. 3.1: Examples of 'food spaces' in mainstream publications.

indulgent lifestyle and do little to educate urbanites about the physical and psychological distances between food production and the city. 'Food space' is a broad system that includes all stages of the food cycle; from production to distribution, preparation to consumption and finally waste. The breadth of this system is largely underrepresented in architectural thinking due to the invisibility of activities taking place beyond the urban limit. Until there is also a food space living and breathing within the city fabric, conveying its diversity beyond consumerism, interest amongst urban residents will likely remain low. The obsession with consuming results in reduced opportunities as viewing food as an urban system.

"The gastro-culture of restaurants and food stores are well chronicled in the press while other life-sustaining aspects of food remain nearly invisible - in education, urban design, planning and architecture" (Franck, Food for the City, Food in the City 36).

Similarly, Steel observes the minimal efforts of the media in way of educating the real effects of food, which has instead given rise to a veneer of the foodie culture,

"...where we are happy to let food take a back seat...while most of us probably suspect, deep down, that our eating habits are having nasty consequences somewhere on the planet, those consequences are sufficiently out of sight to be ignored" (5).

Visibility of the food system in the urban construct is lower that that of other systems such as transportation, housing, employment and the environment, a fact highlighted in Pothukuchi and Kaufman's 1999 publication Placing the Food System on the Urban Agenda. The paper underlines the four key reasons for this as: 1) urbanities take food for granted where few see serious problems related to food access, availability, or affordability; 2) the definition of specific issues as being either rural or urban, this separation in thinking results in food not being considered an urban issue in the same magnitude as are housing, crime or transportation; 3) technological advances in transportation, food preservation and processing since the industrial revolution have rendered an acceptance to sweep 
away rural land to make way for new suburbs, what is offered in place of local farmland that historically served cities is the grocery store; 4) the persistent contradictions between policy departments (authors refer to the US) such as the Department of Housing and Urban Development which rarely addresses food issues and the Department of Agriculture which pertain mostly to farms and agriculture, yet their policies significantly impact cities (214).

None of these factors are currently at the forefront of the agendas in developed cities. The full potential of food in the urban system is far from being realised because of the top-down false sense of security about its ongoing availability and overshadowing by more immediate demands. The sharp and powerful dichotomy between what is considered urban versus rural conceals the many interconnected activities that make up a food system from urban residents and professionals. With agricultural food production assumed to take place in rural areas, it becomes a matter of rural policy, treated independently from urban policy and problems (Franck, Food for the City, Food in the City 37). Modern zoning controls as set out by urban authorities do little to help and are instead instrumental in creating a segmented and sterile environment. It becomes quickly evident that opportunities lay with policymakers to make changes about the urban food system, beginning with a need for more flexibile land use policies. Making progress in this regard will by necessity call into question what it means to be urban.

The path to truly viable food cities would seem to be obstructed by many peripheral issues when in fact it all boils down to one; without farmers and farmland, cities could no longer exist. Emerging out of this realisation, one architectural thinker has begun to give shape to manifestos that explore future 'foodscapes'. In Smartcities + Eco-warriors (2010) and Food City (2014) Lim examines the potential for food to become fully re-integrated with urban environments - how the creation, storage and distribution of food can once again become a construct for everyday life. With the realities of achieving such a condition seemingly beyond reach in contemporary socio-political conditions, radical constructions such as Lim's Food Parliament set in London brings these issues to the forefront. Food cultivation becomes reinstated at the core of national and local governance in this proposal and is the essential driver for restructuring aspects of everyday life (Lim). Here, food space is truly realized in all its diversity, where consumers are also growers. Though Lim presents fictional fabrications, his message is precise and clear, raising serious questions about the priorities of governing bodies. Similarly, in the final chapter of Hungry City Steel speaks of a 'sitopia' (from the Greek sitos, meaning food, and topos, meaning place) as a practical alternative to the unattainable utopia (291).

In an era of unrelenting urbanism, it is appropriate for cities to adopt a more holistic outlook on food, to encourage projects and experimentations that embrace the complete food cycle. Authorities could reprioritize their agendas to engage residents to real and palpable 'food spaces' in all its forms. Quite possibly, it is only through a built reality experienced by residents themselves that they will begin to recognize any effective outcomes, in the hope that it can change the ways people think about the cities they live in.

\section{Urban + Farming + Architecture}

The current world population of 7.3 billion has just over half of its inhabitants (54\%) living in urban areas and by 2050 some $66 \%$ of the then 9 billion people will be urbanised (United Nations). The cheap and ongoing availability of food to meet the needs of many urbanised people, and in particular those who make decisions on infrastructure development, ensures that few city dwellers are aware of emerging problems with the linear metabolism of its production and consumption. Nevertheless, some are beginning to see the potential benefits of a 
closed-loop food system in cities and urban farming has been revisited across several disciplines to address the opportunities. Architecture is one of those disciplines.

It is commonly assumed that urban farming is a recent phenomenon, brought on by sustainable initiatives. Although it has gained traction in recent years, urban farming has been practiced since the origin of village settlements. Jacobs argued that the act of growing food amid dense settlements likely dates back to the origin of cities. When organized agriculture began to be recognized as a system for tradable commodity, cities grew dramatically, relocating agricultural activities to surrounding land and thus creating the urban/rural divide. "Rural work is city work transplanted" (Jacobs, The Economy of Cities 16).

Before the modern world overcame difficulties of failing produce and means of distribution, cities had to produce enough food to sustain themselves. It is only with developments such as chemical fertilizers, refrigeration and mass transportation, among other technologies, that the current global food system is possible (George). It is also heavily reliant upon non-renewable resources. In the recent past it was concern about food shortages that saw urban farming revisited. Many cities across the United States and Britain for example had flourishing 'Victory Gardens' during both world wars in response to the threat of shortages created by blockades. After the wars however, many garden allotments were returned to their original uses or lost to developers (Doron 53). Similarly, a food crisis in Cuba in 1989 forced the government to innovate, to introduce food production and agricultural initiatives into the existing urban fabric. This resulted in a successful city farming model where, by 1998 , there were more than 8000 urban farms infused into Havana's urban landscapes and producing nearly half of the country's vegetables (Clouse, Farming Cuba: Urban Agriculture from the Ground Up). Cuba's government continues to promote and even finance urban farming practices today. Perhaps it is this history that can teach the modern world of its potential; "sometimes to move forward, we must look back. Our past can inform our present (Smith 5)."

Today, many urban farming efforts seen around cities appear to have been distilled down to light-hearted amenity to consolidate harsh urban environments or to provide for the recreation of those who tend to them. A few planter boxes distributed around the city will have little effect in activating anyone's way of thinking about their food. The problem with some examples of 'pocket' size urban farming in modern metropolises is that they are merely inserted into undesirable leftover spaces to increase attractiveness, but with inadequate consideration of how they connect with surrounding amenities, activities and landscapes. Furthermore, community gardens (the most common form of urban farming) are often hidden away between suburban plots and run by volunteers, without a strict work schedule (fig. 3.2 left image). This can only function with small scale, low yield and low maintenance farms. For city residents to truly start taking the practice seriously, it needs to operate at a larger scale. And most importantly of all to break down conceptual barriers, its processes need to be as transparent as possible to the public eye.

In the contemporary architectural discipline, strategies addressing food are surfacing through the incorporation, at various scales, of agriculture into designed urban spaces. This includes farms established within/on/around buildings, though many of the projects have to date been speculative. Recently, urban farming has gained attention from architects as it is being commercialized into an emerging industry. Some of these proposals have, unfortunately, been taken out of context with concepts of sustainability being overstated and clichéd. Many lush photo-realistic landscapes are 


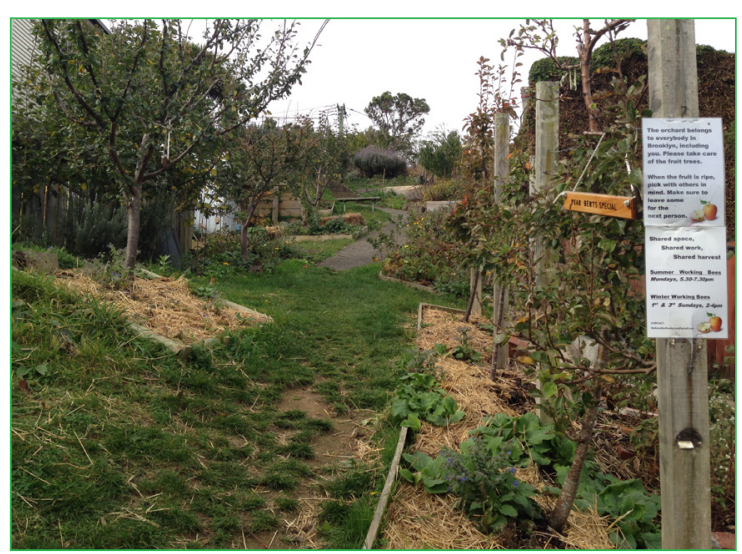

Fig. 3.2: A community garden between suburban plots in Wellington, New Zealand (left) and a rendering of Paris' future smart city by architect Vincent Callebaut (right).

no more than backdrops for the main architectural proposal and plants are often brushed onto buildings to pass as a sustainable design contribution (fig. 3.2 right image).

In his essay titled Post-Sustainability, Jarzombek criticizes recently designed eco-cities, noting how they demonstrate that any approach could be taken to make a project look green,

“...but has anything really changed?...the tendency to drip green ivy on buildings or plant grass or trees on roofs makes a parody of what needs to be done...this is not about the need for local produce, but about the destruction of the conceptual barrier between city and farm (249)."

One can argue the need for both local produce and a better conceptual understanding of a food system. Jarzombek's statement applies equally to the minimal efforts of urban authorities in the way small community gardens, a few scattered trees and open areas are used to market 'green cities.' His point is valid - little has changed in the preconceptions of food for the majority of city residents, and if anything, the barrier is wider thanks to a thriving consumerist culture.

Recent technological developments such as high efficiency LED grow lights and automatic control systems have aided hydroponic urban farming. The indoor controlled environment agriculture (CEA) model is efficient, does not rely on weather conditions and makes it more viable to grow in city centers as demonstrated by recent examples such as Gotham Greens in New York and Lufa Farms in Montreal (fig. 3.3). It has raised the topic of urban farming to new levels of interest amongst professionals such as growers, urban designers, planners and architects. The desire for maximum yield while being close to urban centers has sparked a contemporary urban agriculture movement across many disciplines as the realisation of interrelated city patterns is triggered by food, along with their commercial value. This growing interest is also extending to consumers, who want a closer connection to their producers in seeking to be more conscious of food origins. With urban farming now identified as an opportunity for a viable food production system, rather than as a result through fear of war or economic hardship, it is important that appropriate time and energy resources can be dedicated to experimentation.

While some projects only touch upon the tip of urban farming principles, others can be found at the extreme end of a totalitarian city run by the 

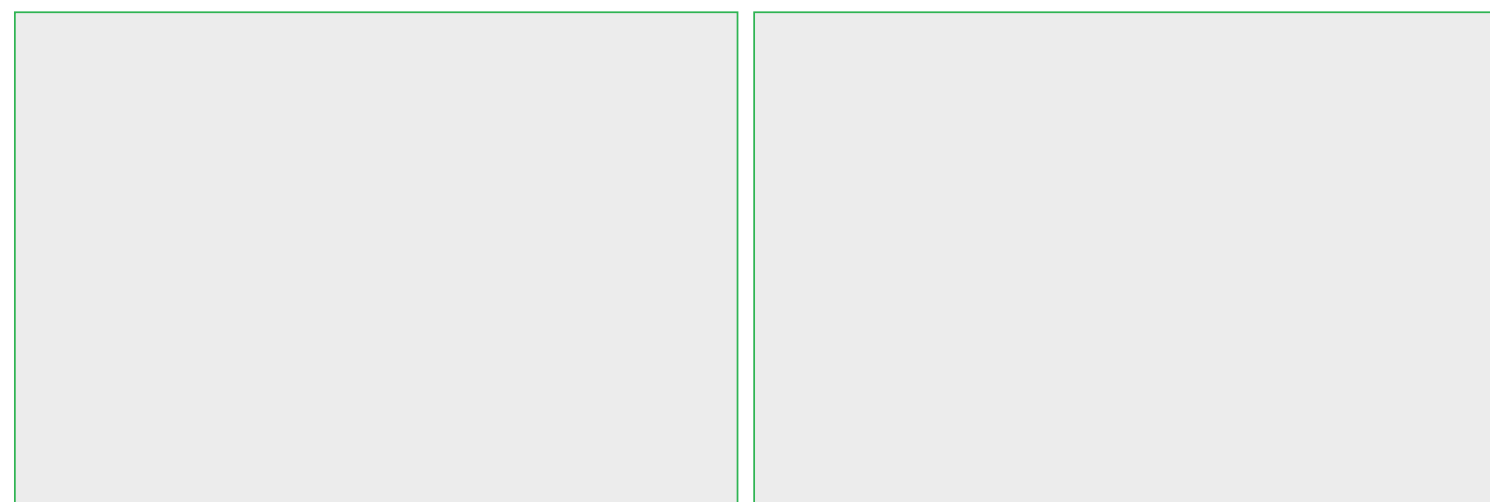

Fig. 3.3: Lufa Farms grows their produce inside controlled environments in their rooftop greenhouses.

food system. Without question, these proposals are utopian and ideological and have yet to prove their feasibility beyond a rendered landscape. Nevertheless, it is these idealists who push the discourse, in the hope that one day, the visions can be realized, or at least come close (e.g. Despommier's The Vertical Farm). However, there would appear to be time for innovation between now and then and this gap needs addressing through the combined efforts of science, technology, architecture and planning. Pilot projects are underway as seen in the proposal of ReGen Villages (fig. 3.4), an offgrid, self-sustaining village featuring at this year's Venice Biennale (Dezeen). The first of its high-tech farming villages where food and energy is produced in a closed-loop system is expected to be completed in 2017. This village model is designed for a greenfield site west of Almere, Netherlands, and therefore skirts around issues of integrating such a system into an existing city, where the majority of consumers live. As such it can be seen as a continuation of current practices.

To date, architecture has not been integrated with urban farming proposals and it has instead been used to depict a backdrop to show how urban the farming proposal is, or the farming takes place inside a standard commercial greenhouse, no different to what is being used on the outskirts of the city. At times these greenhouses are constructed on rooftops in urban centers, but they do not capitalise on the opportunity to innovate nor to engage with the surrounding environment. Architecture's contribution has resultantly been underutilized in
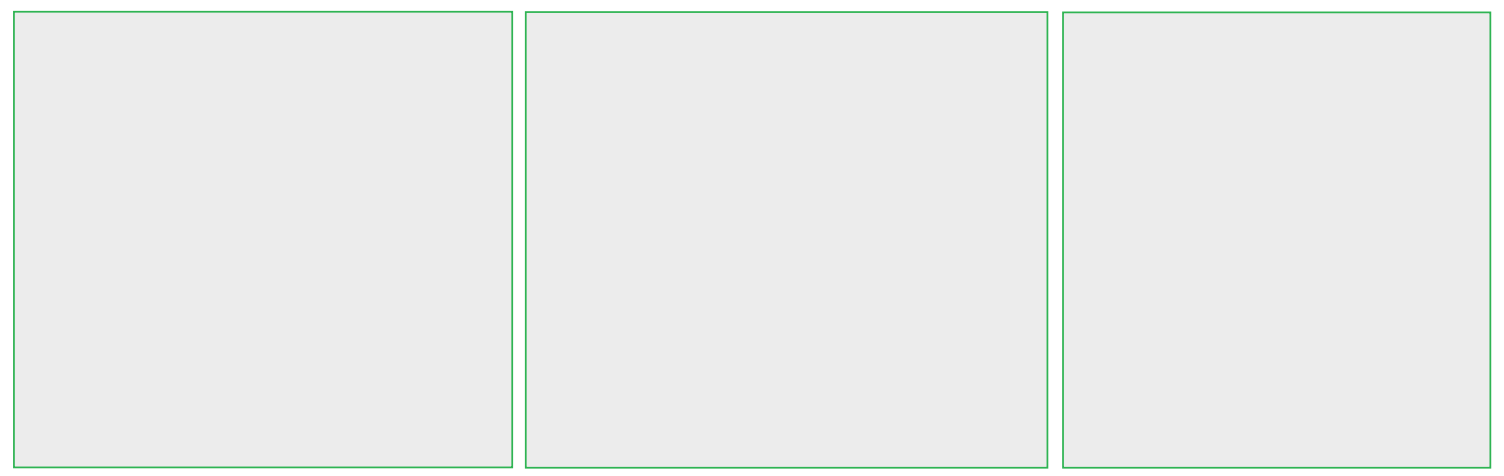

Fig. 3.4: Regen Villages by Danish stuido EFFEKT. 
the relationship between farms, residents and the cityscape.

Across many developed cities, conditions such as largely unused surfaces (such as rooftops) indicate that there are a plethora of vacant space available for urban farming. Other environments, such as vacant building interiors and unused land present different opportunities for urban farming that falls outside the scope of this research. Creating rooftop greenhouses has, in recent years, begun to emerge at a commercial scale in cities across North America and Canada (fig. 3.3) but their practical requirements tend to outweigh design possibilities that engage with their context, and hence the people of the city. Urban farming, in the context of a strong design focus, could help make food systems more visible, adding to the definition of urban 'food space'. Architecture's role could operate beyond simply designing functional growing environments for farms, as rooftop constructions (in this case rooftop greenhouses) have the potential to shape cities by operating symbiotically in their urban settings (Melet \& Vreedenburgh), adding to the complexity and dynamism of urban life.

\section{Food + Identity}

A key player in distinguishing urban food space is the supermarket, whose form and public presentation is driven largely by economic efficiencies. In the past it was local markets that influenced presentation and distribution of a city's food, today it is supermarkets, in the hands of a few corporations. The issue is not just about the limited choices available to consumers, but the lack of civic life caused by the many homogenous supermarkets.

"Supermarkets today are impersonal filling stations: pit stops designed to service the flow of life. They support individual lifestyles, not sociability (Steel 114)."

Nothing about their sterile environments identify their place in the city. In his analysis of modern life, supermarkets are what Augé refer to as 'non-places' where there is little chance of social interaction (Augé). Contemporary supermarkets and the motivations behind them have never been about human scale, their aim is simple and singular, to maximise profit. The influence of this approach extends to the rural agricultural industry that serves to supply them.

"...internally the smell and look of the food is suppressed by air conditioning, lighting and packaging. The bland space extends well beyond the building to meet the requirements for bulk transport and car parking (Wigglesworth, 103)."

The importance of the market as building type has resurfaced in conversations about urban regeneration. Preservation and renovation of market buildings to their earlier architectural glory are presented as alternatives to the supermarket in Esperdy's article Edible Urbanism. By 1800, covered markets were recognized as a building type that "symbolized urban modernity and enlightened civicism" (Esperdy 45). Whether covered or not, markets are inherently chaotic and unlike highly ordered supermarkets, but in a manner that is anticipated as part of the experience. As a reemerging part of the food system, they are seen as part of the consumer culture as well as helping to provide insight to the value of food in the way the raw produce is displayed and sold by growers.

However, differences between markets and farmers' markets can be profoundly misguiding. One thing to note about normal produce markets is the little known journey of food from growers to consumers (fig. 3.7). It can often take up to a week, handled and resold numerous times as highlighted by the 2012 investigation of the Harbourside Market in Wellington, New Zealand (Rashbrooke). Nevertheless, the weekend market in Wellington draws huge crowds no doubt thanks to its lower prices and adds to the dynamic civic life of the city harbour. Reality can often conflict with what 

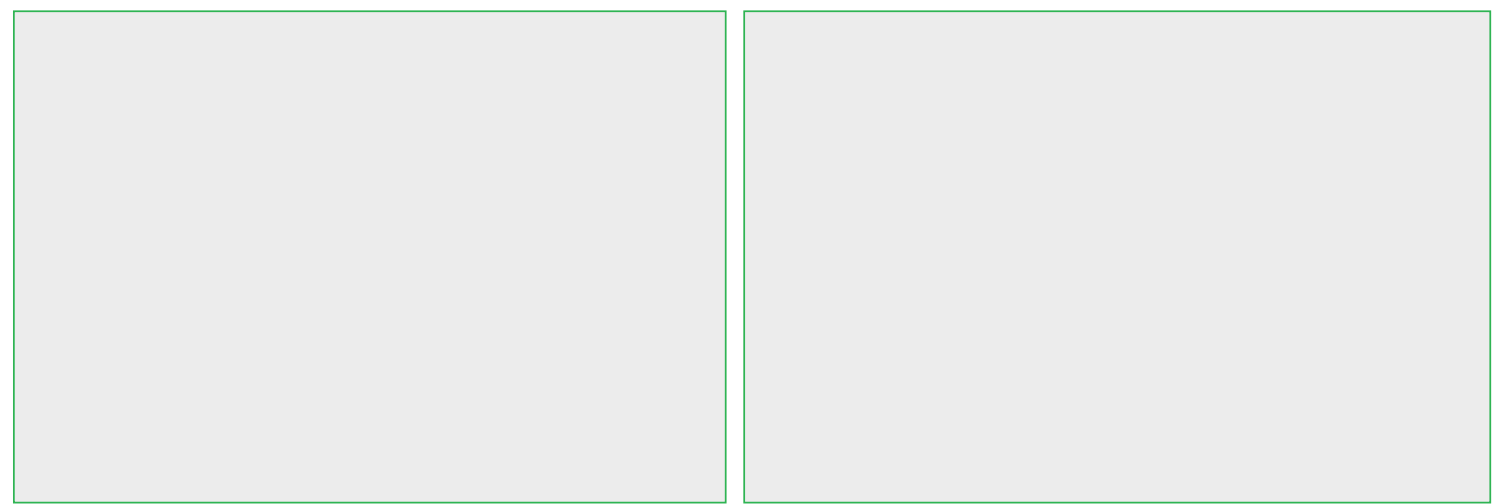

Fig. 3.5: Borough Market in London (left) and La Boqueria Market in Barcelona (right).

consumers know or care to know. With urban farms, not only are food miles reduced, but the produce can be harvested on the same day as it is consumed, giving access to the freshest possible food.

Covered markets in Britain and Europe have highlighted food as an urban revitalization tool. Examples inlcude London's Borough Market and Barcelona's La Boqueria (fig. 3.5), where fresh produce is bountiful. These markets have been particularly successful with tourists but more importantly restauranteurs would prefer to buy their produce there as well. What if a trip to the market for weekly or even daily produce could be a part of normal civic life for the urban resident? And why would this routine be desirable when the supermarket offers other conveniences? A solution could be to incorporate an urban farm. The additional program of production into a market's current consumption imperatives could have rippling effects in the urban food system, not only through educating residents but also by increasing chances of social interactions, creating jobs and closing the perceptual divide around where food production should take place. The consumption stage would, in this scenario, be icing on the cake.

Consequently, the equation could be: urban farm + market + building. Along with aims of providing shelter, the architectural building element can contribute to a spatial and visual identity, strengthening a vibrant program. Where marketfarms can be established, the areas physical character could be enhanced over time as a reflection of the activities, not unlike Seattle's Pike Place Market, but with the added appreciation of production occurring at the same venue.

This notion of production-as-spectacle is starting to take shape within the context of food space in Wellington, with a number of specialist businesses centred at the recently developed laneways in the CBD (discussed in the following precedent studies chapter). Some of the more contemporary food spaces, though still highly focused on making a profit (as expected of any business) are choosing to display their production processes as a kind of performance to add dynamism to the consumer experience. This additional program can be communicated by the designs of these spaces, presenting a valuable architectural opportunity. Over time, as with markets, these places and their activities have established a distinct local identity to their respective locations.

"Over and over again, spaces of food contribute to the specificity and recognisability of a place when they attend to what is local (Franck, The 
Space of Food 12)."

Another example of food contributing a layer of identity to urban environments are places that are often considered 'ethnic' due to the combined presence of particular foods in their evidently unnatural settings. Places such as Chinatown, Koreatown or Little Italy to name a few examples are present across predominantly western cities that are inclusive of diverse cultures. These places are often full of sights, sounds, smells, tastes and perhaps even touch that are unique to that environment only. The enhancement of the senses (largely due to the cuisines on offer) leads to a greater association of food with the identity of a particular part of a city, often extending to the built environment where the typology is reflective of the food's respective cultures. Used to its advantage, this relationship between food with the identity of an area has great influence over the vitality of cities.

Though there are some examples of successful food spaces in many city centres, ultimately the food consumed today is highly driven by economies of scale, rather than by local cultures. Through design, the potential for uniting the ambience of markets with sustainable farming initiatives could see cities once again take control of their own food systems.

\section{Urban Farm as Place}

With the introduction of a farm into an urban environment, it is important to consider factors that have influence over its successful integration. If the farm were indeed to form an identity (objective), then image is the combination of identity and the way it is perceived (subjective). This touches upon the central notion of place-making and requires an understanding of cities as a complex system. Though this has been a topic of conversation since the latter half of the 20th century, it has enduring relevance in the practice of urban design. With theorists such as Lynch (1960), Jacobs (1961) and Cullen (1961) presenting different yet valid views of what constitutes a good place, Montgomery (1998) made a seminal attempt at combining these theories that will subsequently be taken into consideration for the farm's design proposal.

Lynch in his 1960 publication The Image of a City analyses the psychological perception of place between the observer and the observed through the notions of 'imageability' and 'legibility' - the extent to which a cityscape can be 'read' using mental maps to make an impression on the observer. The relationship is that of a two-way visual process meaning the perceived 'image' varies among observers, whom endow places with their own meanings. This environmental image has three components - identity (of individual urban elements); structure (how urban elements relate to each other and to the observer); and meaning (its emotional value). This sets out a valuable framework whereby the goal is not to design with specific/ detailed preconceptions for an observer of a place but that it presents opportunities for them to make their own stories. Lynch summarizes the mental maps as consisting of five urban elements - (1) paths: routes along which people move throughout the city; (2) edges: boundaries and breaks in continuity; (3) districts: areas characterized by common characteristics; (4) nodes: strategic focus points for orientation like squares and junctions; and (5) landmarks: external points of orientation, such as an easily identifiable physical object (De Lange). The observer's sense of emotional security increases when there is little disorientation in the way-finding/organizing of a city's pattern. Thus, according to Lynch the legibility of a city must not cause confusion as this has direct influence on imageability.

Cullen's 1961 publication Townscape emphasizes visual coherence in understanding the urban environment. This is based on the physicalities that make up a city including (but not limited to) its distinct design style, building positioning, street patterns, openings, greenery, gateways, landmarks 


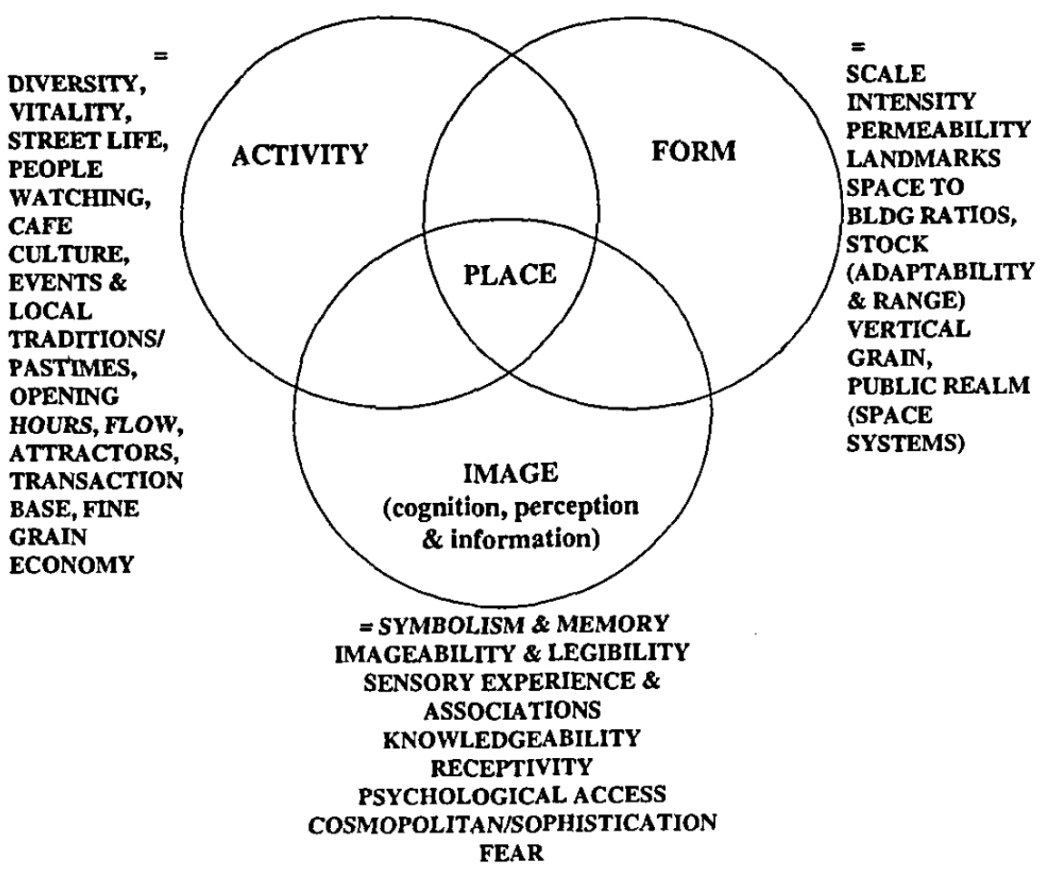

Fig. 3.6: Montgomery's policy directions to foster urban sense of place.

etc. Of particular interest is Cullen's depiction of serial vision - the capturing of images as one moves through city spaces, influenced literally from its physical make up. Through particular urban arrangements, Cullen depicts a very visualorientated approach on good place-making.

The works of Lynch and Cullen have both been major contributions to the field of urban design and especially relevant for this thesis, their angles on what constitutes well-designed places. Of Lynch's environmental psychological approach, Montgomery describes it as romantic subjective and of Cullen - a more rational/objective classical view of urban design. And yet combining the two approaches physical elements with the psychology of perception - is inadequate in defining urban quality.

"...the notion of urban quality is clearly more importantly bound up in the social, psychological and cultural dimensions of

\section{place." (Montgomery 95)}

Enter Jacobs and her contribution in 1961 The Death and Life of Great American Cities where along with other notable themes, she presents activity as the underlying ingredient for developing healthy cities. In allowing opportunity for activity, four essential factors are outlined: (1) a mixture of primary use; (2) intensity; (3) permeability; and (4) a mix of building types, ages, sizes and conditions. With this contribution to the discussion of placemaking, it bridges the theories of Lynch and Cullen and as Montgomery notes, activity is the premise of producing and mirroring quality in the built environment.

Thus it is the combination of the qualities of physical space, the sensory experience and activity that make for urban quality. Montgomery in his 1998 article Making a city: Urbanity, vitality and urban design produces a composite derived model as a 
summary of good place-making. In it, he depicts the elements or characteristics that contribute to good place-making (fig. 3.6).

Taking the above considerations for the design of an urban farm, it is possible that the program of 'farm' may not be enough to establish itself as a successful place. As noted, diversity in the use of space is essential for vitality so site considerations will be crucial. This leads on to an exploration into public realm design to complement the farm in its overall integration into the city, to be illustrated in the design chapter.

\section{Conclusion}

Food is emerging as a catalyst for urban design and architectural discourse around issues of infrastructure, security, resilience, sustainability and identity. However, further encouragement of the discussion requires that it move beyond discipline specific contexts to the mainstream media. The food supply chain had been a key force shaping cities since their origins, and should again be a topic of conversation among urban residents and authorities.

Conceptual thinking about production as rural and consumption as urban can only be redefined through a fresh and holistic view of a city's multiple functions. This can in turn only be achieved by diminishing the physical divide, a matter to be addressed by planning authorities and other public decision makers in allowing for experimentation. At the moment it would appear that the architectural contributions to the discourse can only be speculative. Sustainable design does not equate with how green an image is but rather the opportunities it presents for the activities and functions it encourages.

Opportunities for experimentation exist in a city's fabric, the many unused rooftops could be a logical starting point. City residents need to experience the transparent processes of productive farm food spaces in urban centres themselves to truly understand their significance. Architecture can be a protagonist and, although places will naturally take on site-specific design approaches, their resultant effect could be felt across the city through an invaluable identity of a local food culture. 


\section{CURRENT MODEL}

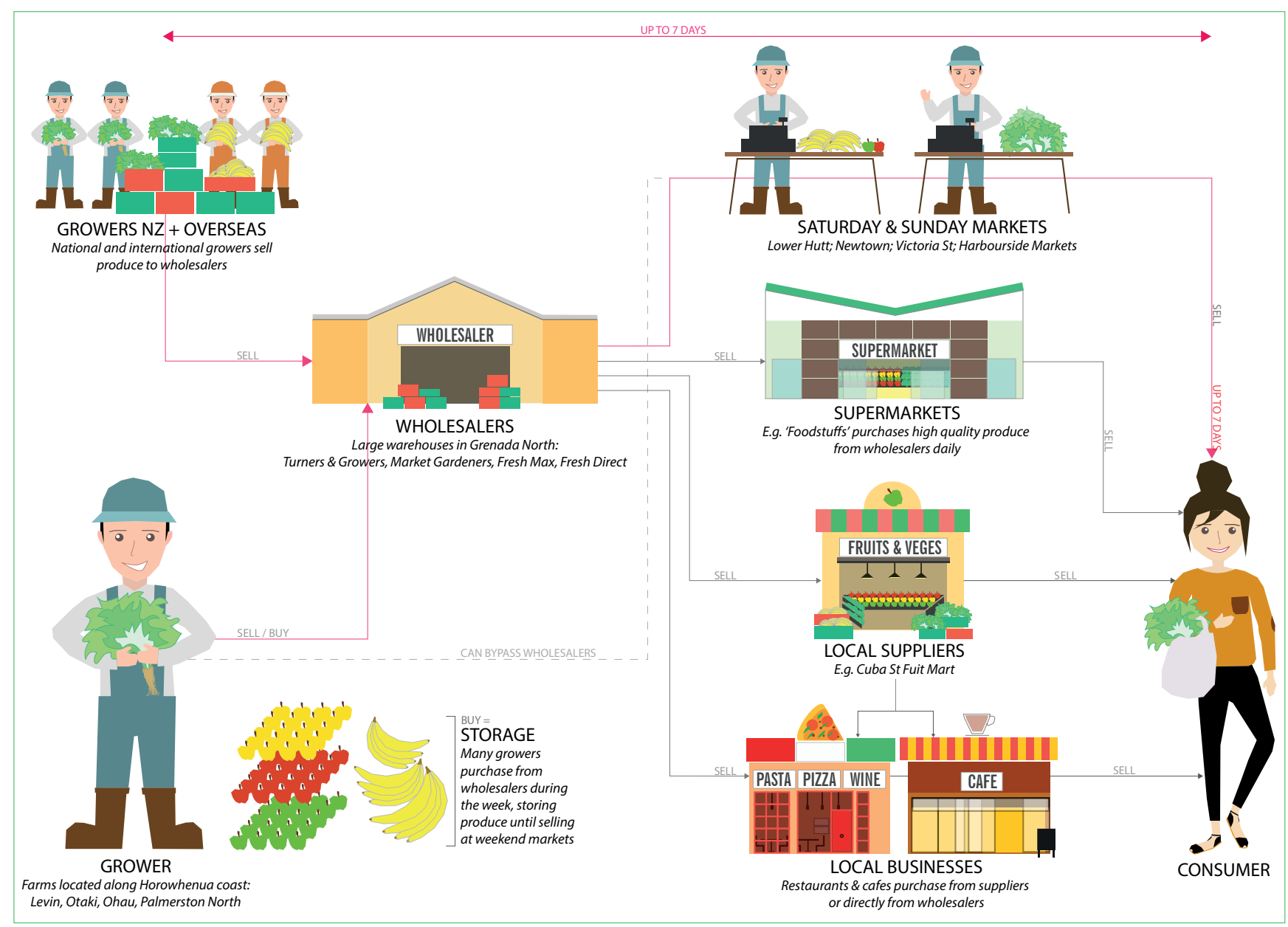

Fig. 3.7: Wellington city market produce from grower to consumer under the current model.

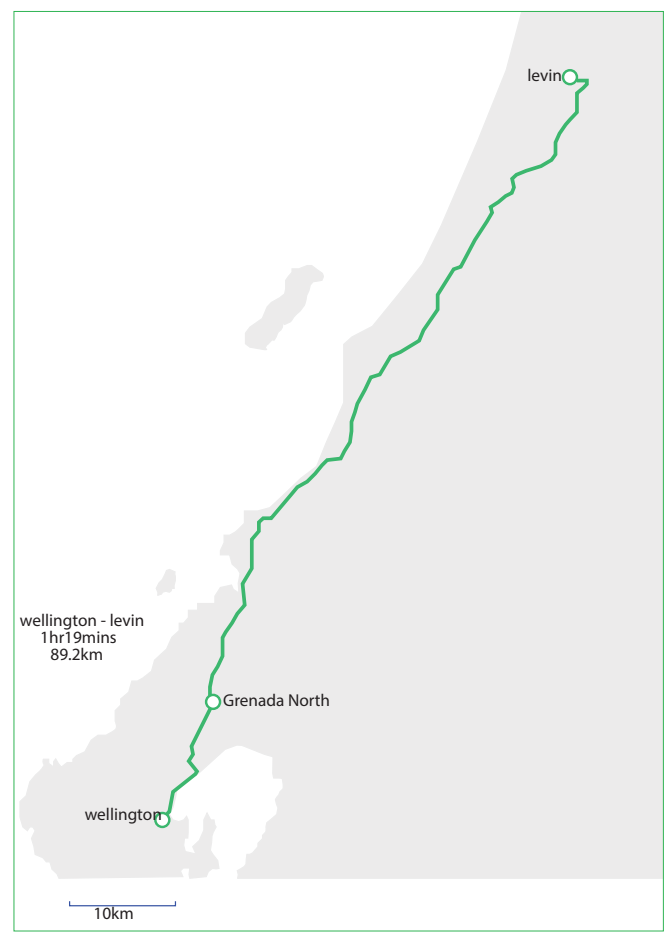

Fig. 3.8: Farmers grow their crops in Levin, buy more produce from Grenada North warehouses throughout the week and sell to Wellington City residents at the end of the week. Distance between the two cities is $92.6 \mathrm{~km}$, approx. 1 hr20min by car. 
[3.0]

LITERATURE

REVIEW

PROPOSED MODEL

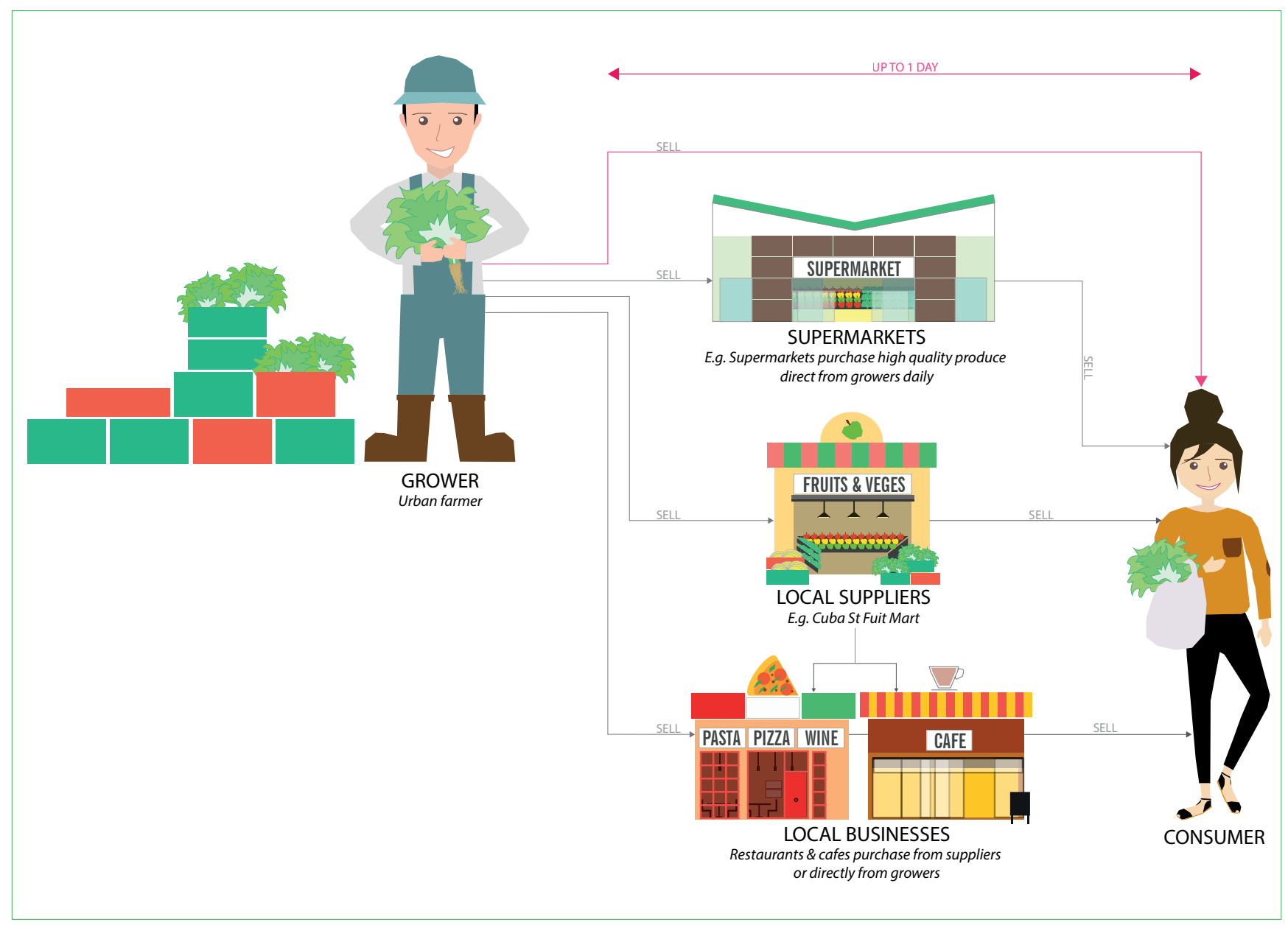

Fig. 3.9: Proposed business model for thesis. 


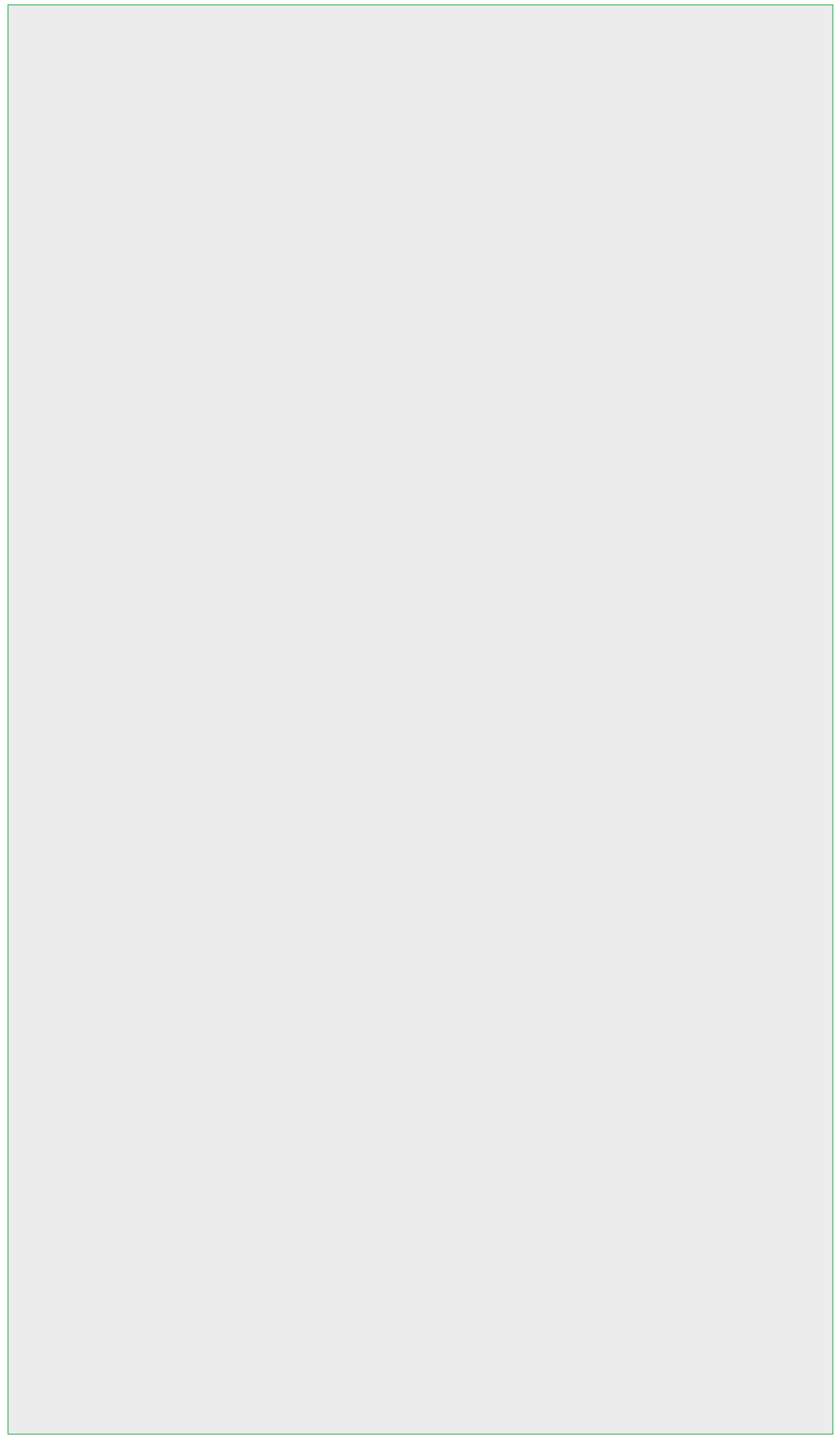


Precedents analyzed in this chapter are divided into four sections: 1) urban agriculture; 2) rooftop additions; 3) elevated landscapes and 4) production as spectacle.

As with any discussion that has the capacity to alter our way of living, looking beyond the obvious topic has value in providing a wider understanding of its significance. The variety of topics above forms the neccesary equation in addressing their combined potential to better inform a design framework. What technologies are involved in urban agriculture? What is the measure of their success/value to their communities? Do they contribute to a sense of place? Precedents are evaluated at varying degrees for their relevance to the project, the aim being to acknowledge their strengths (and weaknesses) as part of the research into designing an urban rooftop farm, to be proposed by the end of this thesis.

\begin{abstract}
Urban Agriculture
Firstly, the practice of urban agriculture/farming operating at a commercial level is analyzed. The majority of examples are from the U.S.A. and Canada. It is important to understand why this practice is necessary and how these businesses operate at a technological level. This is followed by the speculative proposals of urban farming as a product of architectural discourse. What is revealed is the startling contrast between these proposals and urban agriculture in practice, prompting the question of architecture's value.
\end{abstract}

$$
+
$$

\section{Rooftop Additions}

Secondly, rooftop additions in the form of architectural constructions and/or sculptures are investigated for their variance in design responses.

\section{$+$}

\section{Elevated Landscapes}

Of relation to rooftop investigations and the public realm, the thesis explores landscapes that are elevated above the norm of street level. This includes examples of bridges/walkways/roof landscaping in the urban environment.

$+$

\section{Production as Performance}

Lastly, the thesis examines local Wellington businesses that showcase their food-making processes as part of the overall customer experience. How does this translate into a design opportunity? 

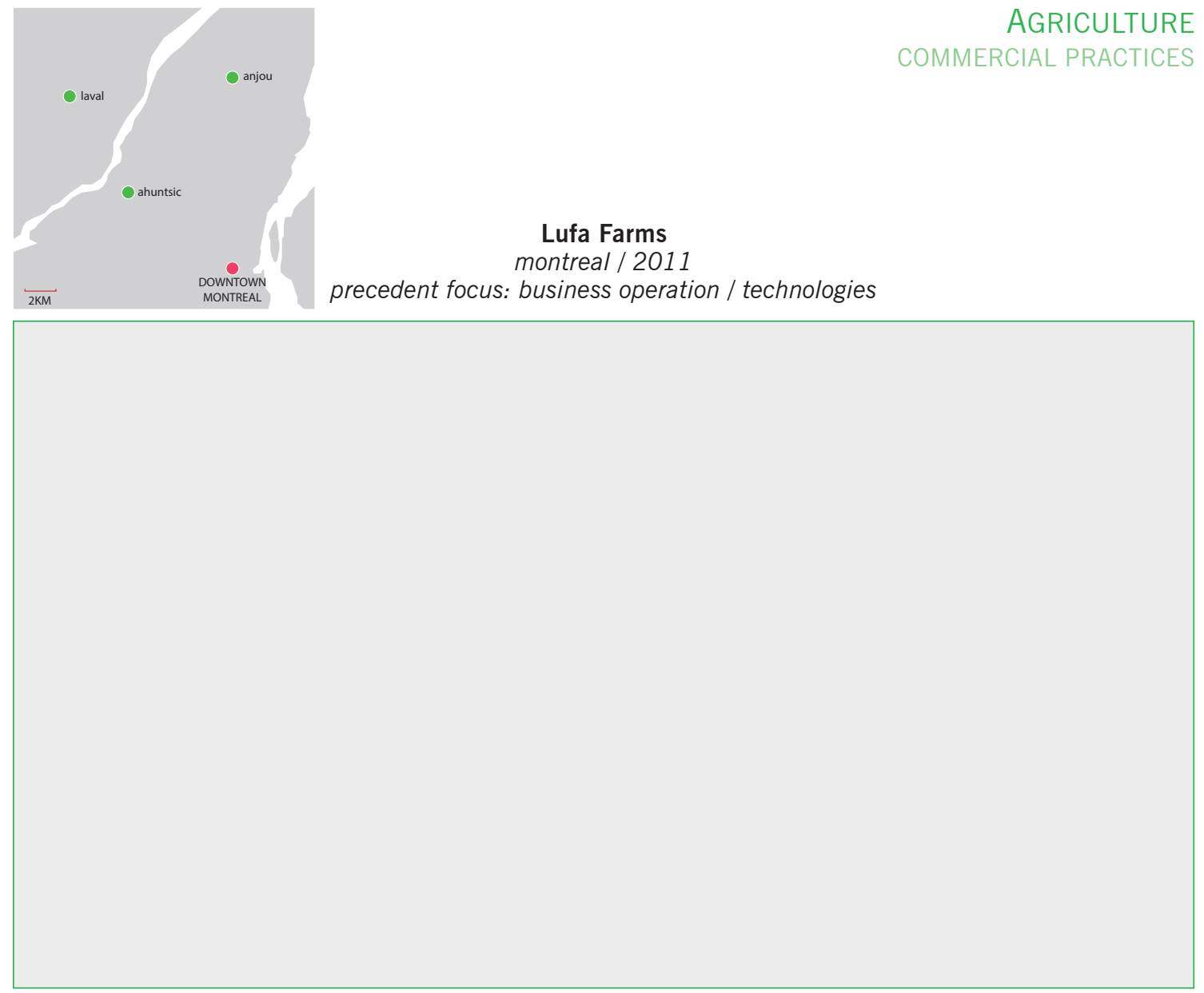

Lufa Farms

montreal / 2011

precedent focus: business operation / technologies

Fig. 4.1 .1 (map): Lufa Farm locations in relation to downtown Montreal.

Fig. 4.1.2: Their prototype farm in Ahuntsic was the first of three Lufa Farms.

\section{The Lufa Story}

Lufa Farms isn't your typical vegetable farm. The company has a vision - 'a city of rooftop farms' to feed the growing urban population and to change the way people eat. With three farms having been established in Montreal, their grower-to-consumer business model has proven a success amongst locals dedicated to buying produce grown within the boundaries of their city. Customers place their orders online (via a subscriber model) and food is delivered to their preferred drop-off point for collection.

2011 saw Lufa Farms opening the world's first commercial-scale rooftop greenhouse in Ahuntsic (fig. 4.1.2). This prototype farm has 32,000sqft of growing space for mainly leafy greens, generating 70 tonnes of produce per year (approx $2.2 \mathrm{~kg}$ per sqft). They claim it feeds approximately 2500 people year-round (Upstart Business Journal). The success of this farm led to the opening of a second rooftop greenhouse two years later in Laval (fig. 4.1.6). At 43,000sqft, this time it was bigger and better, demonstrating what "large scale rooftop agriculture is capable of" (Lufa Farms). It is worth mentioning this farm is focused solely on growing tomatoes and eggplants, amounting to 120 tonnes of produce per year (approx. $2.8 \mathrm{~kg}$ per sqft). And with the close of 2016, they've just announced the opening of a third rooftop farm in Anjou (fig. 4.1.7) that will also be their biggest at 63,000 sqft. As of 2016, Lufa Farms claims to be feeding just over $2 \%$ of Montreal's urban population (GreenTech), though this figure is sure to rise with the growth of the business. As city residents connect on a deeper level with their food origins, this is a success in itself.

\section{Hydroponic Farming}

In a hydroponic system, food is grown more sustainably than conventional soil farming due to the recirculation of water for irrigation. Rooftop greenhouses have the advantage of receiving free heat energy released from the building below and 


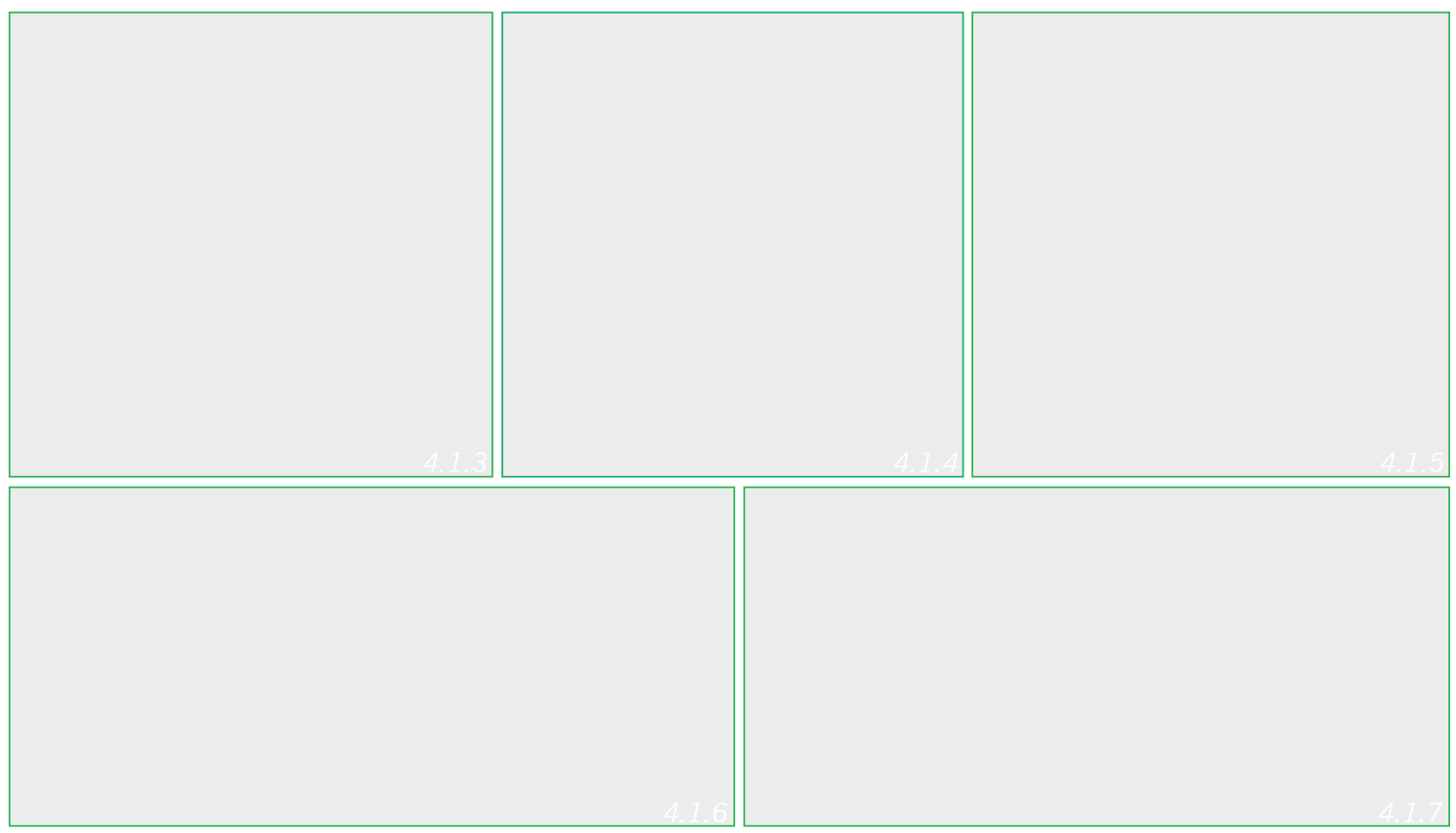

Figs. 4.1.3 - 4.1.7: Plastic gullies prepared for the opening of Lufa Farms' second rooftop greenhouse in Laval 2013; produce being prepared for delivery; vegetables grown in Laval greenhouse; Laval greenhouse; Anjou greenhouse.

can incorporate rainwater collection. Through innovation and technology, urban hydroponic farmers are striving to change the way cities eat. Growing indoors also offers the advantages of not using synthetic pesticides, herbicides or fungicides (Lufa Farms).

\section{Rooftop Realestate}

Lufa Farms' greenhouses are sited atop large scale rooftops. Their Ahuntsic farm sits on a twostorey commercial building giving the rooftop renewed life in becoming a space of production. With Lufa Farms expanding their business in the same city, perhaps this is an opportunity for their constructions to have more architectural input, so as to avoid an army of repetitive greenhouse structures. The practical requirements of these farms outweigh any architectural distinctivity in providing identity to their environments, no doubt due to low expectations of a financial return and resulting in a missed opportunity to enrich the city's built character. Whether or not rooftop farms can contribute to their built environments depend on their design and location. Lufa Farms' greenhouses do not appear to be situated in areas that have high pedestrian levels, so their functional designs could be justified. The question is how should an urban farm be designed if it were to exist amongst a built environment that is highly populated? To test this, a farm may essentially require a location at the very centre of a city.

Strengths: innovative business strategies. Includes marketing; day to day operations; technological expertise; desire to expand business in Montreal making their presence known.

Weaknesses: low design contribution to physical environment/street level. Buildings sited on rooftops are repetitive and non-contextual, though very functional.

Opportunity: incorporate design character into greenhouses to complement farming program. Could create stronger connection between people and food if experience is heightened. 
Gotham Greens

new york / 2011

precedent focus: business operation
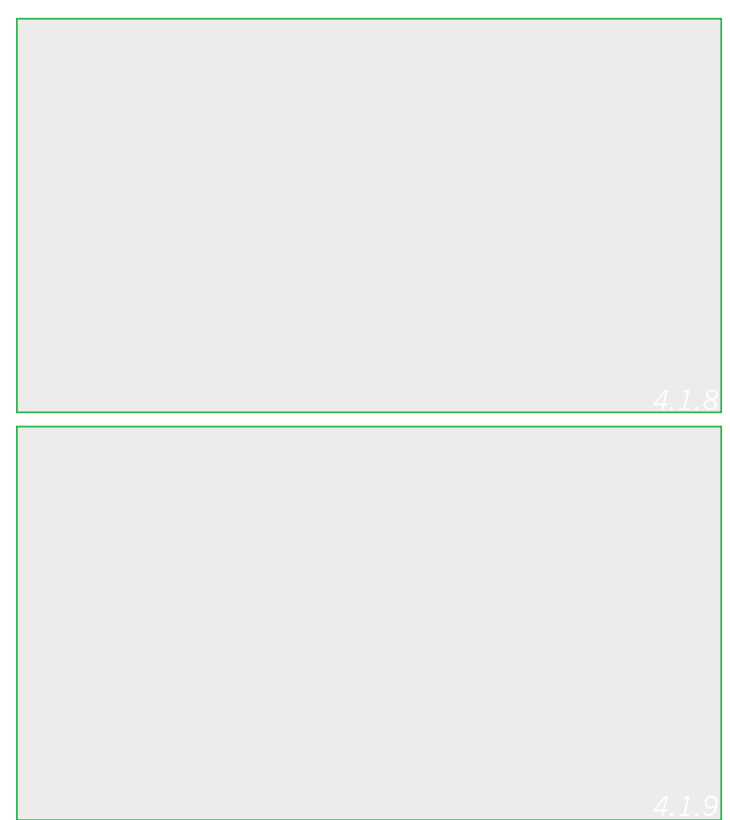

Fig. 4.1.8: Gotham Greens' first farm in Greenpoint.

Fig. 4.1.9: Their second farm designed with Whole Foods.

\section{The Supermarket Target}

Much alike Lufa Farms, Gotham Greens has several rooftop greenhouses across New York and Chicago. They use the same hydroponic method to grow vegetables (mainly leafy greens). Their first farm suggests a similar building model to Lufa Farms, where the greenhouse is an acute addition to a large scale rooftop. But it was in 2013 where the business took a turning point, being approached by Whole Foods Market to incorporate a Gotham Greens on the rooftop of their Brooklyn flagship store (fig. 4.1.9). This groundbreaking project represents the first commercial scale greenhouse farm integrated with a supermarket. With this partnership, the project has demonstrated capacity to exhibit and educate the public on local food production and the technologies involved. Aesthetically speaking, it does show a degree of thoughtful design.

Strengths: integration with supermarket allows for production + consumption at the urban 'food space'. Combined program strengthens the concept of urban food production.
Brooklyn Grange

new york / 2010

precedent focus: social impact

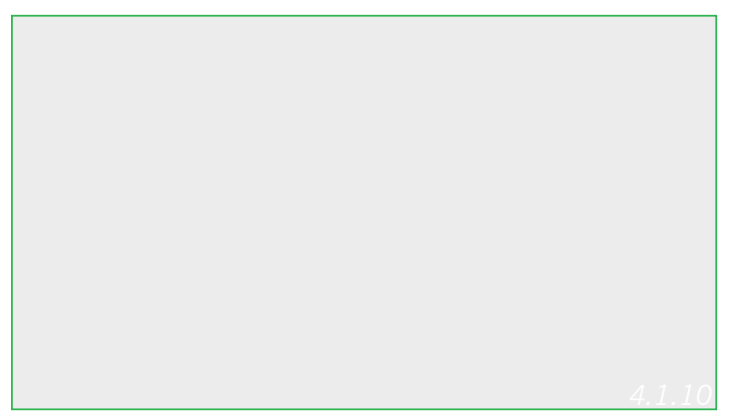

Fig. 4.1.10: The flagship farm in Long Island City.

Fig. 4.1.11: Their second farm at the historic Navy Yard.

\section{Farming with a View}

Unlike the hydroponic farms discussed so far, Brooklyn Grange operates large open-air rooftop soil farms, a model undoubtedly inappropriate for windy climates such as Wellington. The distinctive focus of this precedent is that although their farms operate at greater heights than other rooftop precedents (12 storeys!), they've managed to engage with their city on a social level around the culture of growing food. In addition to growing/distributing produce, Brooklyn Grange also hosts events/educational programming, provides urban farming/green roof consulting/installation services with numerous nonprofit organizations to promote healthy and strong local communities. All the while, making the most out of their rooftop vistas. This sort of urban farming isn't just about profit but about changing the core meaning of being urban through the power of social engagement.

Strengths: social and cultural sustainability/ community engagement. The farm is a public destination visited by many, even though it is fairly disconnected from street level. 


\section{GrowUp Urban Farms}

london / 2014

precedent focus: business operation / technologies

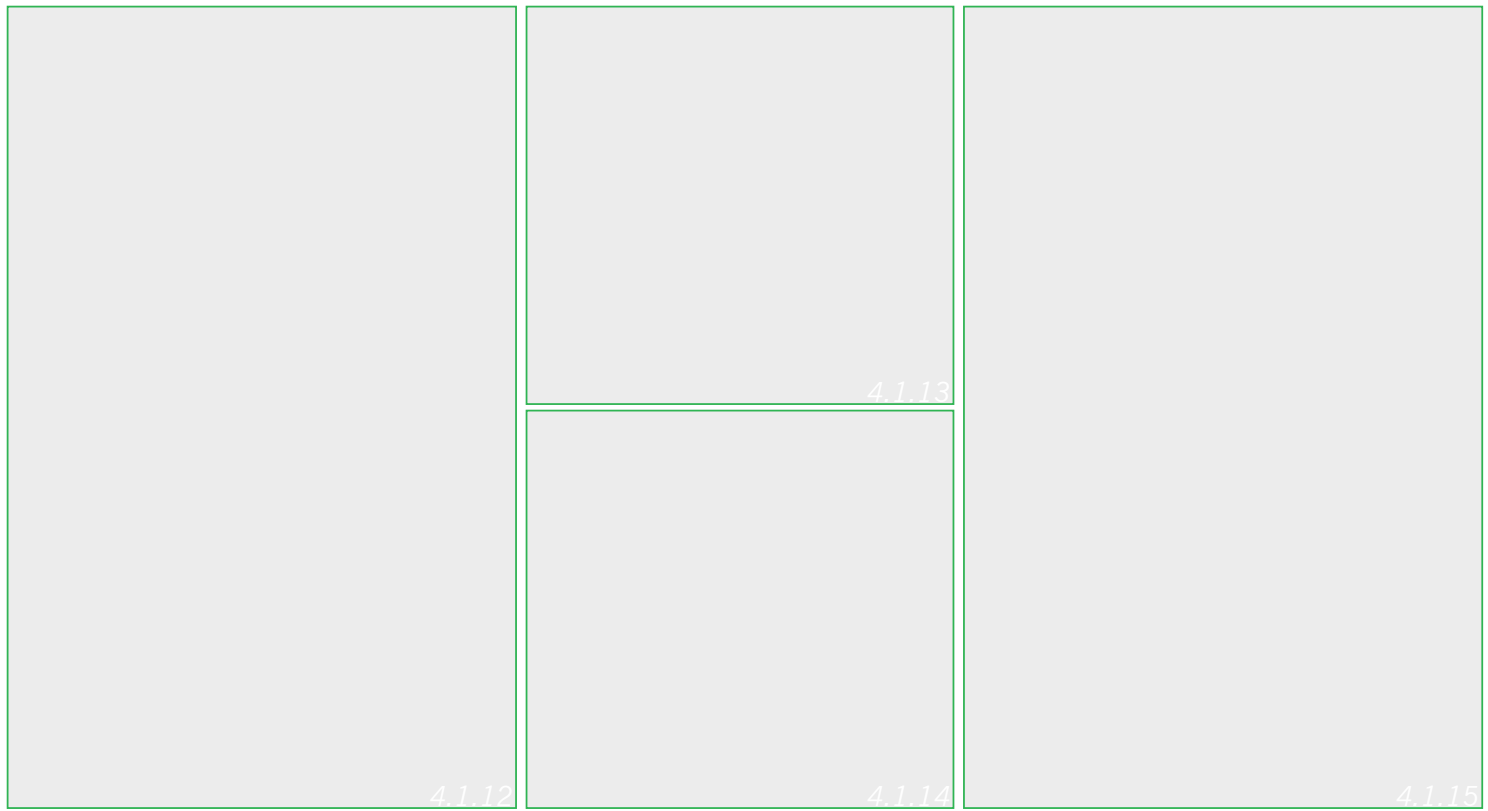

Fig. 4.1.12 - 4.1.15: GrowUp's aquaponic farming facilities and equipment.

\section{Aquaponic Farming}

UK's first commercial-scale aquaponic farm is located in a shed. This vertical farm combines the practices of aquaculture (farming fish) and hydroponics (farming vegetables sin-soil) into one recirculating system known as aquaponics. When fish produce waste, the water is enriched with nutrients. Beneficial microbacteria in the water converts waste into fertilizer for plants to absorb, which in turn filter clean water back to the fish. This system is (almost) closed loop with the added input of fish food.

\section{Vertical Farming}

Using LED lighting, GrowUp can supplement sunlight in a controlled environment which allows for intensive farming in smaller spaces. Located inside an industrial warehouse in Beckton, the farm has only 6000sqft of growing space, producing 20 tonnes of salads and herbs each year (compared to
Lufa's first farm at 32,000sqft, yielding 75 tonnes). The use of LED over natural lighting however can increase operational costs. In addition to growing vegetables, $4000 \mathrm{~kg}$ of fish are farmed at GrowUp each year. Tilapia are the fish of choice, preferring to live in large colonies. They have been well-trialled in aquaponic systems, according to the business on talks of fish welfare (GrowUp Ltd).

If this system were to be incorporated into the thesis proposal of a rooftop farm, a question quite simply could be 'where to put the heavy fish tanks?' Surely weight issues need to be addressed. Further comparisons of why an aquaponic system would be preferable over traditional hydroponics and soilbased farming is discussed on the following pages.

Strengths: innovation and technology. An (almost) closed loop system. Fish can be sold as produce as well as vegetables. 


\section{Hydroponic Farming Systems}

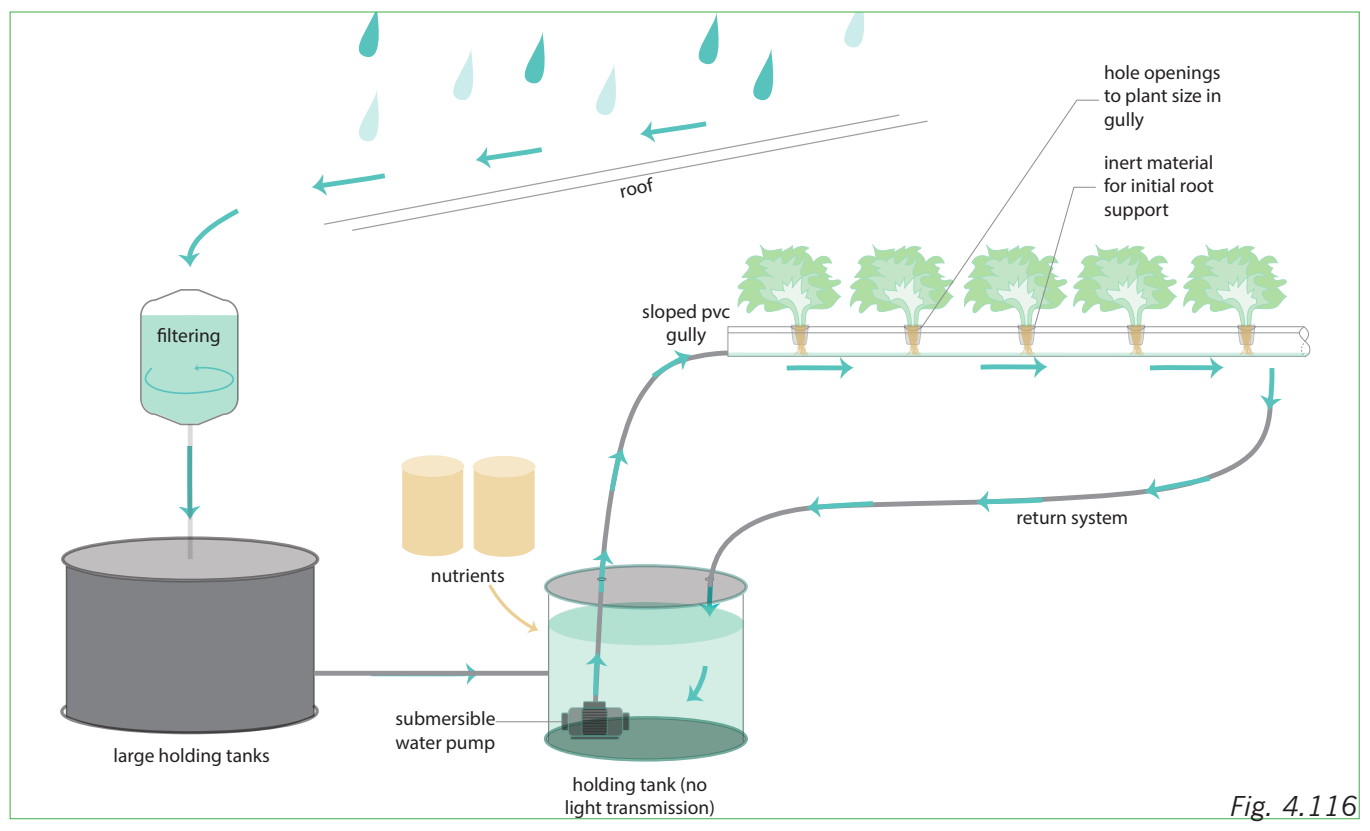

Traditional Hydroponics

- NFT (nutrient film technique)

- Man-made nutrients added

- Water needs careful

monitoring at all times

- Water needs to be discharged

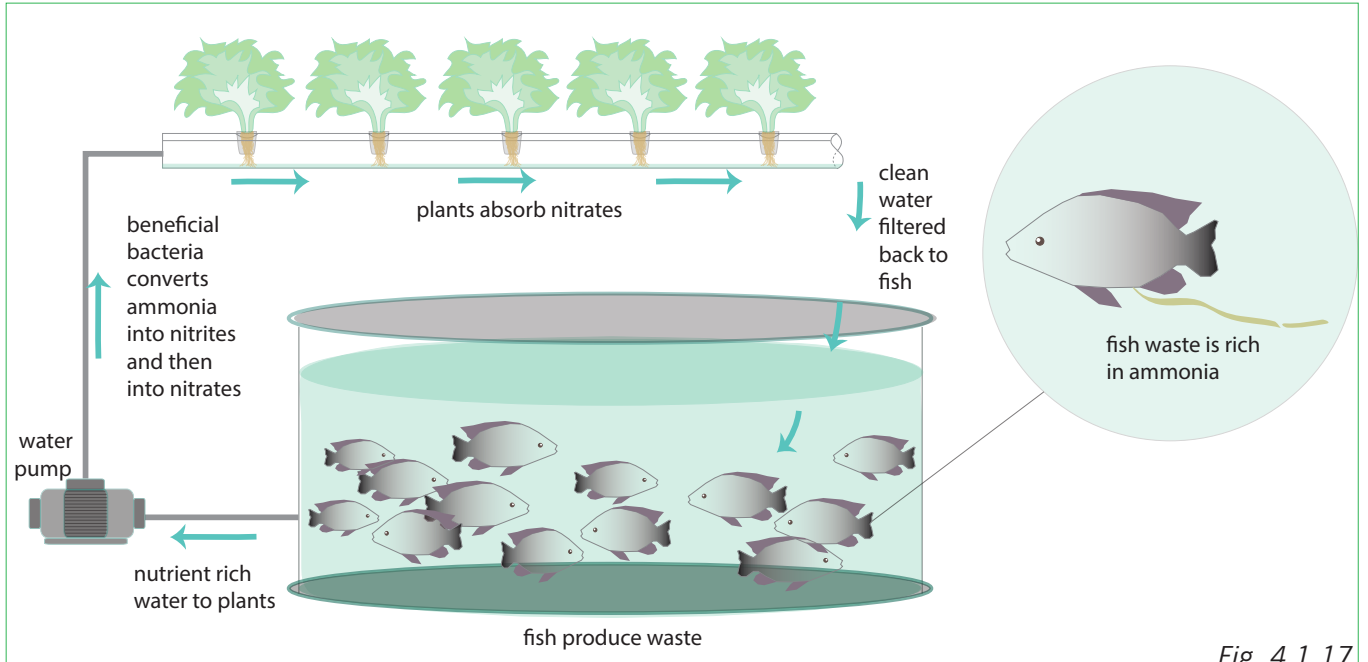
regulary

\section{Aquaponics}

- Aquaculture + hydroponics - Fish waste provides nutrients for plants as a natural food source

- Near closed-loop system

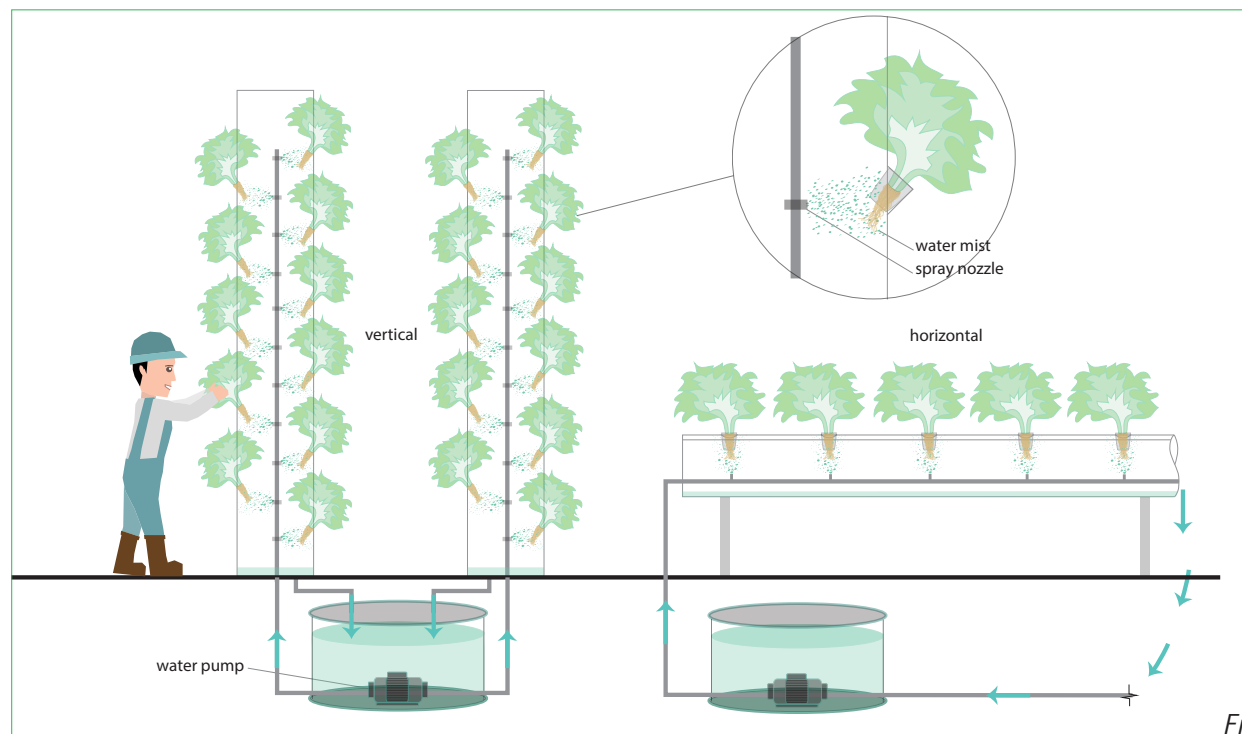

\section{Aeroponics}

- Suitable for vertical growth - Mist ensures even application 


\section{Hydroponic Farming Configurations}

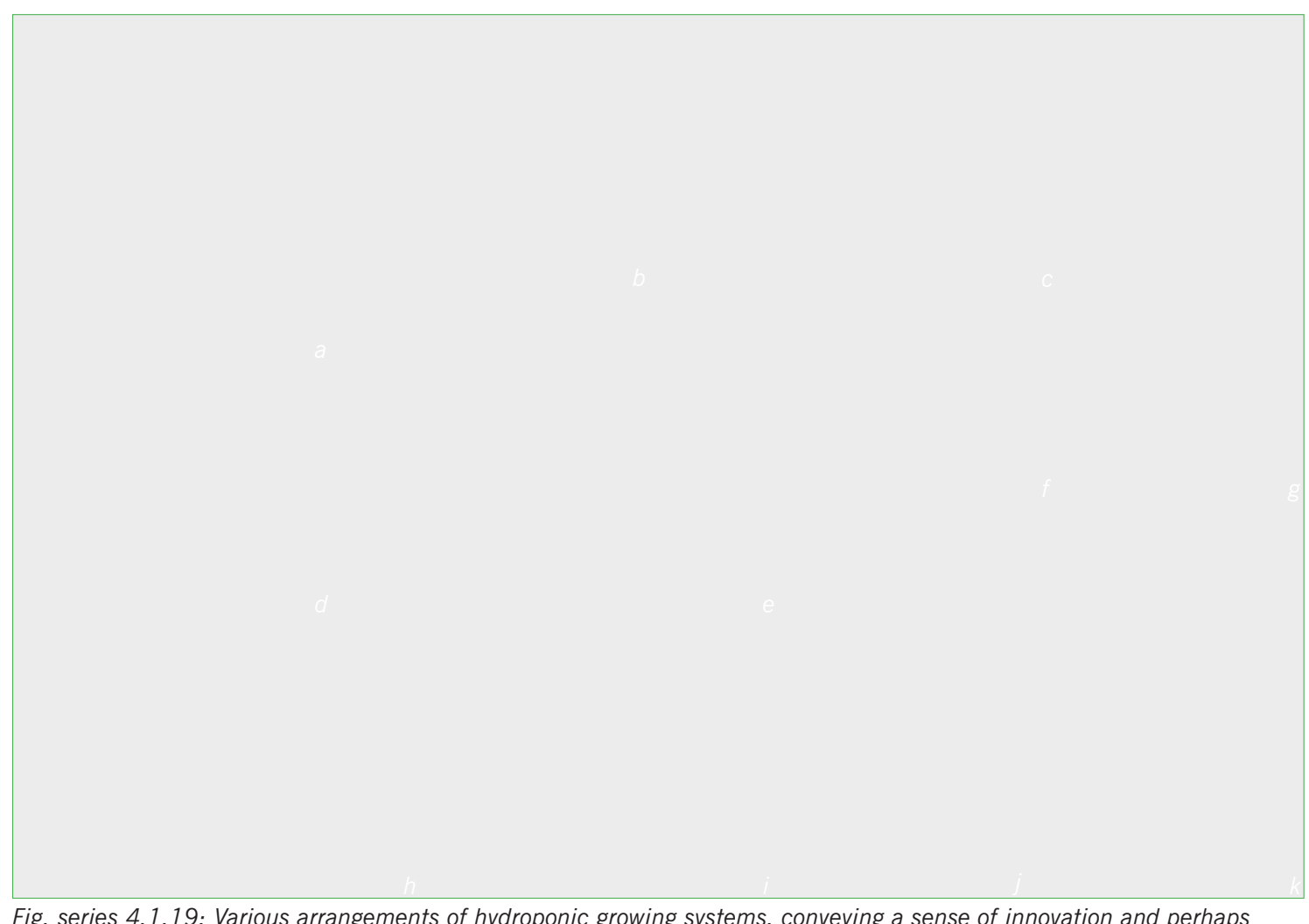

Fig. series 4.1.19: Various arrangements of hydroponic growing systems, conveying a sense of innovation and perhaps even providing a heightened experience at a human scale.

Compared to traditional soil-based farming, indoor hydroponics allow more control of the overall production process. It eliminates problems with weeding, water quantity, soil-borne insects/outdoor pests and importantly - the reliance on weather conditions, resulting in highly consistent produce quality and quantity.

The options to configure hydroponic systems are bountiful, so long as crops receive adequate water and lighting. From a design perspective, this implies and offers opportunities to be creative with hydroponic crop arrangement. Fig. series 4.1.19 shows numerous methods of setting up such systems. The evolvement from soil to hydroponics has potential in achieving aesthetic character and even a spatial experience in intensive farming compared to traditional soil based farming of the single plane repetitive row.

At this design scale, it becomes a matter of human interaction. The crops can be treated not as an 'insert' into the greenhouse but rather, a part of the architecture itself. This very human scale of design will be explored as part of the design development of an urban farm for this thesis. 


\section{Food Parliament}

Iondon / cj lim / 2014

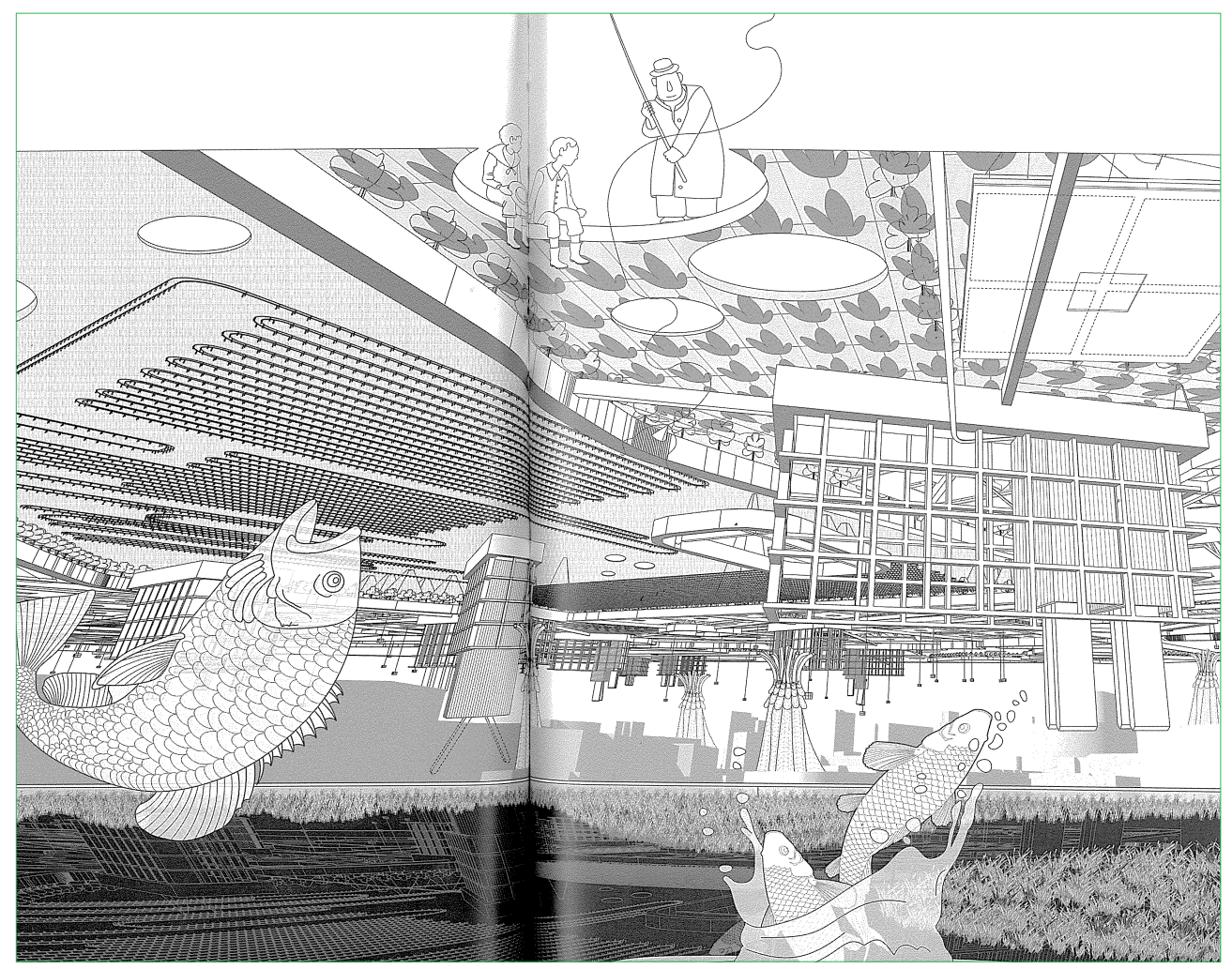

“...food

ultimately

promotes

dilution of

cultural

boundaries,

and restores

the primal

link between

urban

inhabitants

and their

sustenance."

-Lim, CJ. Food

City. (2014)

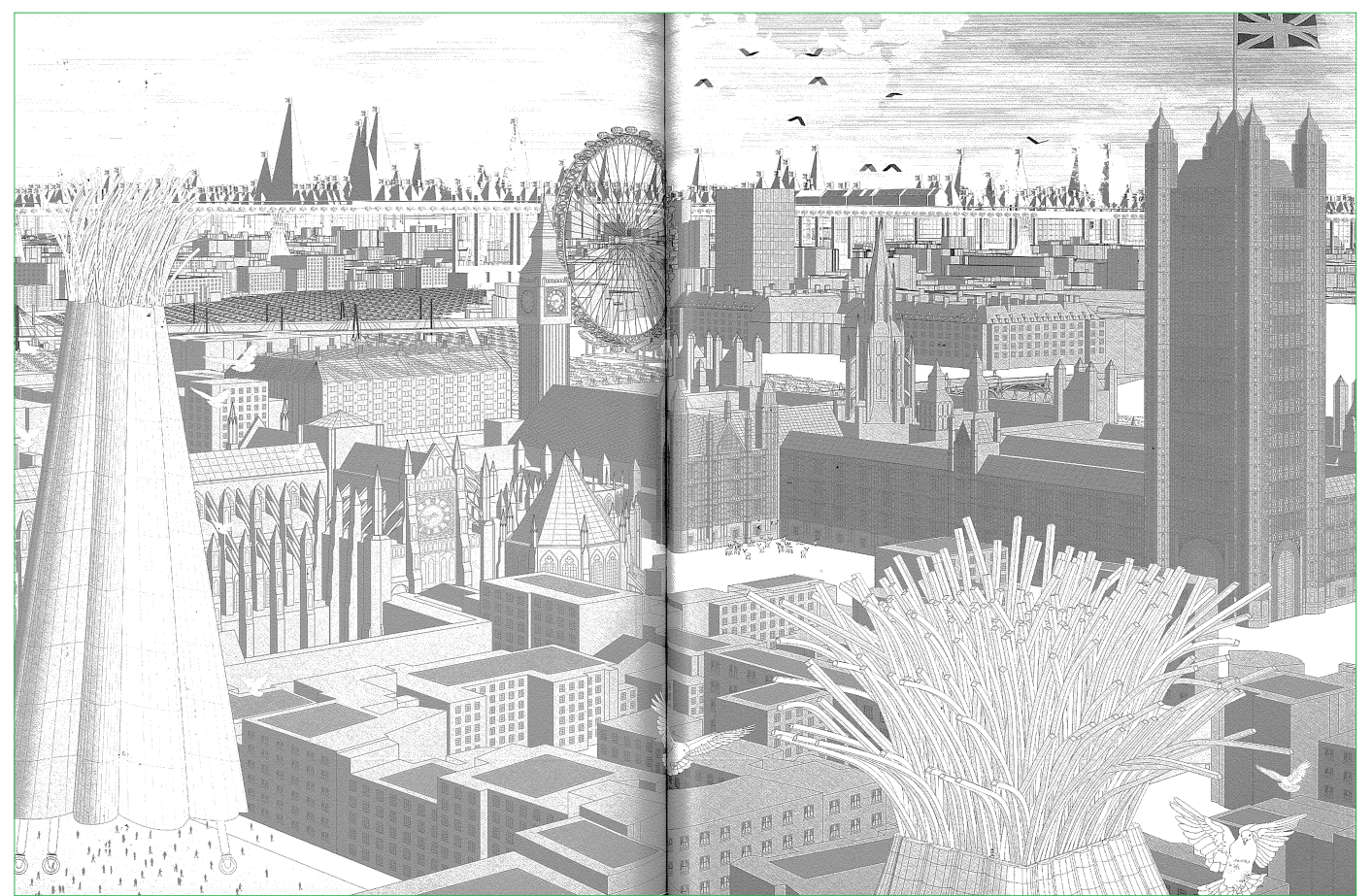

Fig. series 4.1.20: Renderings from Lim's Manifesto for The Food Parliament of London 2080. 
Urban Skyfarm

seoul / steve lee / 2009

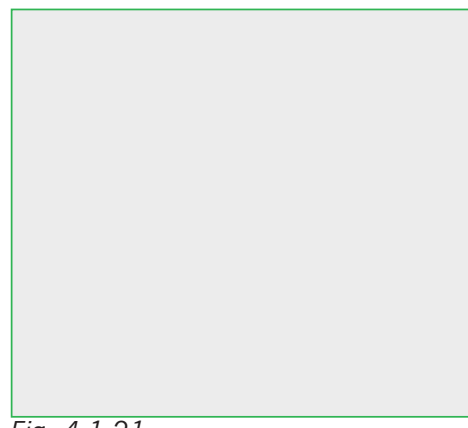

Fig. 4.1.21

Locavore Fantasia

new york / work architecture / 2008

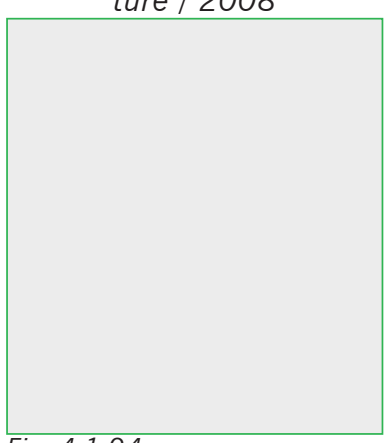

Fig. 4.1.24

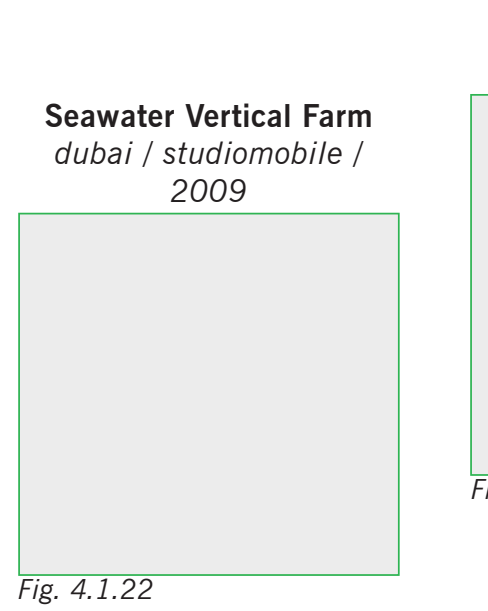

Urban Food Jungle new york / AECOM / 2012

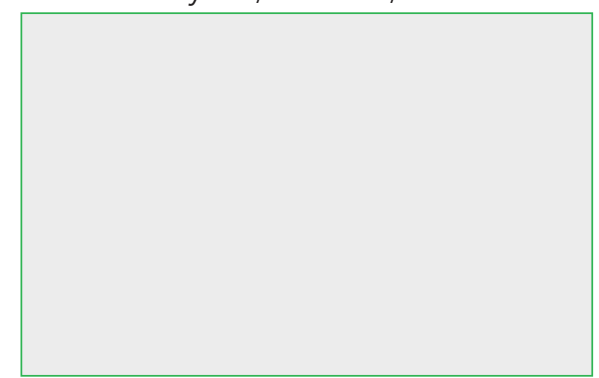

Fig. 4.1.25

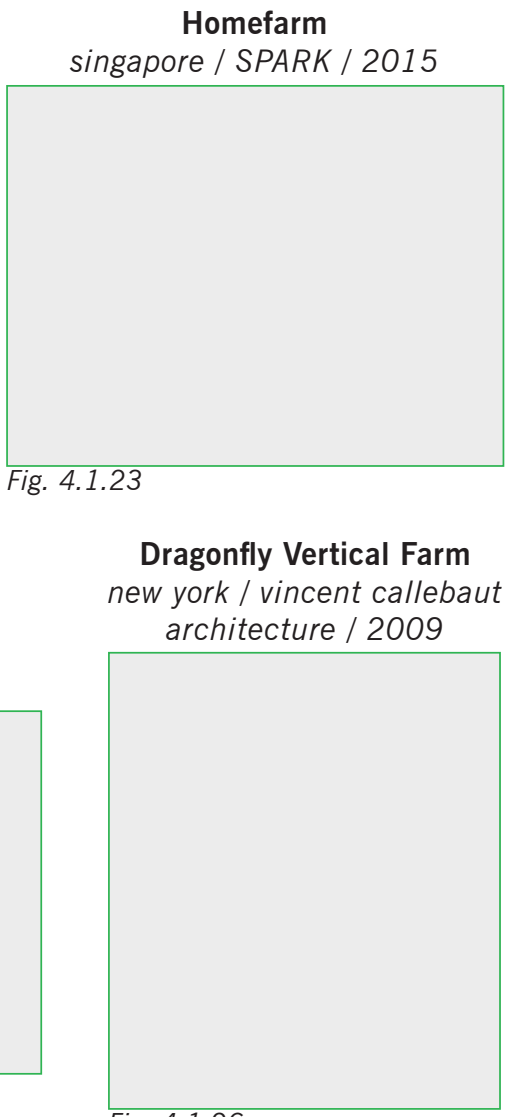

Fig. 4.1.26
Even among urban farming proposals of a speculative and at times utopian nature, there are varying degrees of viability. Some such as Homefarm (fig. 4.1.23), a conceptual retirement village in Singapore, appears more achievable than the immensely ambitious Dragonfly Vertical Farm in New York (fig. 4.1.26). Perhaps to some extent, it comes down to scale but ultimately their ability to respond to their contextual environments would either confine or liberate these proposals as purely "paper architecture". It becomes clear that a well-integrated farm in the city should be inclusive of all people whether or not they use the new facilities as intended. There should be activities that cross over with the existing social, economic and environmental context. The significance of such places are meaningless when there is no relation to people.

The modest practice of growing food has been taken to radical levels of innovation in the Food Parliament for London (facing page). Such visionary constructs - undoubtedly confined to be paper architecture - do more in advocating for awareness and understanding of a very real issue, given very little attention by those in power.

Having big visions is hardly a hindrance on design. It is in fact a necessity in opening the door for change - not of the physical environment but in ways of thinking, where the foundation is set. 
Elbphilharmonie

hamburg / herzog \& de meuron 2016

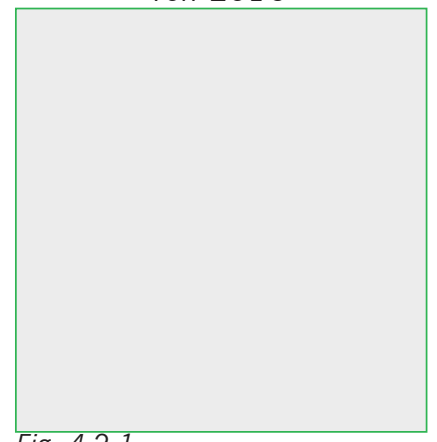

Fig. 4.2 .1

Art Museum lillehammer / snøhetta 2016

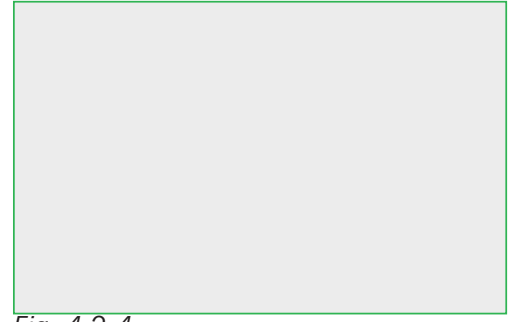

Fig. 4.2 .4

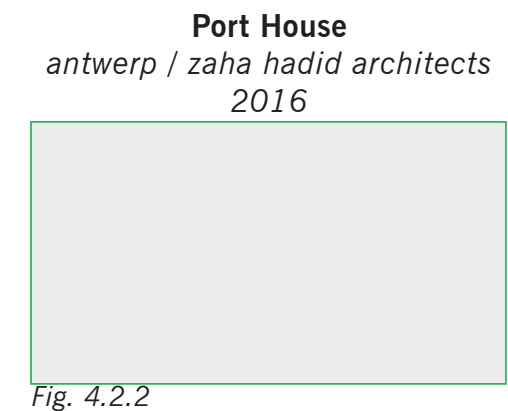

Fig. 4.2 .2 Iondon / tonkin liu 2001

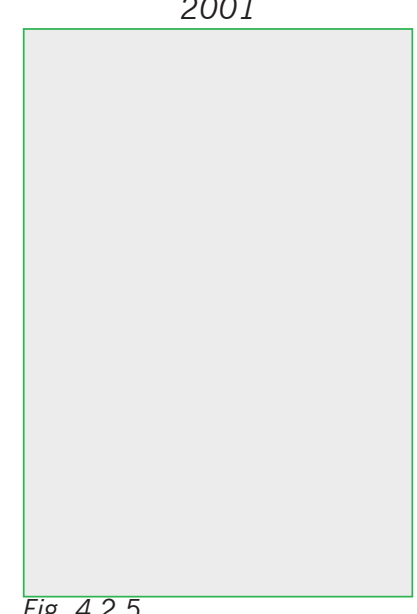

'Priceless Milano' milan / park associati 2015

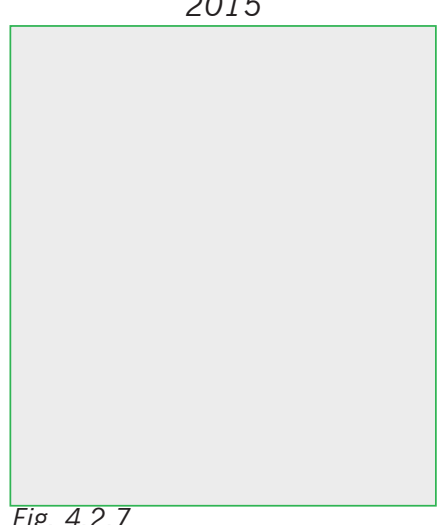

Giovanni e Marella Agnelli Art Gallery

torino / renzo piano 2003

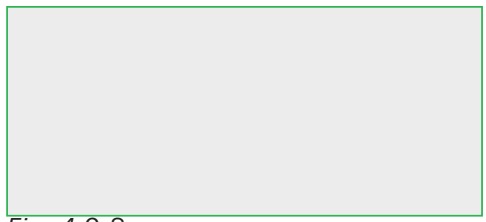

Fig. 4.2.8
'Detached' Urban Hut

athens / panos dragonas \& varvara christopoulou

$$
2015
$$

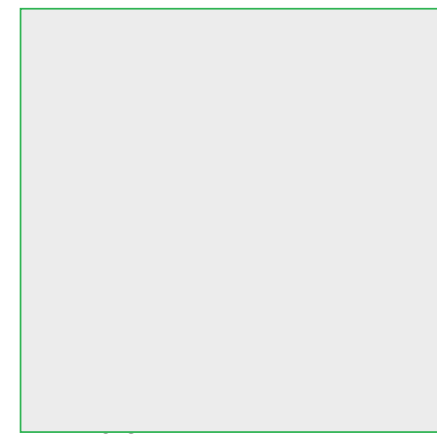

Fig. 4.2 .3

DVF Studio

new york / work architecture 2008

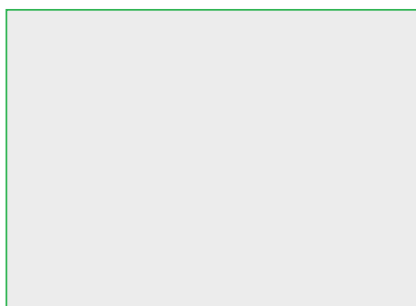

Fig. 4.2.6

Office Extension

Falkestrasse

vienna / coop himmelb(I)au 1988

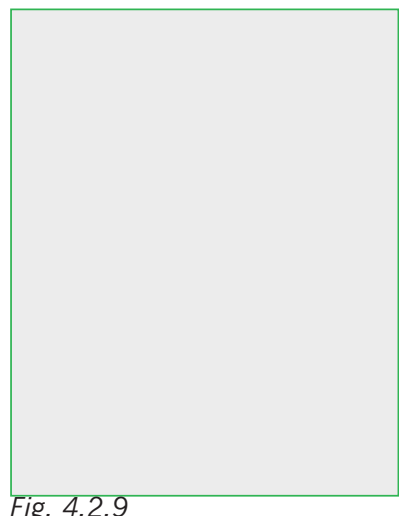

Fig. 4.2 .9 


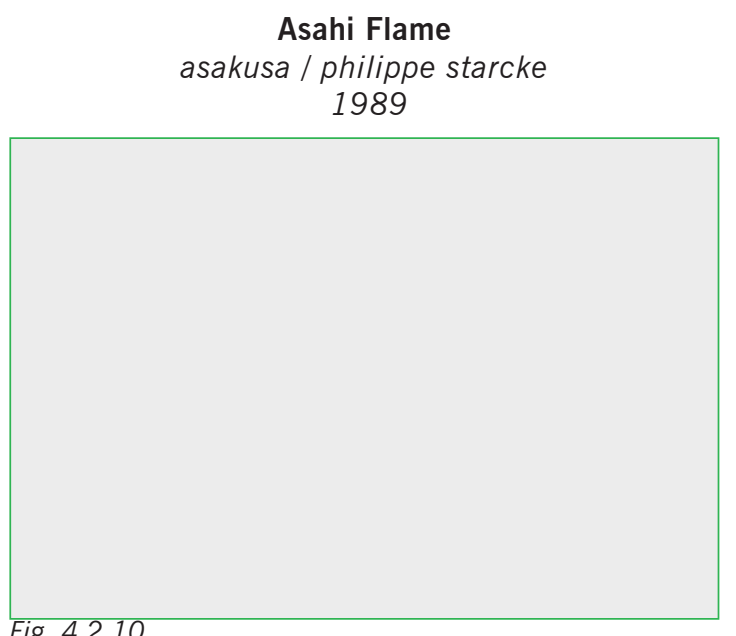

\section{A Top Job}

With the decreasing availability of land in developed city centres, the need to build 'up' has never been more critical. This often takes the form of rooftop additions to existing buildings, the more noticeable examples owing to strong design intentions. They range from extensions of the host building in a similar fashion to constructions taking on an entirely different nature.

One attribute they have in common is how the host building often presents itself as a platform - a stage ready to be graced with a new act. In cases such as Growing House (fig. 4.2.5), the addition is mindful of existing structural proportions. The stark contrast in building materials reflects a new era, allowing it to pose elegantly atop the old warehouse. In other cases, designs tend to take on a more daring nature - attempting to achieve the opposite of blending in and taking on sculptural qualities that defy the formalities of the building below. This seems apparent at varying scales of construction. Take the Asahi poo flame for instance (fig. 4.2.10). If its objective is to grab attention from passersby, it surely achieves that.

Essentially as with any architectural project, the outcome is determined by initial design intentions, so there is no singular approach that takes precedence over another. The vast range of rooftop additions shown primarily display it is the method in which they come in contact with their respective platforms that is of most interest here.

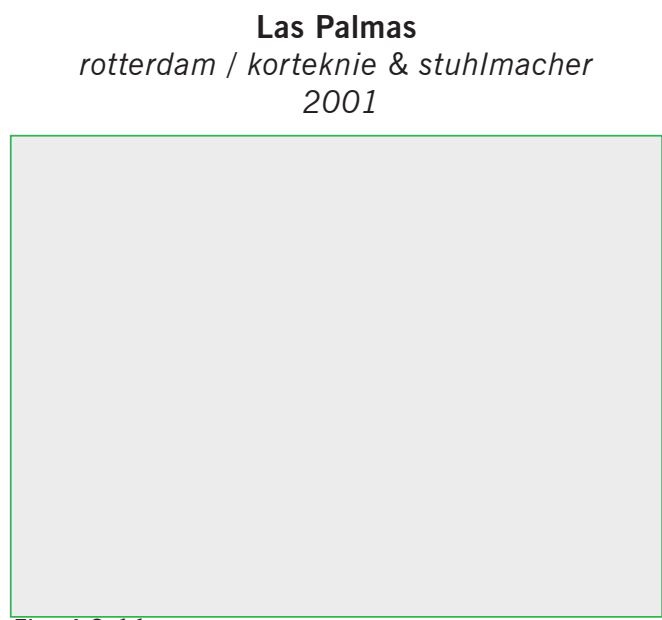

Fig. 4.2.11
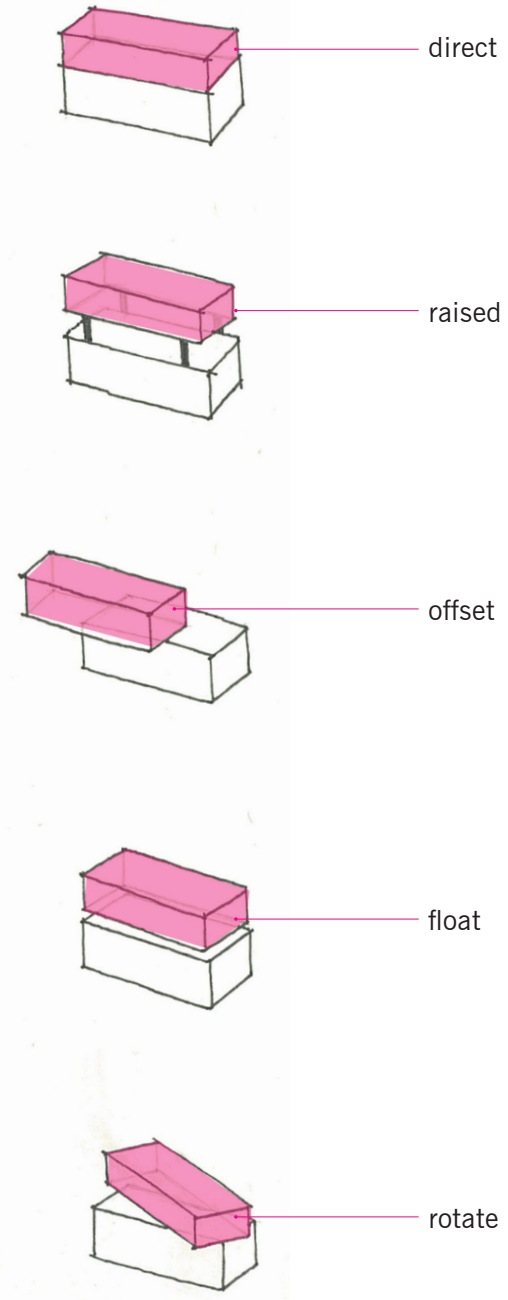

Fig. 4.2.12: Various examples of rooftop addition methods. 
New York High Line

new york / james corner field operations,

diller scofidio + renfro, piet oudolf / 2014

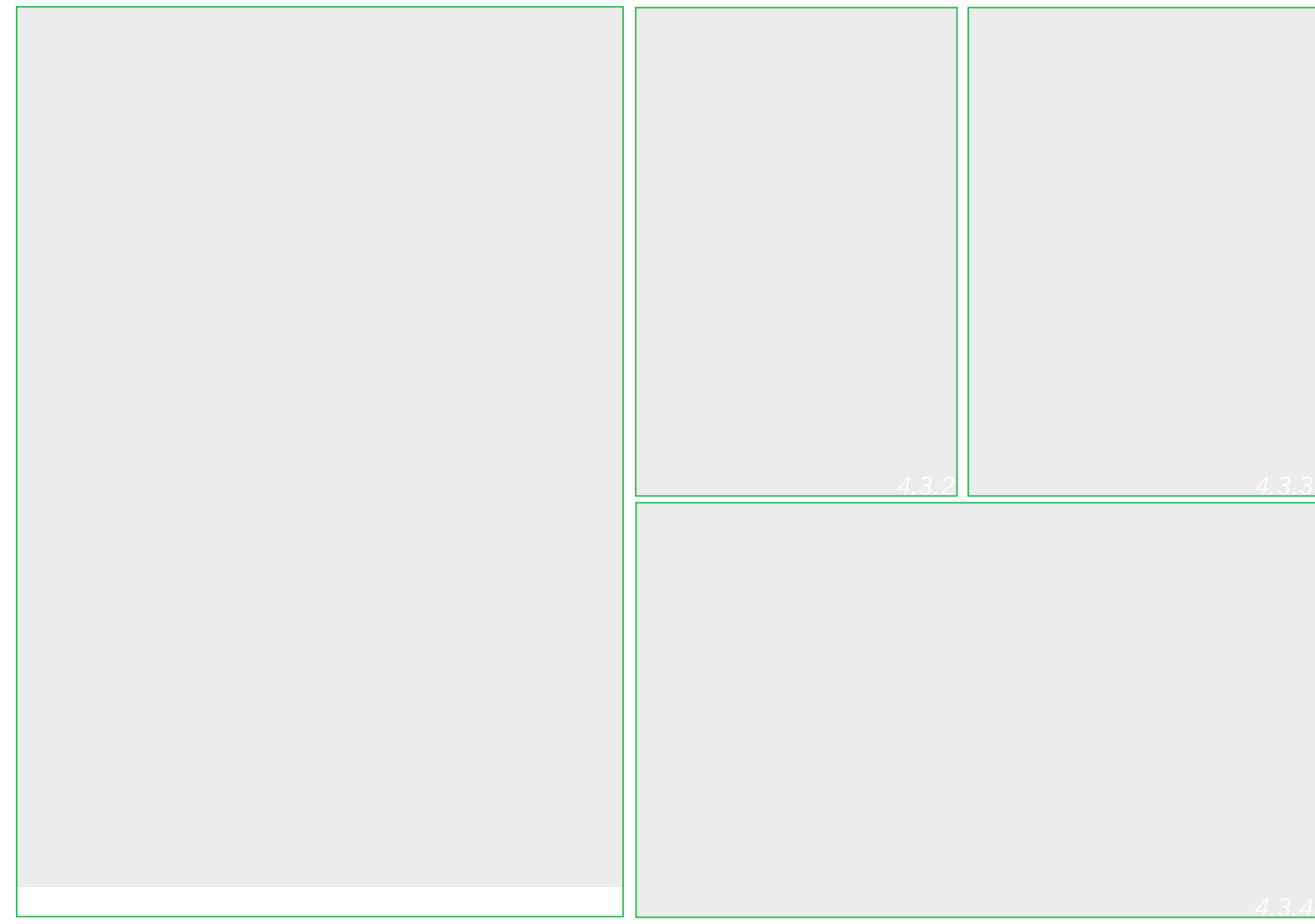

Figs. 4.3.1 - 4.3.4: The High Line as seen from different perspectives.

\section{An Elevated Attraction}

Well documented across a multitude of disciplines is New York City's High Line project. Spanning 22 city blocks at $2.33 \mathrm{~km}$ along west Manhatten, the linear park was born out of an ambitious infrastructural conversion of the former freight railroad. To this day, it remains one of the most successful urban design projects in adaptive reuse. Its success measured not only by popularity but with an identity gifted to the city - an accessible public space that plays host to a myriad of events, offering city vistas and conveniently connects upper and lower west Manhantten. The elevated route attracts crowds of people everyday, encouraged by highlights such as the many points that maximise views, spaces of relaxation and the varied landscaping elements that inspire walking (Center for Active Design). As a precedent for public space design, this project is invaluable. But even more could be learnt of its "architecture." Diller Scofidio + Renfro summed it up perfectly saying that their job was to "defend the High Line from architecture." It was never about a big architectural statement - "it was really pullingback from architecture" (Winston).

Strengths: landscape design, urban/contextual connections, mix of uses, views of the city, accessibility. Designers had an understanding of architecture's value during its inception. 


\section{City to Sea Bridge}

wellington / john gray, rewi thompson, para matchitt / 1994
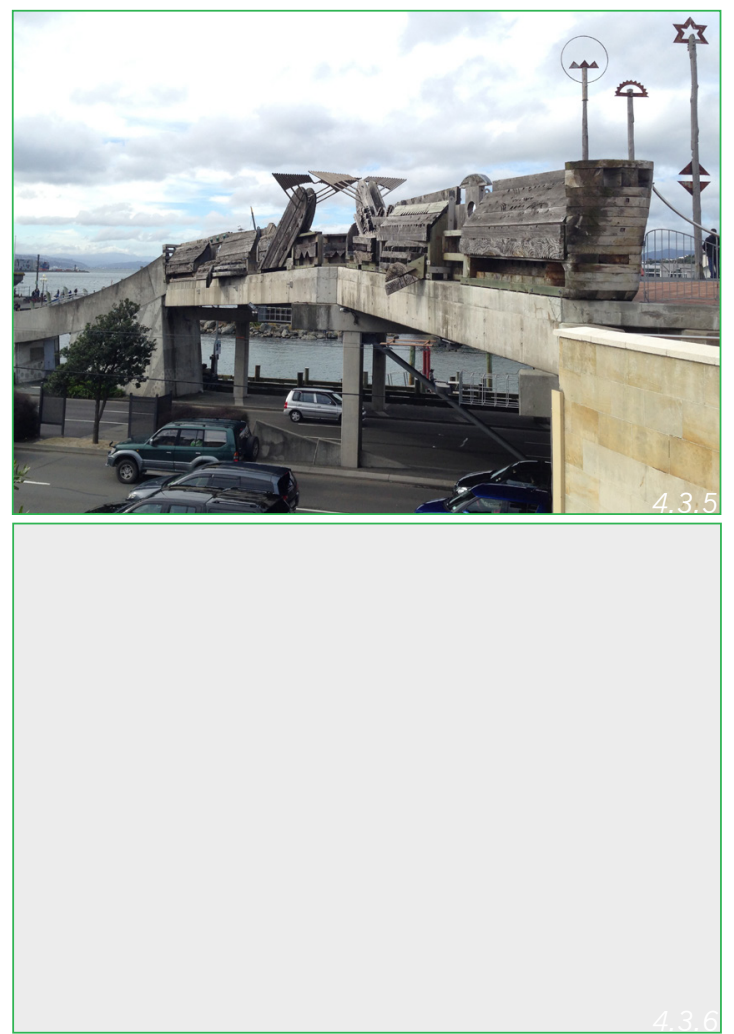

Figs. 4.3.5 - 4.3.6: The City to Sea Bridge is a Wellington icon.

\section{City Character}

The City to Sea Bridge is as much a sculpture as it is a reinforced concrete and timber pedestrian bridge, linking Wellington's Civic Square with the waterfront. The artwork adorning the bridge "signals the increasing prominence granted to Maori culture within the realm of public art" (Harper \& Lister 16). And though some may label the bridge as untidy/ an eyesore/lacking structural logic (Arch Centre), it is arguably much-loved by Wellingtonians due to its distinct quirkiness, reflecting the city as a creative, crafty capital. Though it is no architectural masterpiece, it represents exactly the mix of eclectic design styles that defines Wellington city.

Strengths: urban connections and contribution to city character. Along with city and harbour views, the bridge offers a mix of primary uses from a thoroughfare to intimate spaces for relaxation.
Secondary Landscape tokyo / mount fuji architects studio 2004

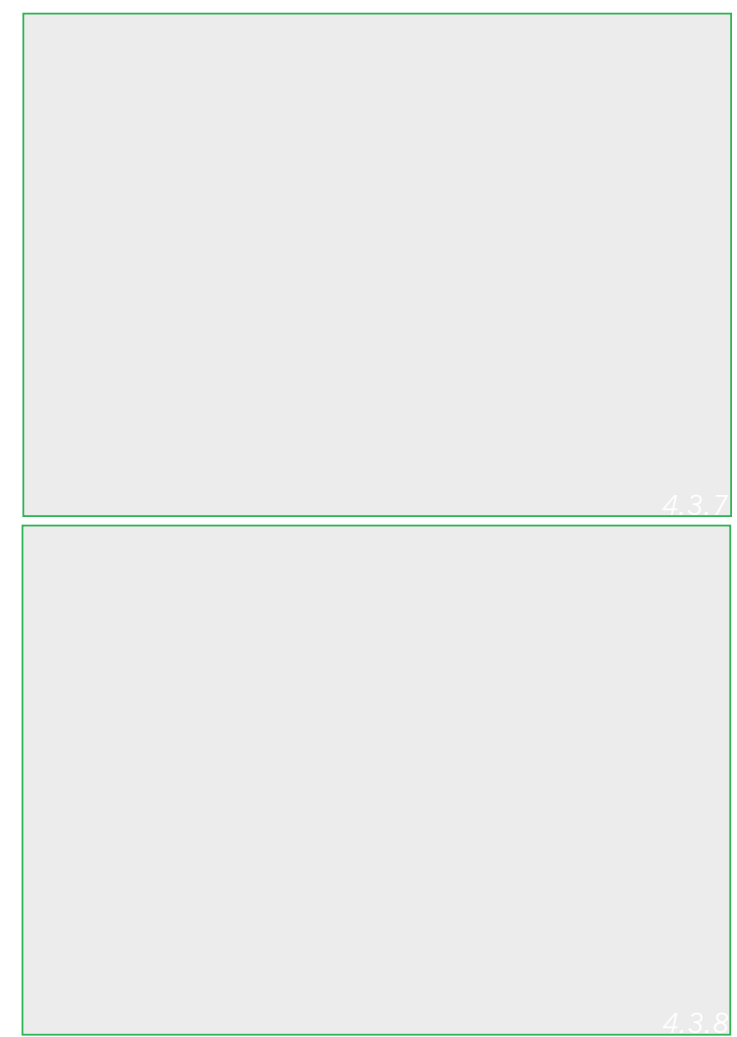

Figs. 4.3.7 - 4.3.8: A rare urban retreat.

\section{Land on Building}

In a concrete jungle such as Tokyo, bare land for outdoor recreation is scarce. Here, the rooftop of a cosmetology school was transformed into an urban retreat by introducing a landscape covered with western red cedar. The slope follows that of the original irregularly-shaped roof, encompassing a void in the centre. This thoughtful design response results from the architects viewing the challenging circumstances as an opportunity to add dynamism to the open space. "Architects are principally expected to build things on land...on this particular occasion, we create a land on building" (Divisare). One uncertainty however is how much this space is used.

Strengths: contextual response to existing roof form. Contrast with host building adds distinctivity to overall form. 


\section{Wellington Chocolate Factory} wellington / 2010

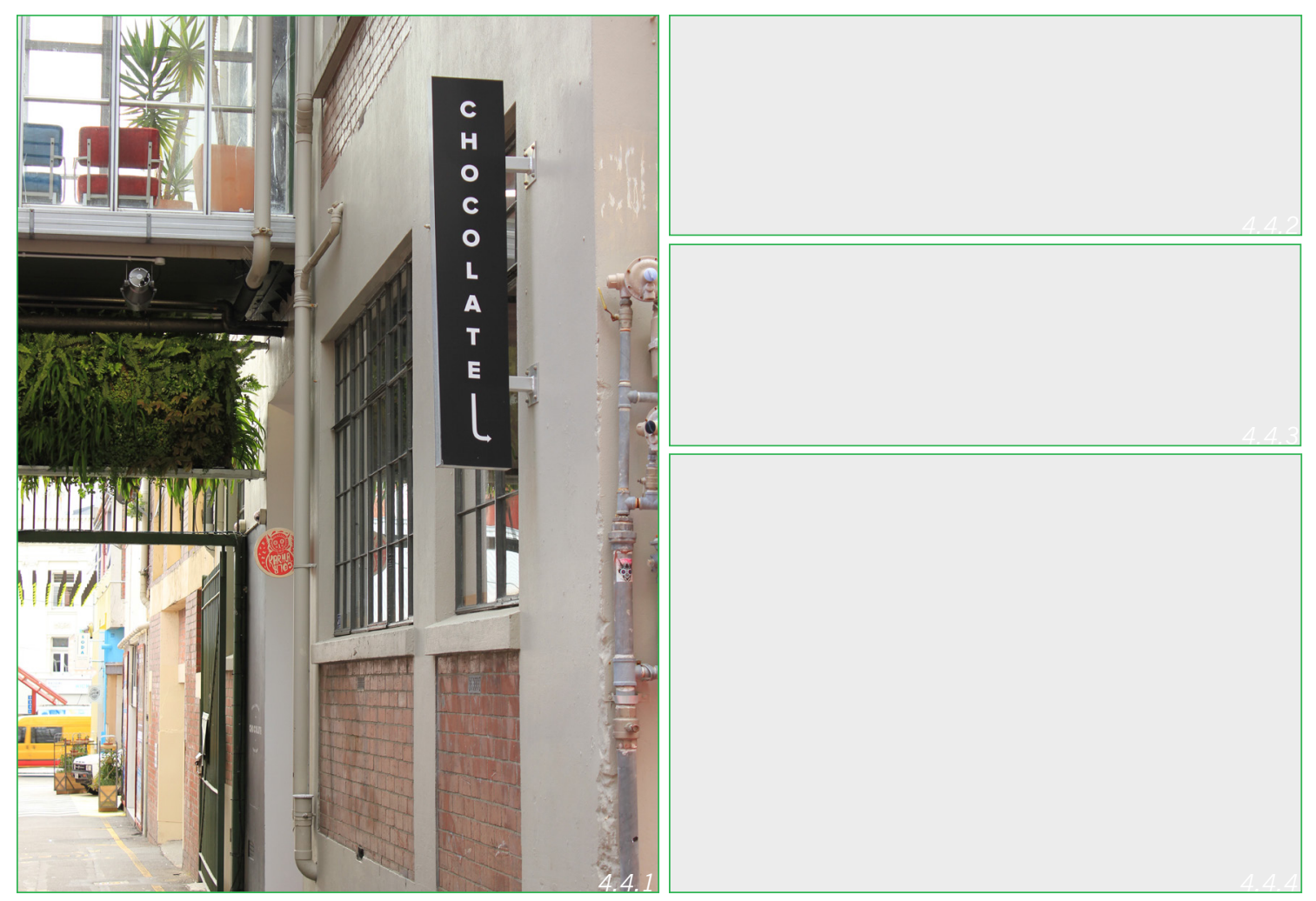

Figs. 4.4.1 - 4.4.4: The Wellington Chocolate Factory on Leeds St.

\section{A Sweet Spectacle on Leeds}

Current trends within the capital's emerging food scene indicates an interest in production processes as part of the consumer experience. On the rise are eateries with open kitchens encouraging customers to engage visually with their food, adding to the drama of a busy dining scene. The chefs perform and the customers watch as their food is prepared. This transparency of business process is at once interesting, educational and dynamic, adding a highly valuable dimension to the overall experience.

The cross-programming of production and consumption (whether purchasing or eating) is exemplified along Leeds Street in Wellington. Stores such as the Wellington Chocolate Factory, its neighbour Leeds St Bakery and the nearby Best Ugly Bage/s (sited a block over) are a few Wellington examples. All exhibit transparent production processes from raw ingredients to shelf/ plate. Their proximity to one another strengthens the production-as-performance concept extending to support each other's local businesses.

The Wellington Chocolate Factory aims to stay true to their "bean-to-bar" motto. They host free public tours every Saturday, display information of their produce origins and even store sacks of cocoa right at the entry. Though the element of consumption is vital in sustaining the business, it is only an option - one that usually takes place due to customer satisfaction in feeling as though they were a part 
Leeds St Bakery

wellington / 2013

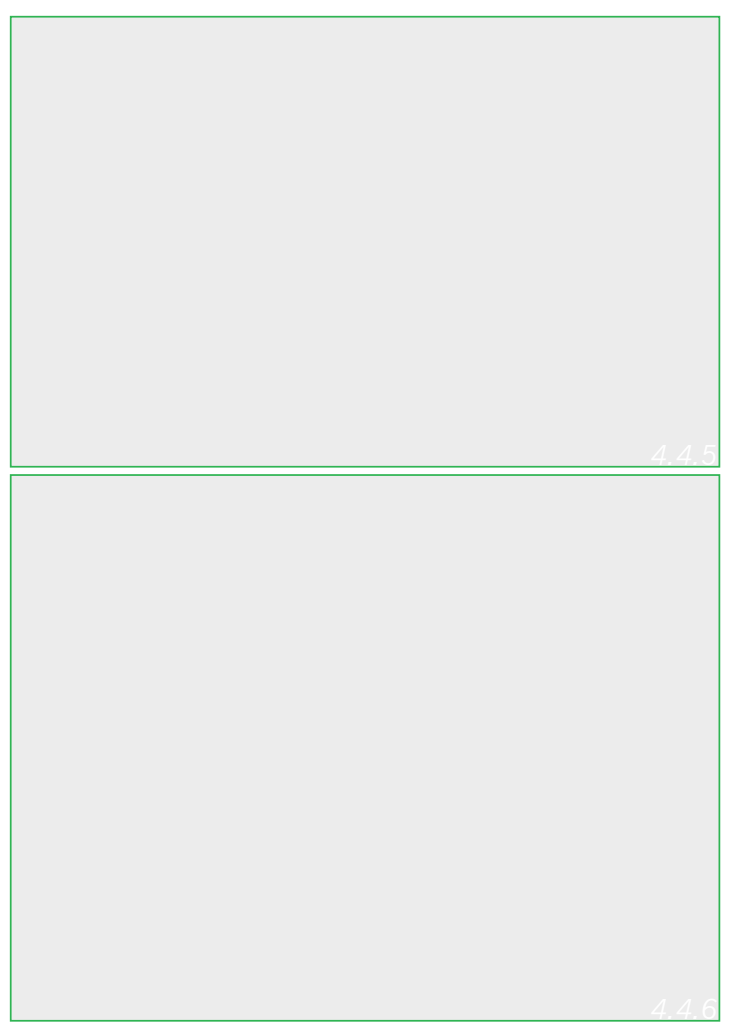

Figs. 4.4.5 - 4.4.6: Freshly baked bread in view.

of the activities around the store. Equally, Leeds St Bakery prepares bread centre stage in their premises. The glass frontage provides effortless visual access into the store where the environment is dominated with machinery and projects continuous baking activity. Best Ugly Bage/s has a similar idea. One exception appears to be their focus on a 'feature equipment piece' being the brightly coloured green shoot in keeping with the industrial theme, where freshly baked bagels miraculously slide out (figs. 4.4.7-4.4.9).

These places of production demonstrate ability to provoke curiosity not only among returning customers but passersby. The strategy in sharing their production process has in turn been rewarded
Best Ugly Bagels wellington / 2016

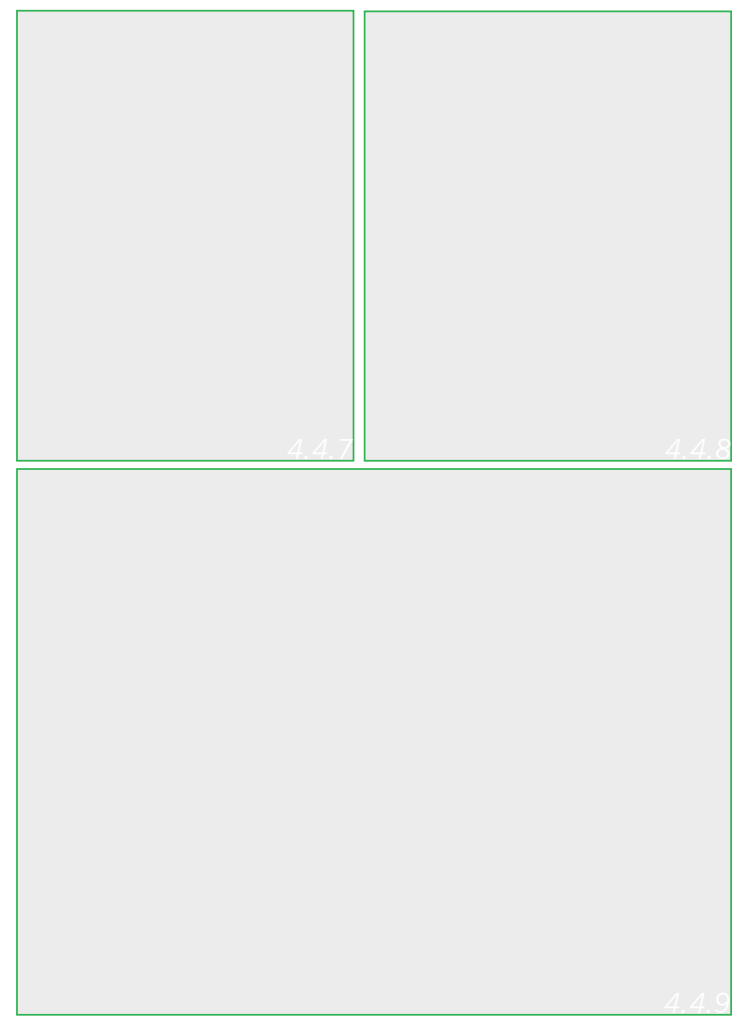

Figs. 4.4.7- 4.4.9: Machinery adds to the anticipation.

with consumer interest in their products, allowing them to achieve economic success even if prices are slightly above average. The design implications point towards allowing for easy visual access, open plan spaces and operational equipment being celebrated in full view, perhaps even custom designed. The application of this to an urban farm would be of high value.

Strengths: transparent production processes engages and educates public. The education is received passively and effortlessly, but the resulting consumer experience is more profound as customers connect on a deeper level with their food. 


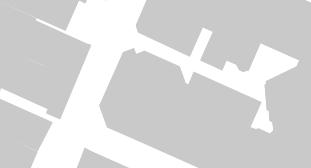


[5.0] SITE

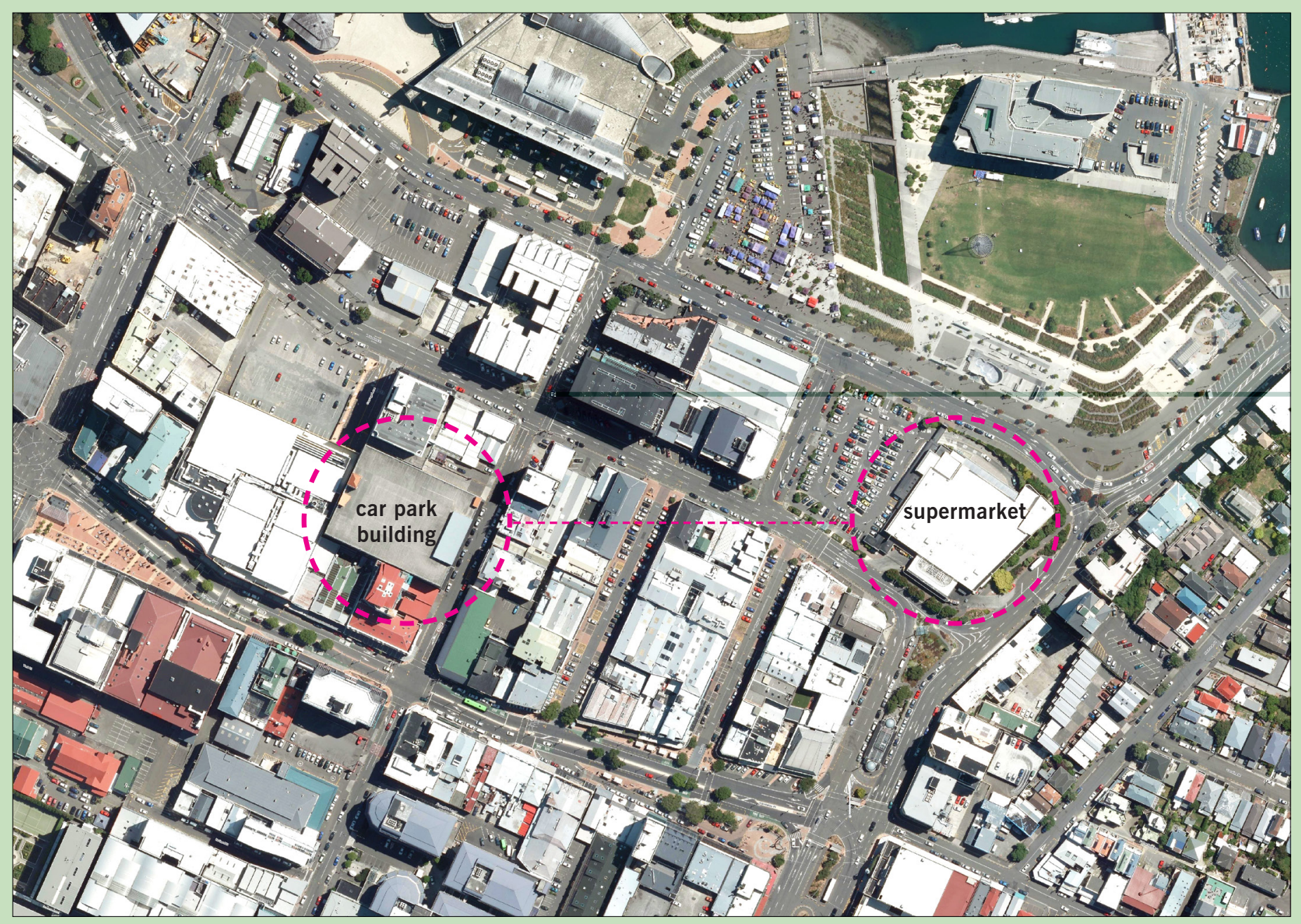

Fig. 5.1: Two rooftops proposed as sites for urban farms.

In selecting a suitable location for the urban farm, factors at the macro, intermediate and micro scales around the site are taken into consideration. Of interest at macro level is the wider city and how the location of the project could offer improved urban connections for pedestrians, but also its proximity to urban 'food spaces' such as supermarkets, specialist food stores, eateries and fresh produce markets. At an intermediate level, the investigation considers how the rooftop addition could impact the surrounding site. Lastly at micro level, the host building for the rooftop addition is examined.

Fig. 5.0 (facing page): figure-ground map of south-eastern Wellington CBD, with selected rooftop sites highlighted.

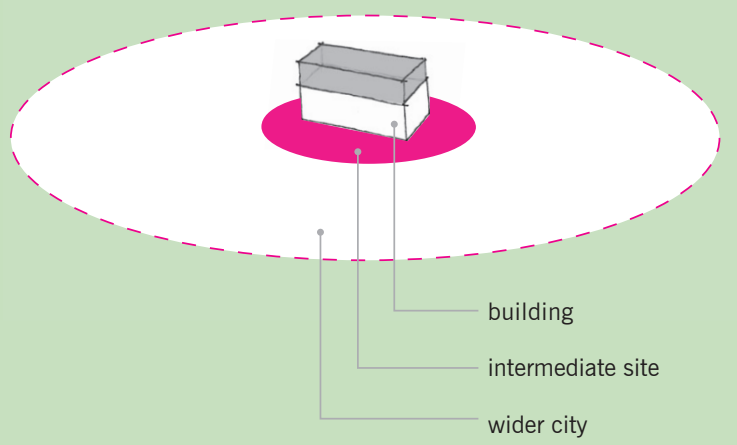

Fig. 5.2: Micro, intermediate, macro levels of analysis (not to scale, indicative only). 


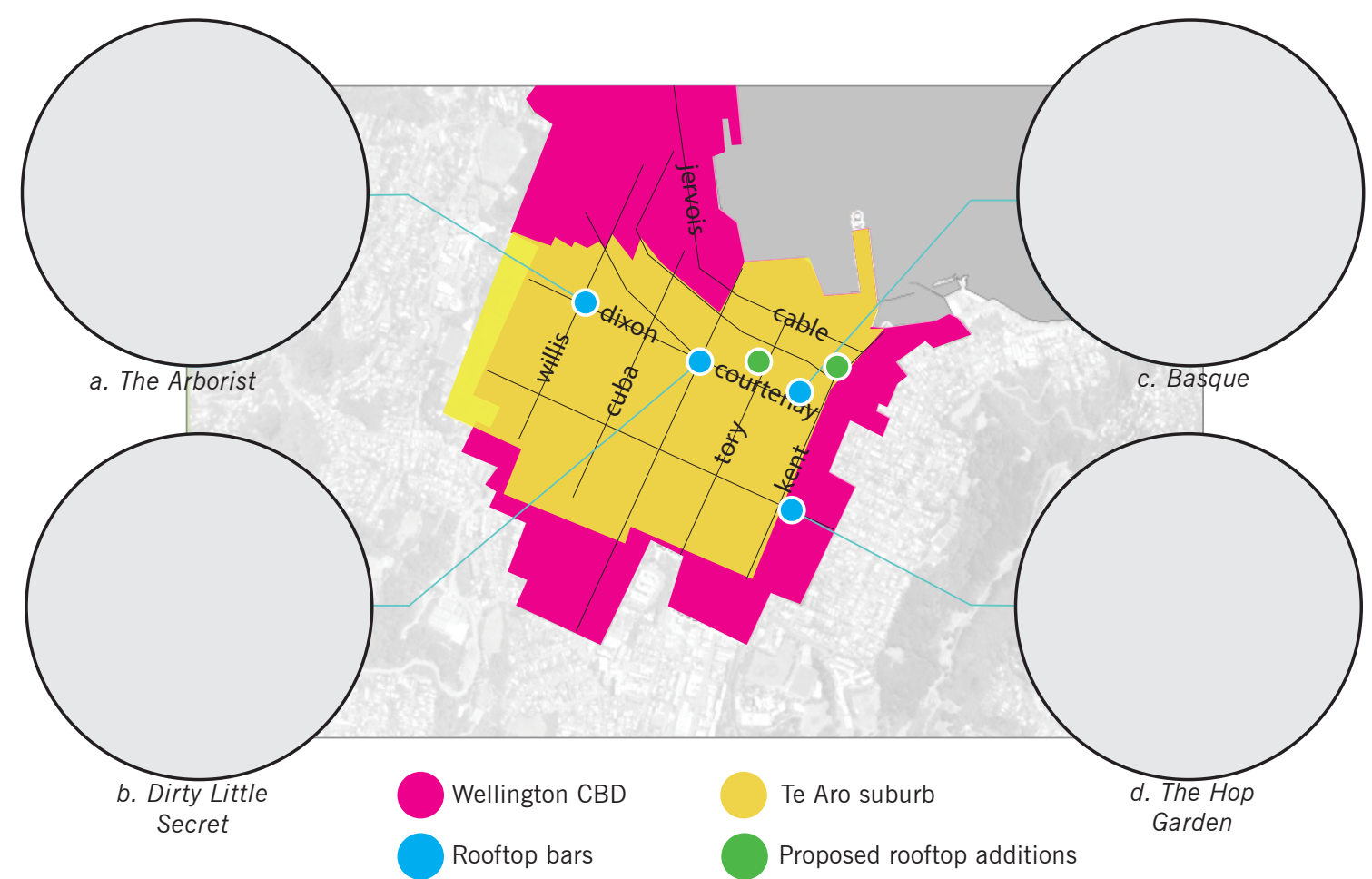

Fig. 5.1.1: Known rooftop bar activity in Te Aro along with the proposed additions to the rooftop scene. Refer to fig. 1.1 for full $C B D$ map.

\section{Macro Analysis}

Wellington boasts a small number of accessible rooftop businesses within the inner city suburb of Te Aro, the known ones being rooftop bars (fig. 5.1.1). Most are sited along the Courtenay route (Wellington's entertainment venue), yet there is little networking between them, perhaps due to distance. A known rooftop network, whether social/ cultural could strengthen Wellington's rooftop scene. This could begin at street level by examining pedestrian routes.

Of particular interest at a macro level analysis is the city to waterfront connection where a number of pedestrian routes are available. The relevance of this stems from using an existing urban connection that could benefit with the proposal of a rooftop addition. Fig. 5.1.2 shows two routes of interest. The wide Cambridge and Kent route was historically a water channel linking the harbour to the Basin Reserve (previously Basin Lake, a lagoon) and provided a path for ships into the city. Basin Lake was hence proposed as a docking area. But the 1855 earthquake eradicated any plans of developing the canal and dock as Te Aro flats were resultantly raised by two metres (Wellington City Council). This city to waterfront connection is evident in plan, but not via a pedestrian experience. It is consequently underrealized due to heavy vehicular traffic taking precedence and along with the erection of $\mathrm{New}$ World supermarket in 1993, harbour views have been interrupted ever since, even when one is upon approach to the water (fig. series 5.15).

Located nearby on the same city-waterfront axis is Tory St. Though this street is of a much narrower build, it still accomodates a fair volume of traffic spanning between National War Memorial Park and Te Papa Museum. The narrow width of Tory is perhaps a strength in providing a more affable environment for pedestrians than the wide Cambridge and Kent terraces. It offers a mix of 
MACRO

ANALYSIS

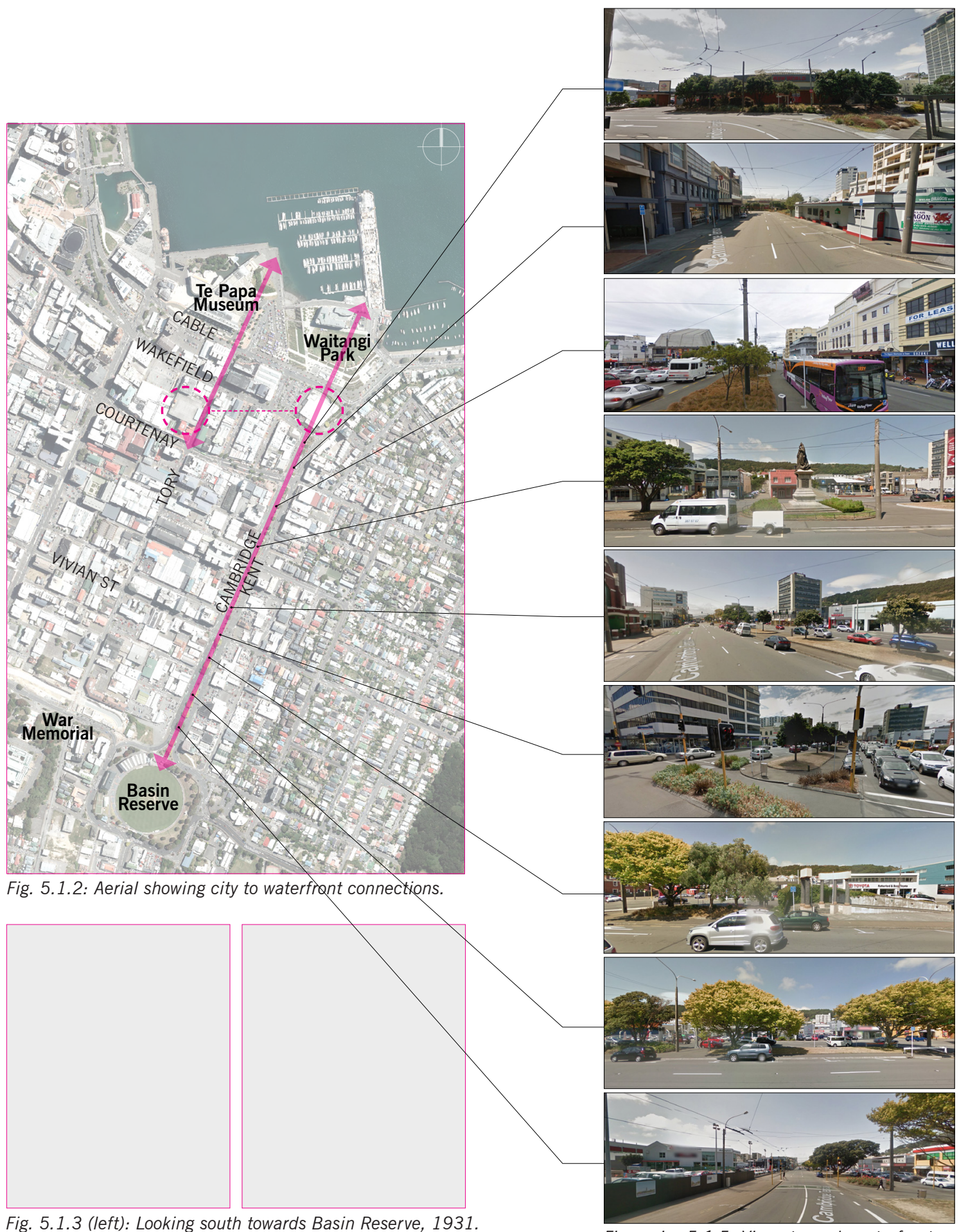

Fig. 5.1.3 (left): Looking south towards Basin Reserve, 1931.

Fig. 5.1.4 (right): Looking north, the old Taj Mahal public

toilets (now Welsh Dragon Bar, heritage-listed) sits between

Fig. series 5.1.5: Views towards waterfront along Cambridge and Kent terraces are dominated by a busy traffic scene, ultimately arriving at a supermarket that must be navigated around to get to the water. 
Urban Form

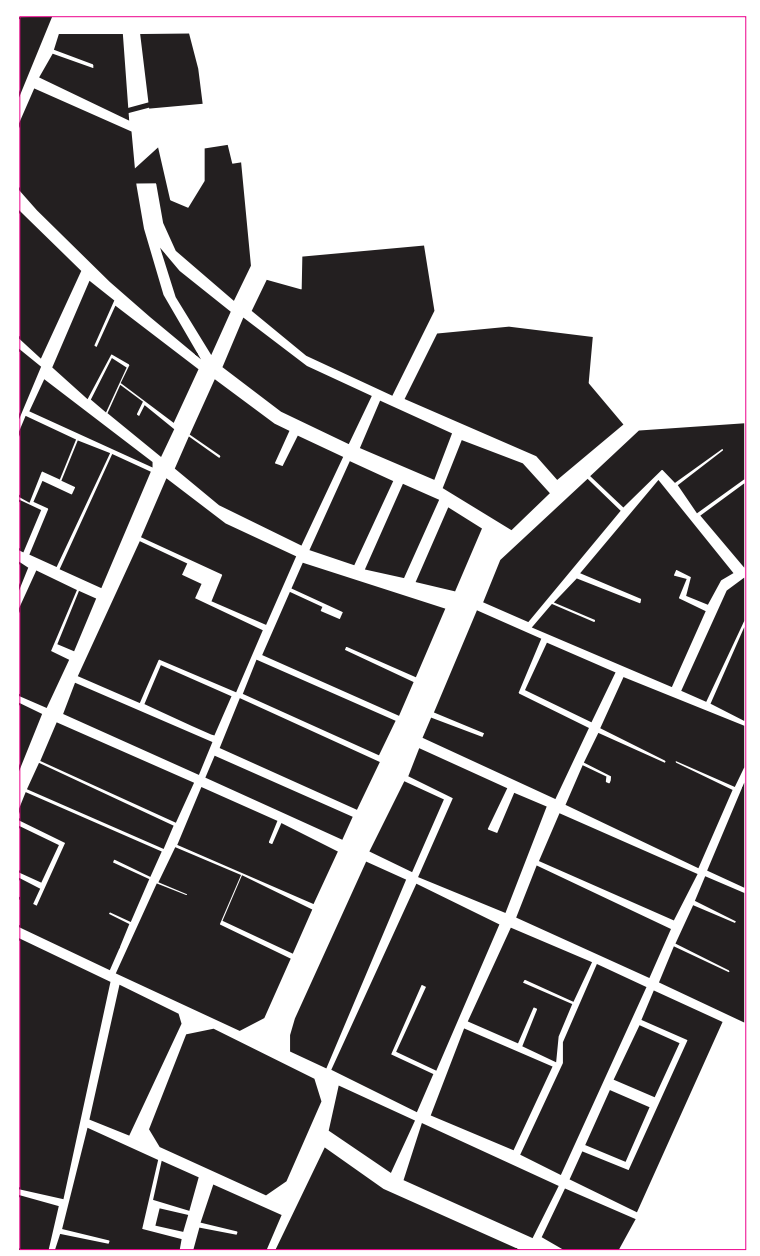

Fig. 5.1.6

retailers and restaurants, being especially busy between Vivian St and Courtenay PI. Heading towards the waterfront however, the pedestrian is interrupted by having to cross the busy Wakefield and Cable streets that is equally applicable to the Cambridge/Kent route.
Site Topography

$1 \mathrm{~m}$ contours

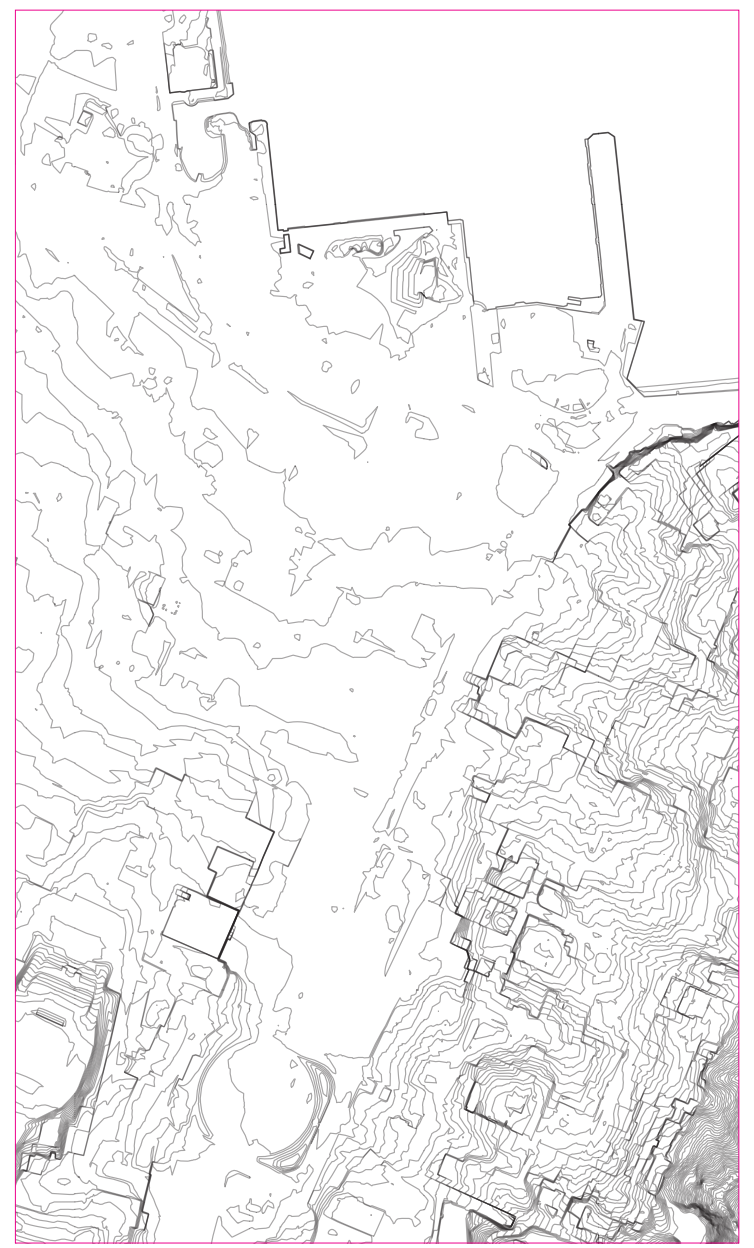

Fig. 5.1.7 
Recreation / Open Spaces open spaces for urban recreational activities

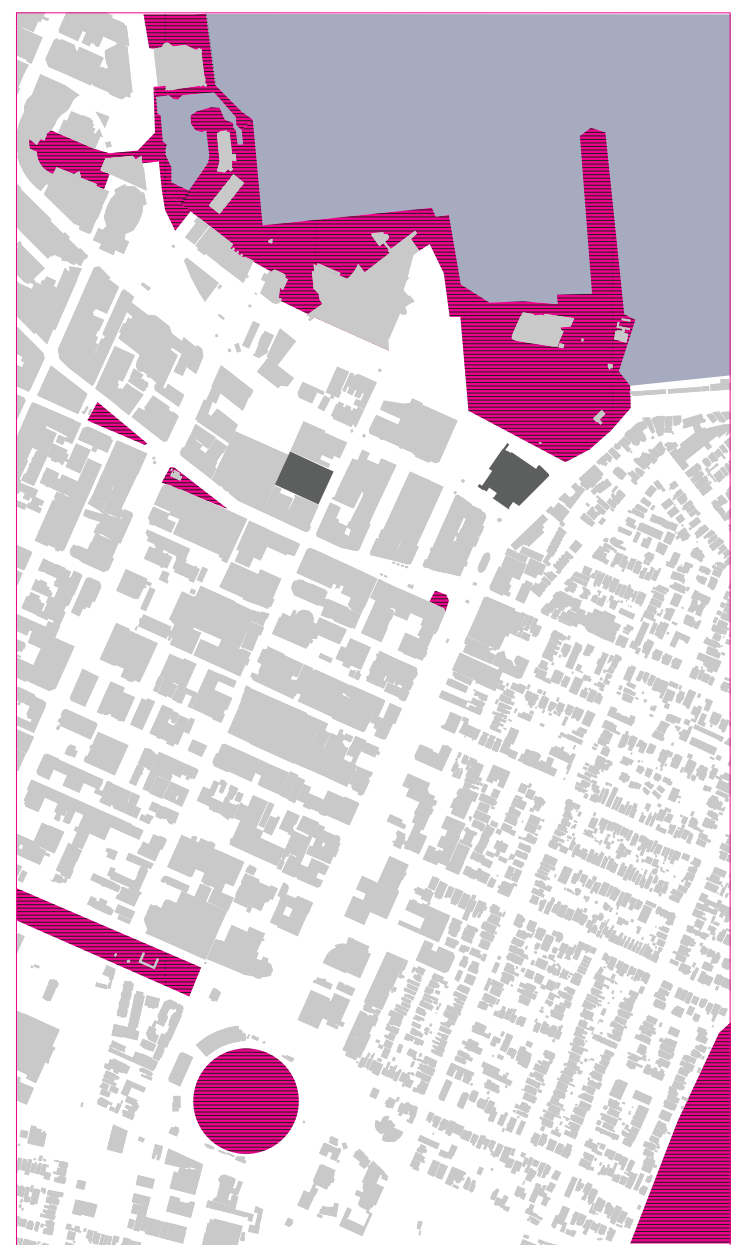

Fig. 5.1.8
Green Areas + Landmarks places/structures of significance

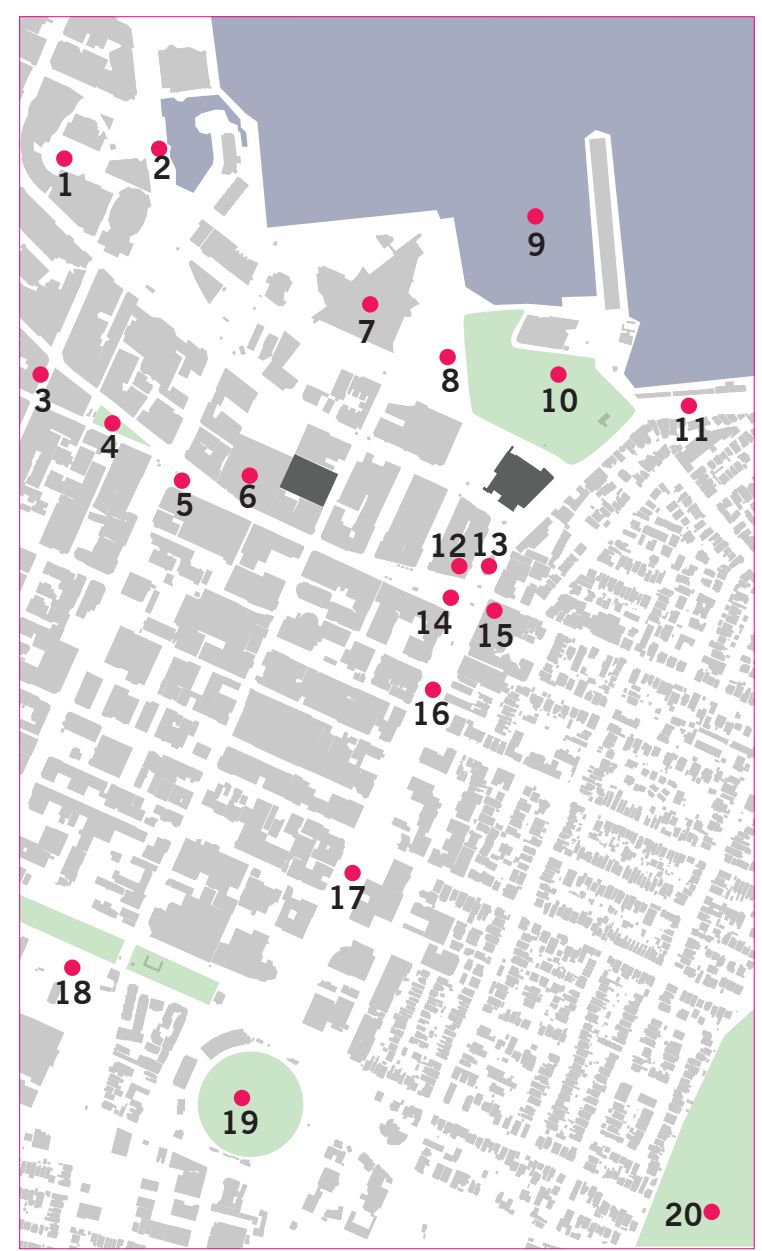

Fig. 5.1.9

\begin{tabular}{|c|c|c|}
\hline & Civic Square (and & 9. Wellington Harbour \\
\hline & surrounding buildings) & 10. Waitangi Park \\
\hline 2. & City to Sea Bridge & 11. Oriental Parade \\
\hline 3. & Cuba Street & 12. Hannah Playhouse \\
\hline 4. & Te Aro Park & 13. Welsh Dragon Bar \\
\hline 5. & $\begin{array}{l}\text { Courtenay Place (west } \\
\text { end) }\end{array}$ & $\begin{array}{l}\text { 14. Homage to Wellington } \\
\text { Cinema Statue }\end{array}$ \\
\hline 6. & Reading Cinema & 15. Embassy Theatre \\
\hline & Courtenay & 16. Queen Victoria Statue \\
\hline 7. & Museum of New & 17. Greek - NZ Memorial \\
\hline & Zealand Te Papa & 18. Pukeahu National \\
\hline & Tongarewa & War Memorial Park \\
\hline 8. & Sunday Harbourside & 19. Basin Reserve \\
\hline & Market & 20. Mount Victoria \\
\hline
\end{tabular}




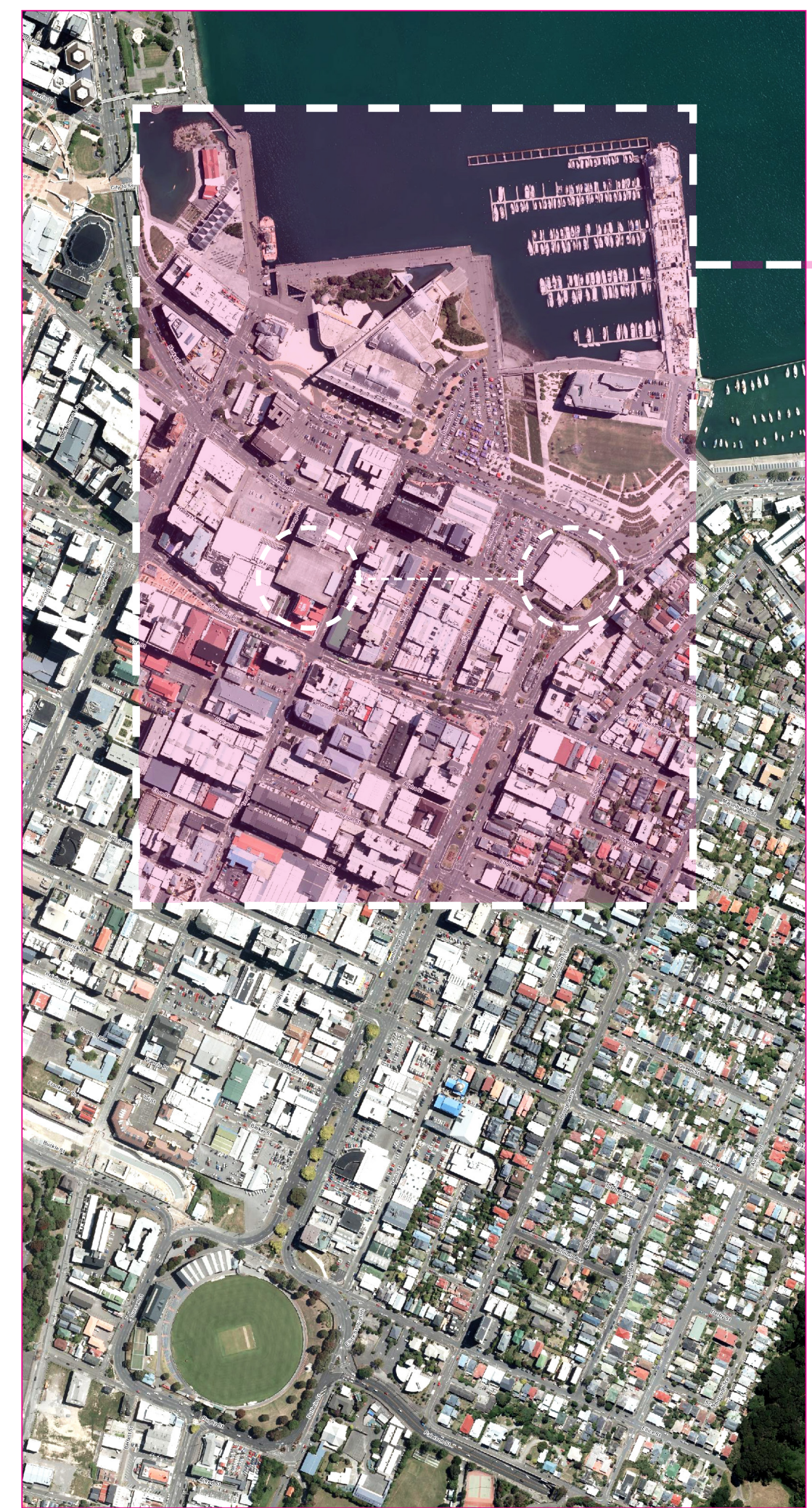

Fig. 5.2.1: Higlighted area will provide a closer analysis.

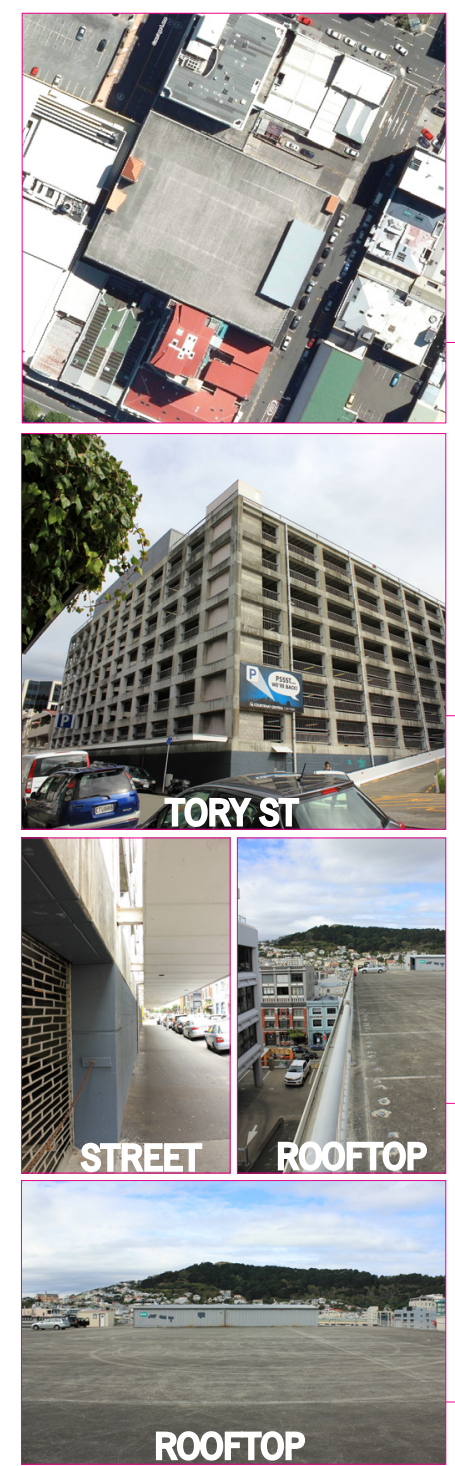

Fig. series 5.2.2: Tory St Reading Cinema carpark building. 
District Plan Zoning: Designated Areas

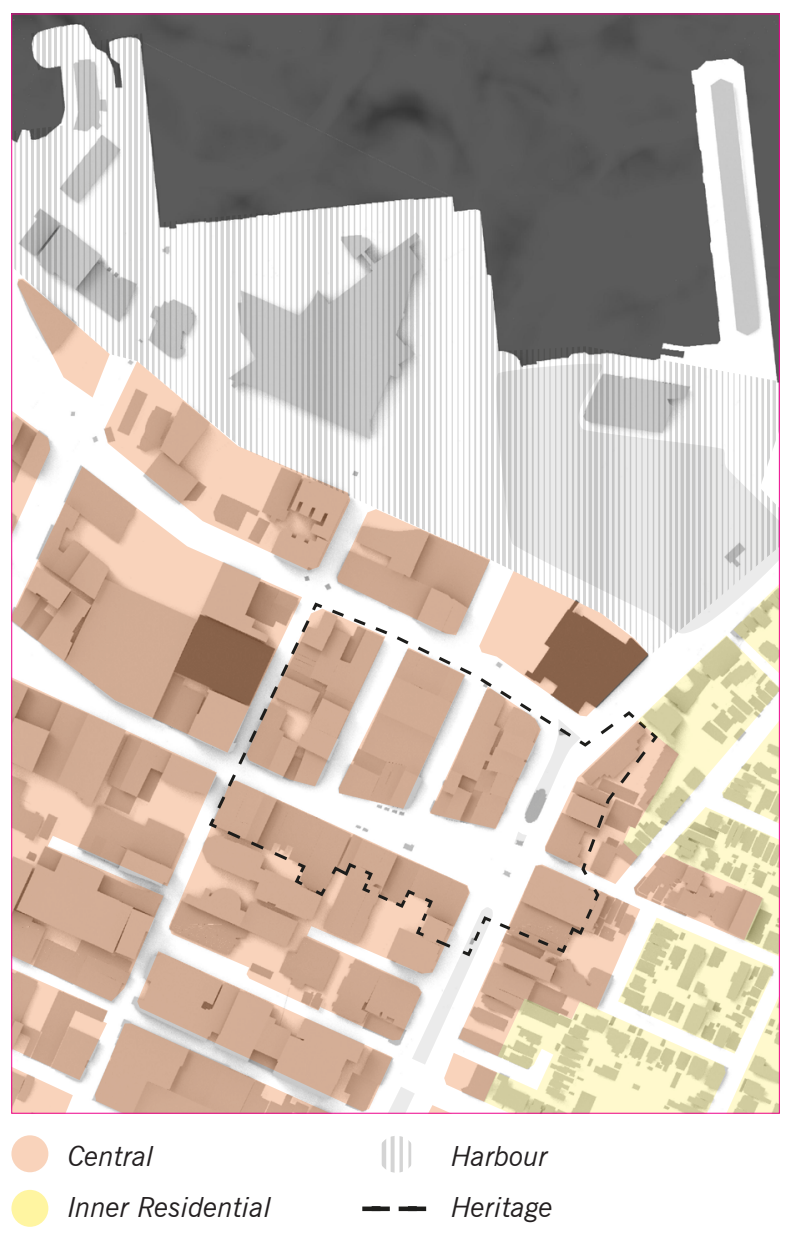

Fig. 5.2.5
Access to Buildings

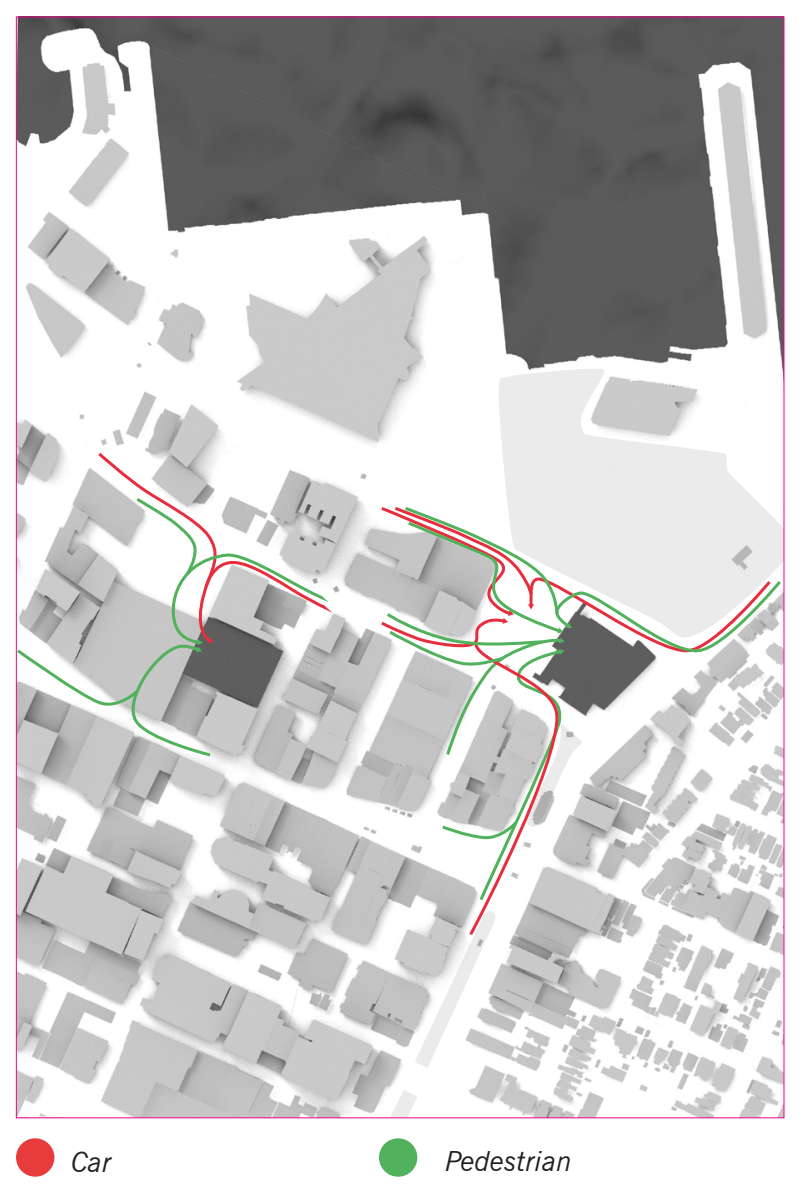

Fig. 5.2.6 
INTERMEDIATE

ANALYSIS

Traffic Volumes

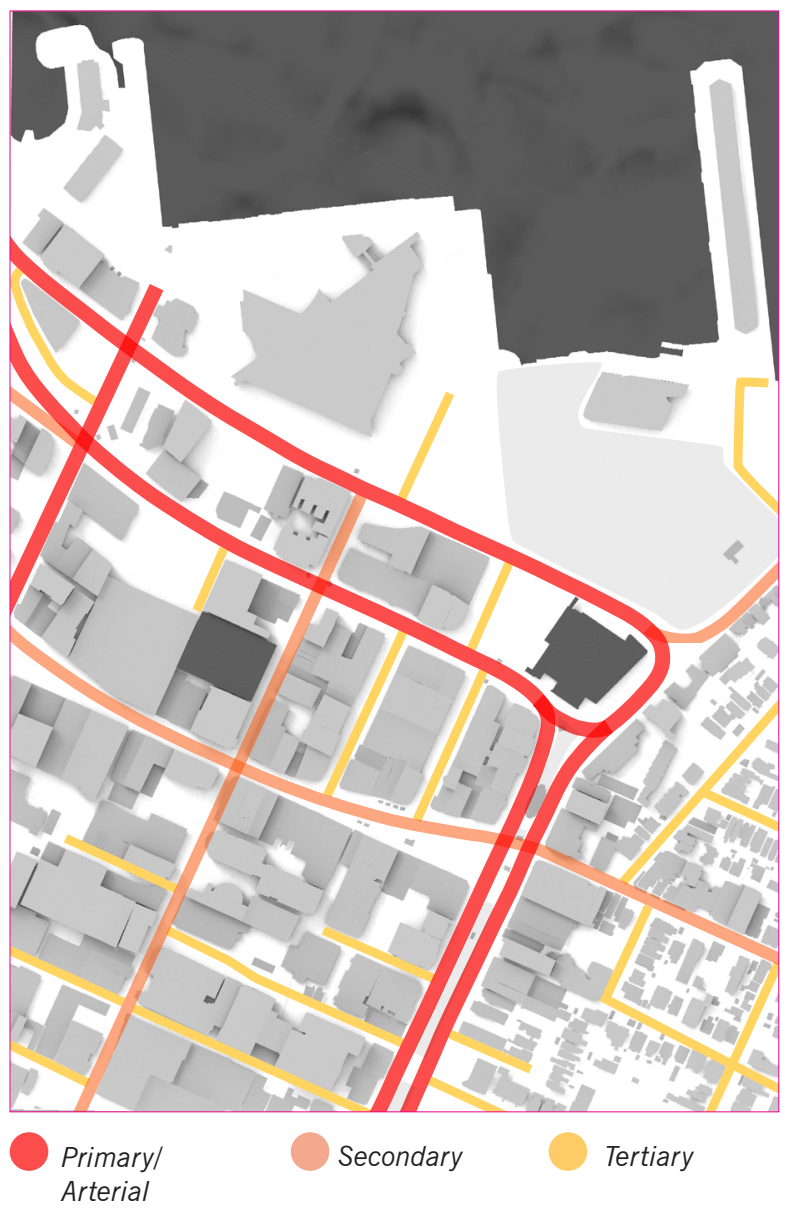

Fig. 5.2.7
View Corridors Towards Waterfront

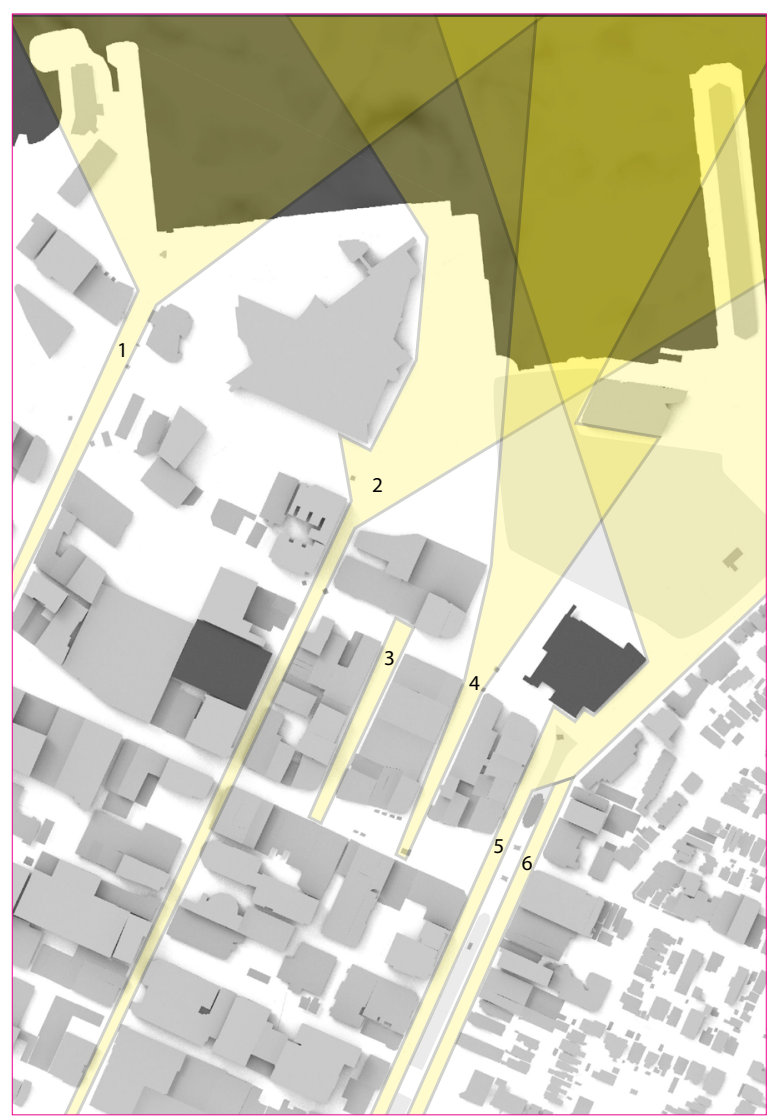
1. Taranaki
3. Allen
5. Cambridge
2. Tory
4. Blair
6. Kent

Fig. 5.2.8 
Cultural Perception Analysis

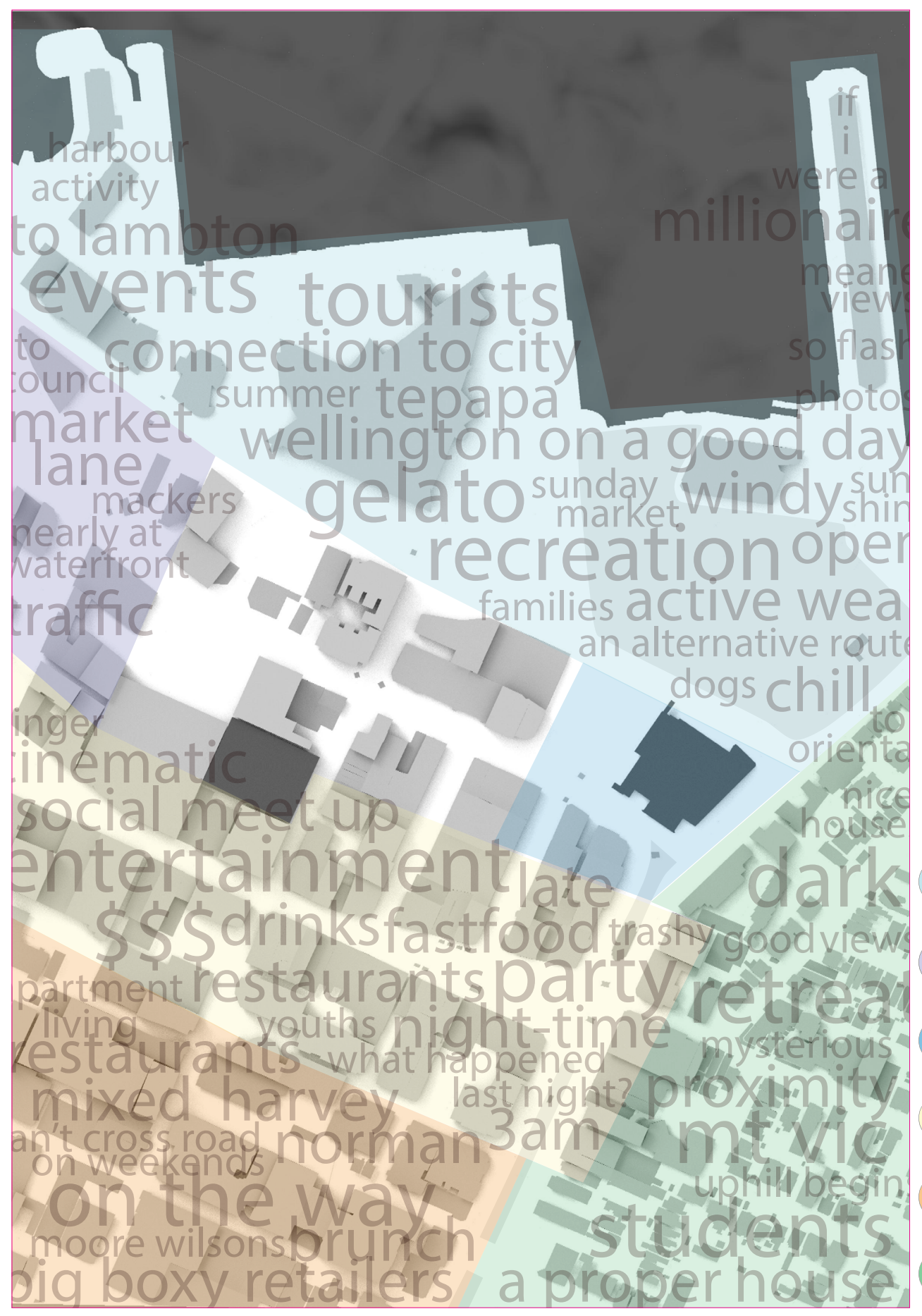

Waterfront Lower Taranaki Chaffers New World Courtenay Place Upper-Central Tory St

Fig. 5.2.9: Cultural perceptions of areas around rooftop sites. The uncoloured space at Tory appears difficult to identify - perhaps a reflection of it as a thoroughfare to travel from one destination to another. 
[5.2]

INTERMEDIATE

ANALYSIS

Proposed Cultural Addition to City

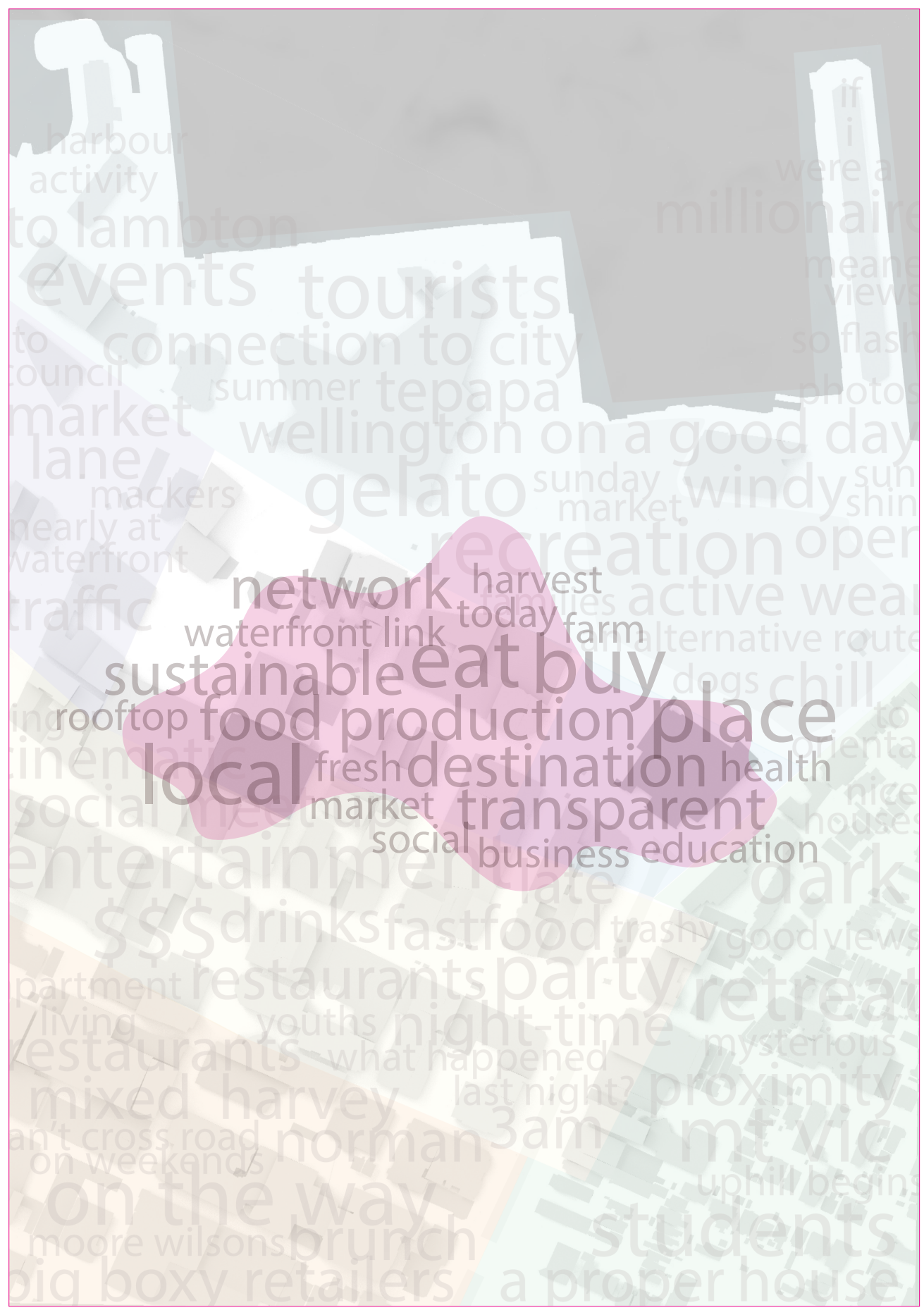

Fig. 5.2.10: Proposed cultural perceptions after urban farm integration with city. Understandably, this would come with time. 
[5.2]

INTERMEDIATE

ANALYSIS

\section{Site Context}

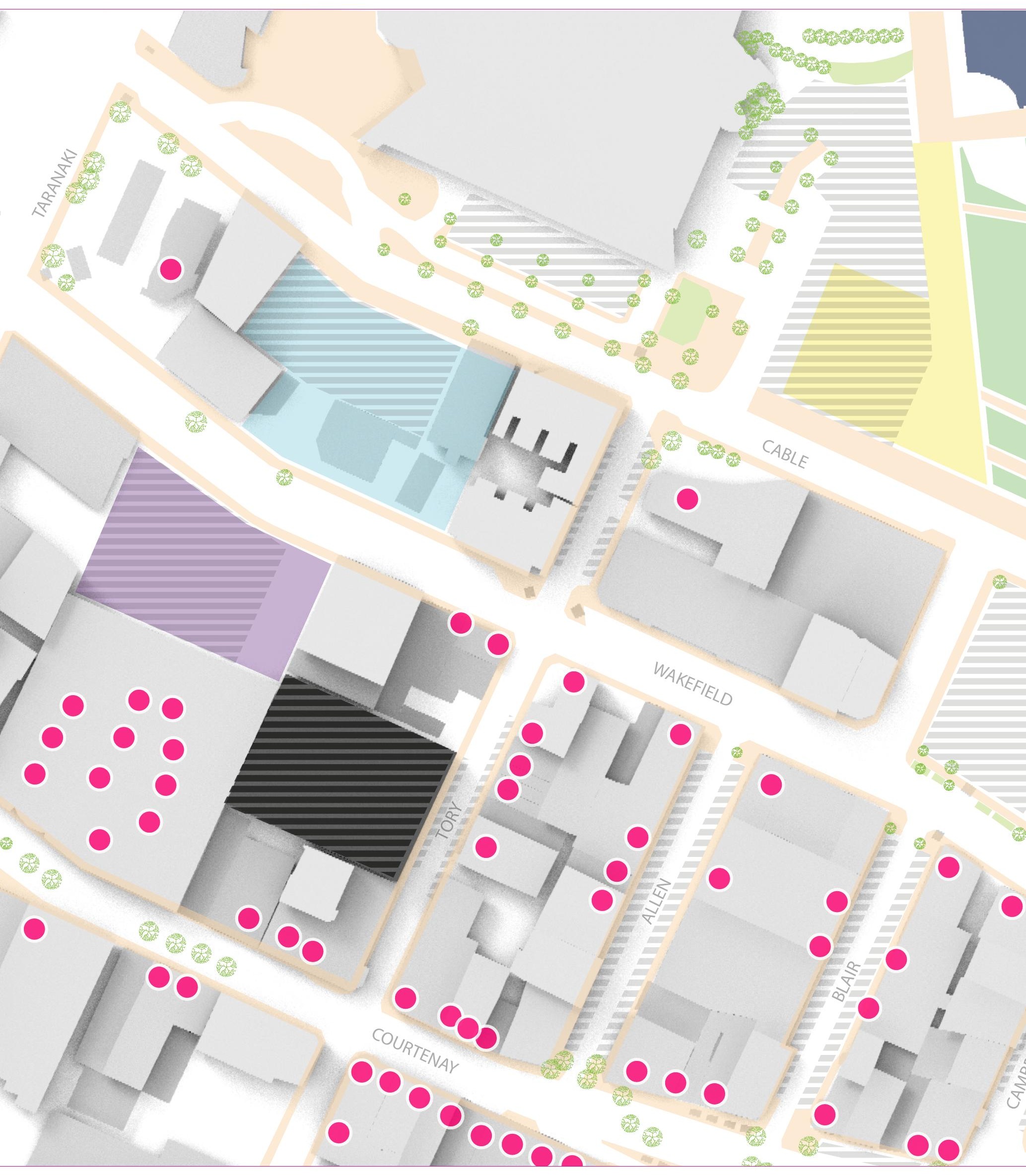




\section{LEGEND}

Restaurants

Carparking (does not include all side-street parking)

Pedestrian footpaths

Trees / plants

Grass

Waitangi Park wetlands

Skatepark \& playground

Sea

Sunday Harbourside Market

PROPOSED PROJECTS AS AT MAY 2016

Proposed Countdown supermarket

Proposed PJ movie museum \& convention centre

THESIS

Proposed rooftop sites for urban farms 


\section{LEGEND}

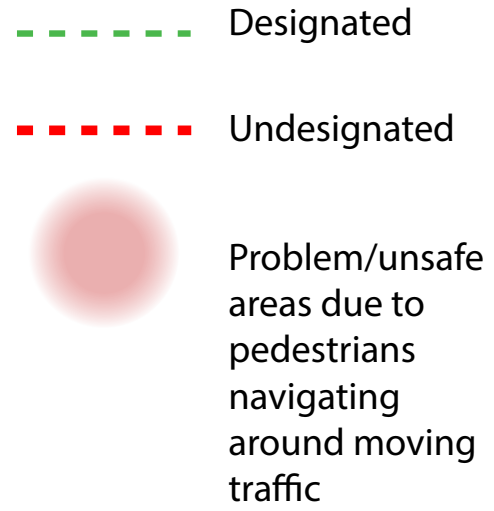

The arterial roads of Wakefield and Cable streets running parallel to the waterfront causes difficulties for pedestrian access to the waterfront from Courtenay $\mathrm{PI}$.

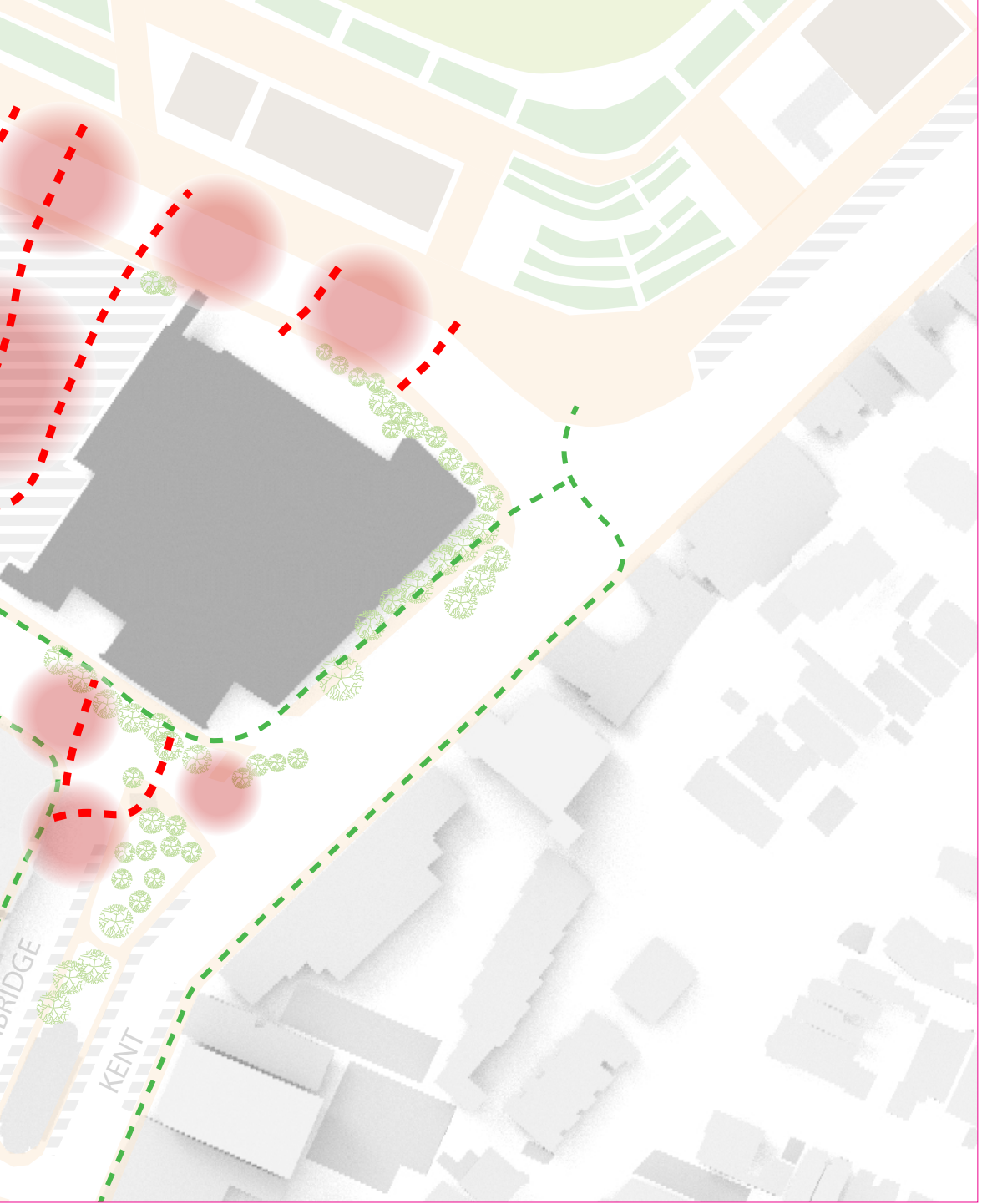




\section{Micro Analysis}

Along with macro considerations, selection of a host building falls primarily on its roof area being of an adequate size (approx. 3000m2 based on Lufa Farms prototype farm being $3922 \mathrm{~m} 2$ ). This would accomodate commercial growing space, though the city of Wellington cannot be compared to Montreal. It could be that calculations are required in later stages to set a 'supply meets demand' model. Though Wellington is a relatively small city compared to the locations of precedent urban farms, it does offer a choice of large scale constructions such as warehouses, universities, supermarkets, some retailers, car parks and possibly civic buildings (fig. 1.1). Of particular interest are supermarkets based on their connection with food, along with car park buildings due to their (commonly dull) utilitarian designs for this thesis.

Two buildings will be explored in the following design chapter for their potential to host an urban rooftop farm. They are:

\section{Tory St Reading Cinema Car Park $+$}

New World Supermarket
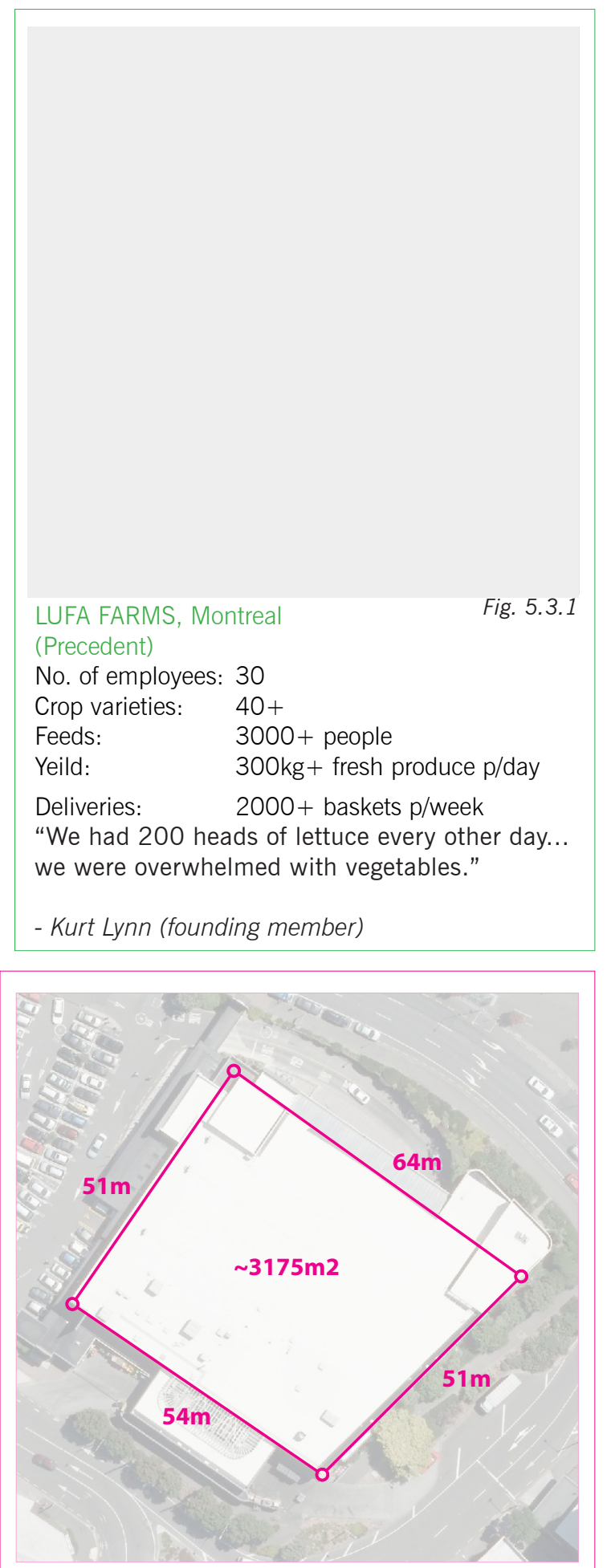

NEW WORLD SUPERMARKET, Wellington

- Produce to be sold on site (sent below to NW)

- Could meet demand of NW customers
- Produce to be sold on site (potentially NW as well) - Could meet demand of the average consumer + nearby suppliers and restaurants 

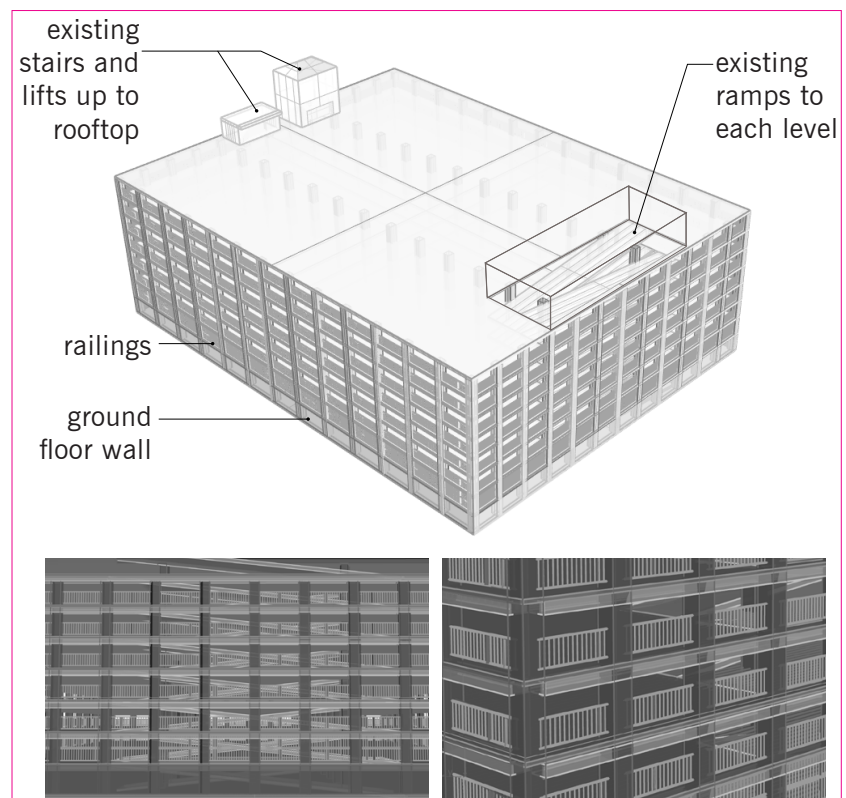

TORY CAR PARK

\section{Address:}

Construction:

Function:

No. of storeys:

Main structure:

Materials:

Access to building:

Access within building:

\section{Solar Radiation:}

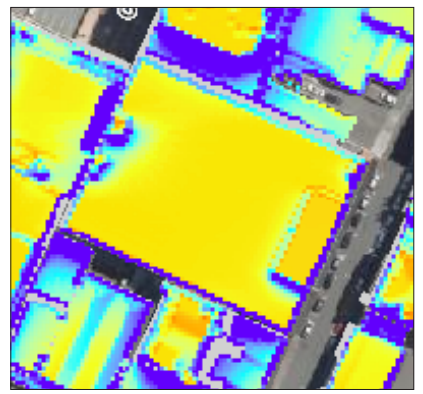

Fig. 5.3.4

Av. total solar radiation $(\mathrm{kwh} / \mathrm{m} 2): \quad 755$

Max. total solar radiation (kwh/m2): 962

8 (9 including roof level) moment frames, both directions reinforced concrete wakefield st (vehicles) + linked to ground floor of reading cinema

ramp (vehicles), stairs and lift at west end
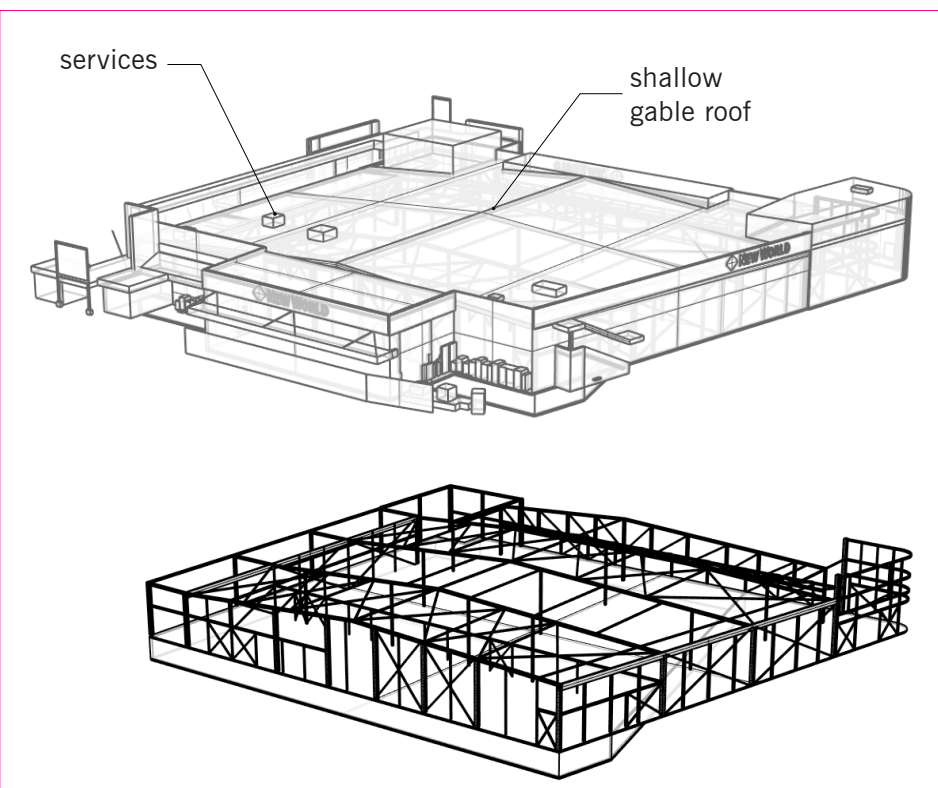

NEW WORLD

Address:

Construction:

279 Wakefield St, Te Aro 1993

Function:

supermarket + basement car park

No. of storeys:

Main Structure:

Materials:

Access to building:

Access within building:
2 above ground (includes mezzanine)

+ basement level

column grid with cross bracing steel

wakefield st, cable st, chaffers st stairs and lifts to basement car park
Solar Radiation:
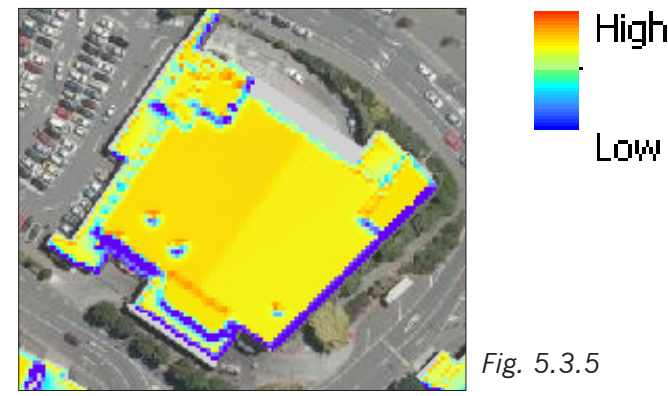

Av. total solar radiation $(\mathrm{kwh} / \mathrm{m} 2)$ :

Fig. 5.3.5

1331 


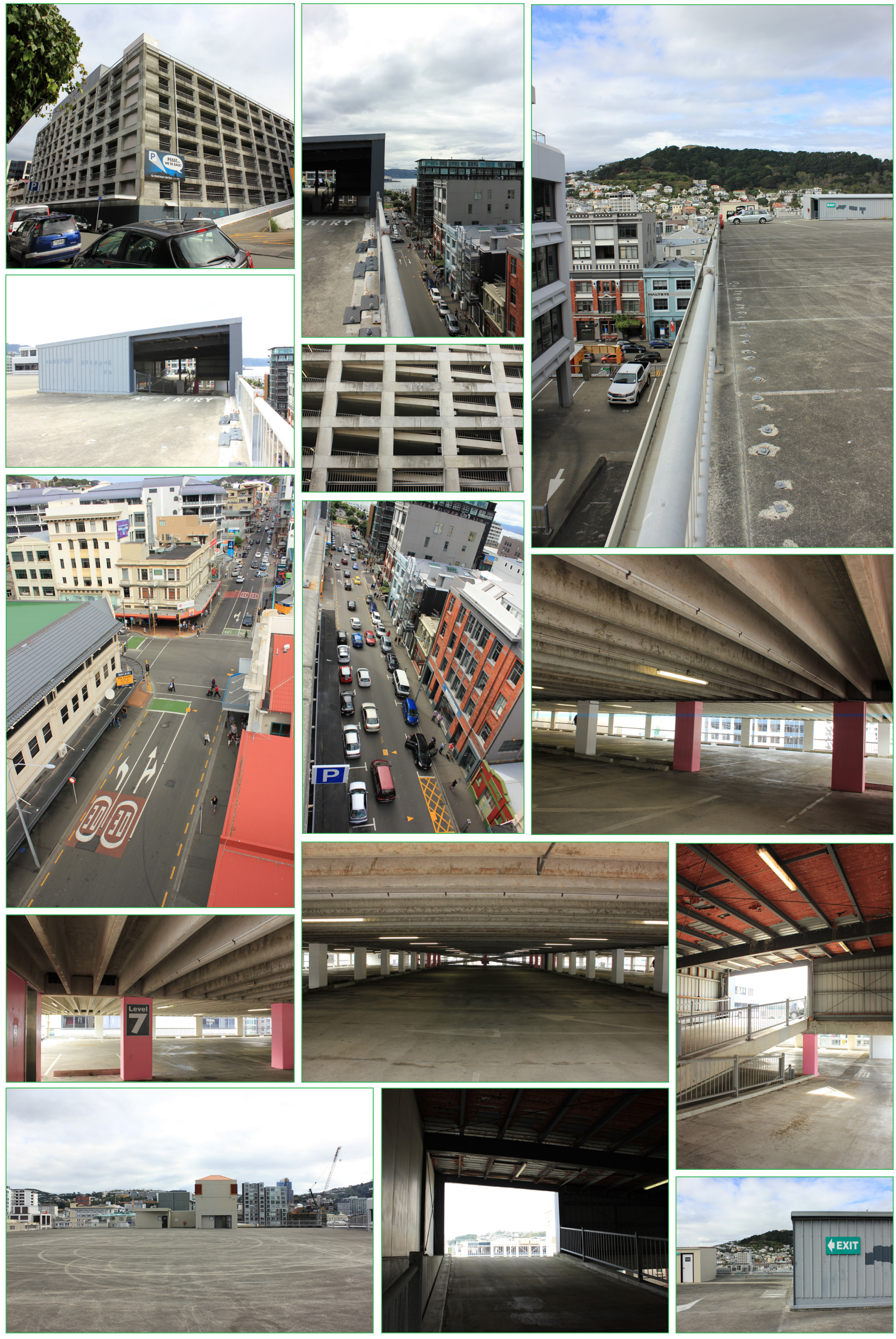




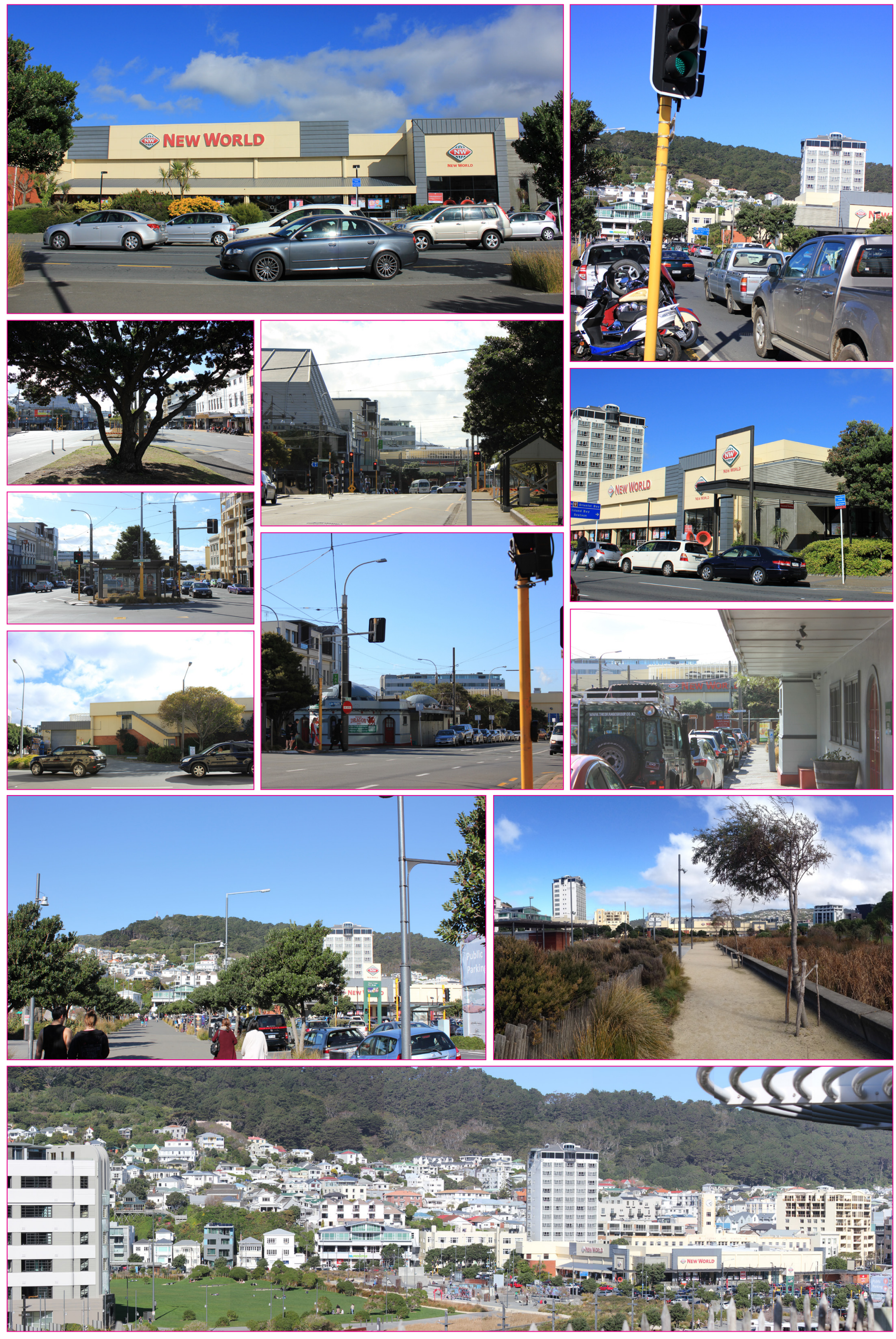




\section{DESIGN FRAMEWORK}

THREE SCALES

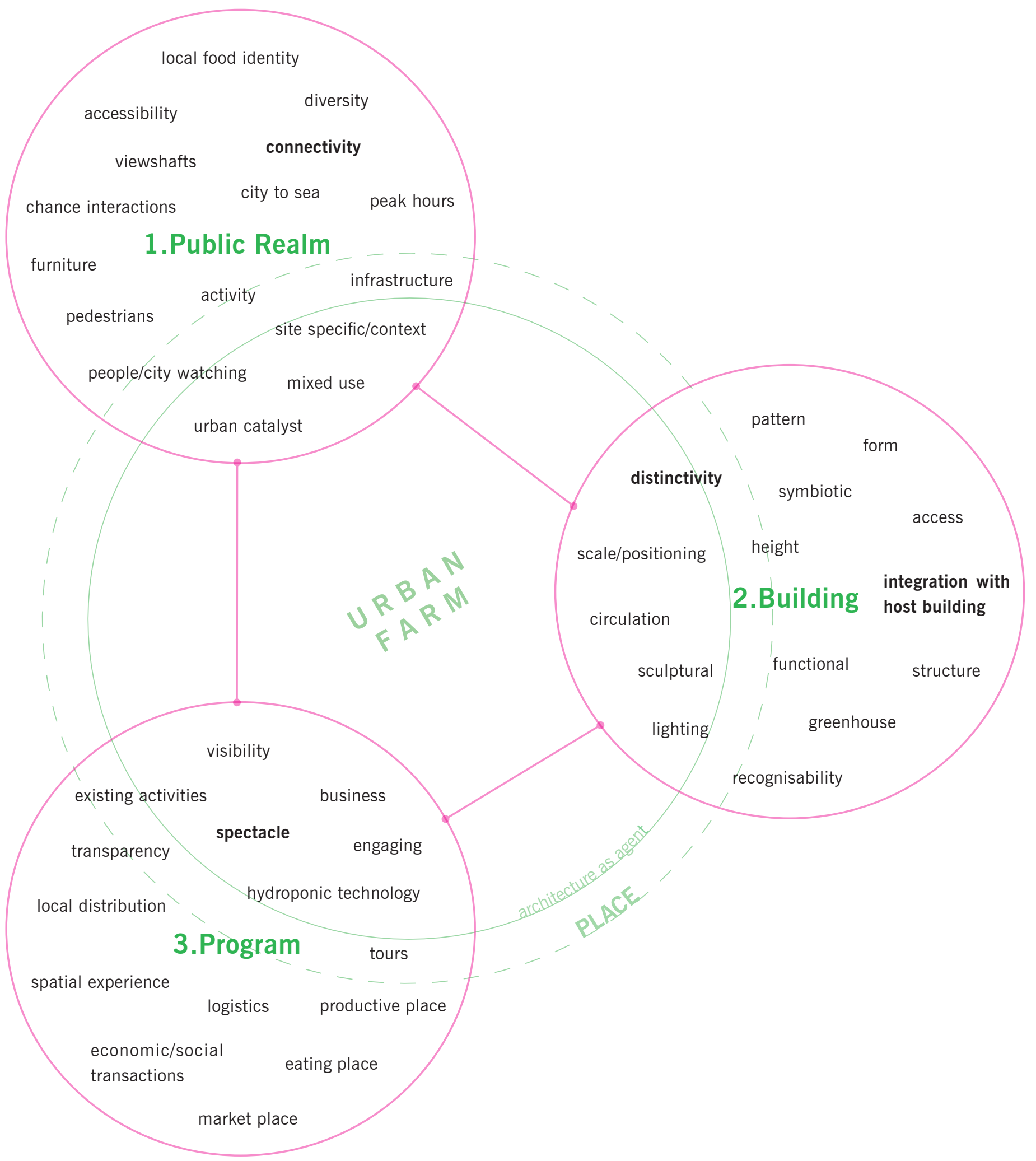

Fig. 6.0: Three design scales in the framework based on learnings so far. 


\section{How can architecture help diversify food space through the introduction of urban farming, breaking down the conceptual divide between urban versus rural?}

Based on the combined learnings from the literature review, precedent studies and site analysis, a design framework has been generated to demonstrate the imperative considerations for the undertaking of the thesis' major design chapter.

The framework identifies three scales of design considered necessary to address the research question (fig. 6.0). Working between the scales of the public realm - building - program is critical in proposing a design response to a concept that is commonly presented as visionary within the architectural discourse.

As a starting point, several key considerations have been highlighted in the design criteria (following page) from each design scale. The public realm centres around an opportunity for improving urban connectivity for pedestrians. The building scale focuses on exploring with form and resolving its method of integration with the host building below. And at the program scale, the focus on allowing farm production processes to be a spectacle will also factor into the design development. By way of researching through design, it will become evident that each scale informs the other in establishing an urban farm at its respective site, presenting circumstances that may not have been anticipated.

This chapter is structured into three phases preliminary, developed and final design ('final' can perceived as the resulting outcome within the thesis timeframe, open for further questioning). Each phase will be mindful of the three design scales at varying degrees. At the end of each phase, a short critical evaluation is presented, before developing the design further. Feedback from presentations during the thesis year will also contribute to this.

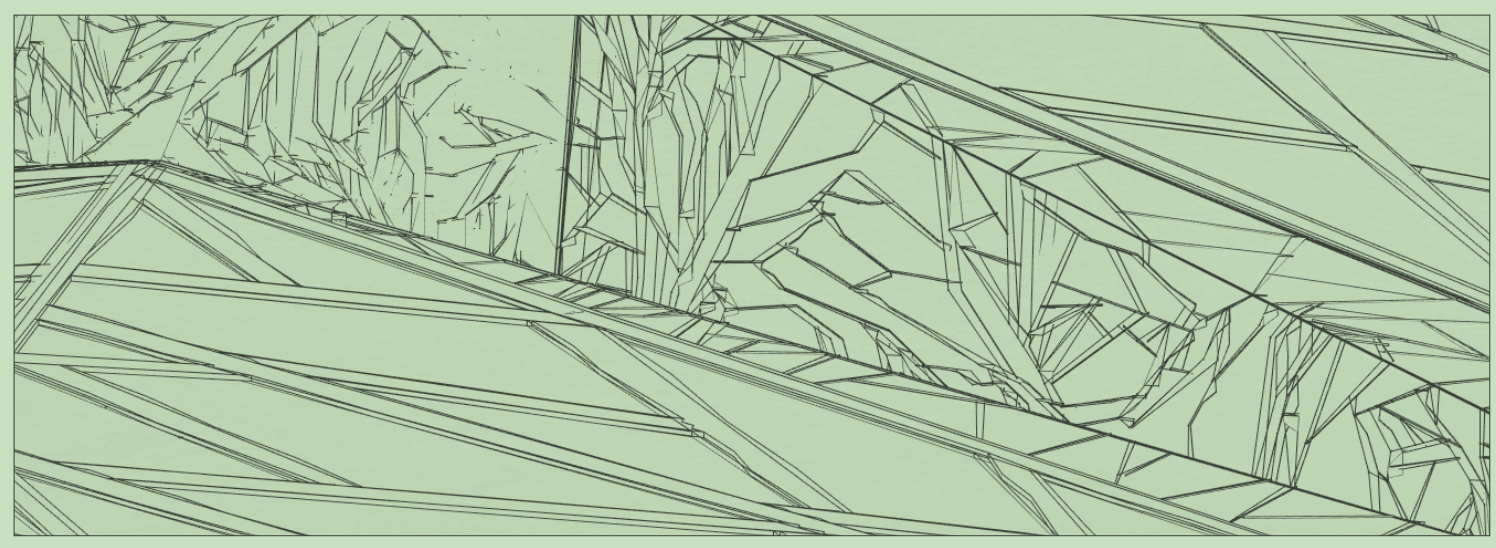




\section{CRITERIA / KEY CONSIDERATIONS}

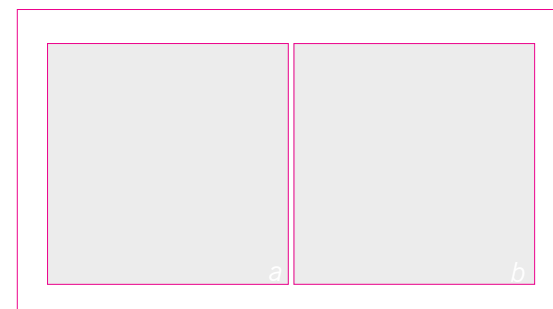

\section{CONNECTIVITY}

FARM TO CITY TO SEA

Project calls for an improved pedestrian link between the city and waterfront of eastern Wellington $\mathrm{CBD}$, with the introduction of an urban farm.

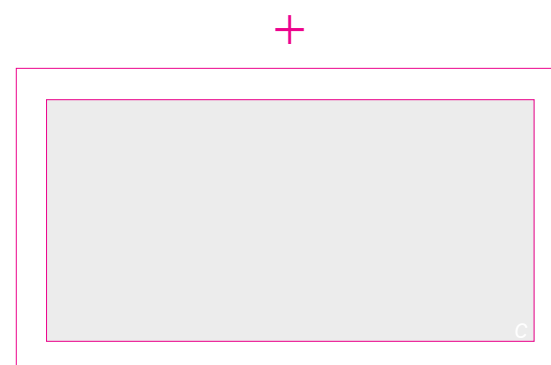

\section{DISTINCTIVITY}

\section{RECOGNISABLE FORM AND PLACE}

Along with the opportunity for an architecturally sculpted form to be added to the city's roofline, the design should allow for a social culture around urban farming through interactions on site in establishing a local food identity.

$+$

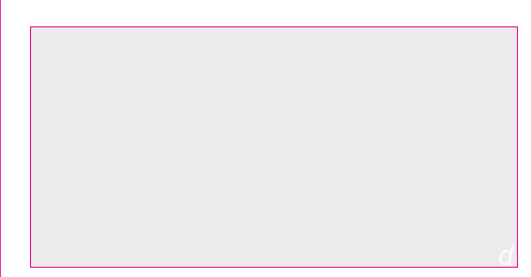

\section{HOST BUILDING INTEGRATION}

\section{SYMBIOTIC RESPONSE}

The rooftop addition should consider the existing physical and programmatic functions of the host building, in order for both constructions to benefit with the existence of the other.

$+$

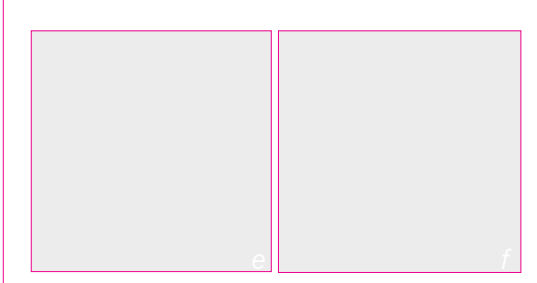

\section{SPECTACLE}

\section{PRODUCTION AS PERFORMANCE}

Production activities of the urban farm should be visible to the public, passively engaging and educating those who not only venture through the farm but are simply passing by.

Fig. series: 6.1 


\section{STRATEGIES}

- Improve pedestrian infrastructure

- Ensure route is easily accessible

- Encourage walking activity

- Allow for a mix of recreational areas

- Visual/spatial journey
- Investigate walkway options

- Sense of consistency along route

- Planting/greening

- Furniture/spaces of relaxation

- Strategic views of farm/city/harbour
- Form explorations/iterations

- Distinctive colours/patterns/shapes

- Building can be seen from a distance

- Form evokes dynamism, a statement

reflecting its stance on the city's responsibility
- Use of materials are "of its time"

- Public vs. private spaces

- Farm as destination

- Program for social/economic transactions

- Form reflects program
- Focus on key spaces e.g. physical connection between buildings

- Understand host building limitations

- Consider new opportunities for both

buildings - form and function

- Integrate new activities with existing
- Decide on extending/contrasting with existing host structure

- Positioning of farm does not "dominate"

- Access rooftop from inside/outside existing - Scale of rooftop addition to be appropriate to site
- Establish/understand farming activities

- Engage public in program

- Public circulation is clear, controlled

- Design highlights specific areas of focus

- Work between the public and program

scales to increase exposure
- Open plan, major functions are visible

- Farm to shelf connection is seen

- Educational spaces/tours

- Hydroponic/aquaponic system is visible

- Use of transparent-opaque materials 

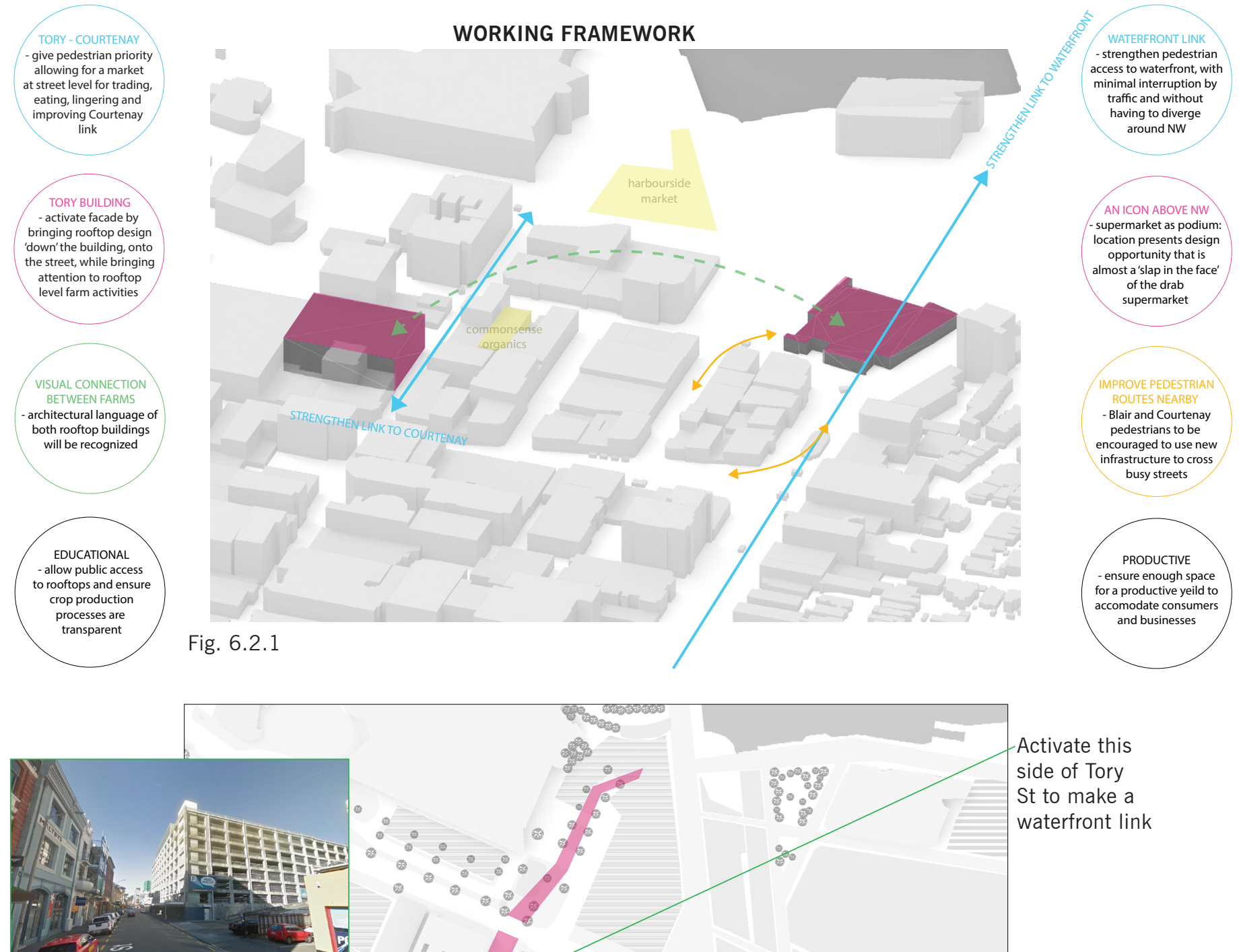

Give pedestrians priority between Courtenay and Wakefield
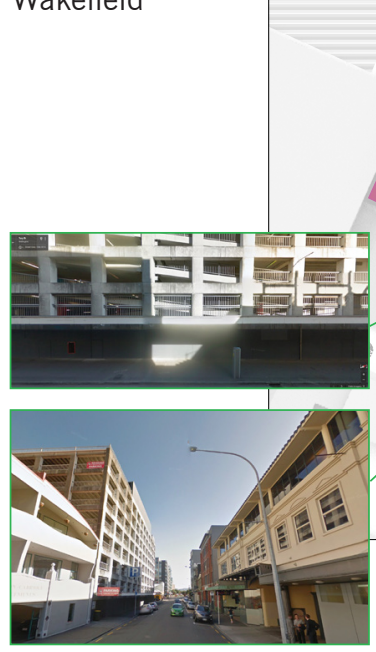

Looking towards Wakefield St

Fig. 6.2.2
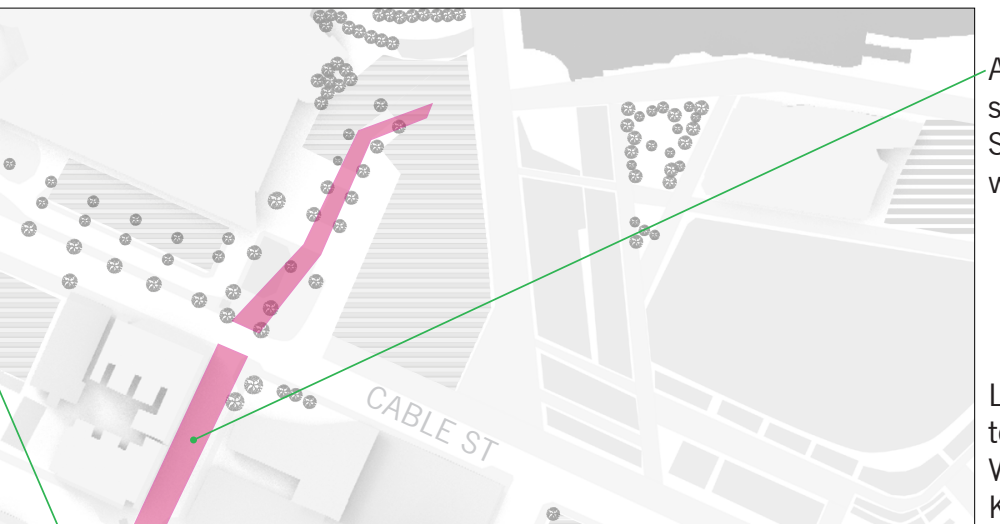

Activate this side of Tory

St to make a waterfront link

Looking towards New World from Kent Tce. Traffic island to the left
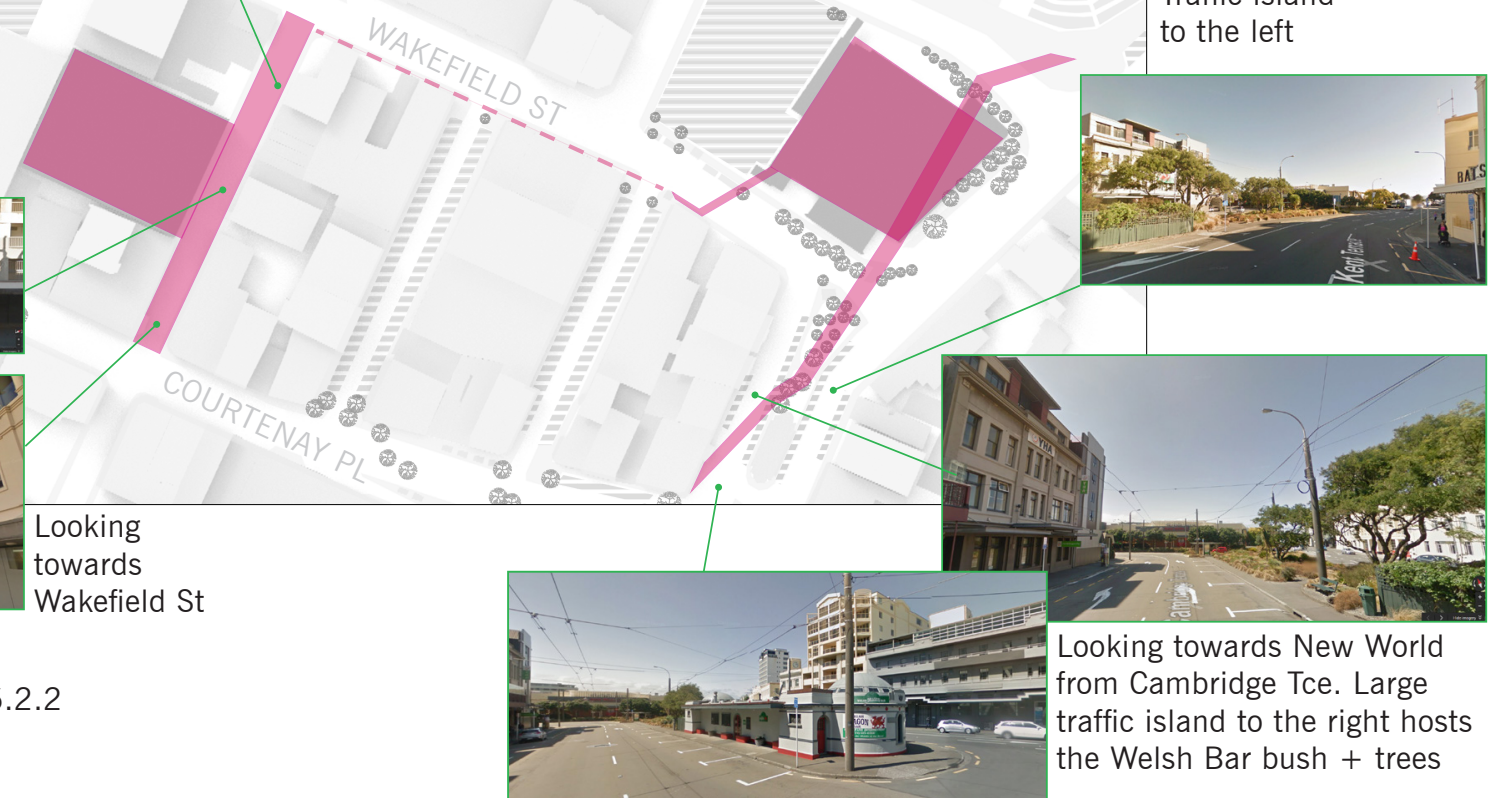


\section{ROOFTOP ACCESS}

\section{Tory St rooftop: a}

large ramp on the north + east facades of the building

New World rooftop: a walkway that changes between a ramp and a bridge, to suit site conditions

External
ramp up
to rooftop
of Tory car
park - need
to check
slope is
appropriate

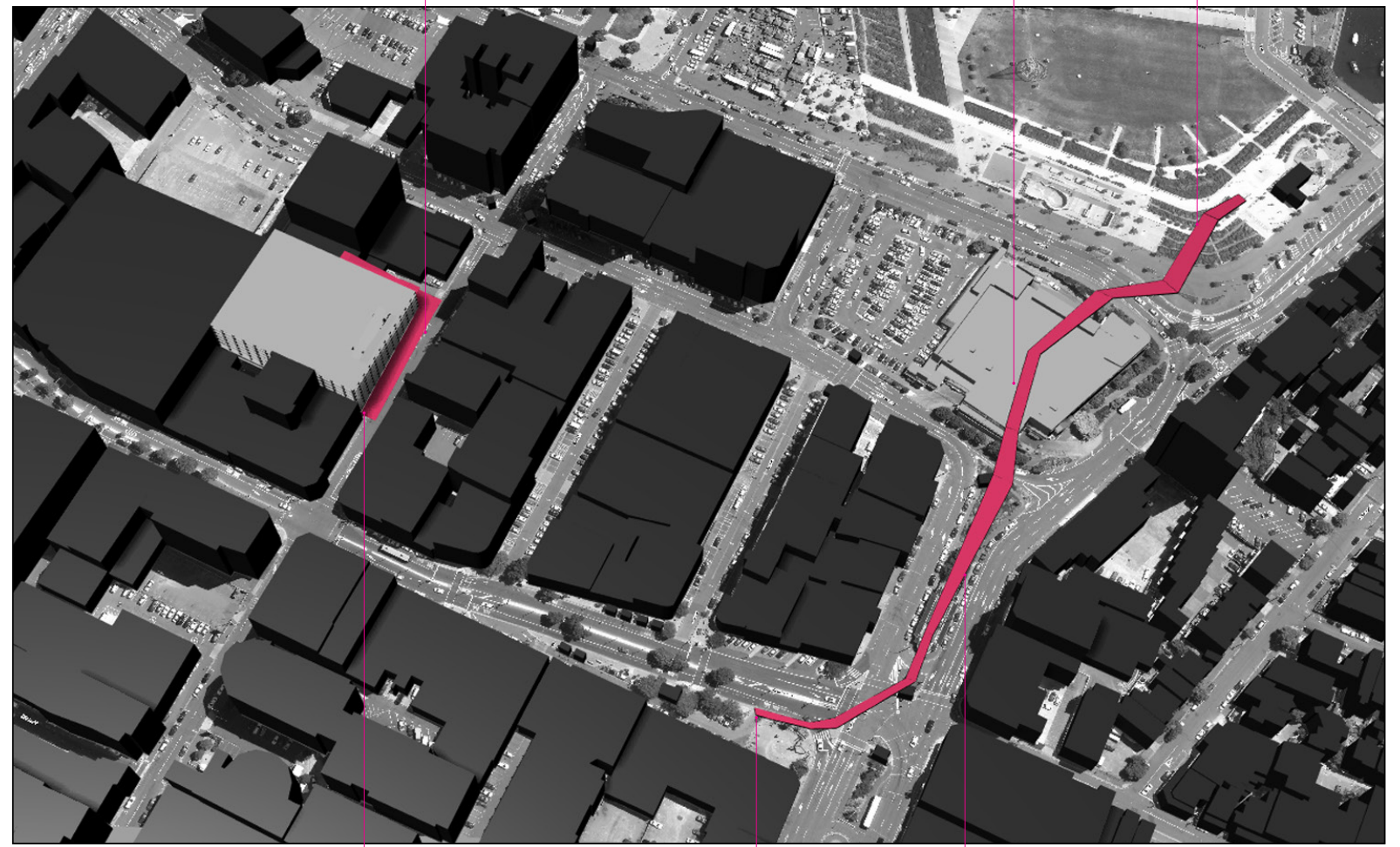

Fig. 6.2.3

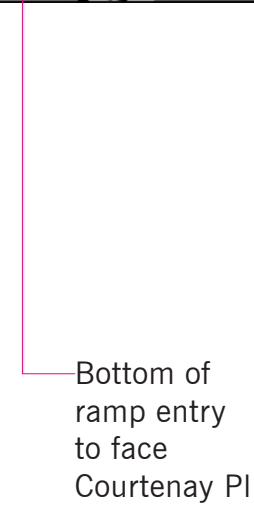

-Ramp potentially landing at Courtenay PI. Will need to address how it crosses Cambridge Tce
Bridge/ramp to use traffic island space (currently the Welsh Bar is located here along with plenty of bush/trees. Not pedestrian friendly being in the middle of two busy streets 

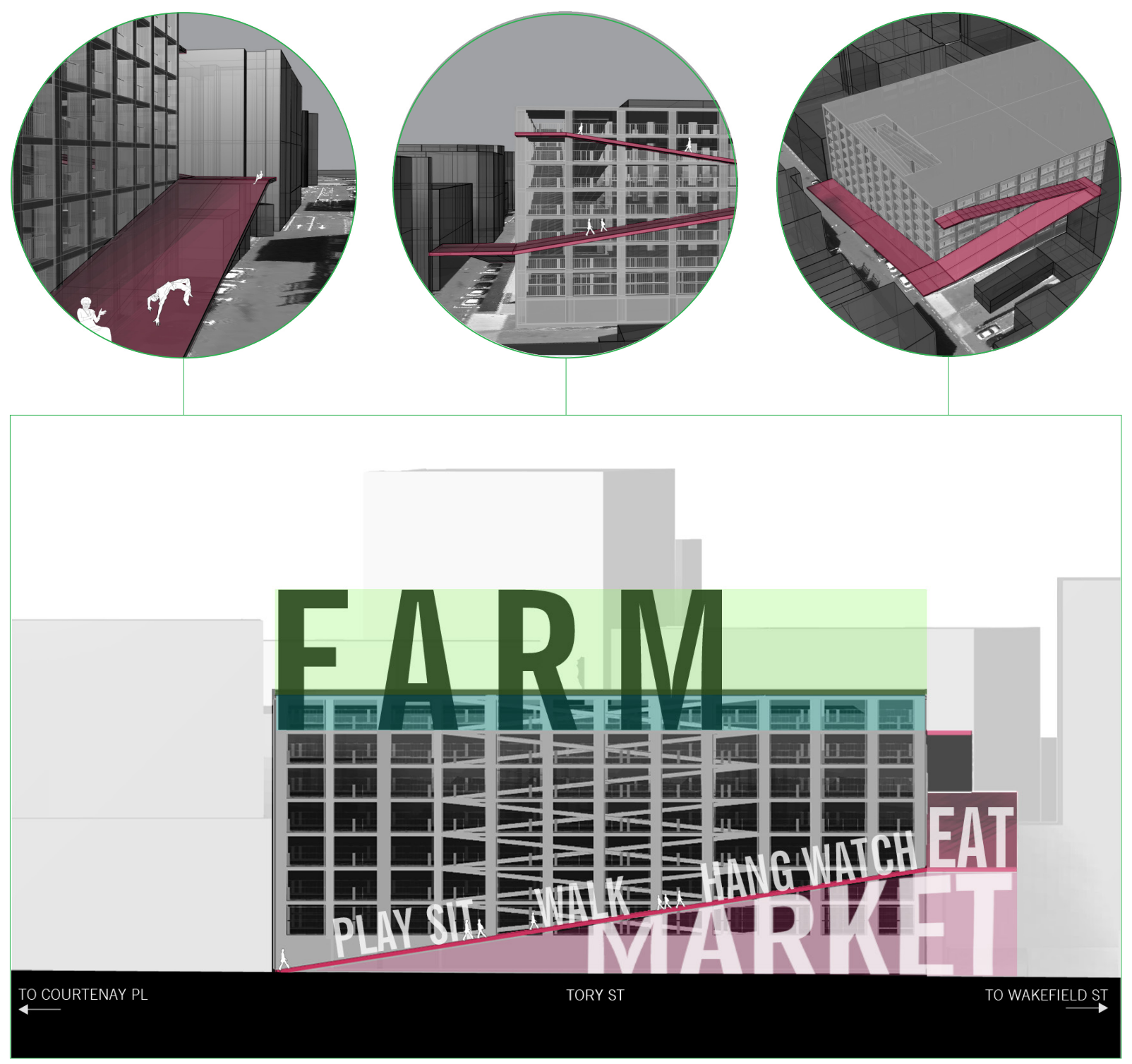

Fig. 6.2.4: Tory St Elevation

The ramp not provides access to level 7, but is a place for urban activities and interactions. A market space is proposed underneath, though this needs addressing further.

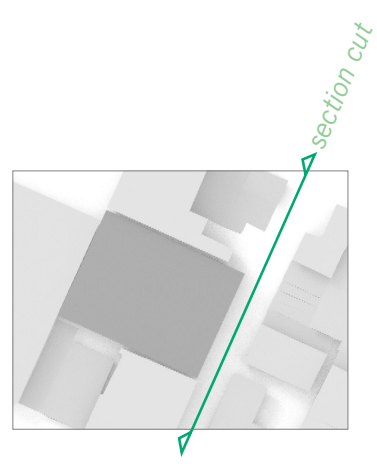


[6.2]

PRELIMINARY

DESIGN

PROGRAM

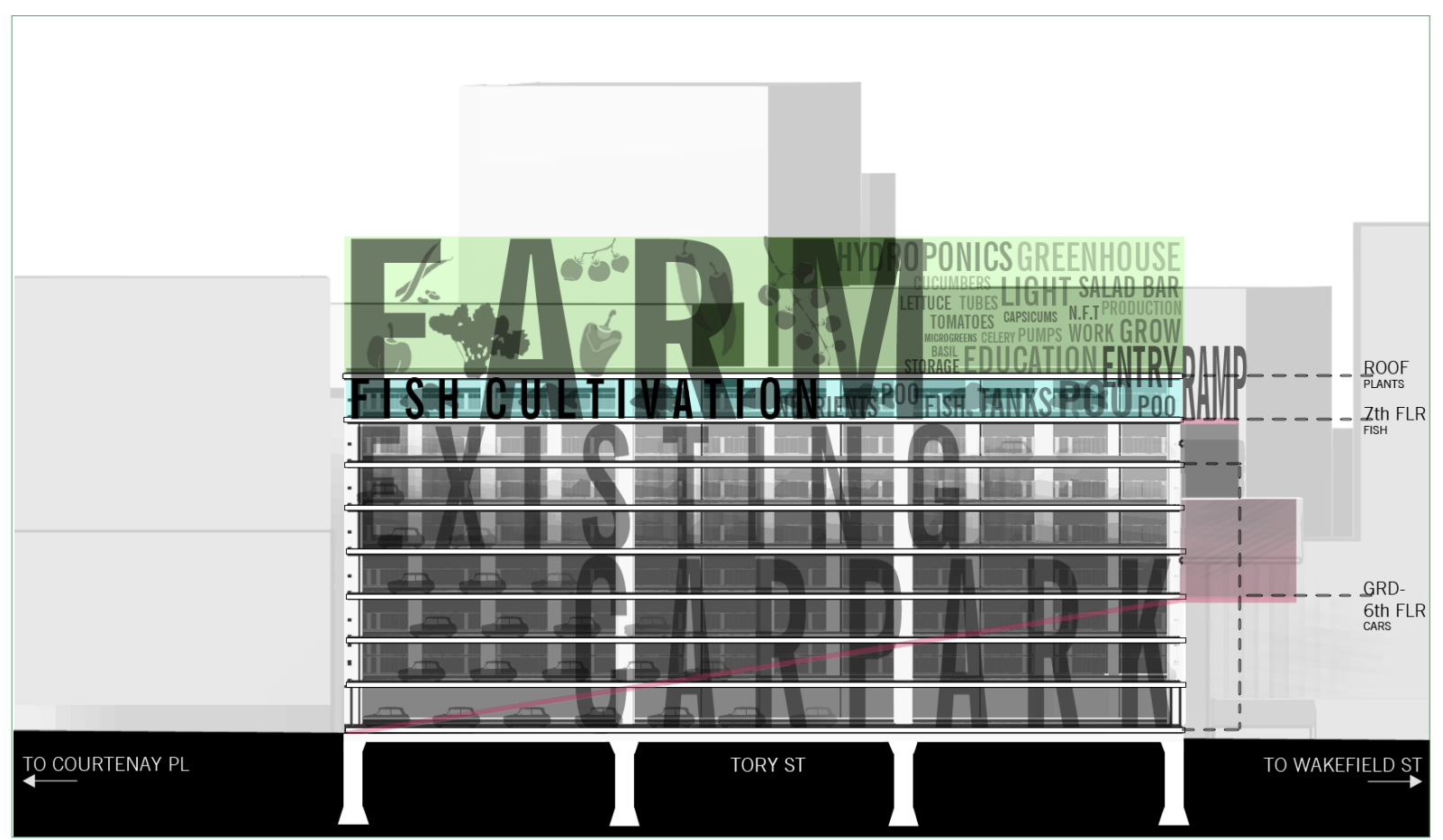

Fig. 6.2.5: Section into Building

From ground to 6th floor, car park functions remain the same. But the 7th floor will host an aquaponic system that pumps water up to the new rooftop farm.

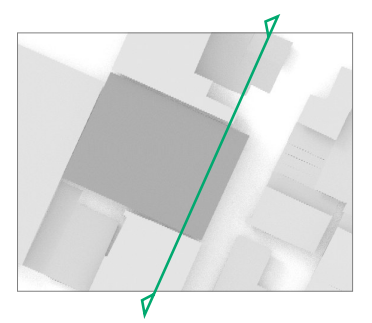




\section{PROPOSED PROGRAM FOR NEW WORLD FARM}

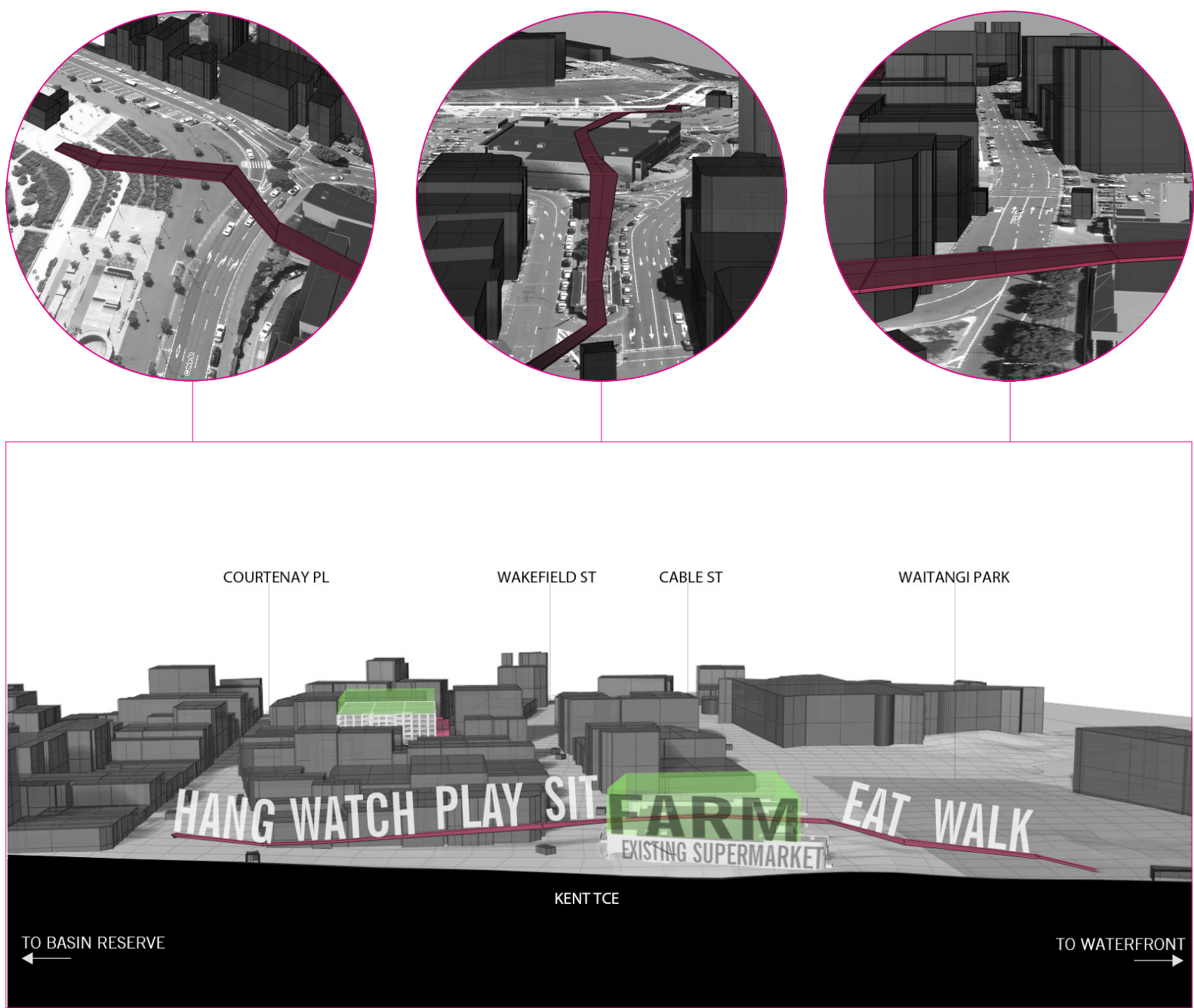

Fig. 6.2.6: New World Walkway

The walkway provides direct access from Courtenay PI to Waitangi Park on the waterfront. Like Tory's ramp, it also plays host to multiple site activities.

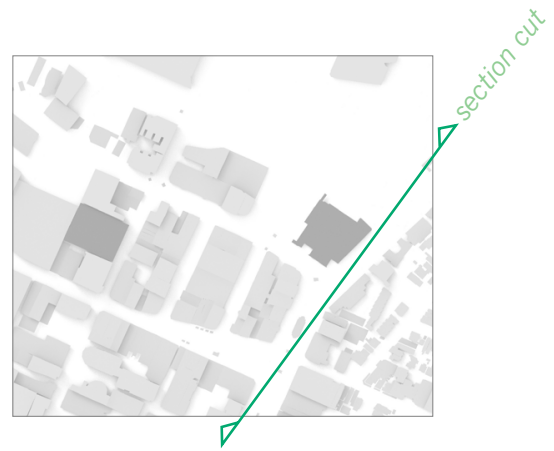


PRELIMINARY

DESIGN

PROGRAM

\section{WALKWAY LANDING IDEAS AT COURTENAY PL JUNCTION}
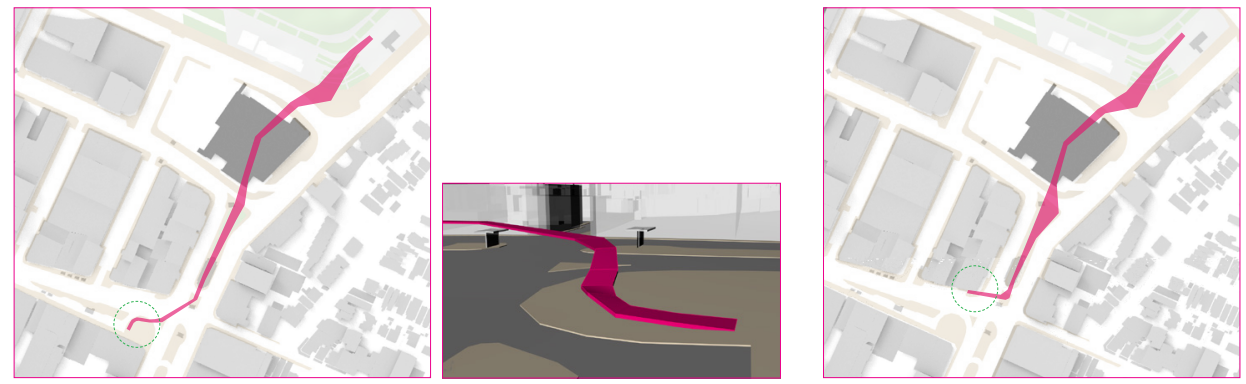

Fig. series 6.2.7: New World ramp landing options for walkway at Courtenay end.
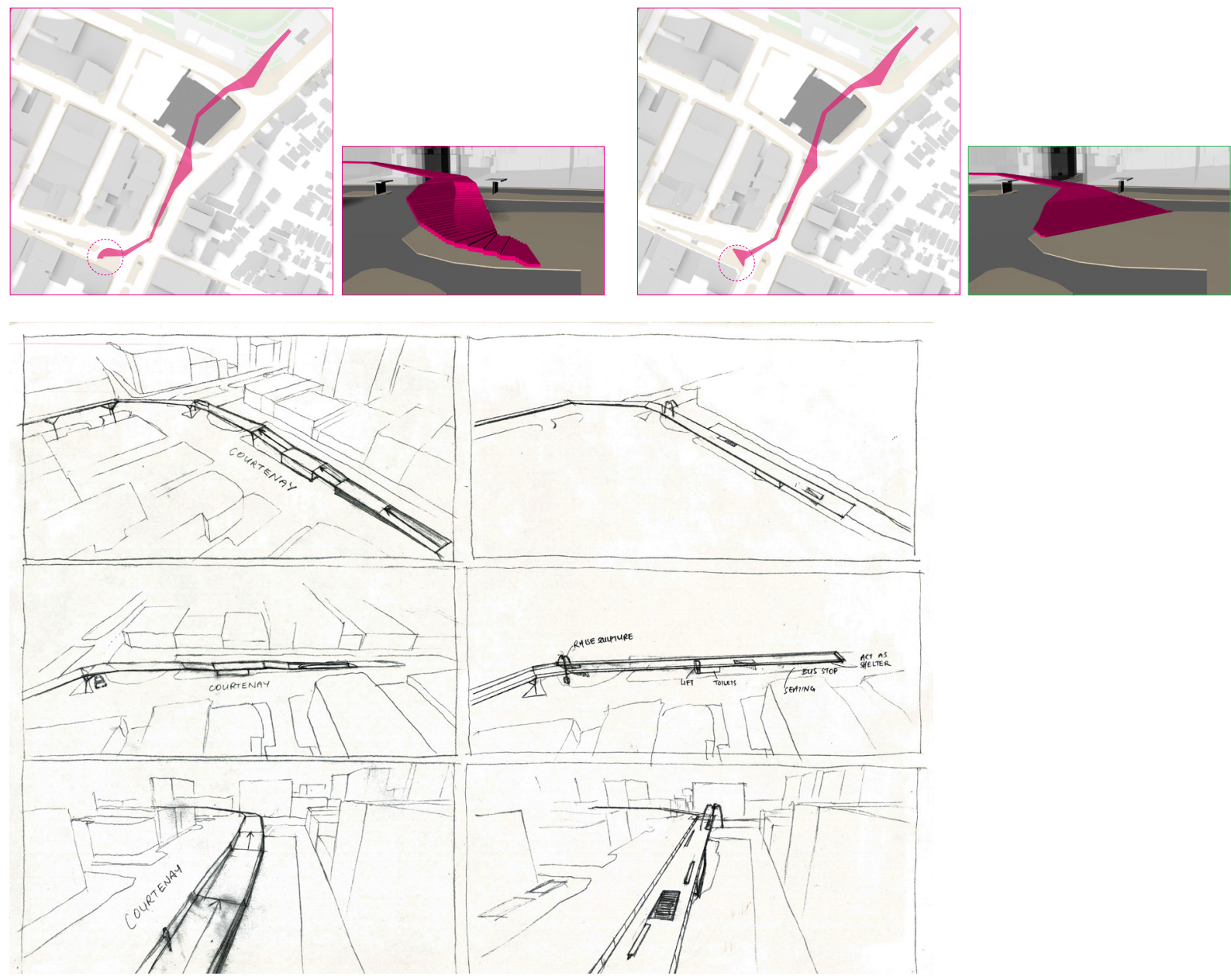

Fig. 6.2.8: Ramp landing option where stairs work with movie sculpture on site.

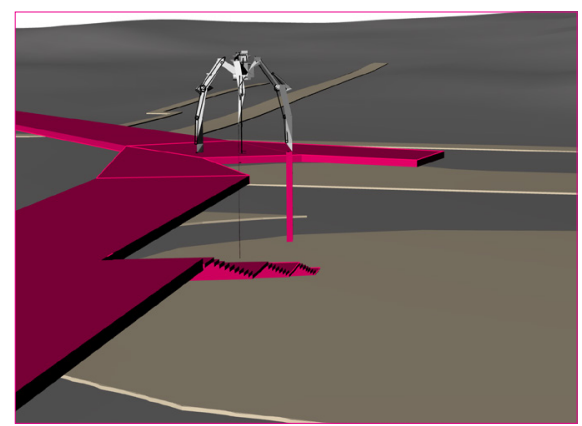


ROOFTOP ADDITION FORM EXPLORATION

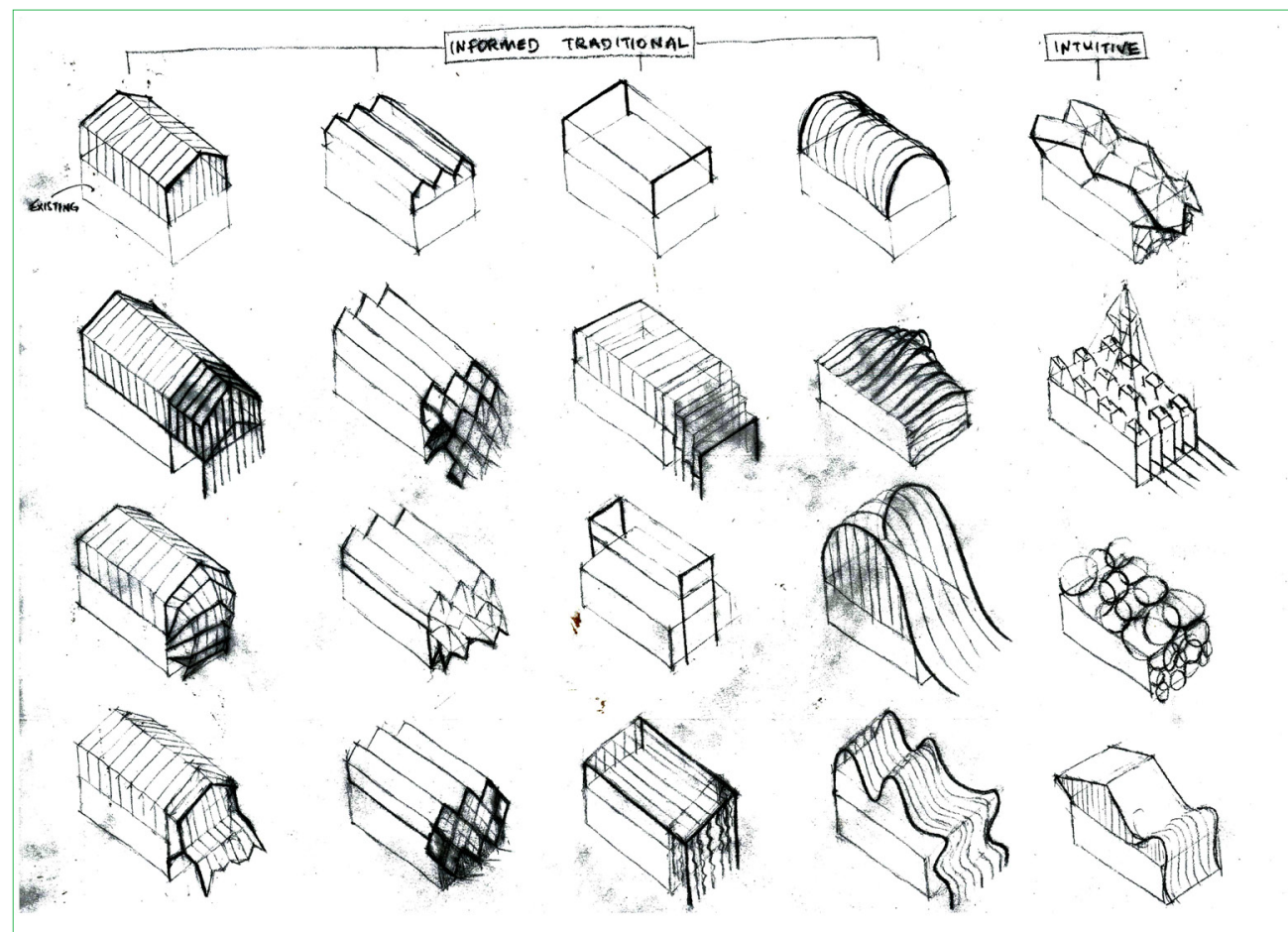

Fig. 6.2.9:

Tory farm -

traditional

greenhouse designs vs. intuitive.

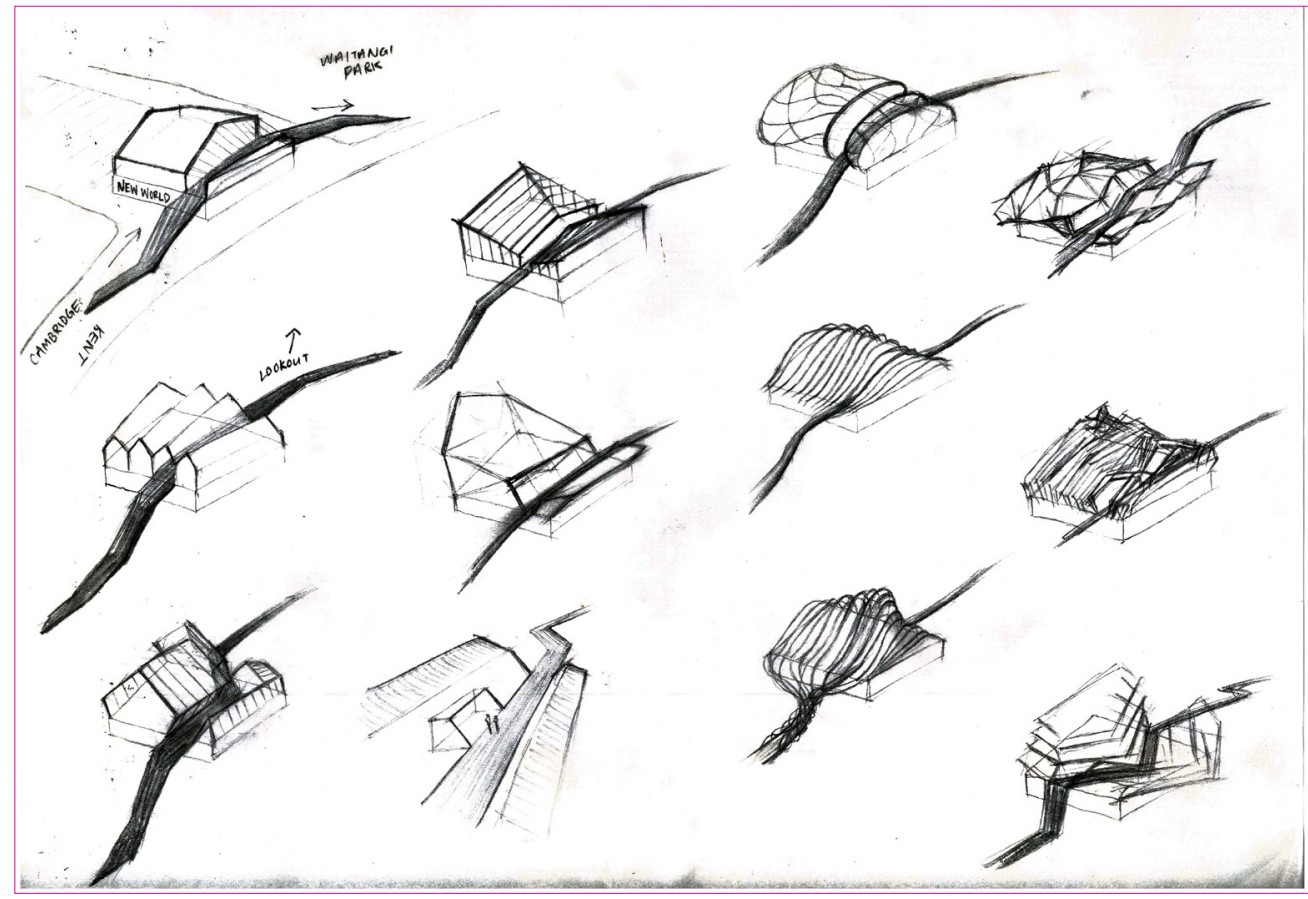

Fig. 6.2.10:

New World, with walkway shown. 
PRELIMINARY

\section{DESIGN}

FORM EXPLORATION
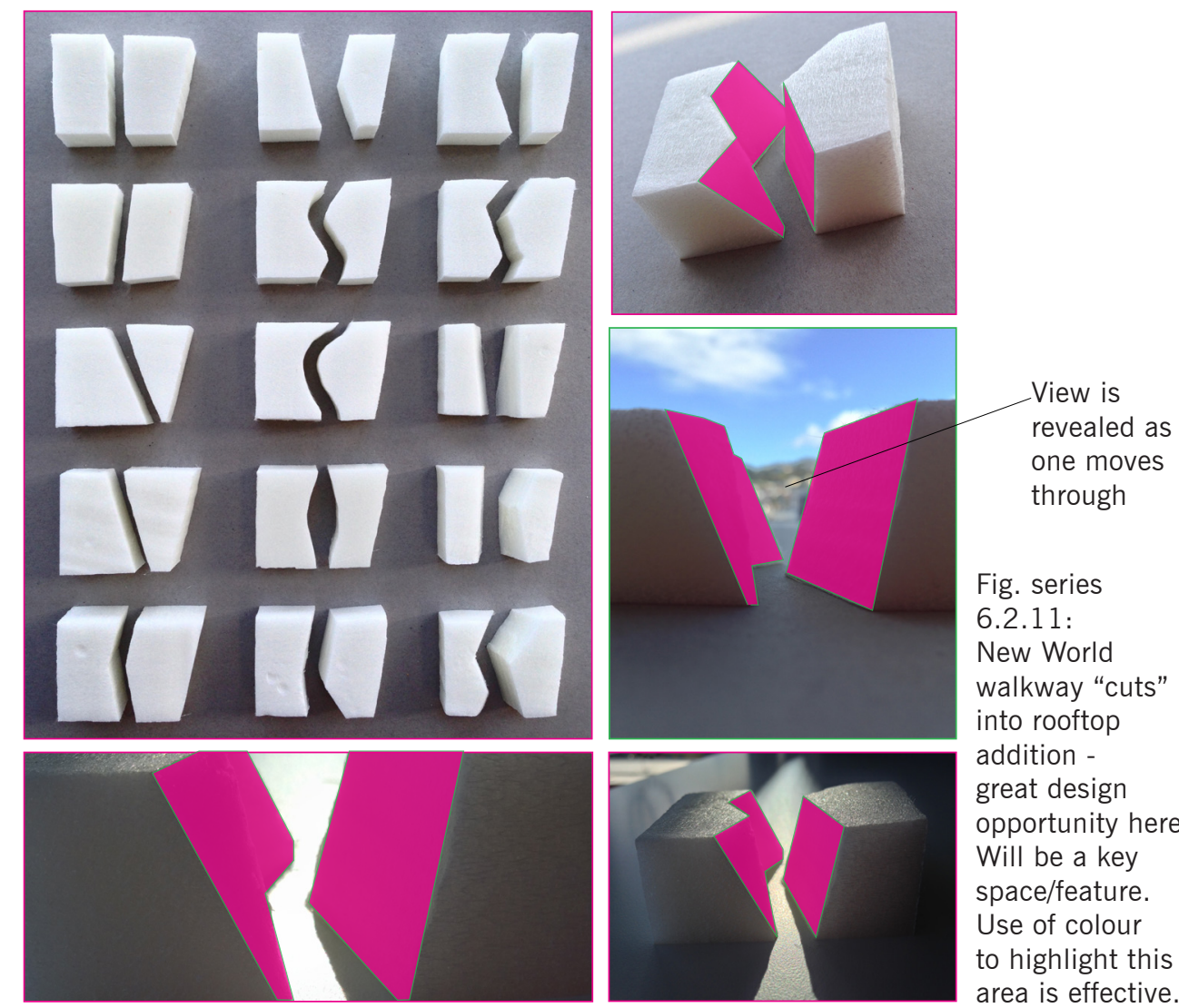

Fig. series

6.2.11:

New World

walkway "cuts"

into rooftop

addition -

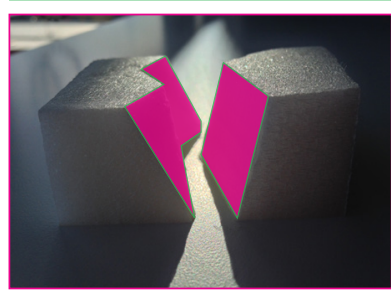

great design

opportunity here.

Will be a key

space/feature.

Use of colour

to highlight this

area is effective.

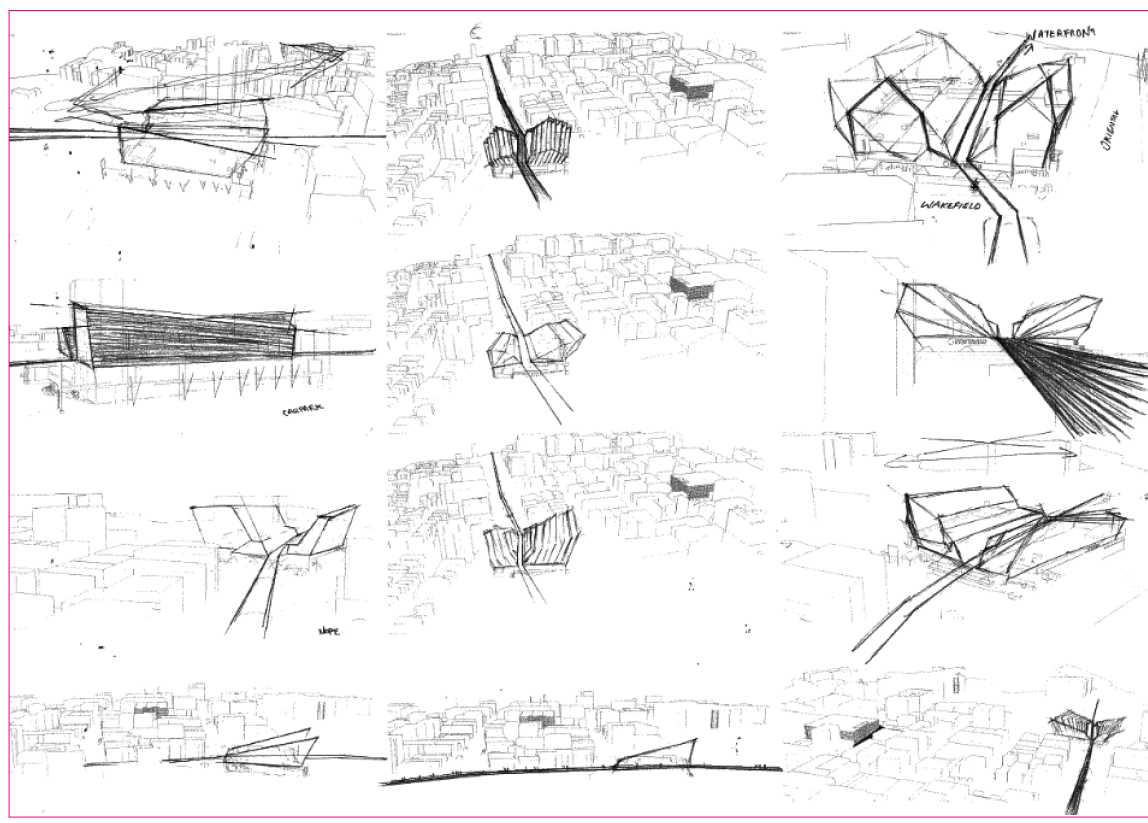

Fig. 6.2.12:

More preliminary form exploration/ sculpting of New World site. The walkway is a fundamental feature. 
ROOFTOP ADDITION FORM EXPLORATION: TORY FARM

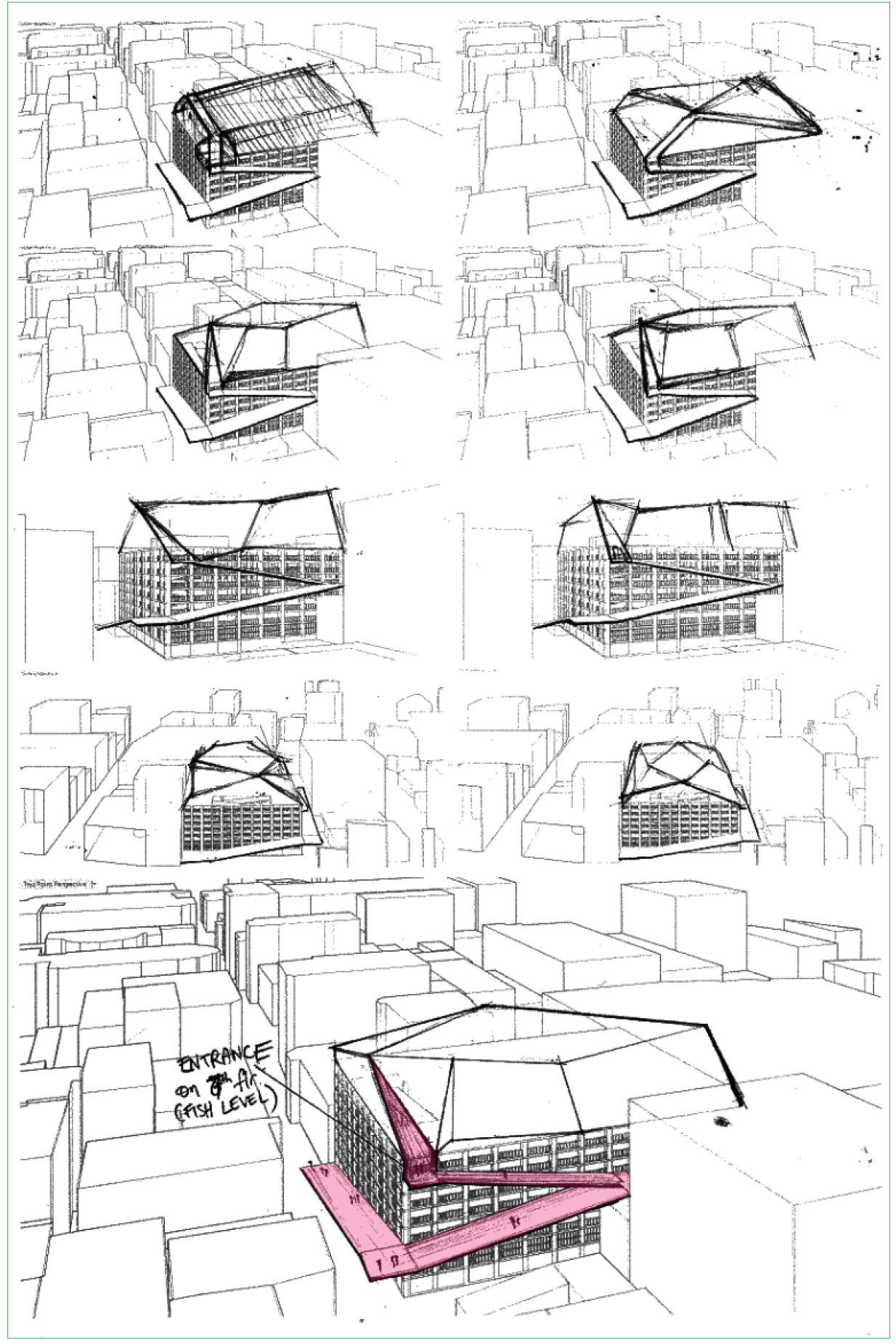

Fig. 6.2.13 
PRELIMINARY

DESIGN

FORM EXPLORATION

ROOFTOP ADDITION FORM EXPLORATION: NEW WORLD FARM

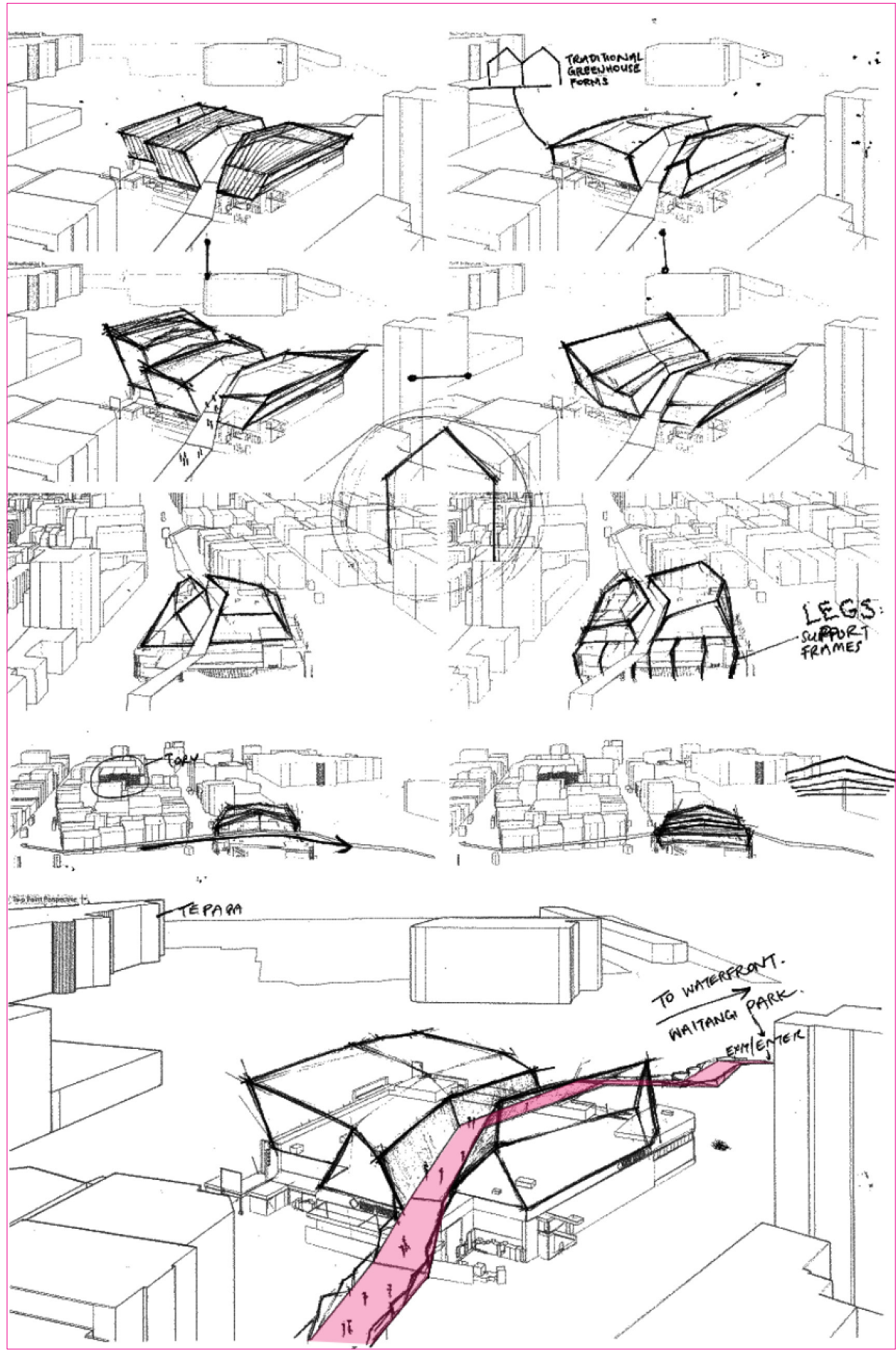

Fig. 6.2.14 
ROOFTOP ADDITION FORM \& STRUCTURE EXPLORATION: TORY FARM
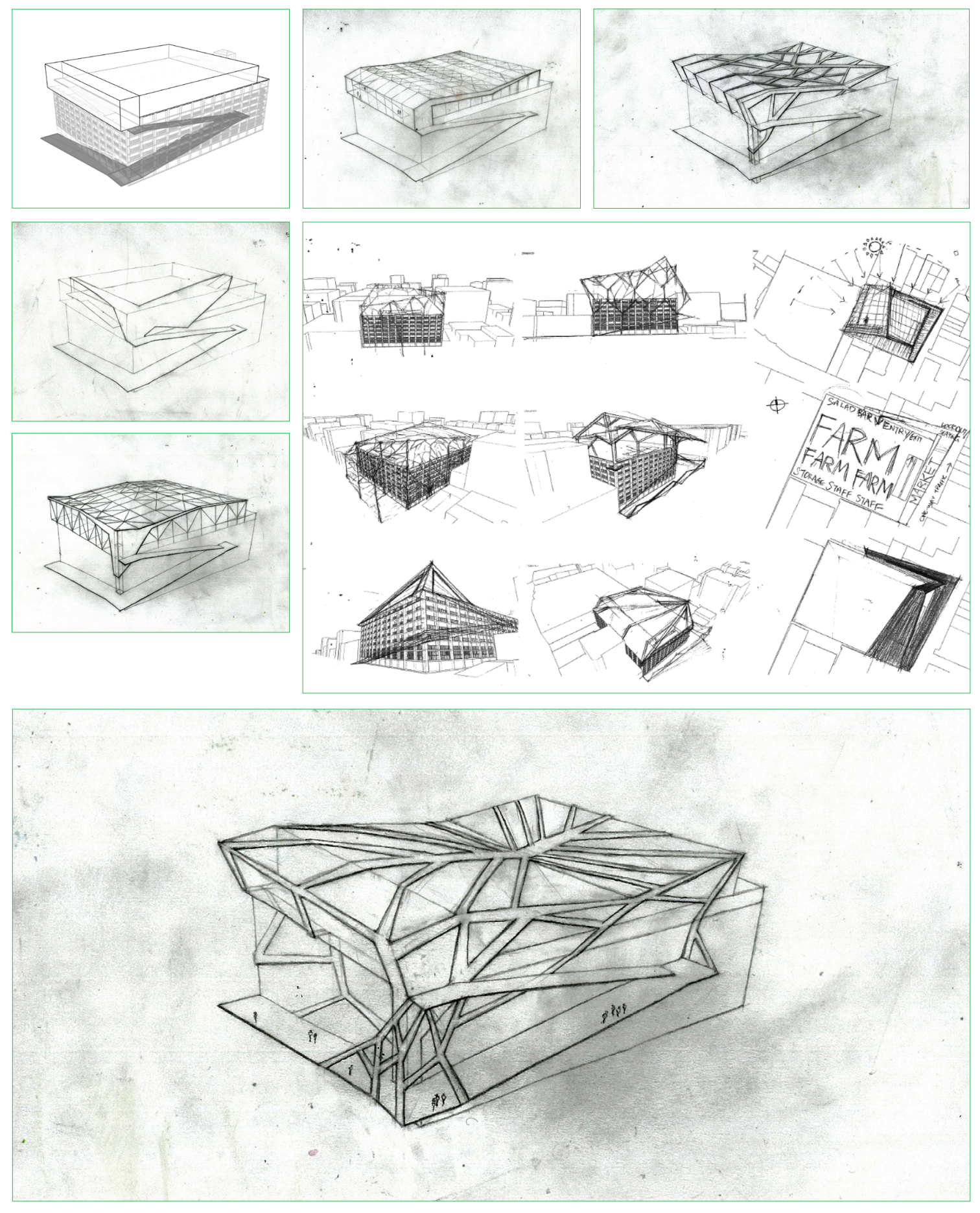

Fig. series 6.2 .15 
PRELIMINARY

DESIGN

FORM EXPLORATION

ROOFTOP ADDITION FORM \& STRUCTURE EXPLORATION: NEW WORLD FARM
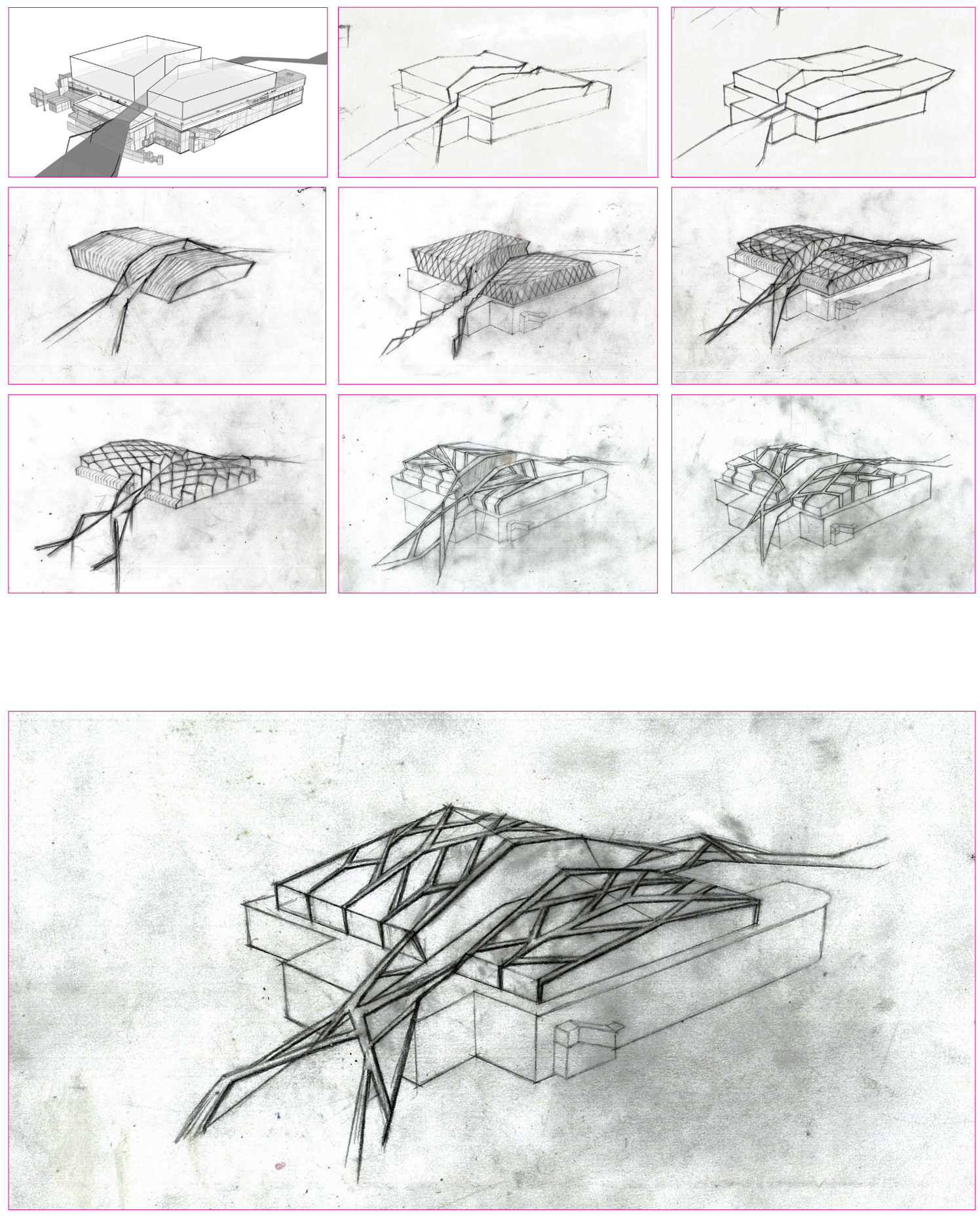

Fig. series 6.2.16: Use of hand renderings in preliminary iterations reflect a degree of intuitive design, in setting a "visionary" foundation for the project. 
PATTERN STUDIES

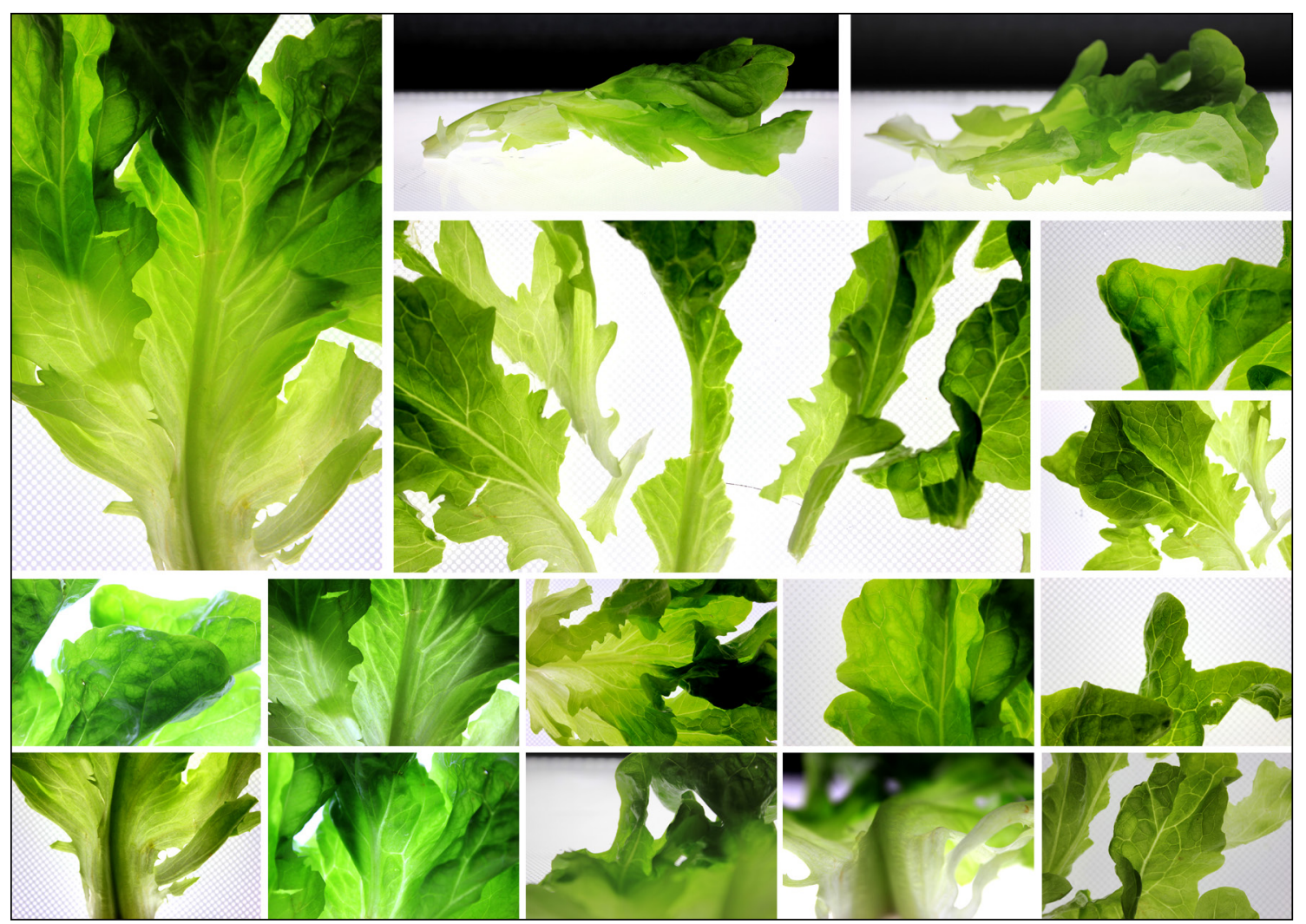

Fig. series 6.2.17
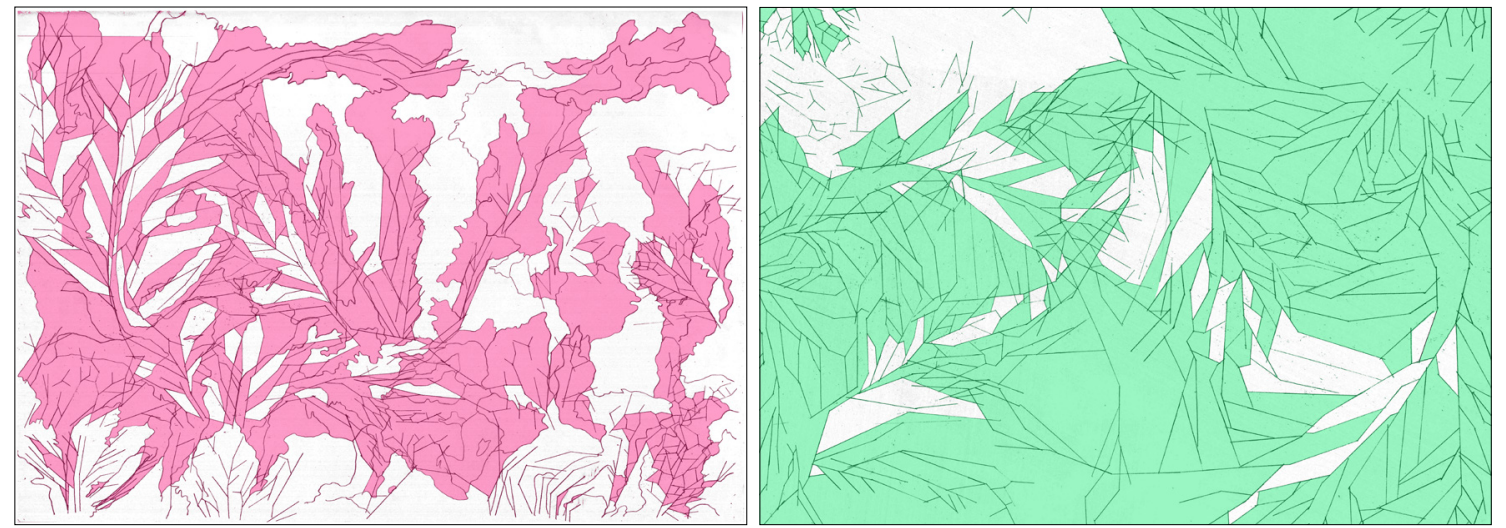

Fig. series 6.2.18

Using a lettuce leaf, its organic structure is extracted and manipulated in a pattern-finding exercise. This is intended to be useful towards later development of the structure/skin of the farm. 
PRELIMINARY

DESIGN

PATTERN EXPLORATION
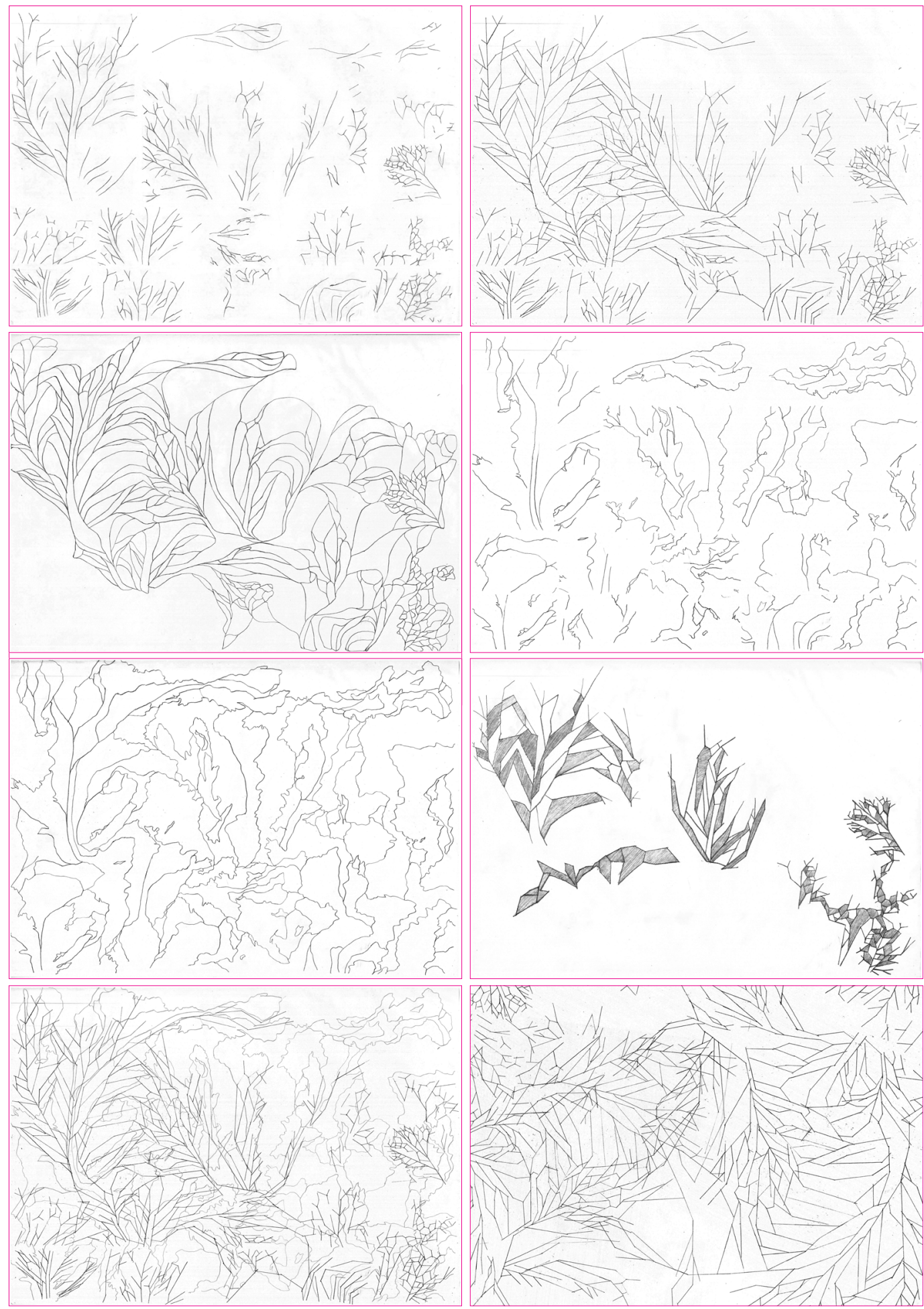

Fig. series 6.2.19 


\section{PROGRAM PLANNING}

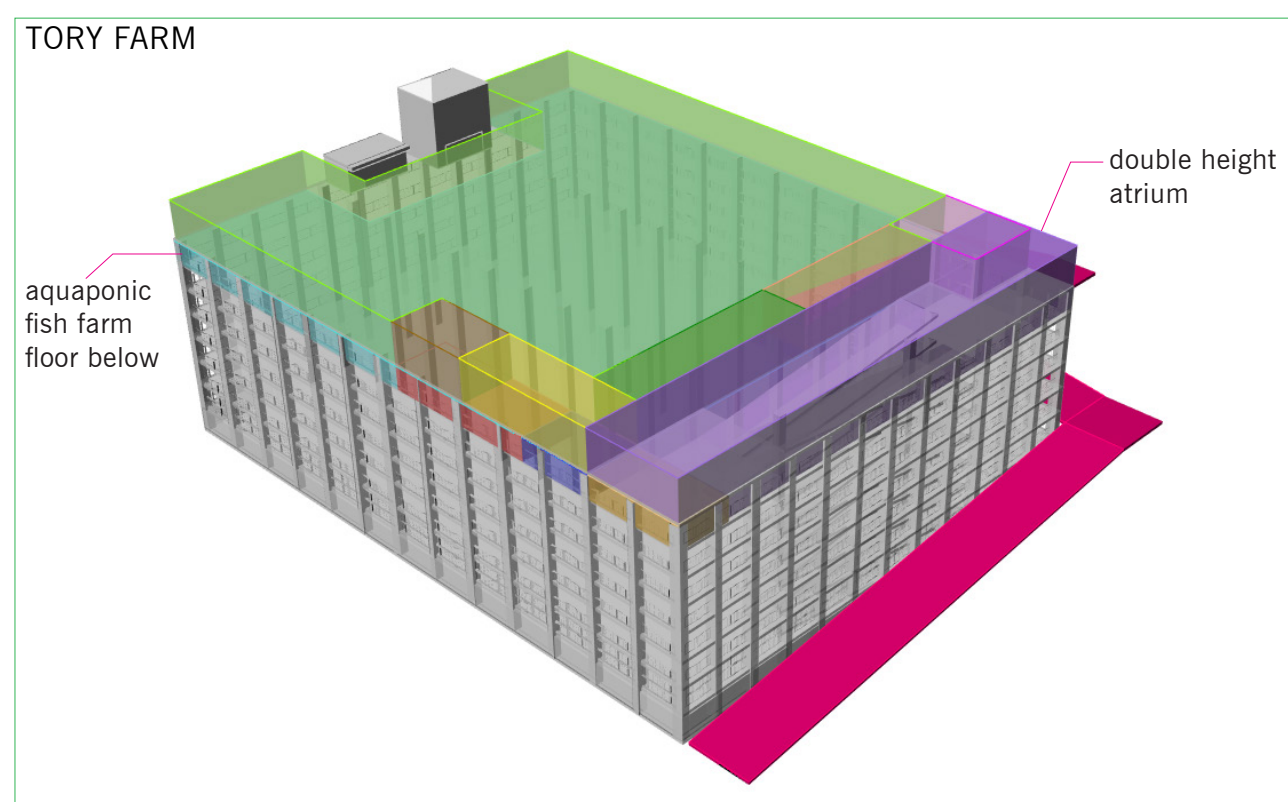

Fig. 6.2.20

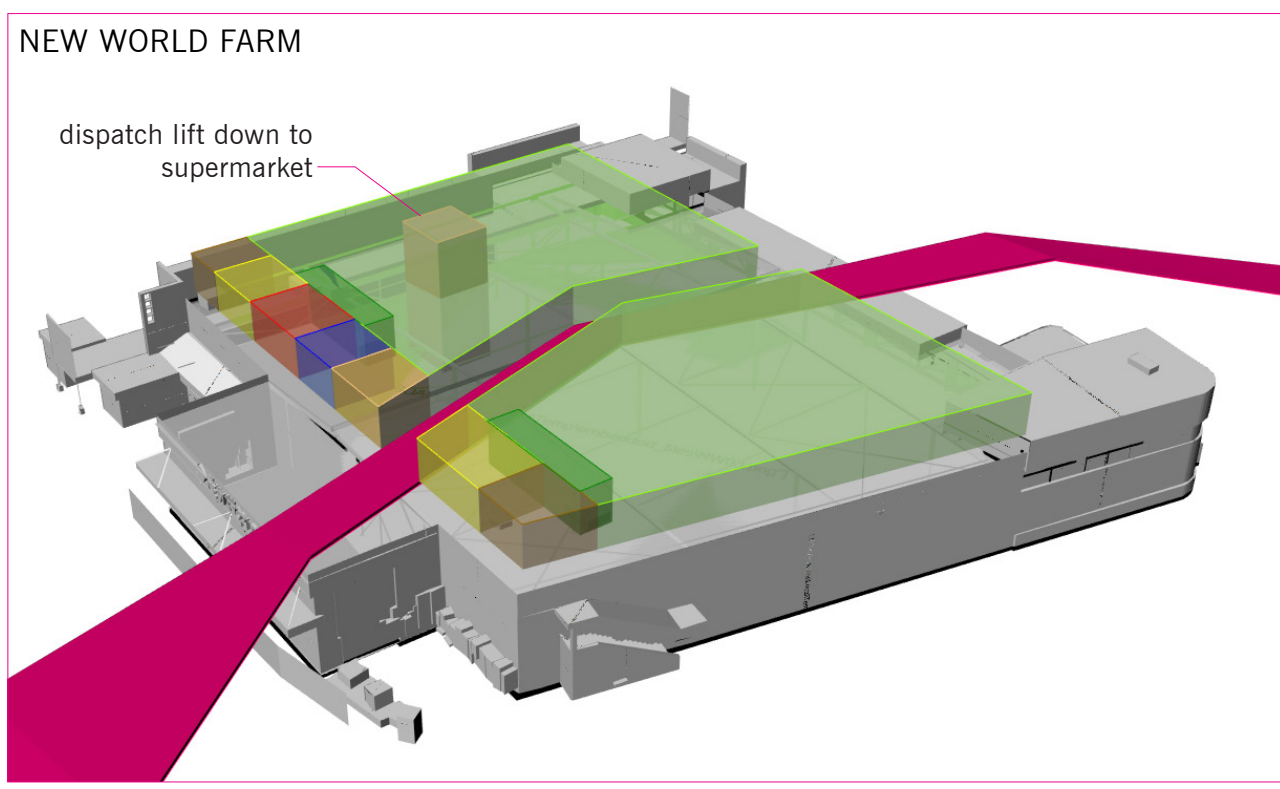

Entrance Atrium

Crops

- Seed Preparation

- Dispatch

- Office

- Toilets

Changing Room

Aquariums

Salad Bar

Equipment Storage

- Climate Control

Fig. 6.2.21

Figs. $6.2 .20+6.2 .21$ : The program is determined from precedent studies of existing farms in practice with most of the floor area given to crop cultivation. Many of the services related to the runnings of the farm (e.g. office and storage etc) are located on the southern side of the rooftop addition - perhaps as a separate structure either in/outside the greenhouse, with less exposure to light.
Figs. $6.2 .22+6.2 .23$ (facing page): A $24 \mathrm{hr}$ programmatic study of both farms shows constant aquaponic activity while other functions start and stop during the day. Ramp activity could be consistent with the hours of farm operation, perhaps peaking during midday with more pedestrian traffic. Harvest occurs each day in the early hours of the morning in time for sales, though this could continue gradually during the day to refill shelves. (Based on OMA's 1991 Yokohama masterplan). 
PRELIMINARY

DESIGN

PROGRAM

PROGRAMMATIC TIMELINE 24HRS - TORY FARM

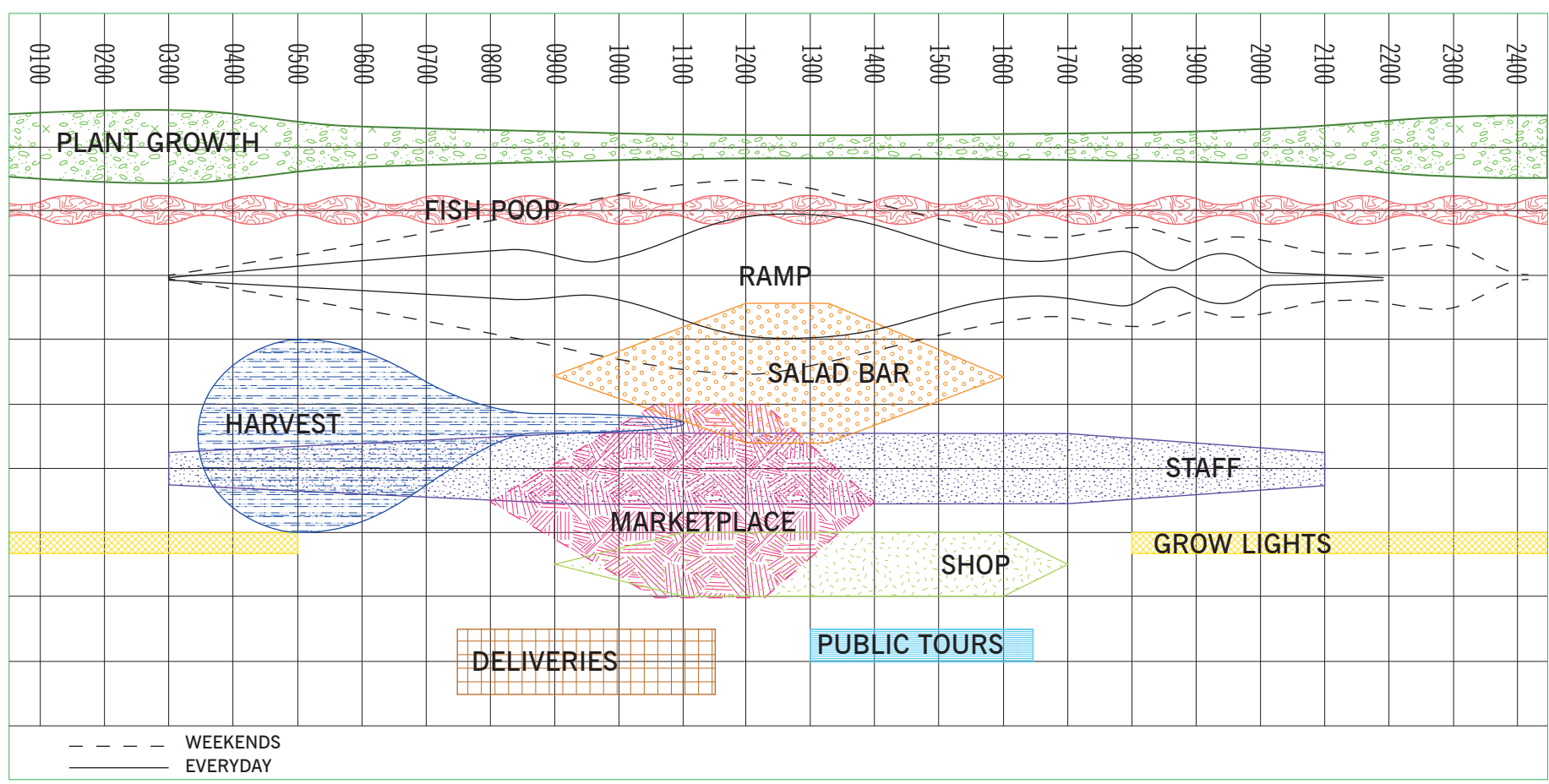

Fig. 6.2.22

PROGRAMMATIC TIMELINE 24HRS - NEW WORLD FARM

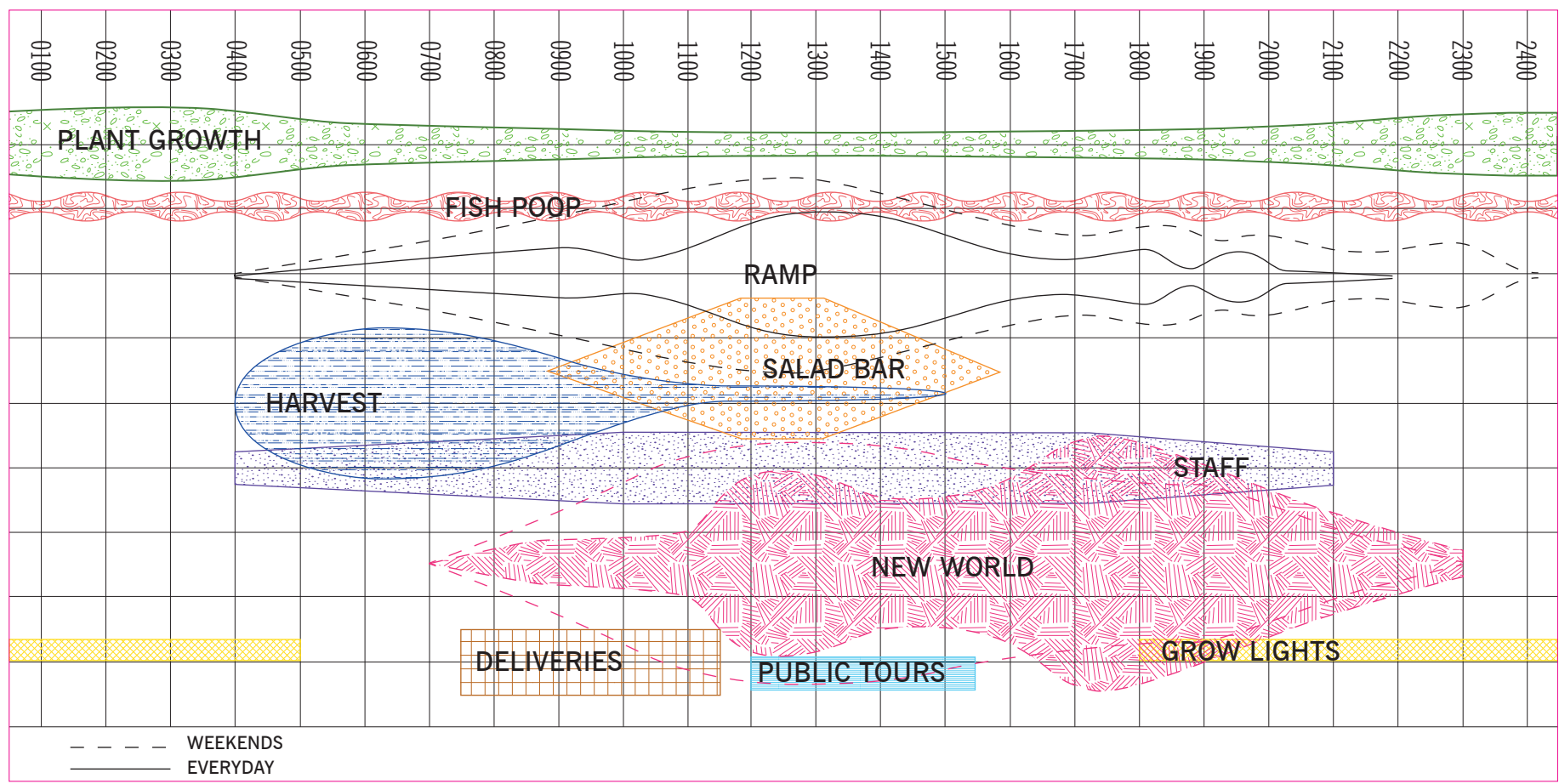

Fig. 6.2.23 


\section{STRUCTURE STUDIES - TORY FARM}
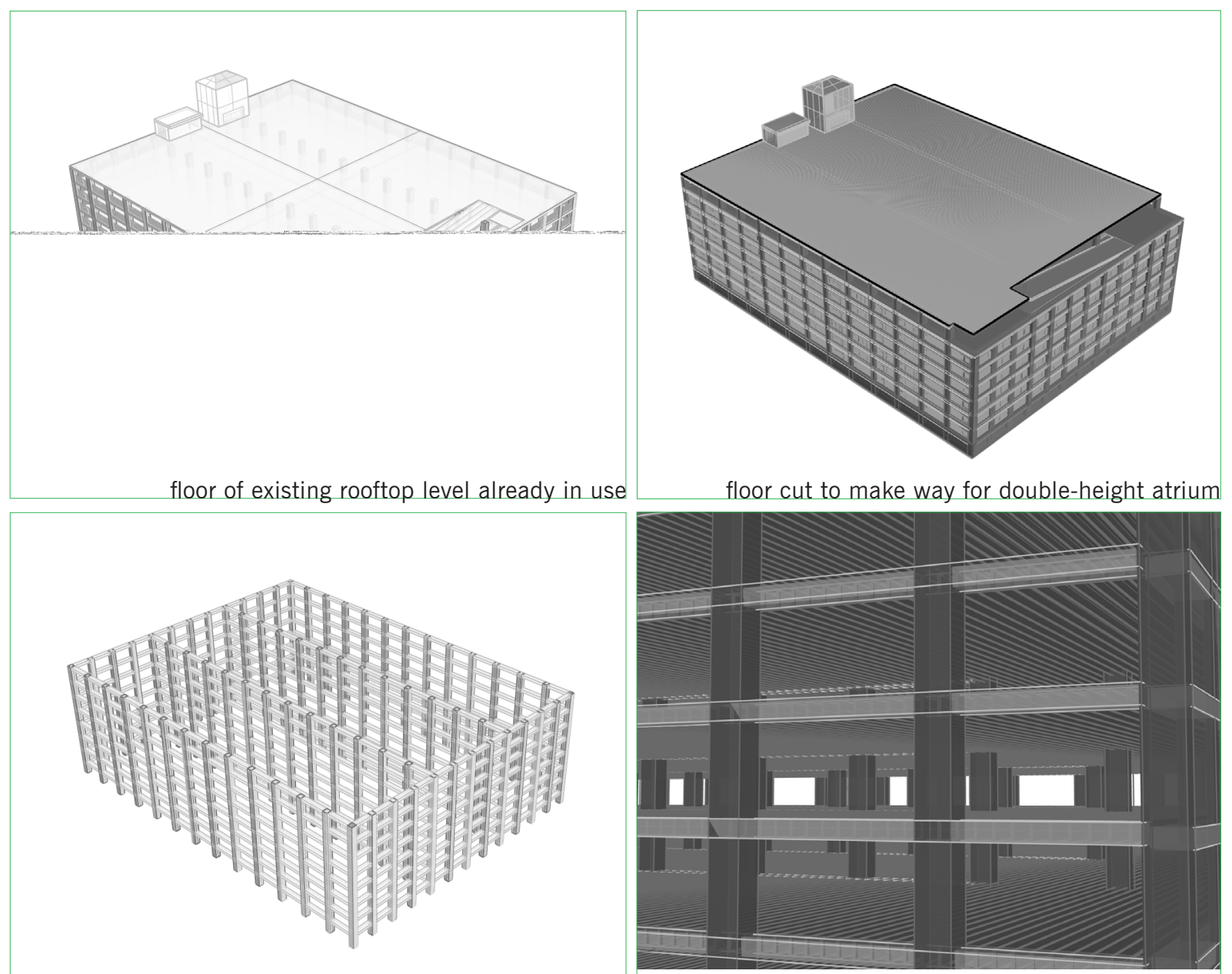

existing columns and primary beams

secondary $x$-direction beams to remain

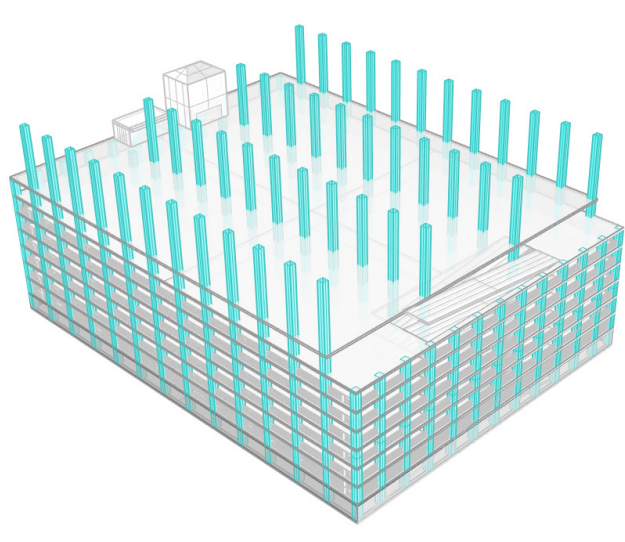

columns extended to support new rooftop level
Fig. series 6.2.24: Gravity loads: column extension (option) for new level. Could explore how this ties into the skin design that will also address lateral loads (building currently uses cross bracing). 

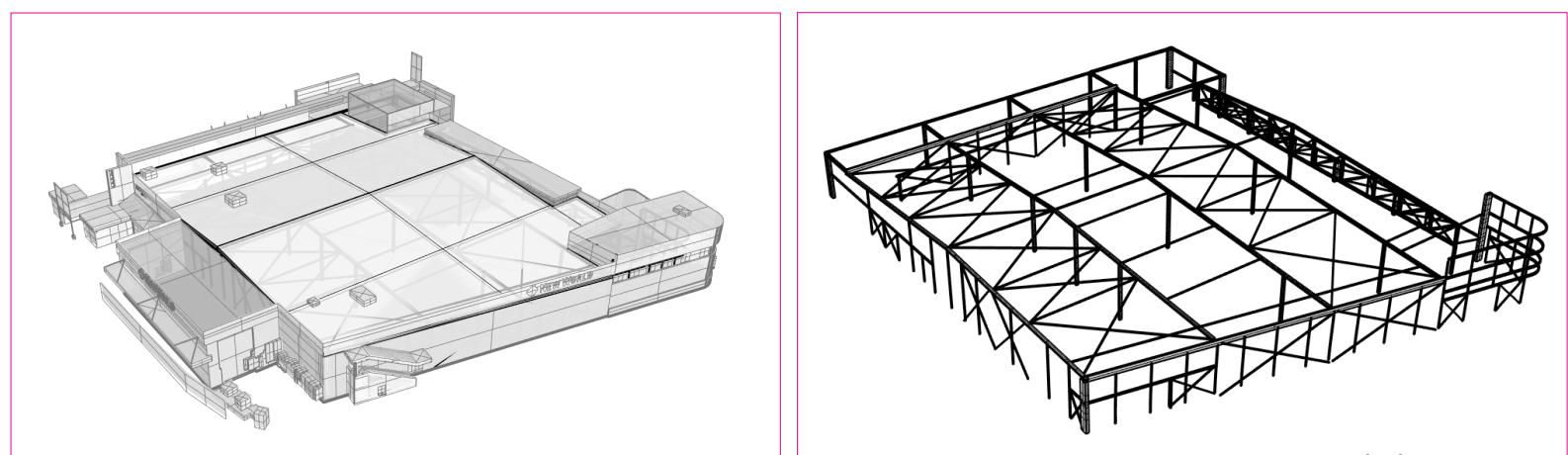

existing new world with shallow gable roof

existing structure
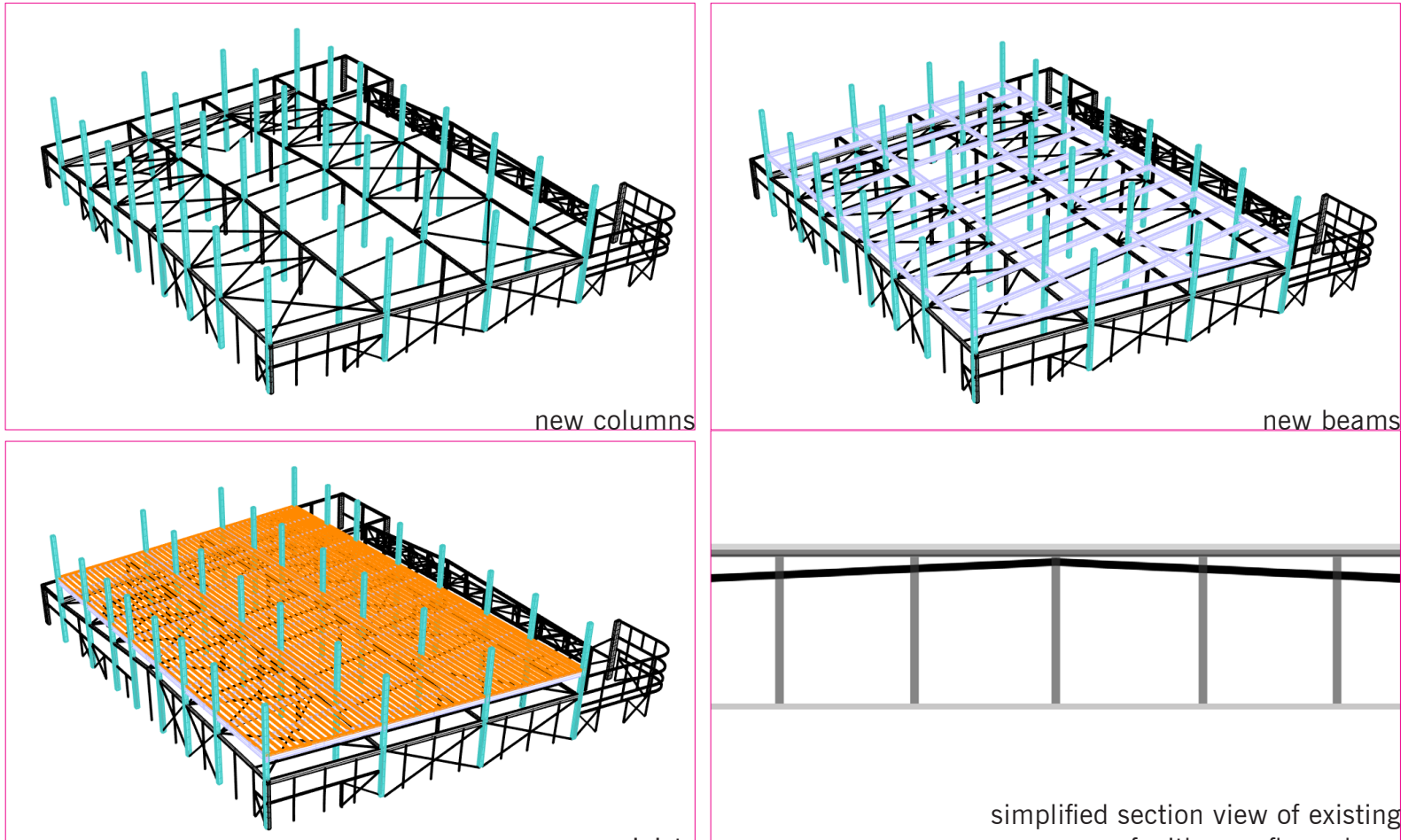

new joists
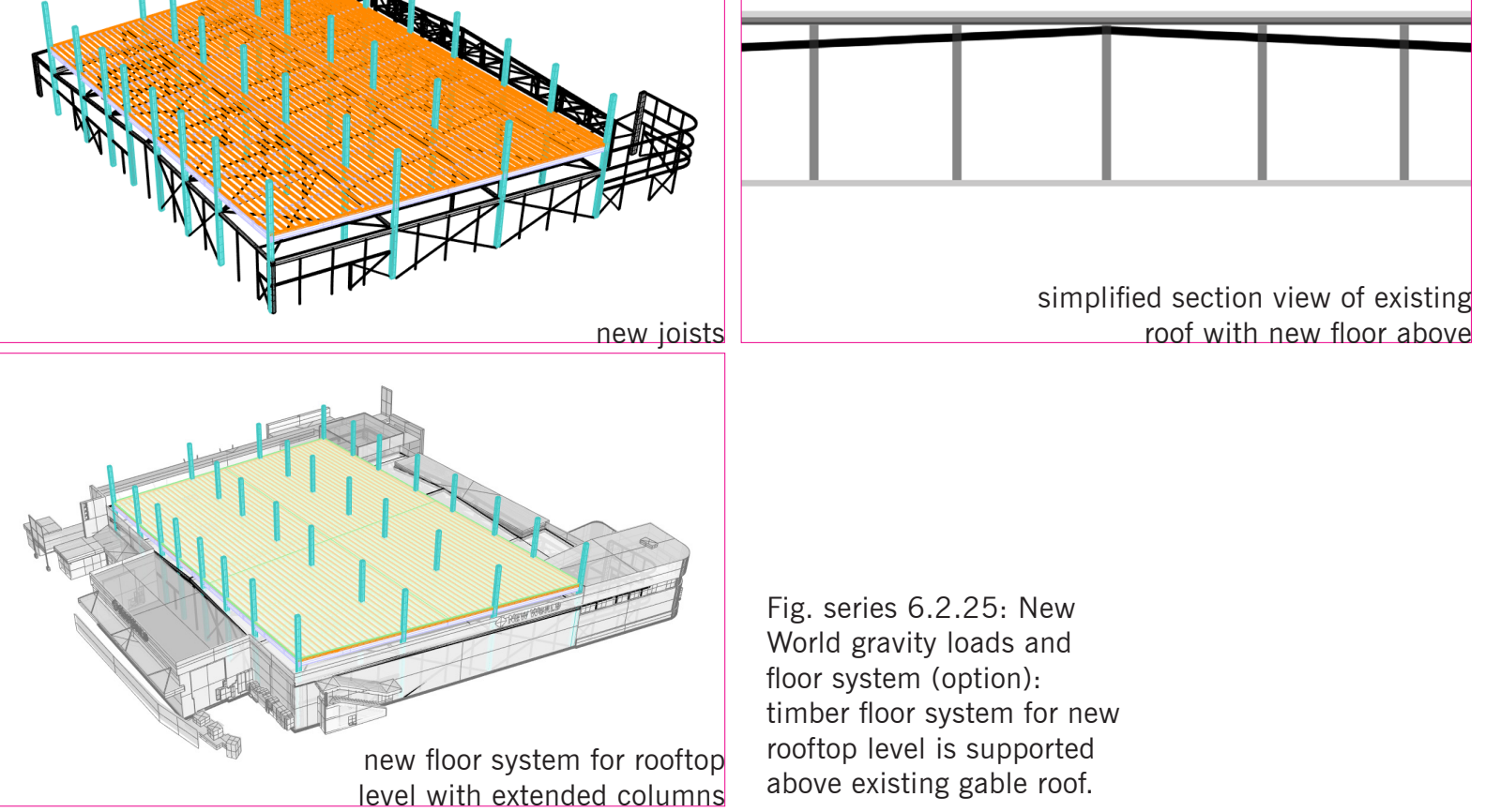

Fig. series 6.2.25: New World gravity loads and floor system (option): timber floor system for new rooftop level is supported above existing gable roof. 

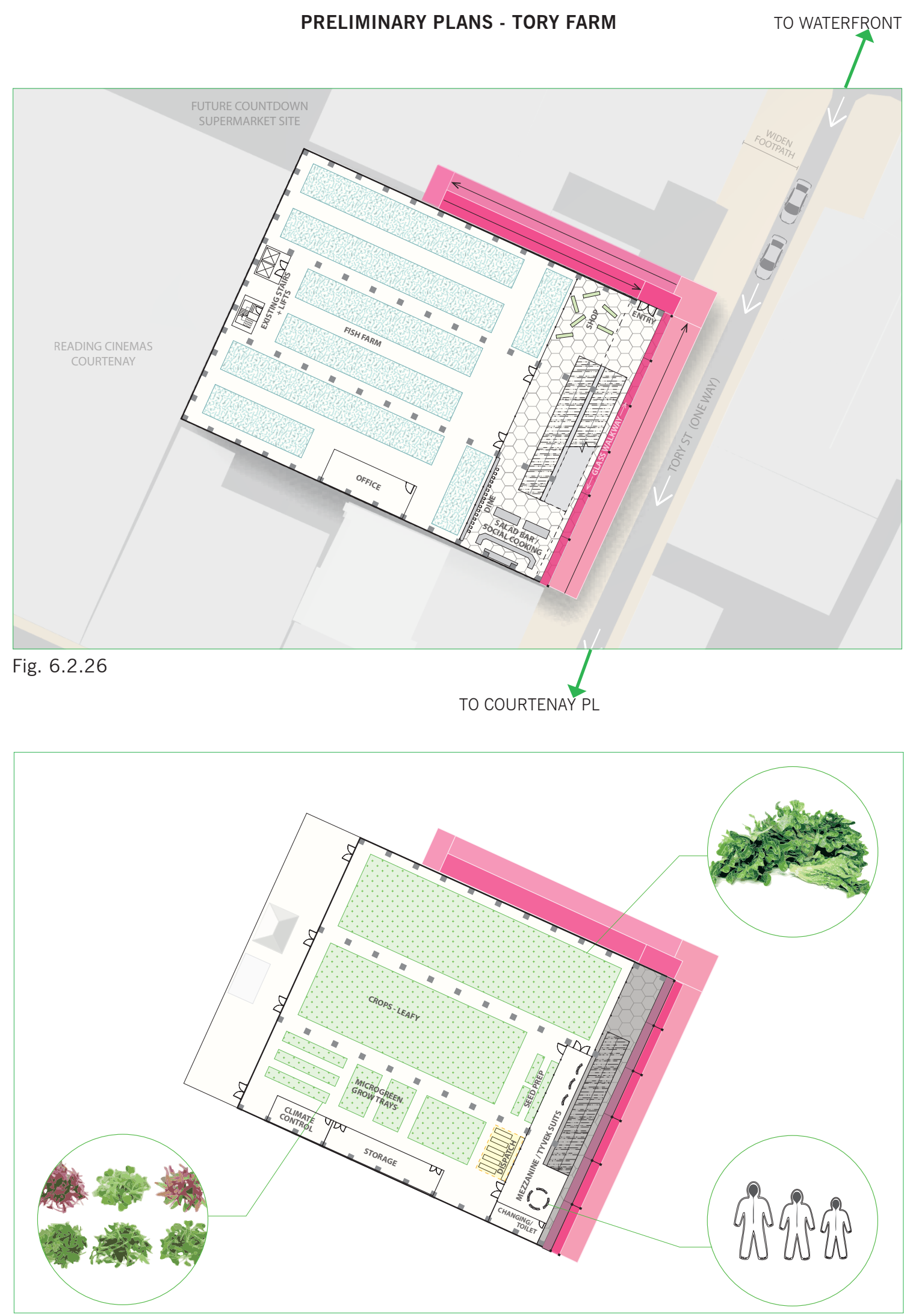

LEVEL ROOF:

Fig. 6.2.27 
[6.2]

PRELIMINARY

\section{DESIGN}

DRAWINGS
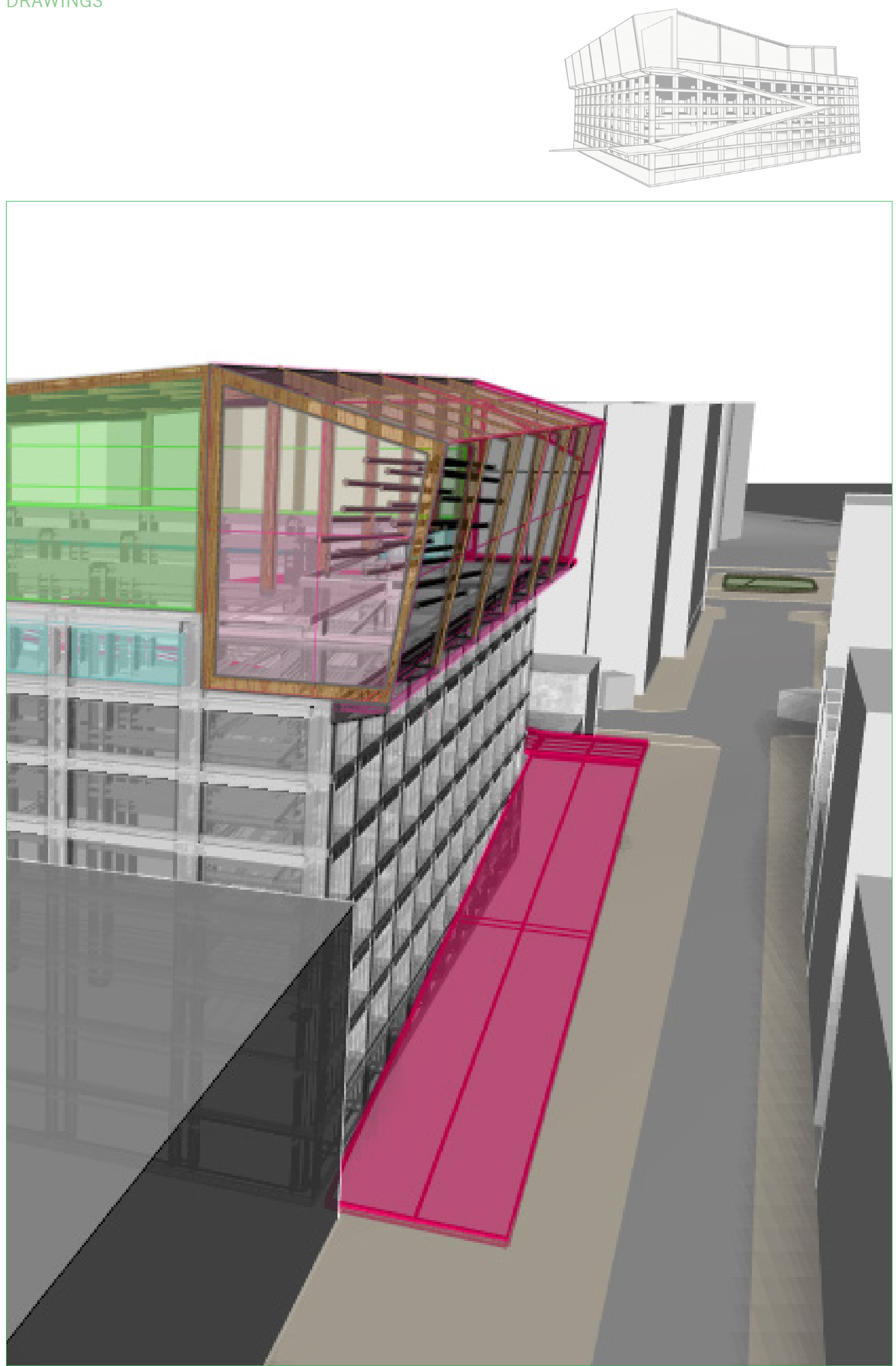

Fig. 6.2.28: Looking north. Tory St with widened footpath to accomodate ramp activities (and street level market). One way traffic is proposed towards Courtenay PI. 


\section{DRAWINGS - TORY FARM}

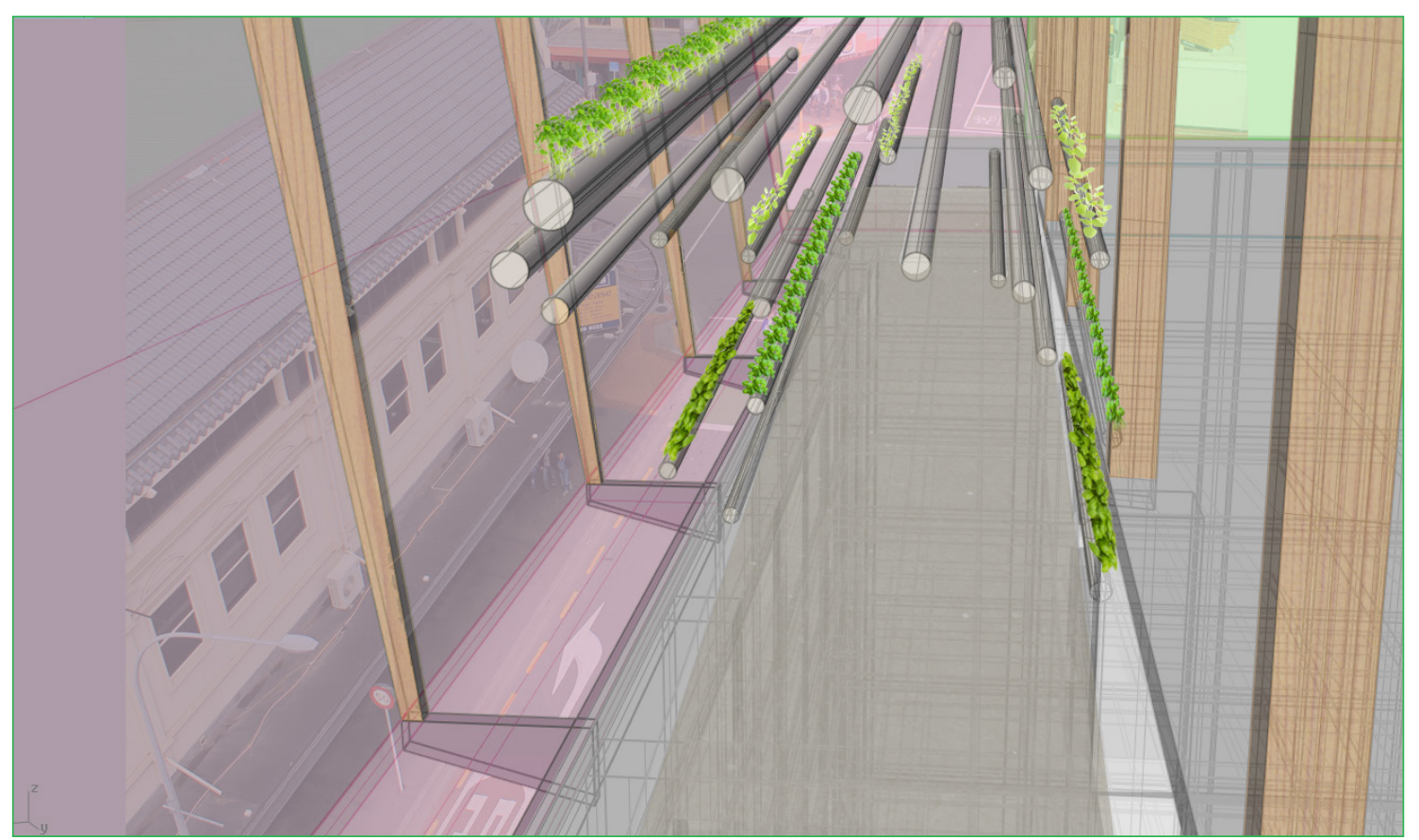

Fig. 6.2.29: Access option to Roof - existing ramp up to farm from fish level.
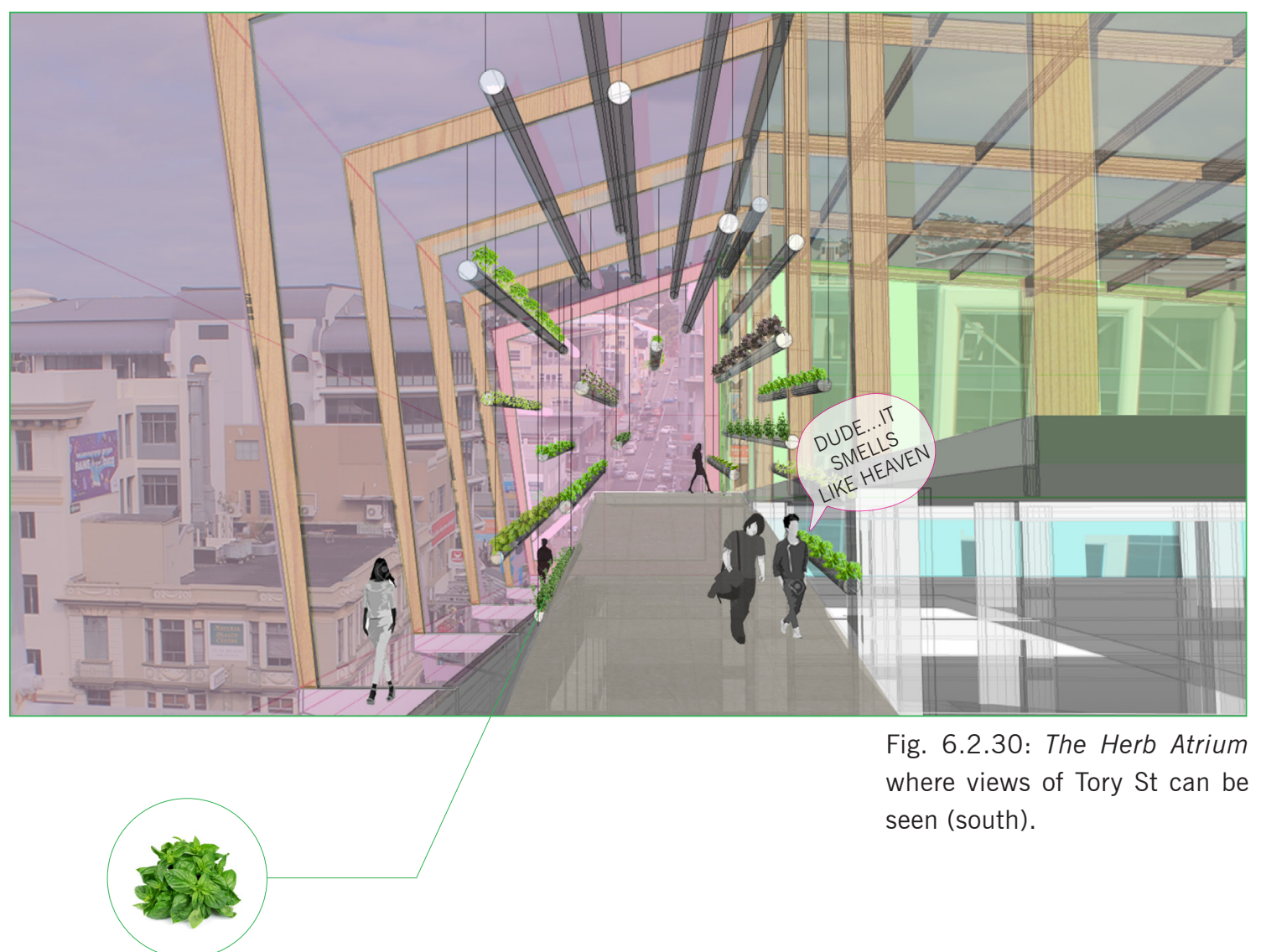

Fig. 6.2.30: The Herb Atrium where views of Tory St can be seen (south).

THIS MONTH: BASIL 
PRELIMINARY

DESIGN

DRAWINGS

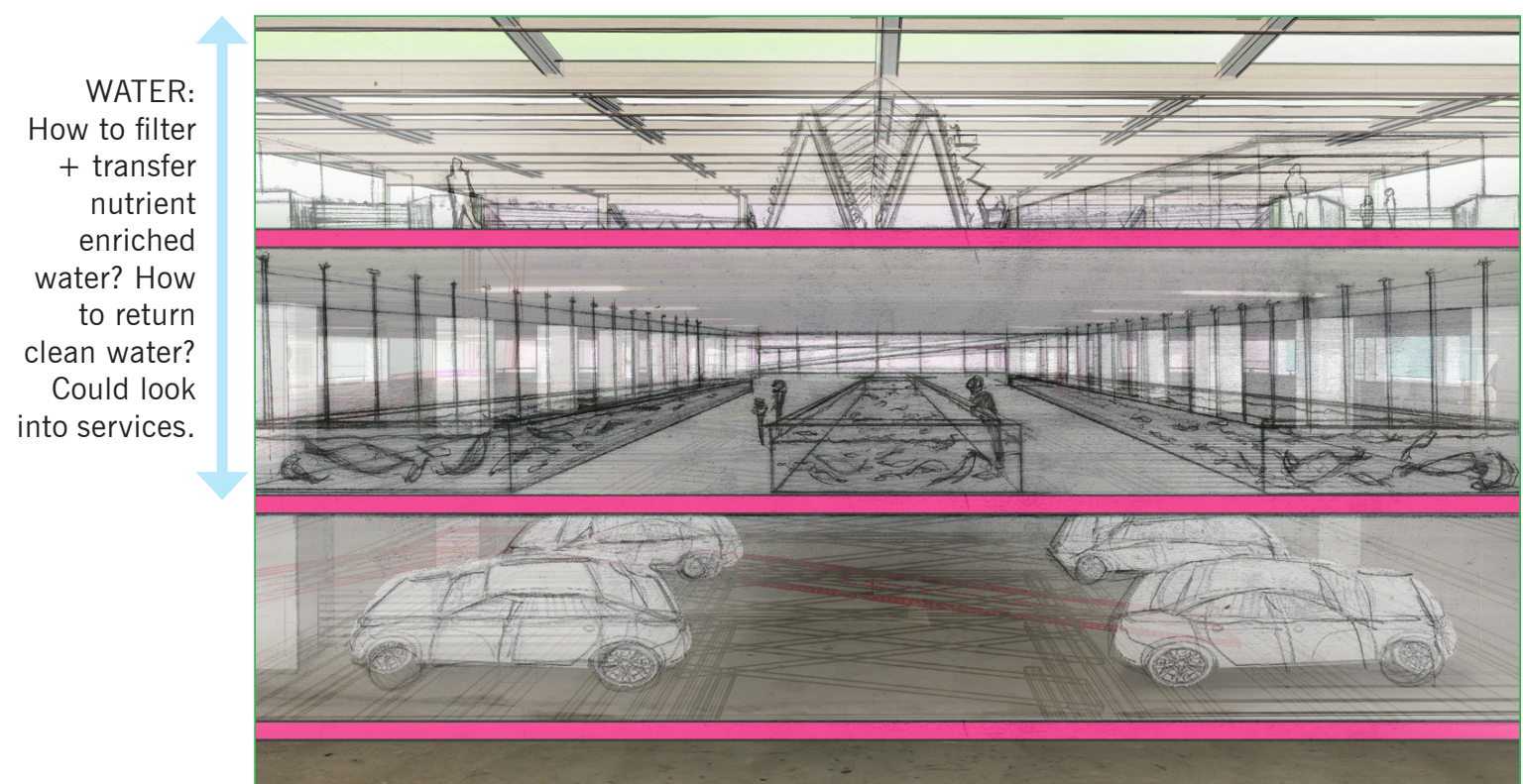

LEVEL ROOF VEGES

LEVEL 7

FISH

LEVELS

G-6

CARS

Fig. 6.2.31: Section into top three levels.

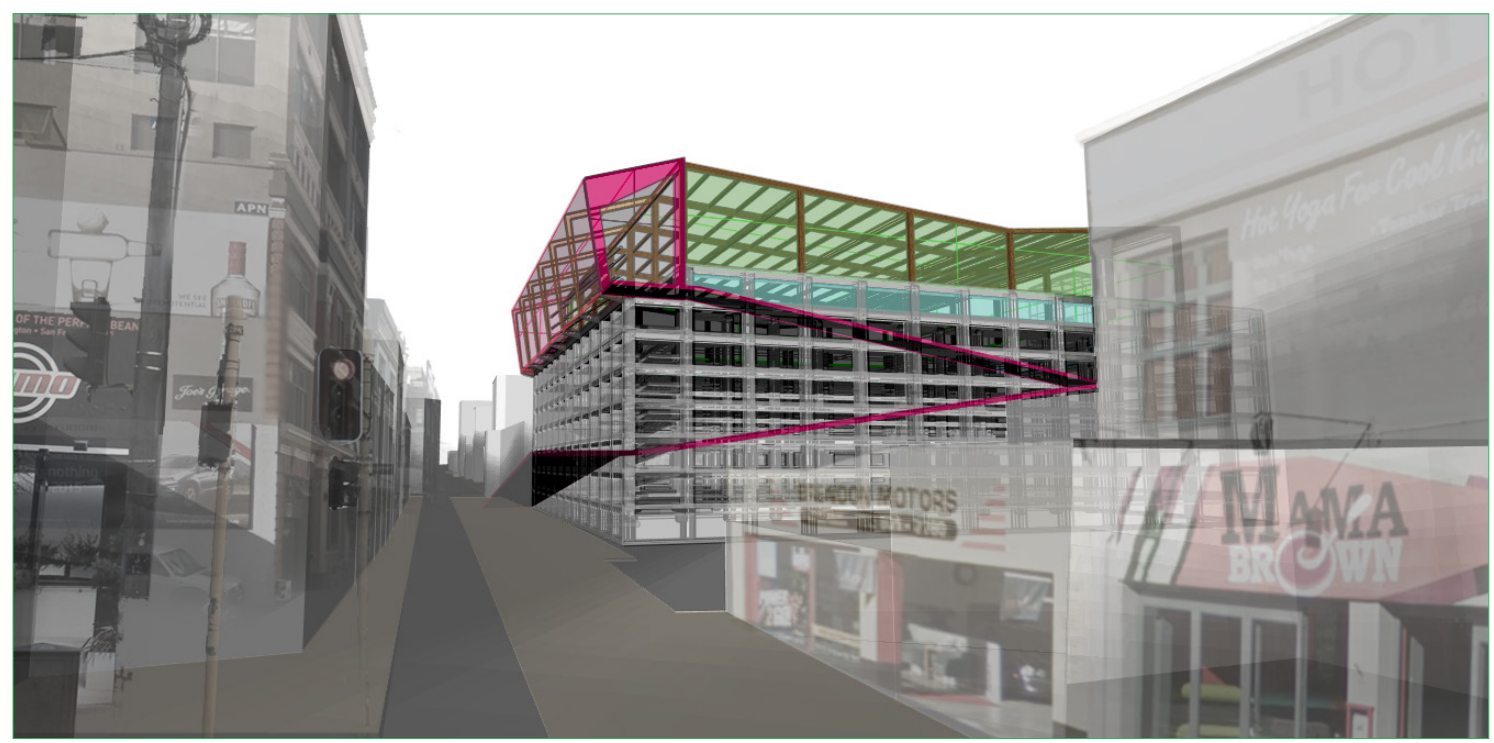

Fig. 6.2.32: View from Wakefield St. 


\section{PRELIMINARY PLANS - NEW WORLD FARM}

note: basement (level b) + mezzanine (level 1) not shown

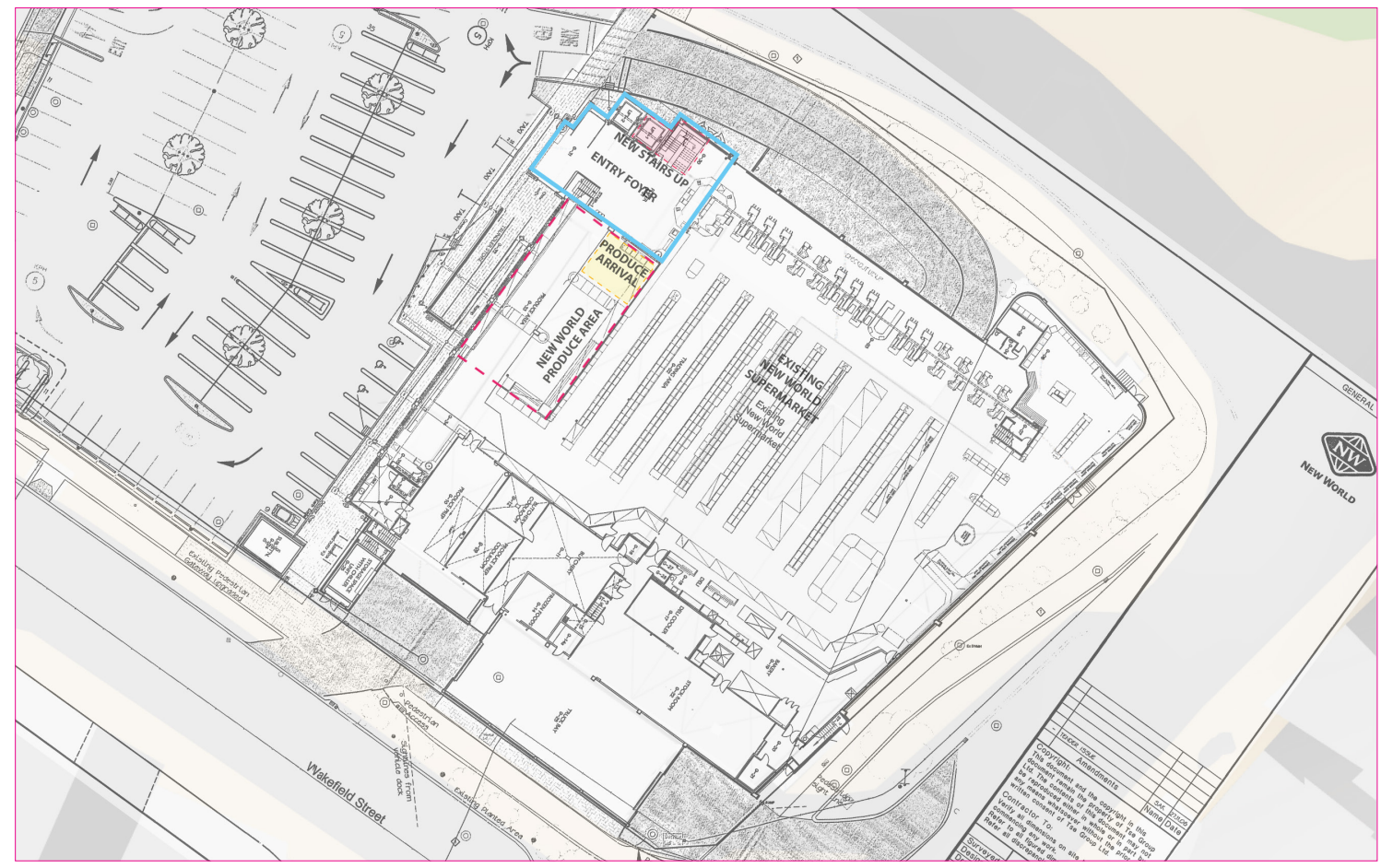

LEVEL GROUND:

Fig. 6.2.33 Emphasis on lift shaft 'dispatch' to be designed to connect with ground level fresh produce area in the supermarket (plan retrieved from WCC building archives)

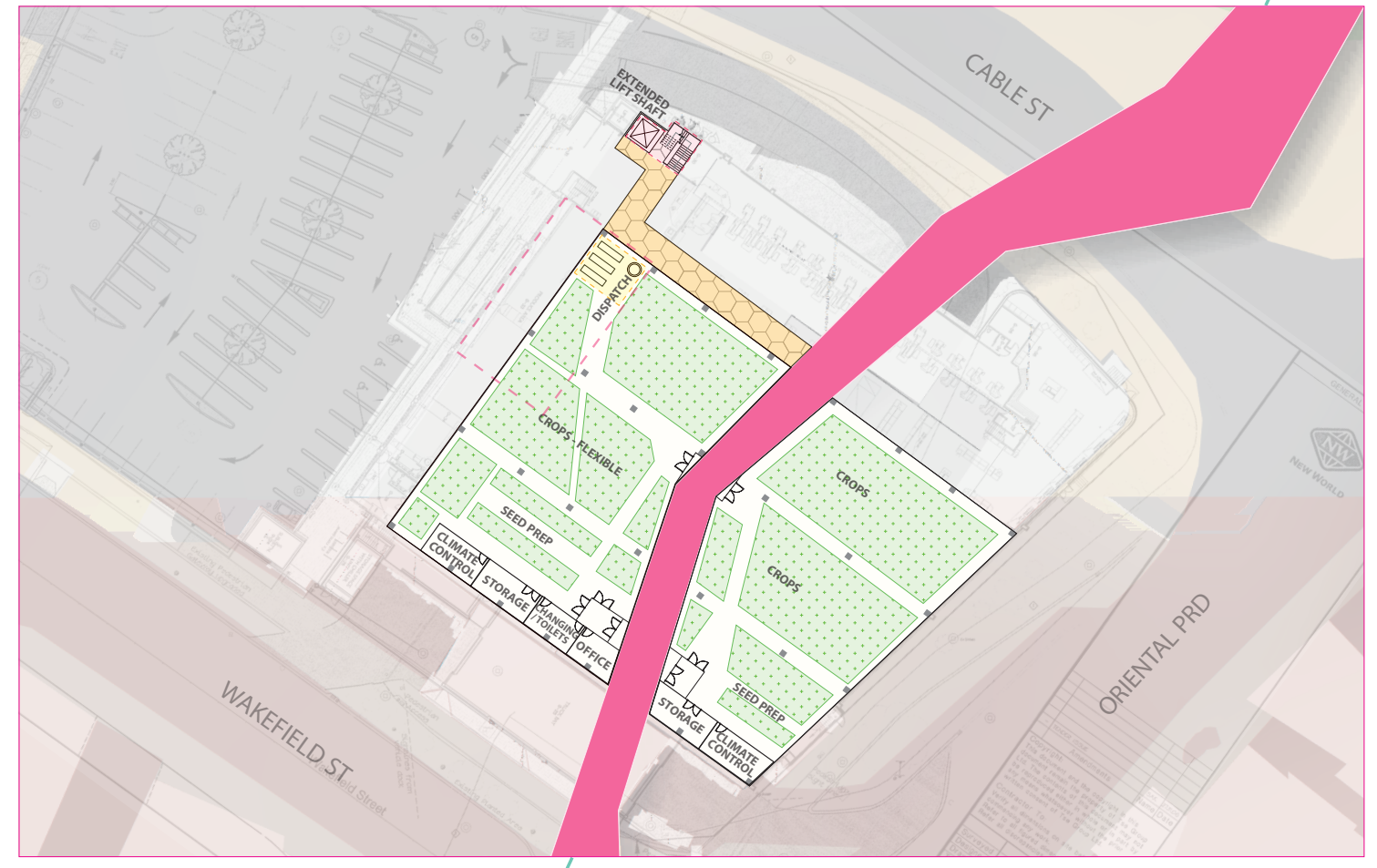

LEVEL ROOF:

FARM \& WALKWAY

Fig. 6.2.34: A developing plan for New World rooftop farm. New internal access to rooftop is provided for by extending the lift at the entrance foyer and installing a set of stairs beside it. Basement level (not shown) could house fish farm. 
PRELIMINARY

DESIGN

DRAWINGS

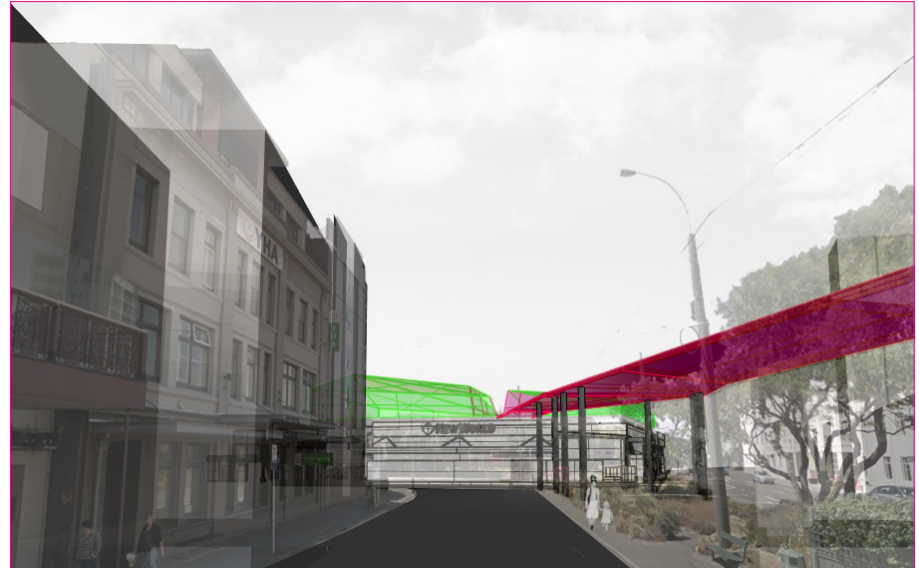

Fig. 6.2.35: View from Cambridge Tce

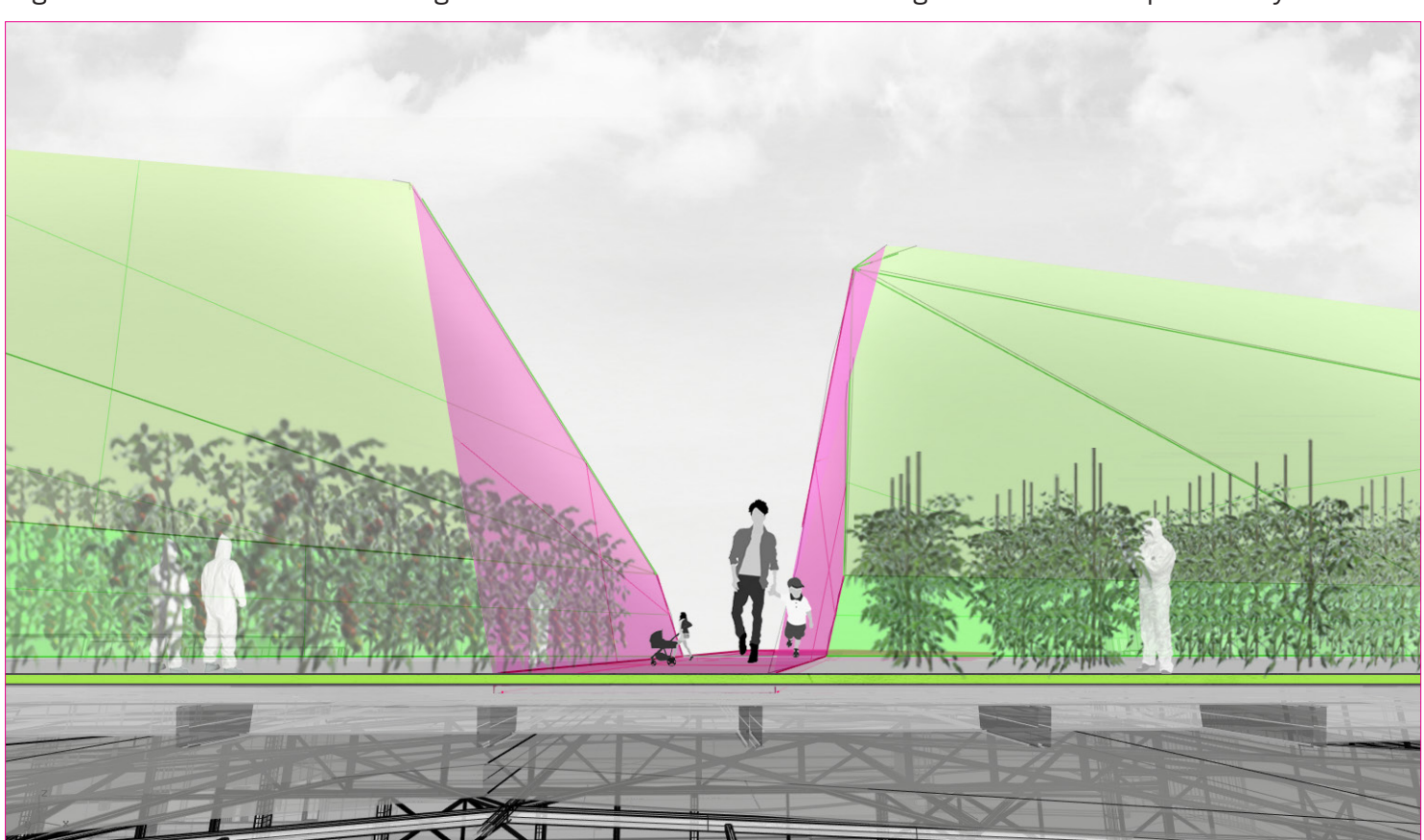

Fig. 6.2.37: Views into the farm

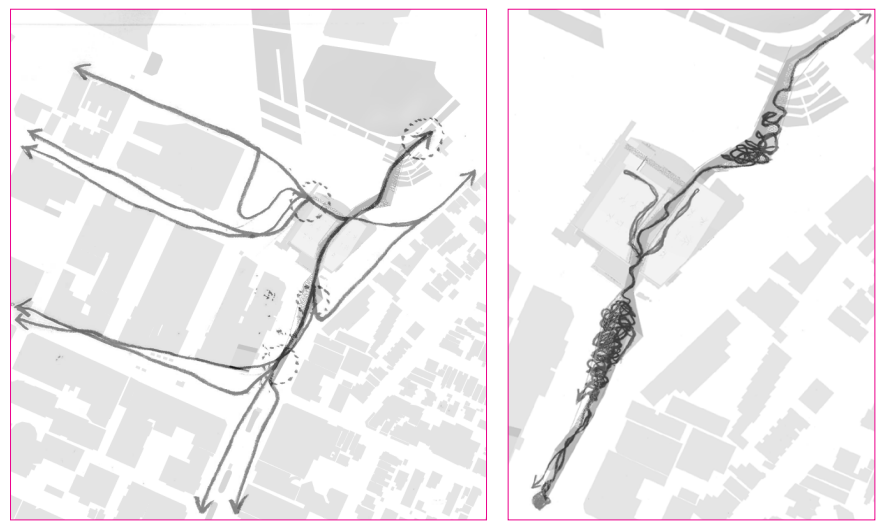

Fig. series 6.2.38: Movement around farm/walkway
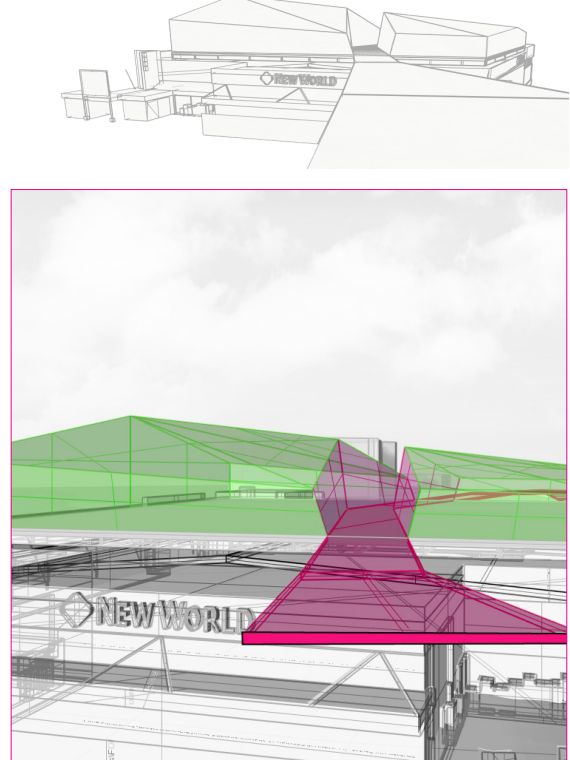

Fig. 6.2.36: Rooftop walkway 

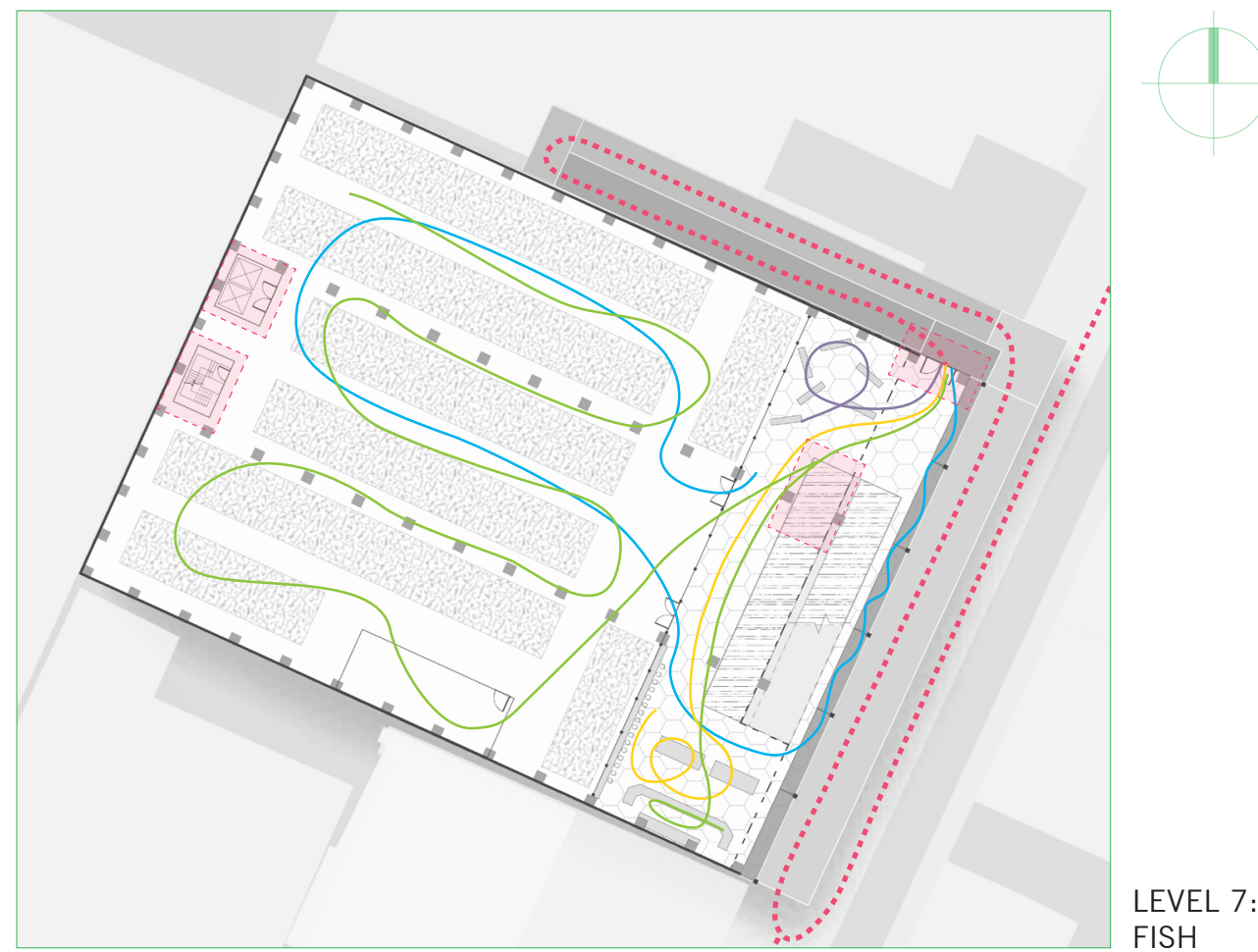

Fig. 6.2.39
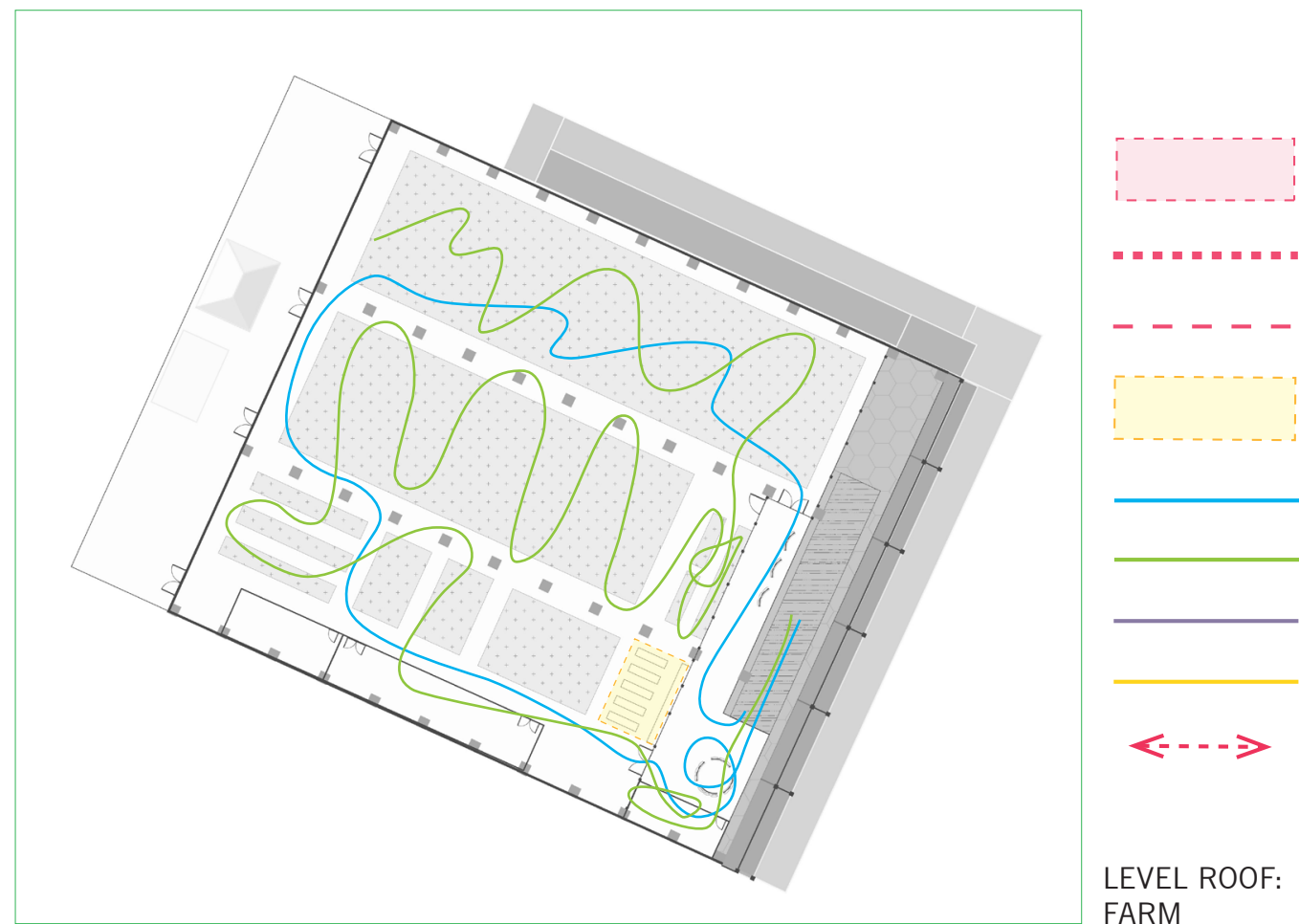

ACCESS POINTS

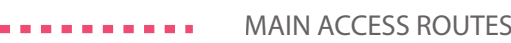

- - - - - NEW WORLD ACCESS
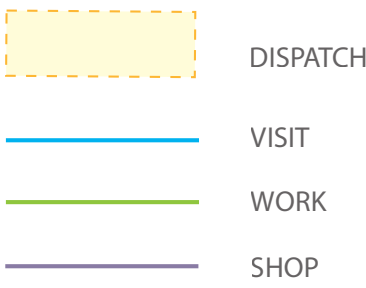

$<--->$

EAT / COOK

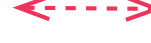

PRODUCE TRANSFER

Fig. 6.2.40

LEVEL ROOF: FARM 
PRELIMINARY

DESIGN

DRAWINGS

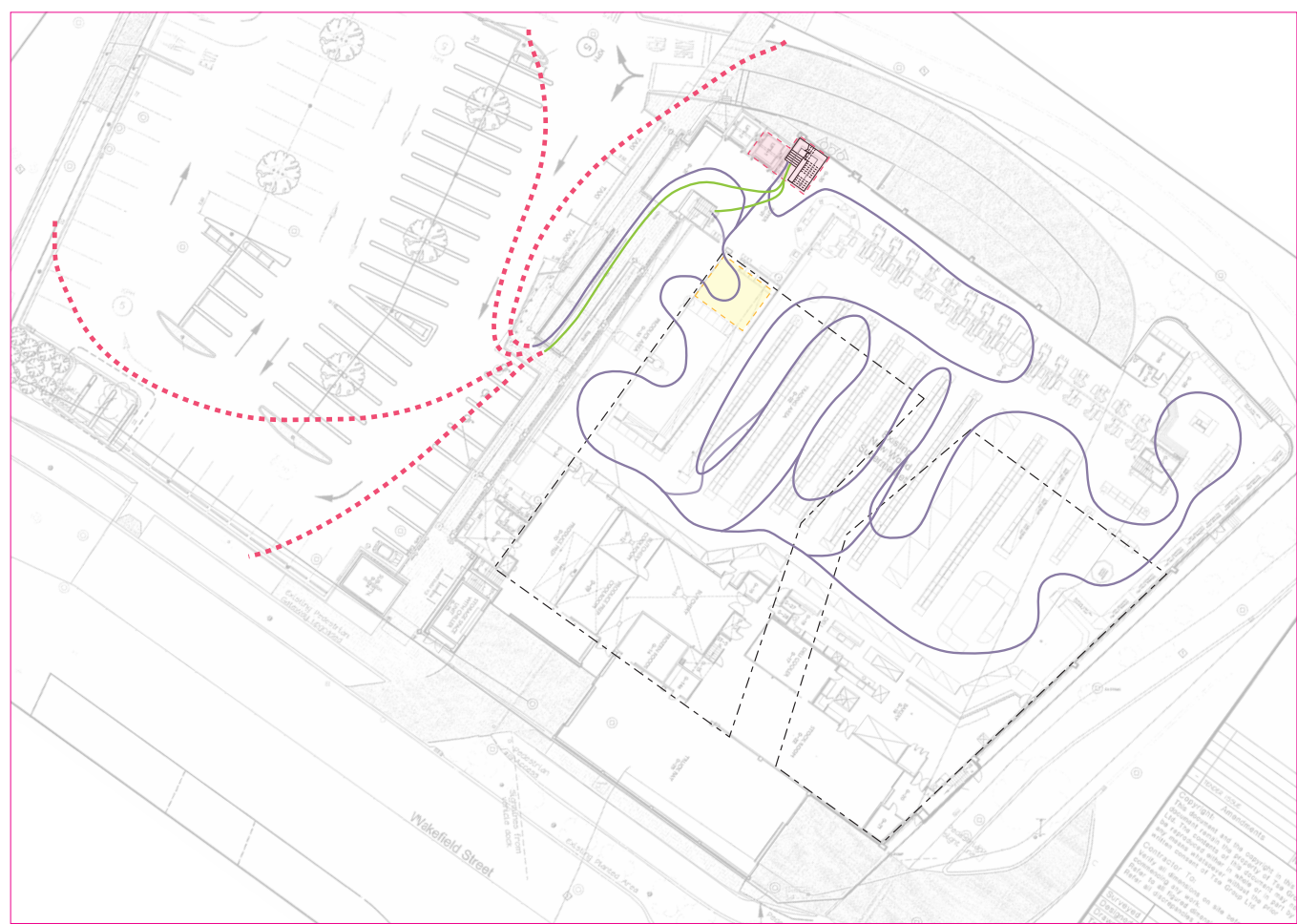

LEVEL GROUND

Fig. 6.2.41 SUPERMARKET

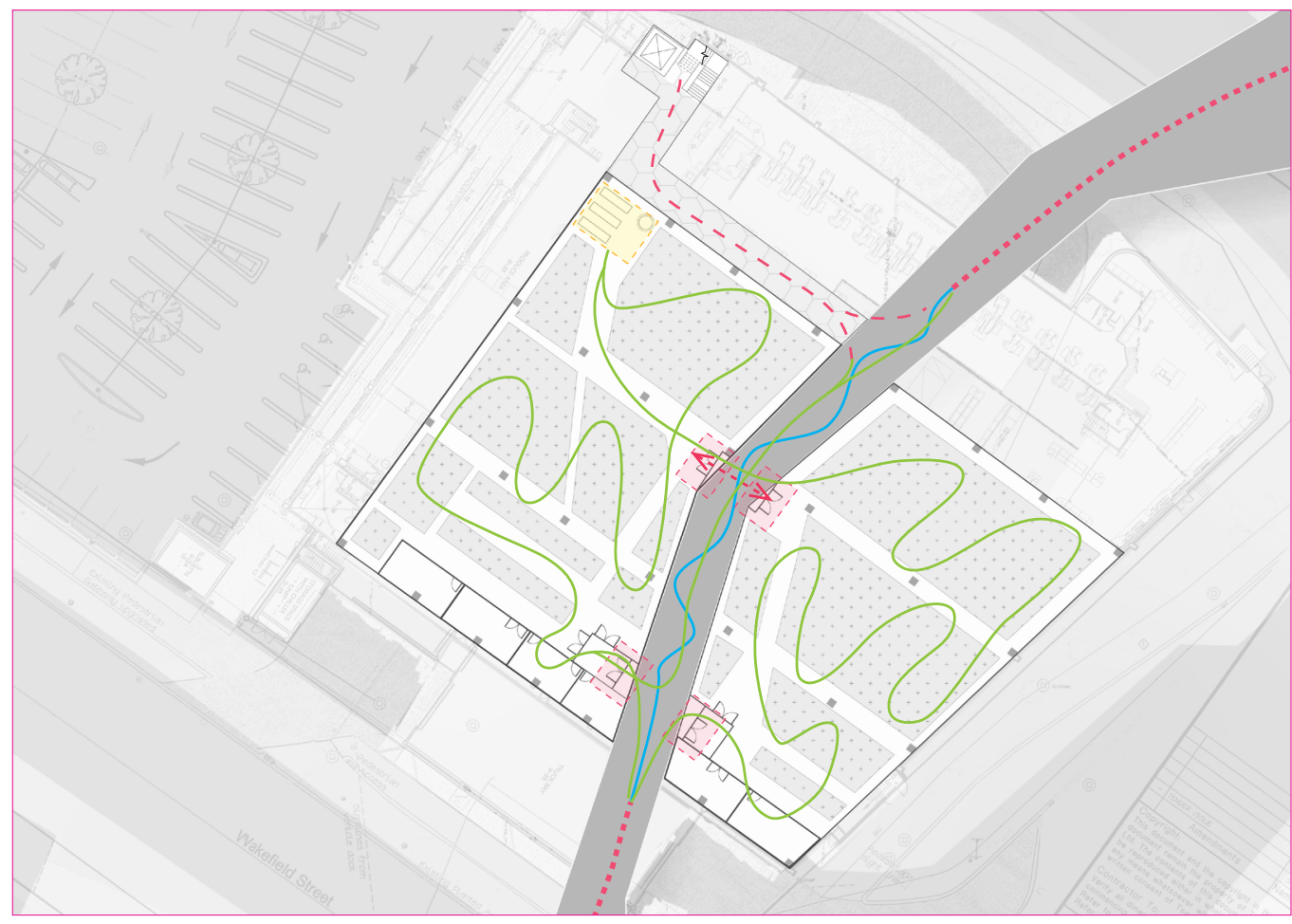

LEVEL ROOF: FARM \& WALKWAY

Fig. 6.2.42 


\section{PRELIMINARY DESIGN REFLECTION + FURTHER DEVELOPMENT}

Both rooftop sites present a valid case for hosting an urban farm. The Tory addition required less structural manipulation of the host building due to its ordered layout, making it easy to add a new level in a repetitive manner. The building's highly utilitarian design was the driver for the exterior access ramp, a strategy to activate the site through movement and continuous ramp activity. But even so, it would be difficult to make this farm an easily accessible destination since there would be no other reason to be on site except if one were a curious visitor, or an employee of the farm. Overall a farm atop the 9 storey building would appear to have minor contributions towards urban quality. It would perhaps do better as a farm that focuses solely on production and less of a 'spectacular' due to its location being relatively out-of-reach due to height. In this case, market demand and supply studies would feed more usefully into the design. Earlier precedent studies of Brooklyn Grange in New York also presents a farm atop a high multi-storey building. However, the business hosts regular events to maintain community engagement and interest in urban farming. Hence another alternative could be that the Tory Farm takes the same approach to increase exposure.

The New World site has considerable potential towards improving urban quality largely due to the added program of the walkway. Initially this walkway was introduced as means of addressing rooftop access and a connective ambition between city to sea. But it has also emerged as an opportunity to develop the site, around what it means to host an urban farm in a highly public realm. If the qualities

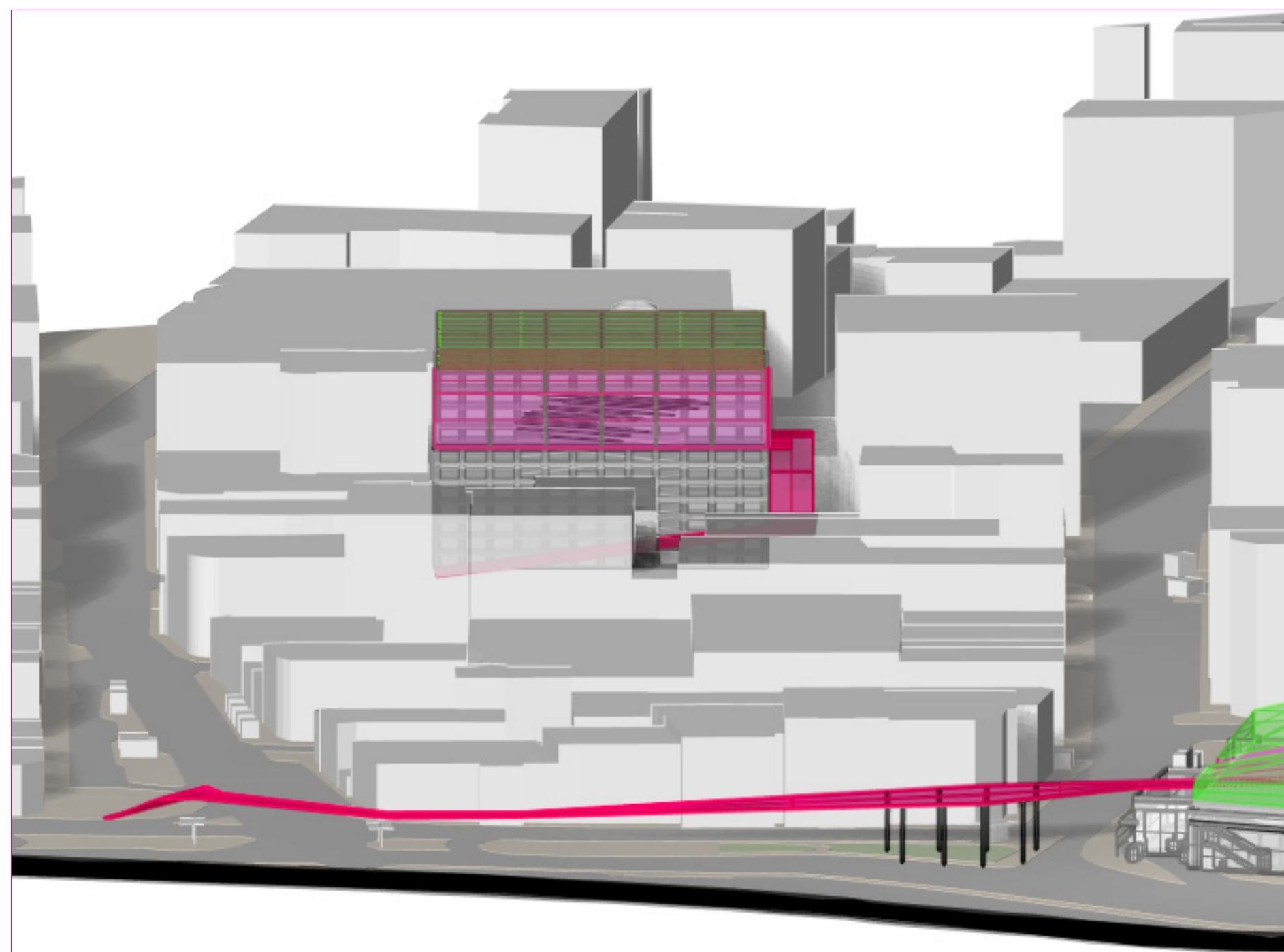

Fig. 6.2 .43 


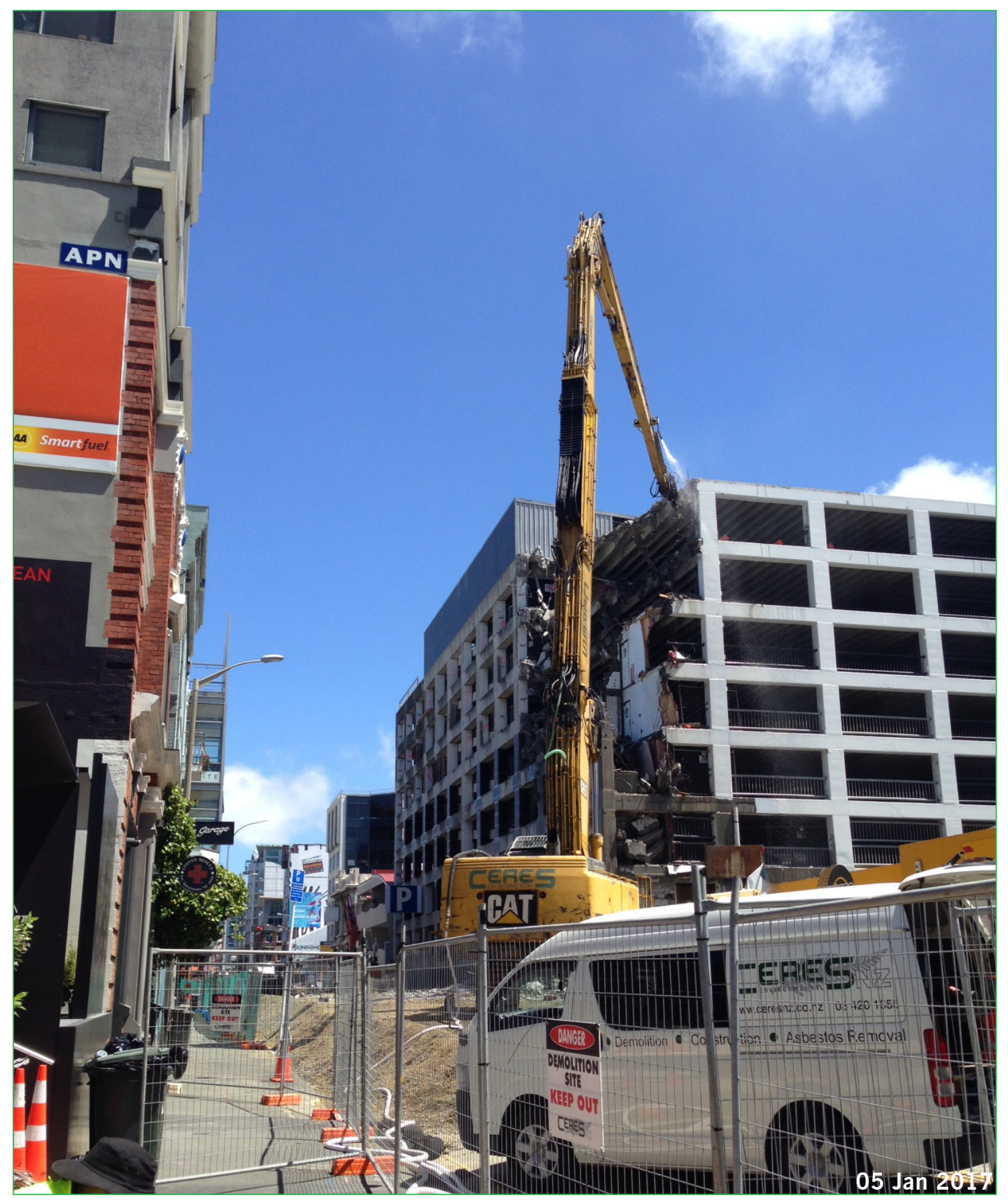

Figs. 6.2.44 - 6.2.46: Following the M7.8 Kaikoura earthquake that struck at 12:02am, November 14th 2016, authorities have decided to demolish the Tory St Courtenay Central Car Park building due to significant structural damage and risk of collapse.
Though this event occured late into the thesis year, long after the decision was made not to continue with the Tory site, it is a stark reminder that rooftop additions should take into serious account the existing structural conditions of the host building. 
UPDATE

TORY CAR PARK
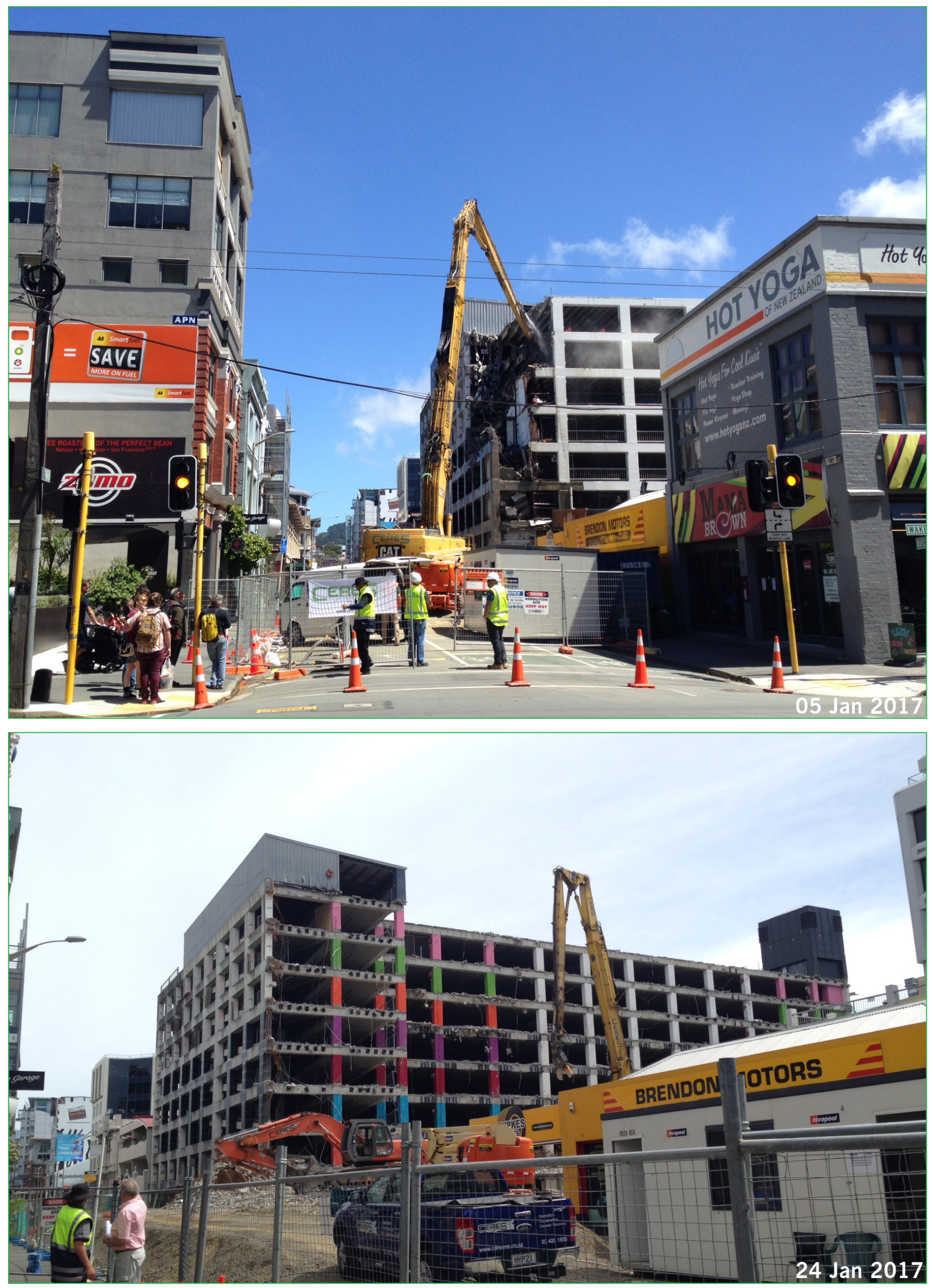
DEVELOPED

DESIGN
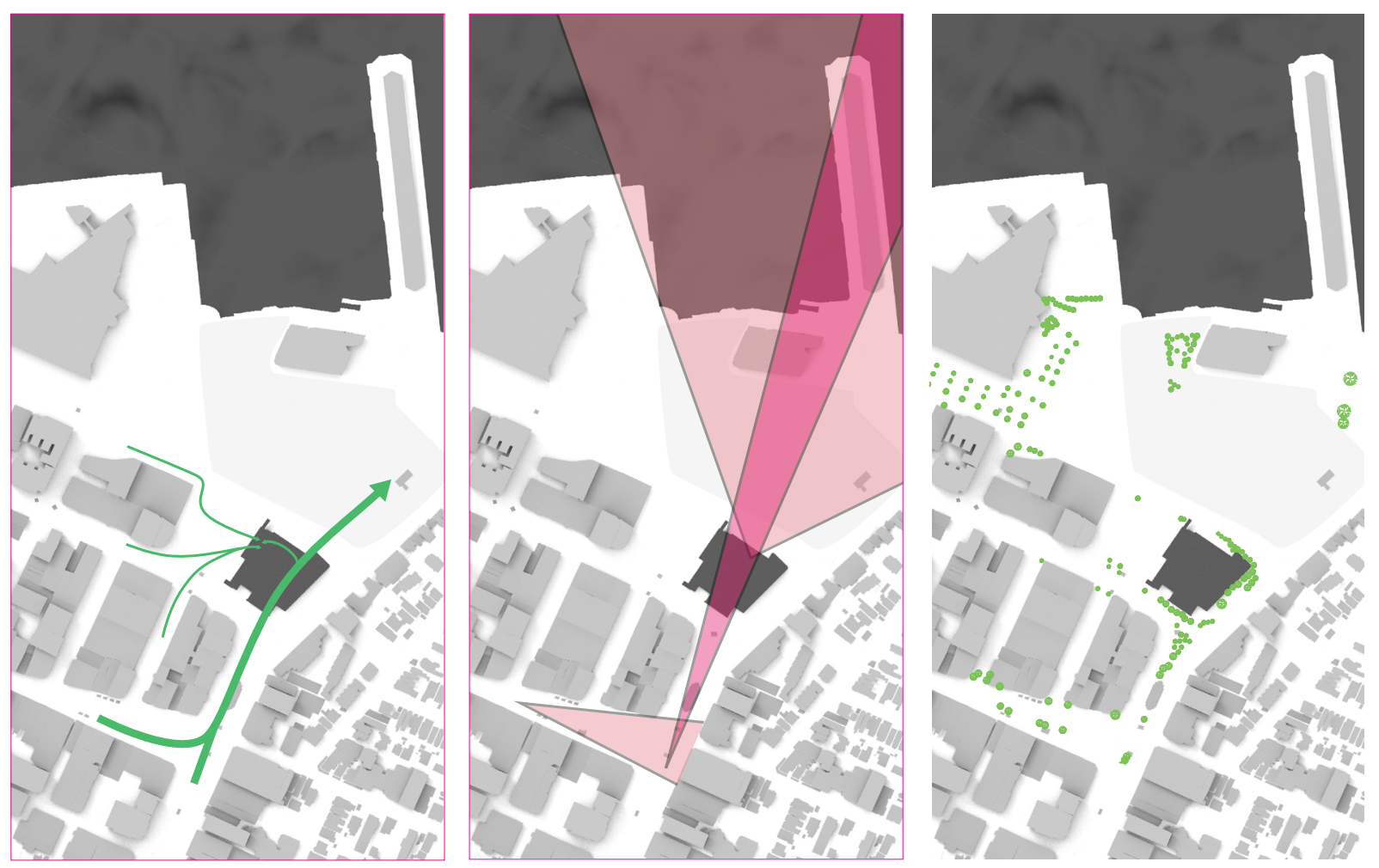


\section{WELSH BAR RELOCATION (perspective section views from east)}

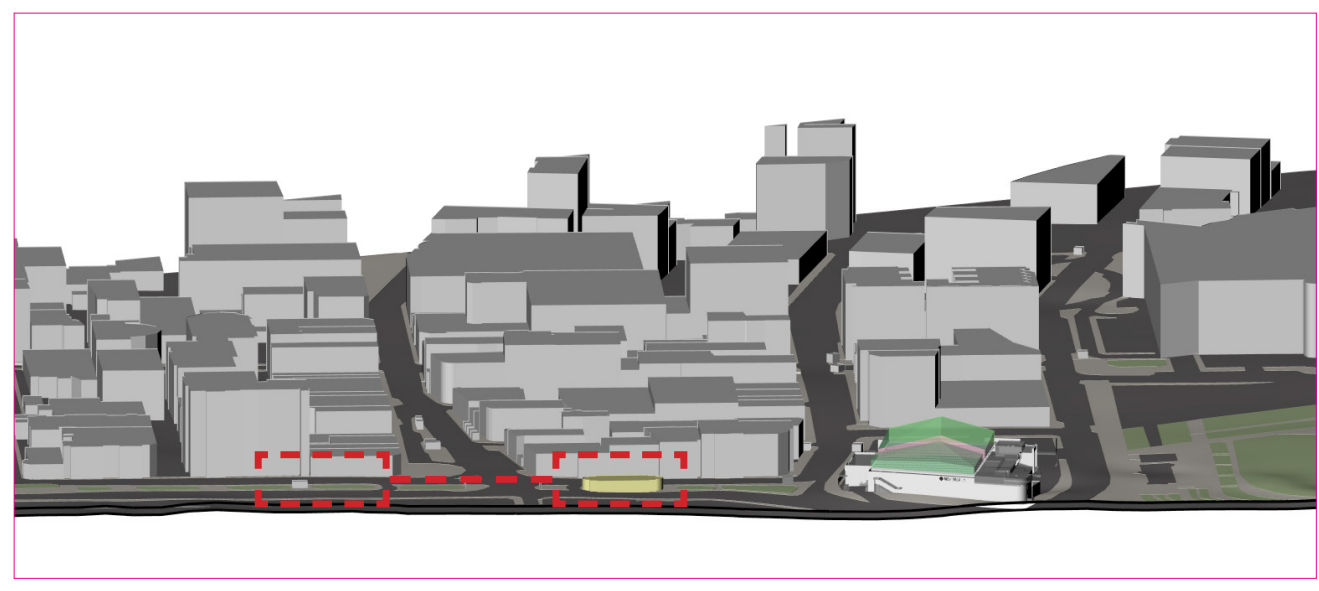

Current and proposed

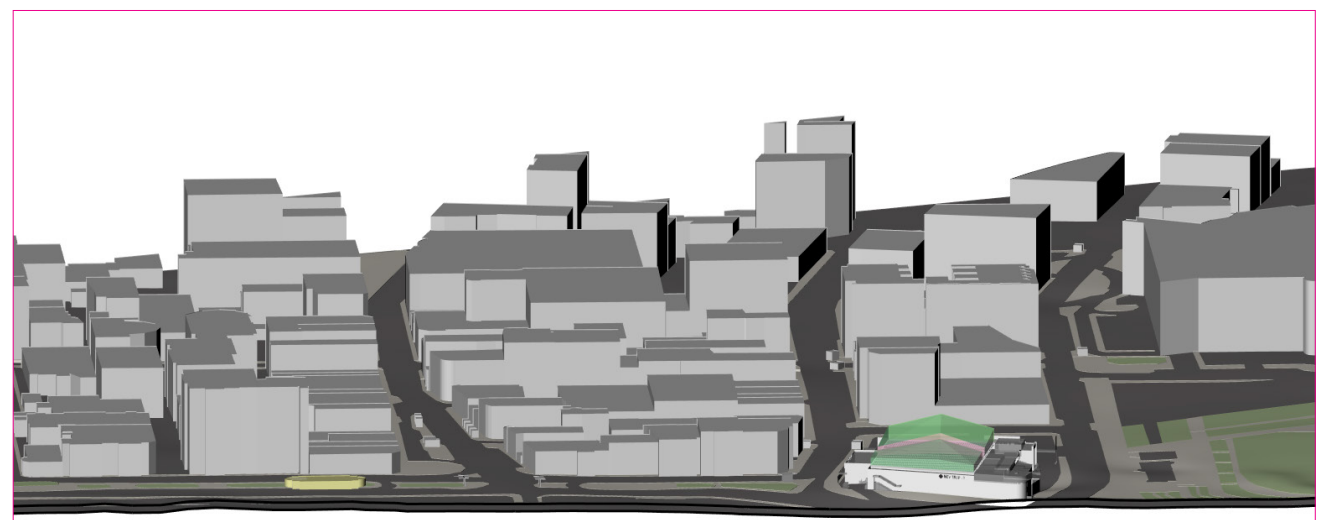
location relocation

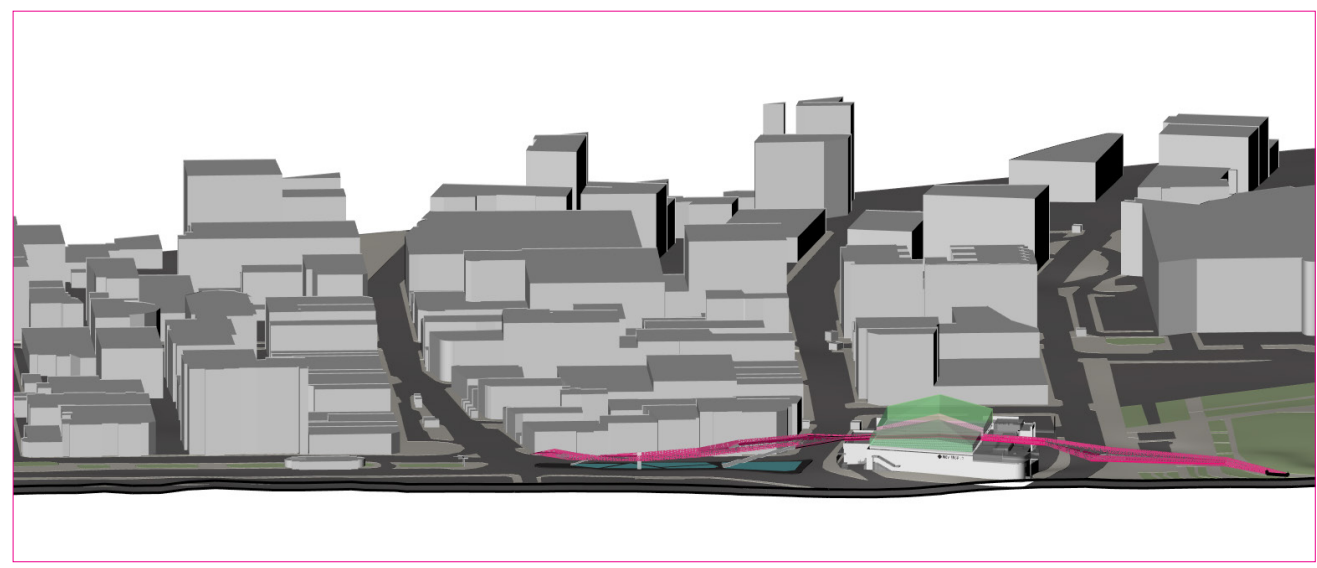

Relocated bar and new

Fig. series 6.3.6: The decision to relocate the Welsh Bar (former Taj Mahal Public Toilets) to the adjacent traffic island is the most appropriate given its heritage status. Considered options for the building included: a) allowing it to remain in its current location and integrate walkway design; b) demolition; or c) relocation. Since Wellington has a history of relocating masonry buildings, it was decided that option [c] was viable for the scope of this project. Other relocated building examples in Wellington include The Circa Theatre - previously at current BP service station site on Taranaki St; Museum Hotel - previously at current Te Papa site. 


\section{WALKWAY DESIGN}

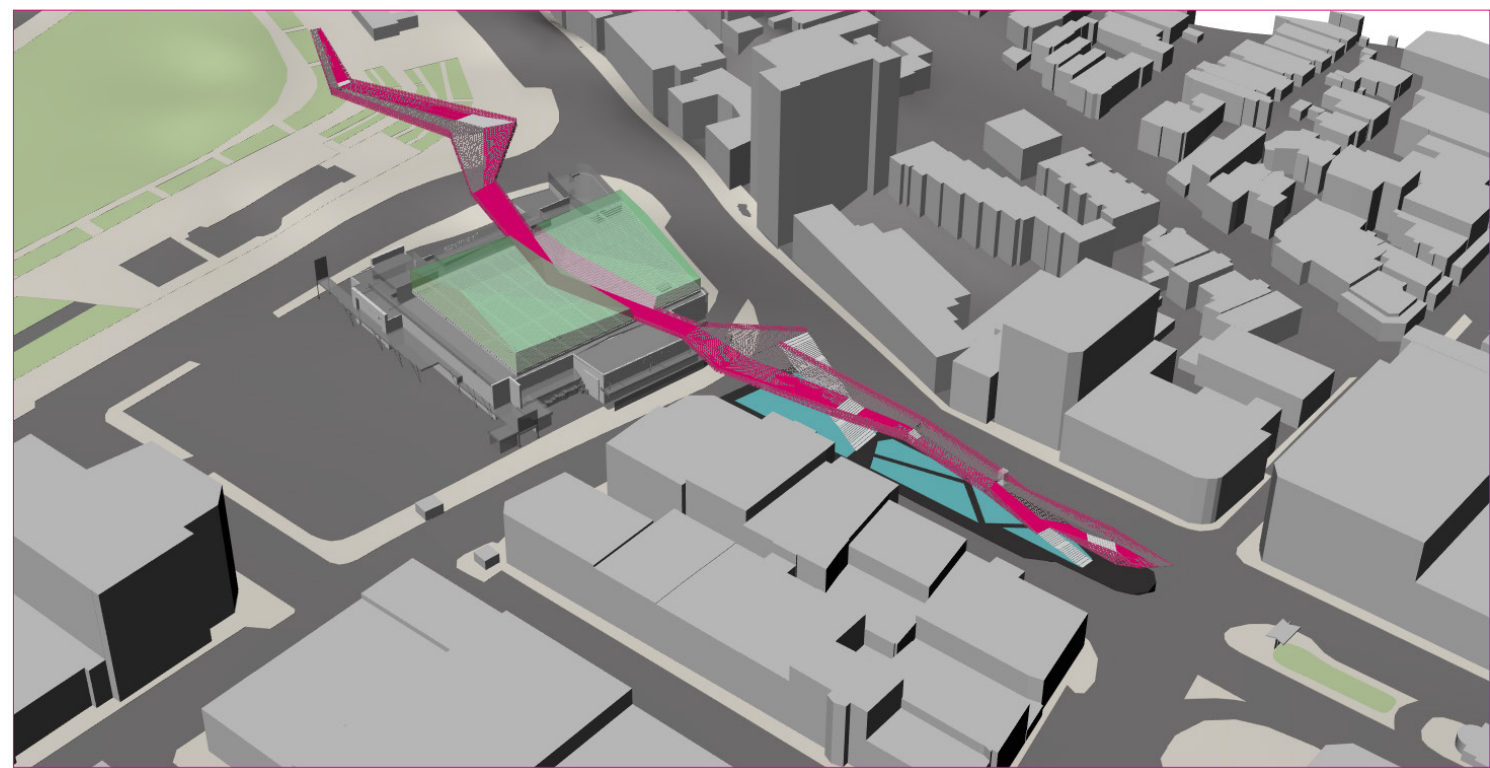

Fig. 6.3.7: The walkway changes from a bridge at the Courtenay end to a ramp landing at Waitangi Park.

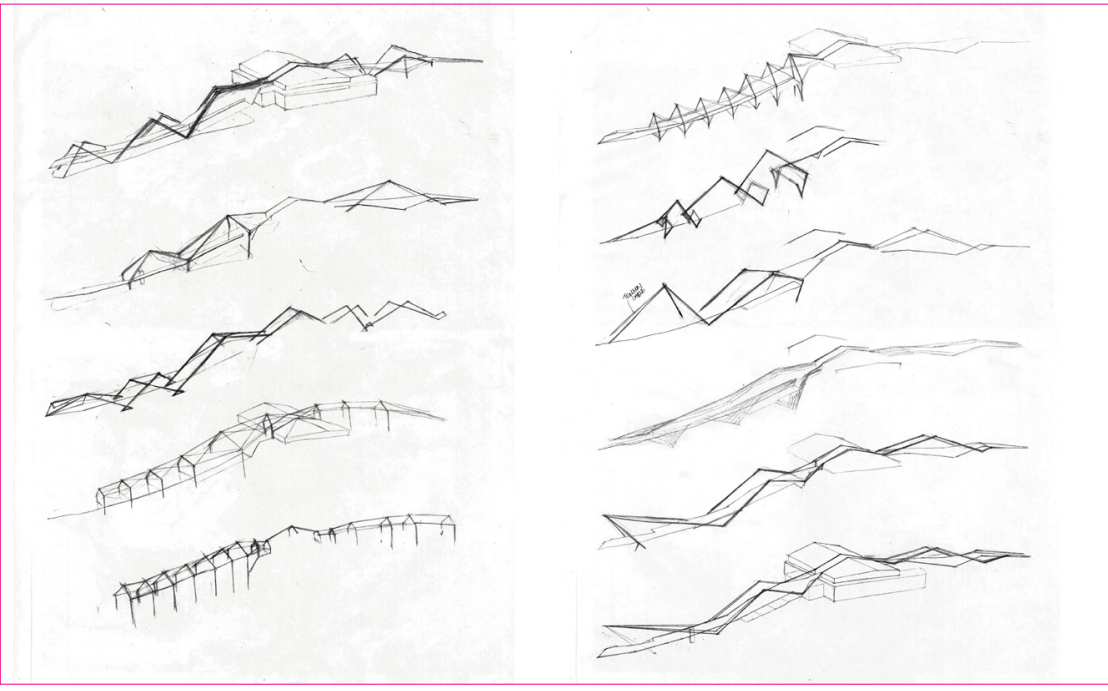

Fig. 6.3.8: Walkway structure design ideas. The intent is for its structure to speak the same 'architectural language' as the structure of the rooftop farm. Further development of the farm is needed for a more cohesive picture.

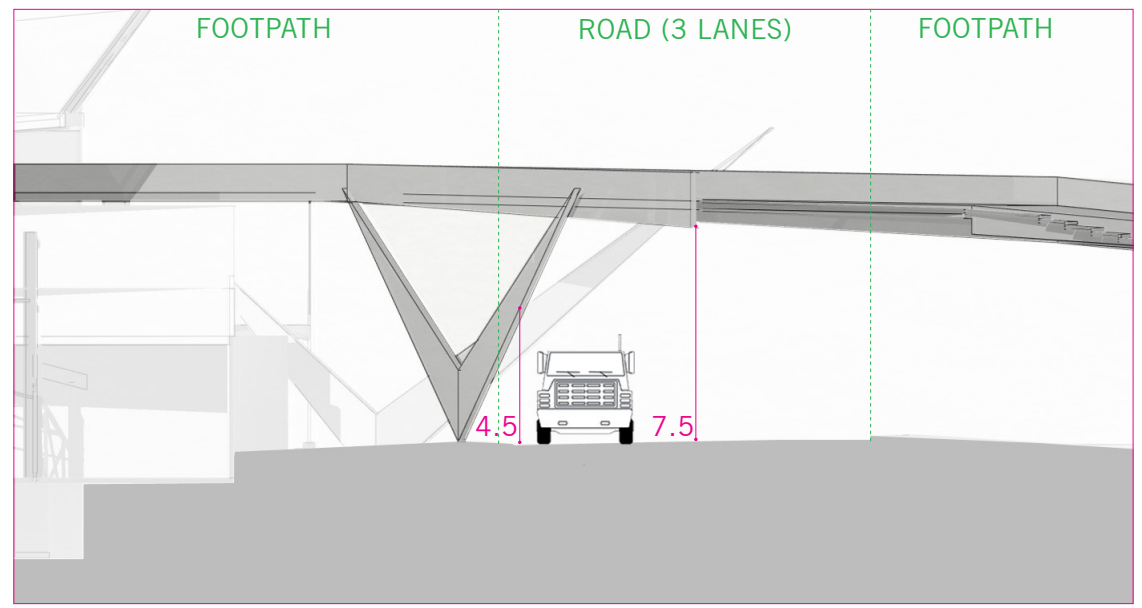

Fig. 6.3.9: NZTA clearances $(m)$ : -Standard Vehicles Height: <4.3 -Over-dimension Vehicles

Height: $>4.5$

Based on this

information from the NZ Transport Agency, the walkway must (at least) be able to accomodate standard vehicles. Currently heights seem to be acceptable. 
DEVELOPED

\section{DESIGN}

WALKWAY

\section{WATER FEATURE UNDER WALKWAY (BRIDGE END)}

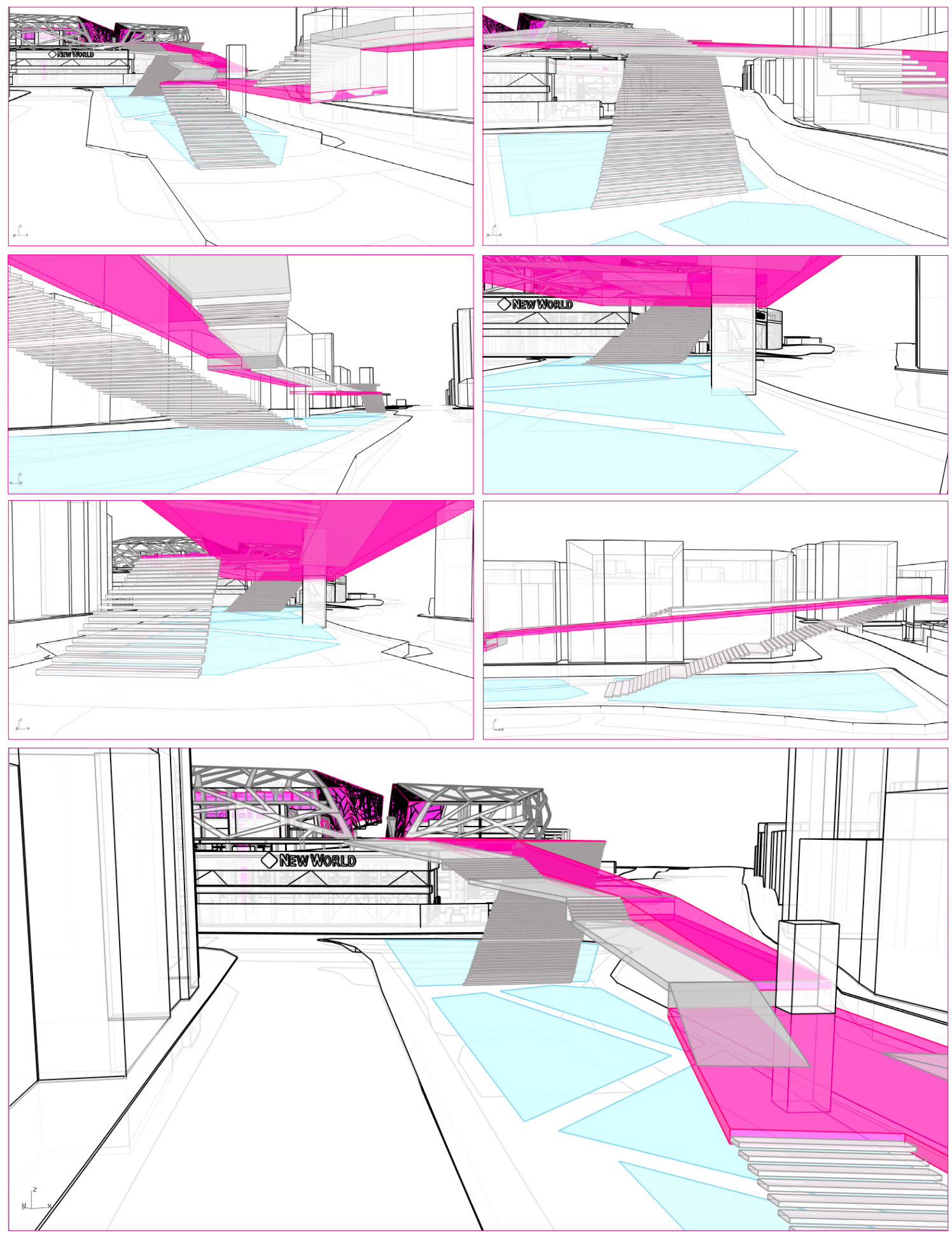

Fig. series 6.3.10: Shallow pools of water feature underneath the bridge (Courtenay end, former site of Welsh Bar). Its location at the traffic island between Cambridge and Kent terraces is inherently undesirable but this has two practical purposes: a) to deter inappropriate activity under the structure e.g. unwanted lingering for long periods; and b) to encourage pedestrians to use the bridge. However, it can also be depicted as a nod towards historical circumstances of the terraces as a water channel linking the harbour and Basin Reserve (see pg. 48). 


\section{SLAB DESIGN - DEFINING PERIMETER}

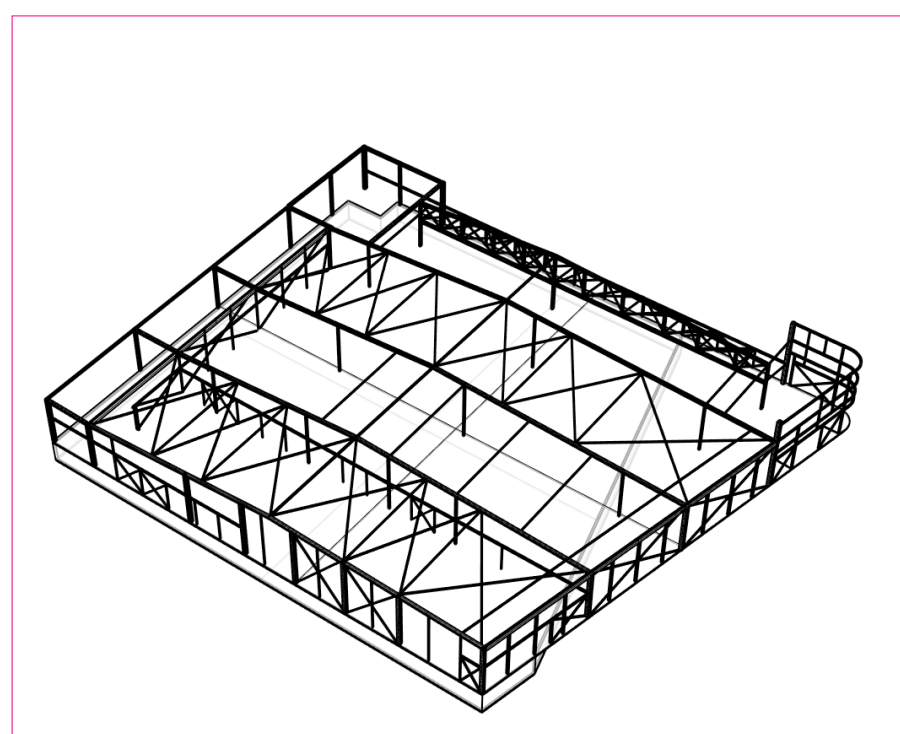

existing new world structure with basement shown

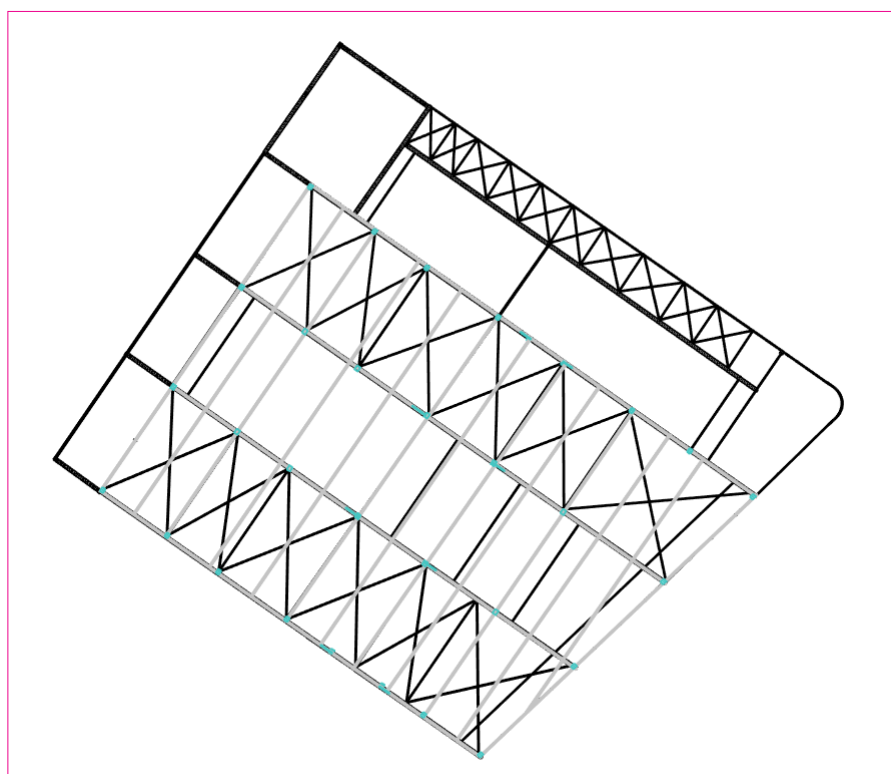

new beam system above gable sits on column grid
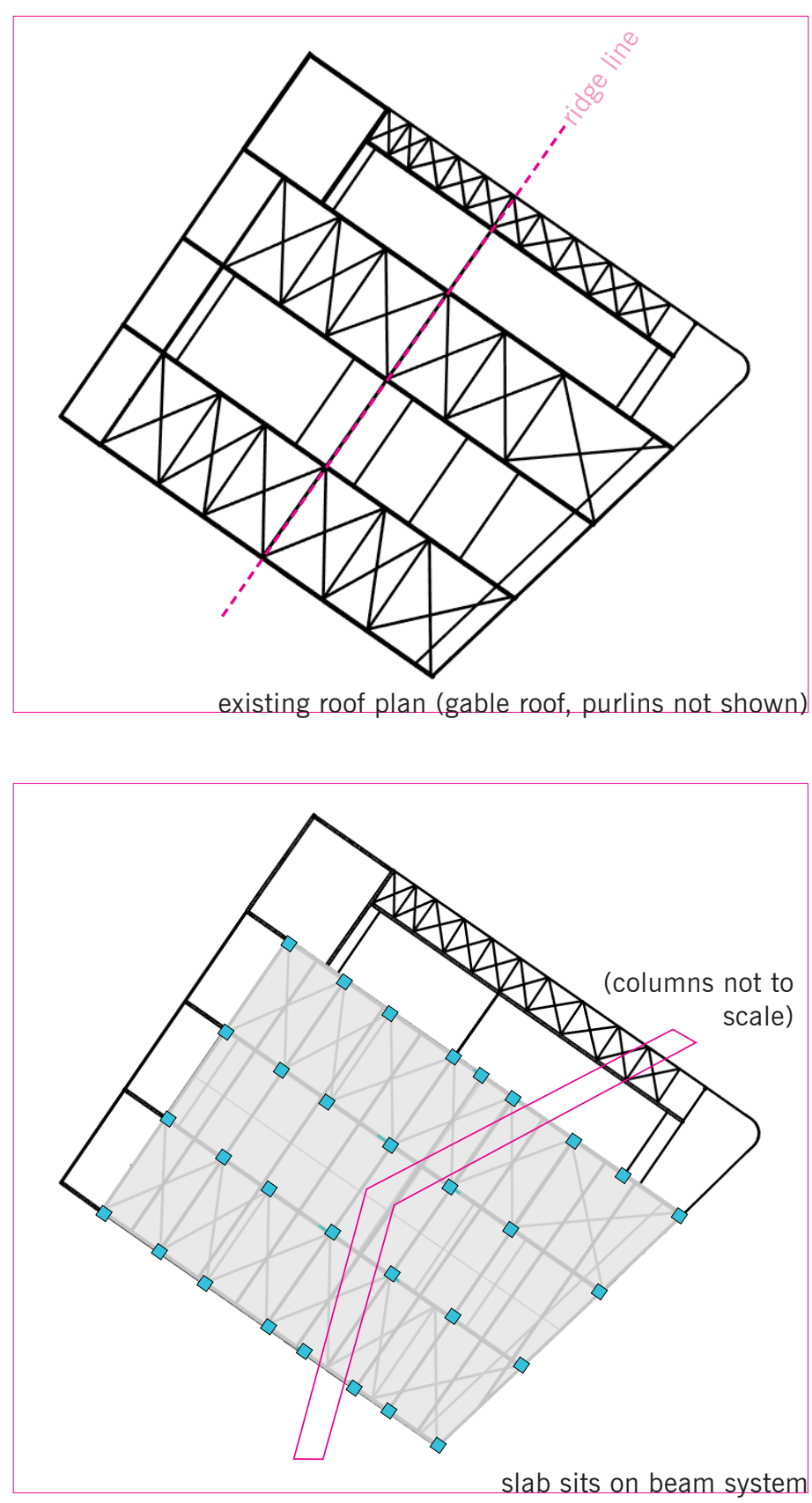

Fig. series 6.3.11: The new slab floor will be supported above the supermarket's existing gable roof by a structural beam configuration that adheres to the existing column layout. Most columns are extended from their original locations, with a few added to help support new gravity loads. A steel composite flooring system is preferable over the initial timber floor system option (pg. 87) due to its ability to accomodate large loads and overall durability. 
DEVELOPED

\section{DESIGN}
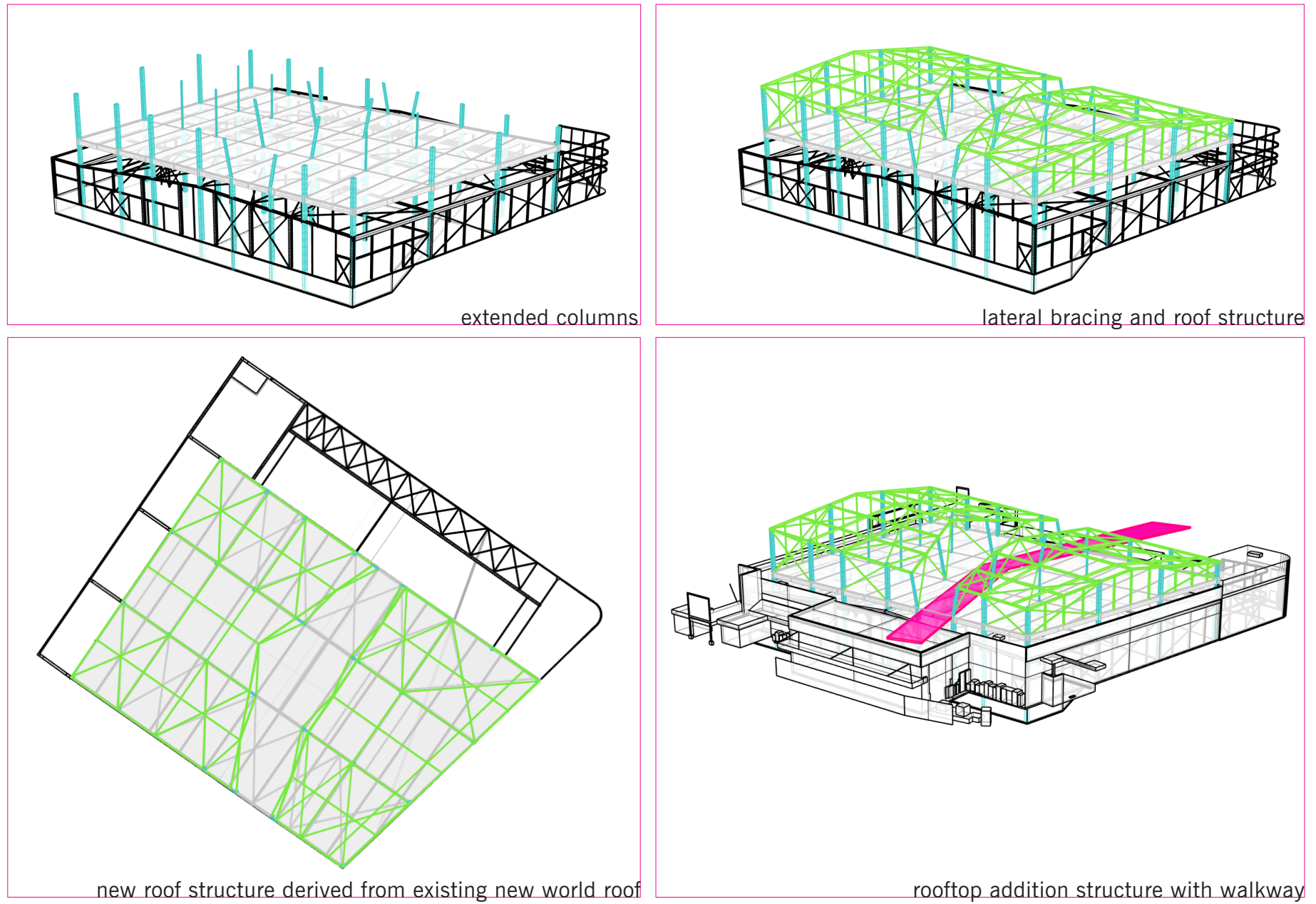

new roof structure derived from existing new world roof

rooftop addition structure with walkway

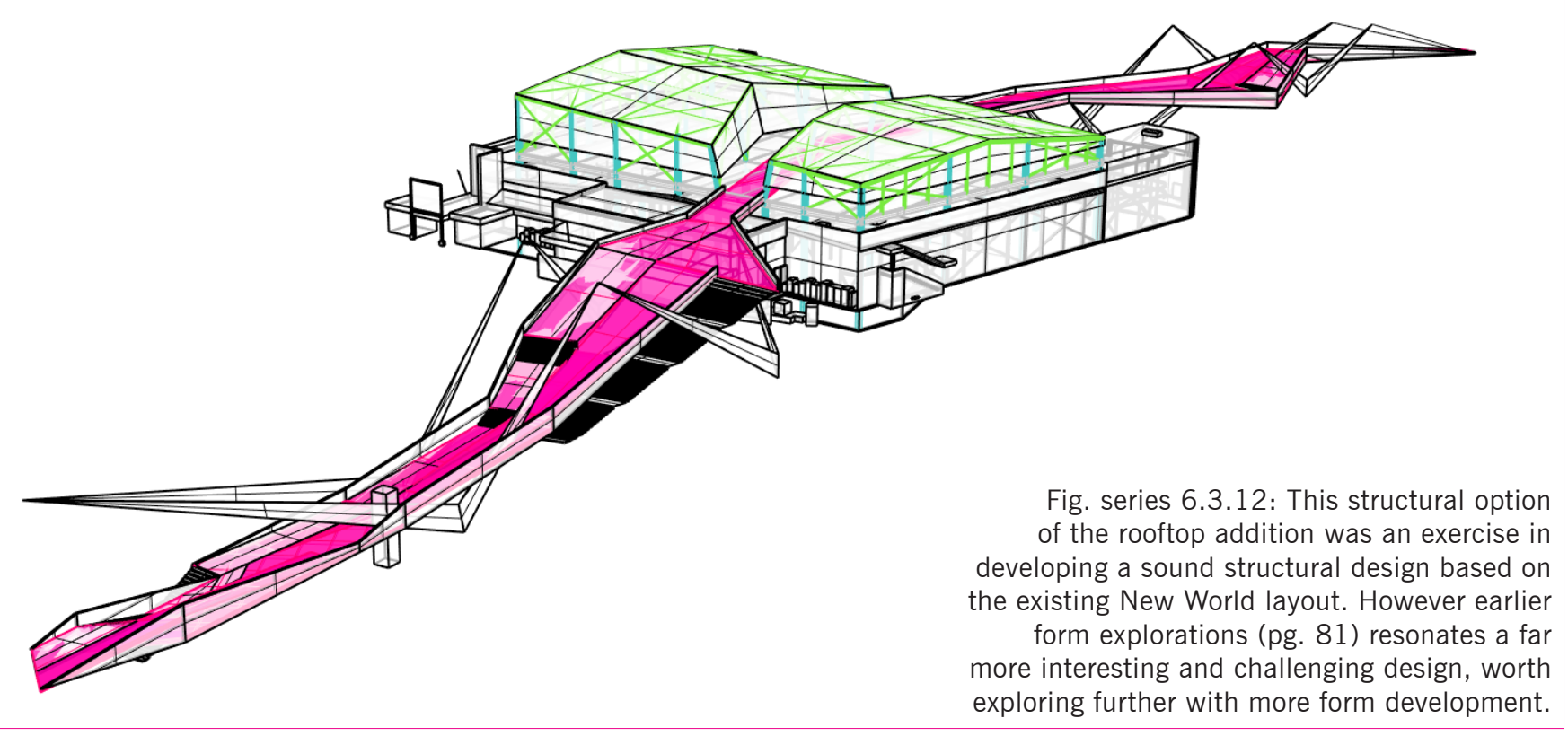




\section{STRUCTURE - INTEGRATED}

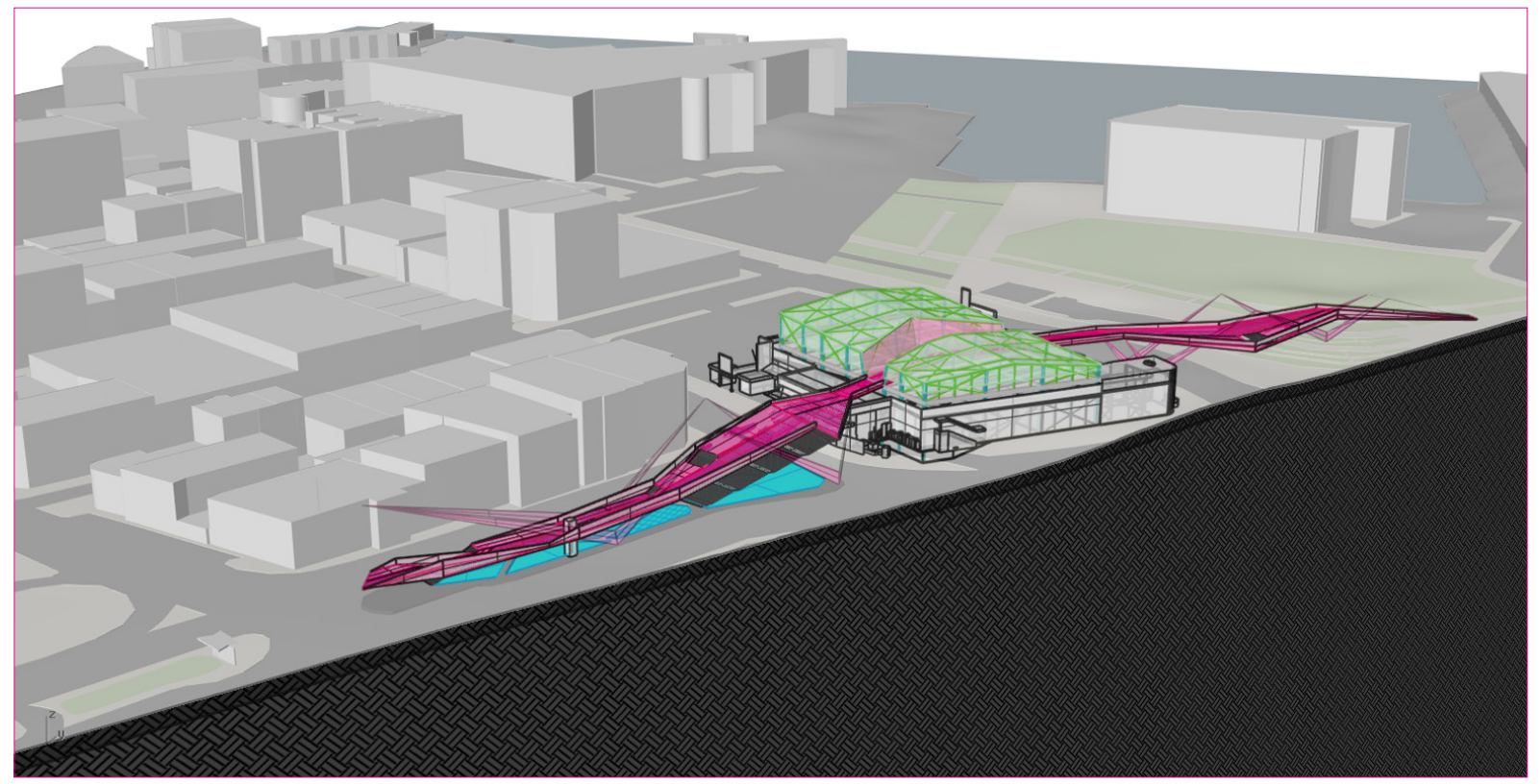

Fig. 6.3.13: Farm and walkway (section through Kent Tce).

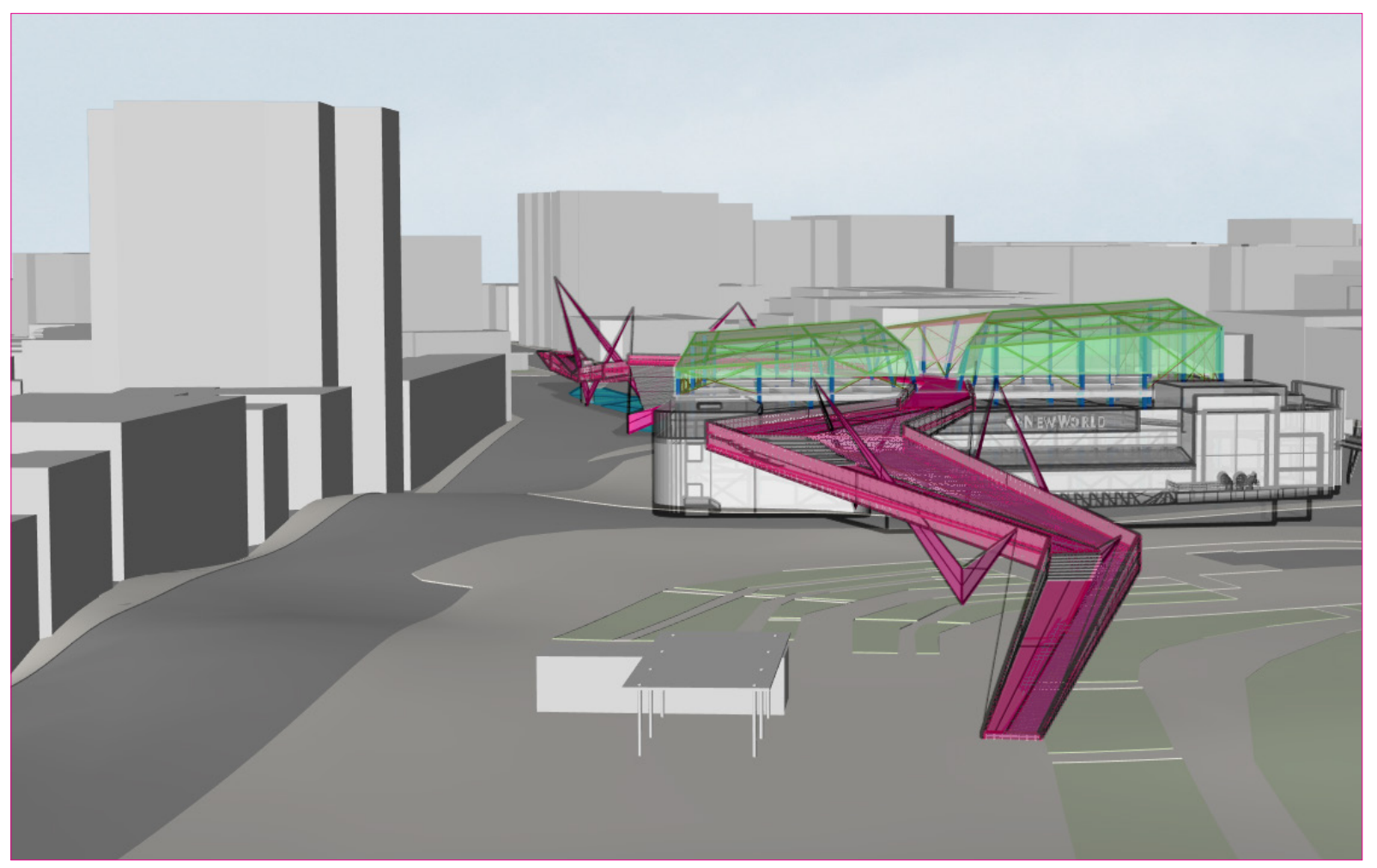

Fig. 6.3.14: View from Waitangi Park. Exterior skin could be slightly receded to expose extended columns. 
DEVELOPED

\section{DESIGN}
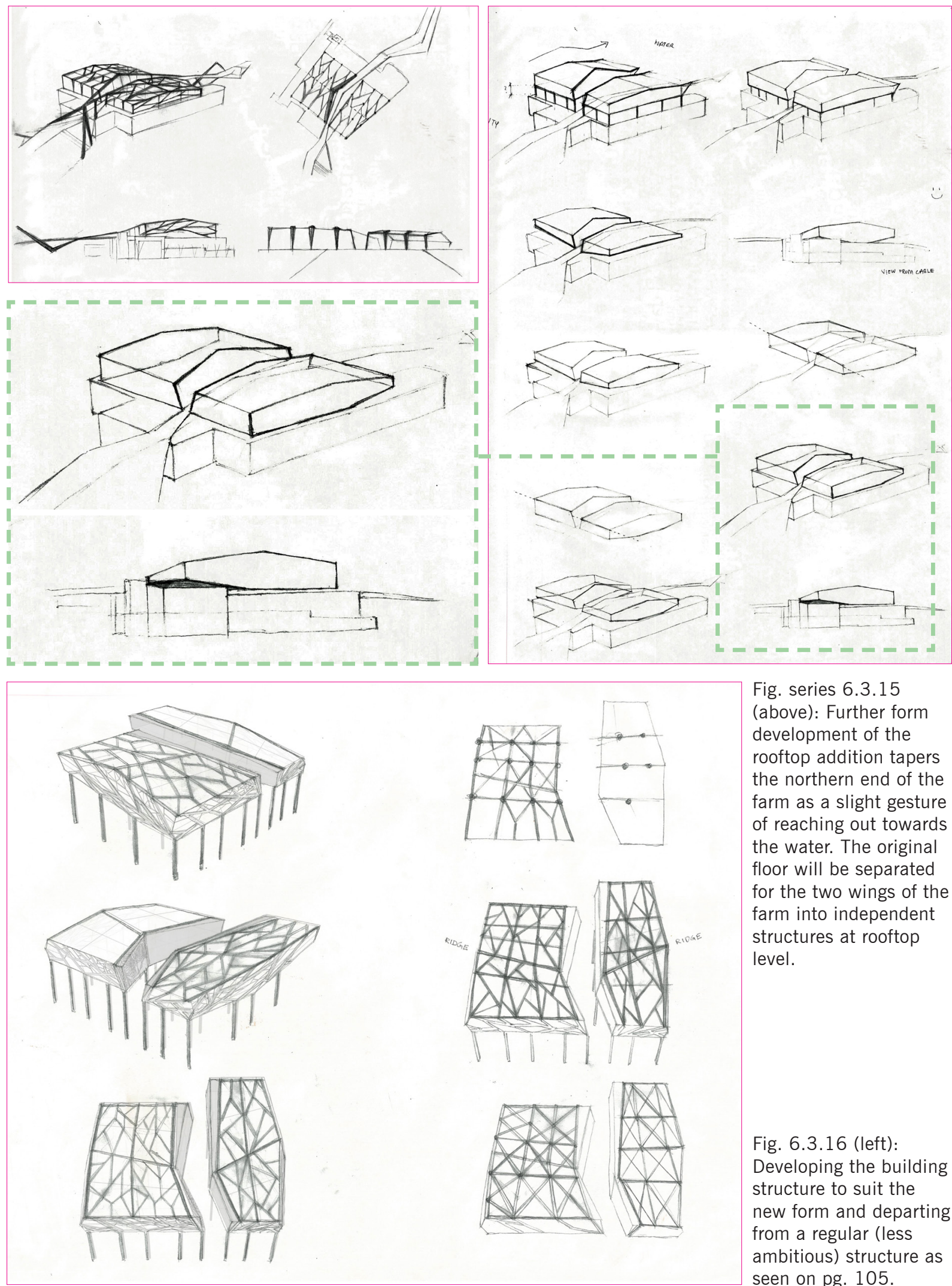

Fig. series 6.3.15 (above): Further form development of the rooftop addition tapers the northern end of the farm as a slight gesture of reaching out towards the water. The original floor will be separated for the two wings of the farm into independent structures at rooftop level.

Fig. 6.3 .16 (left): Developing the building structure to suit the new form and departing from a regular (less ambitious) structure as seen on pg. 105. 

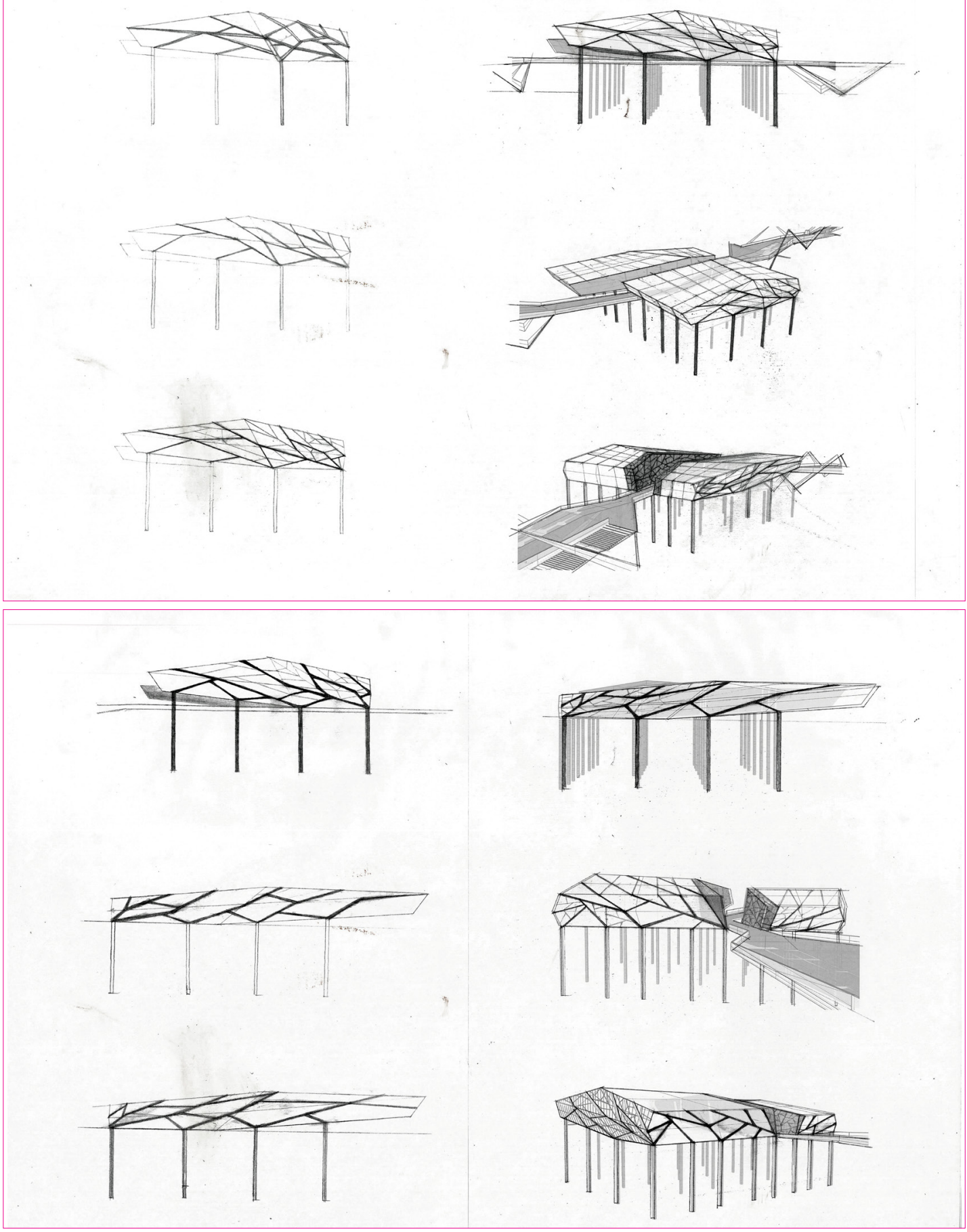

Fig. series 6.3.17: Main steel structure exposed on facade, loads transfer back down to columns. 
DEVELOPED

DESIGN

FORM / STRUCTURE

FORM / STRUCTURE DEVELOPMENT

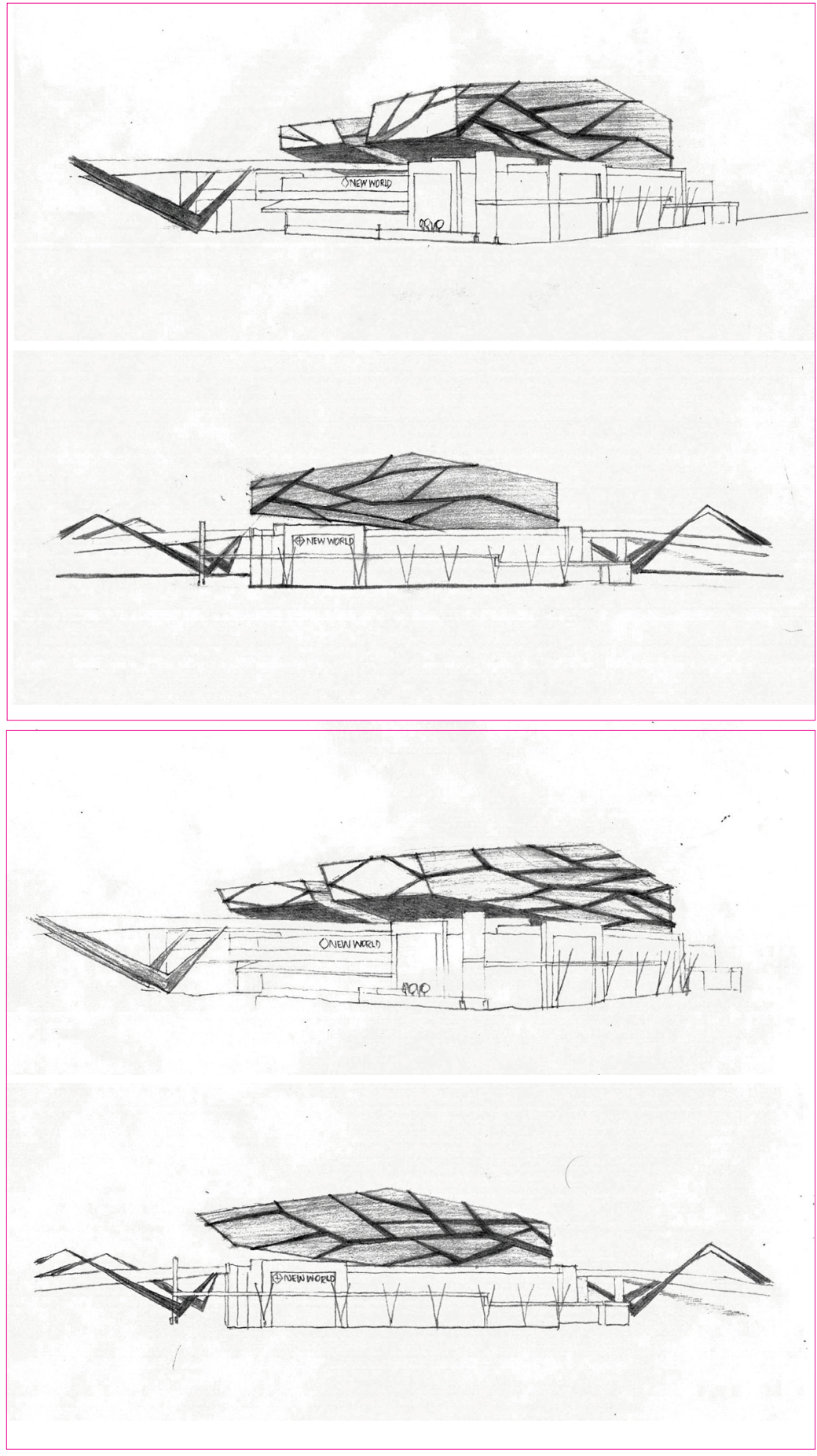

Fig. series 6.3.18: Exploring options for exposed structural pattern on building facade. 


\section{APPLICATION OF PATTERN ON GLASS (VIEWS INTO FARM)}
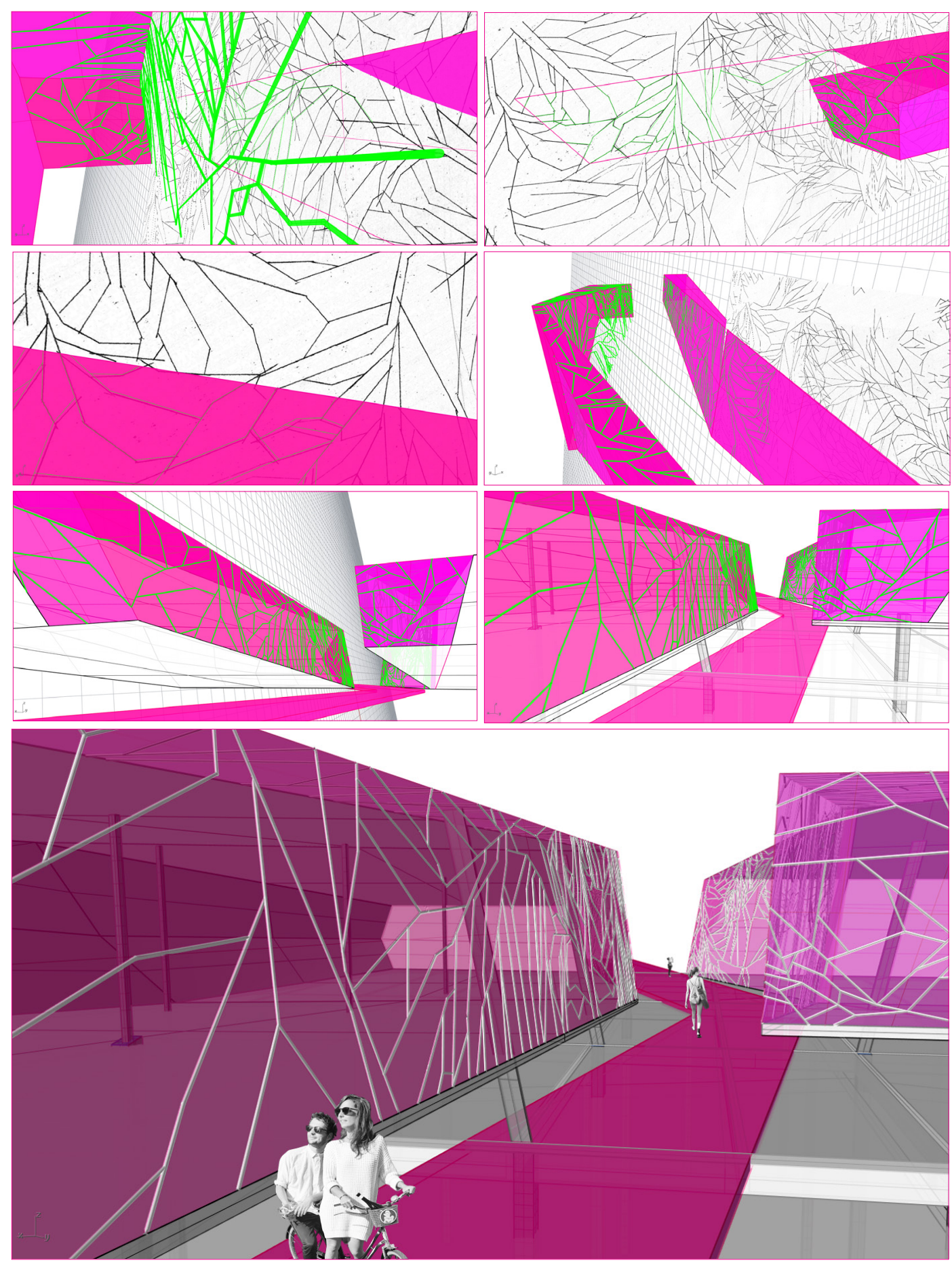

Fig. series 6.3.19: Upon crossing the rooftop of New World, the walkway offers a continuous view into both wings of farming activities through glass as a transparent medium. The vibrant colour "cuts" into the building strengthening the walkway connection between city to sea. The applied pattern derived from preliminary explorations of a lettuce leaf structure provides variation as pedestrians make their way through the rooftop. 
DEVELOPED

\section{DESIGN}

FORM

PARAPET TO GABLE
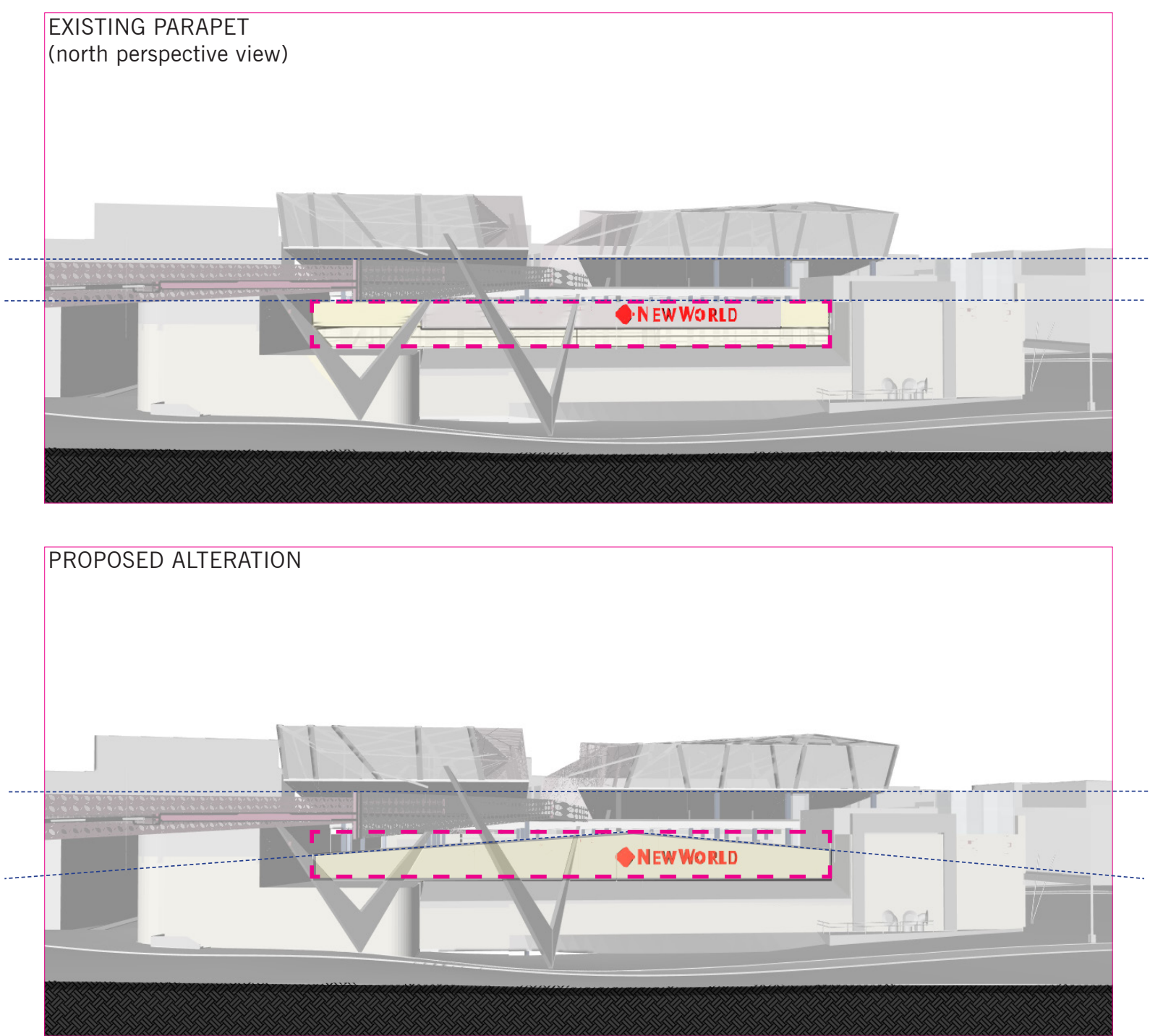

Fig. series 6.3.20: With the rooftop addition raised above New World, one idea is to lower existing parapets of the supermarket from the north and south facades to highlight its original gable roof form. This allows emphasis on the very distinct rooftop addition to the building. With the farm seemingly 'balancing' above the gable roof, it illustrates an intent to contrast the 'old' and 'new'. 


\section{ELEVATIONS}

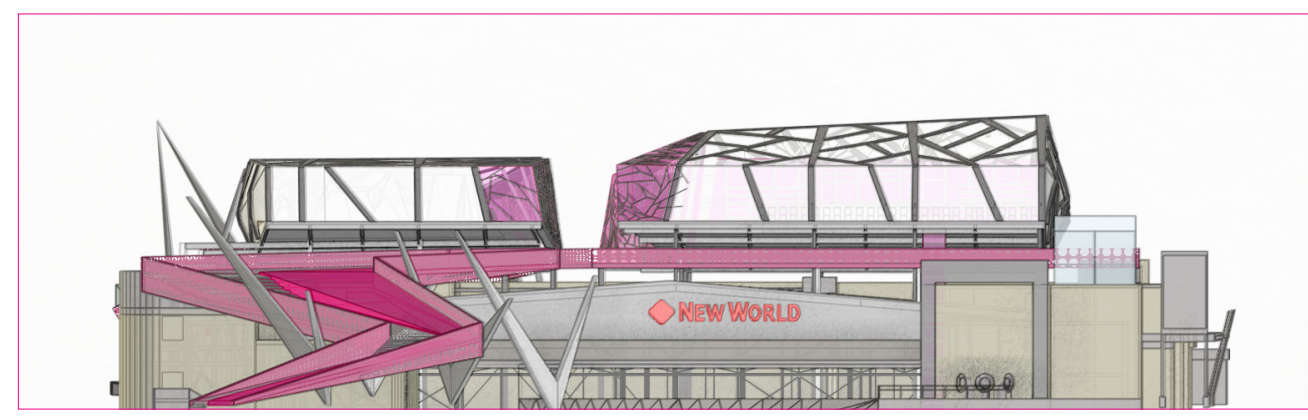

NORTH

(with proposed exposed gable roof of host building)

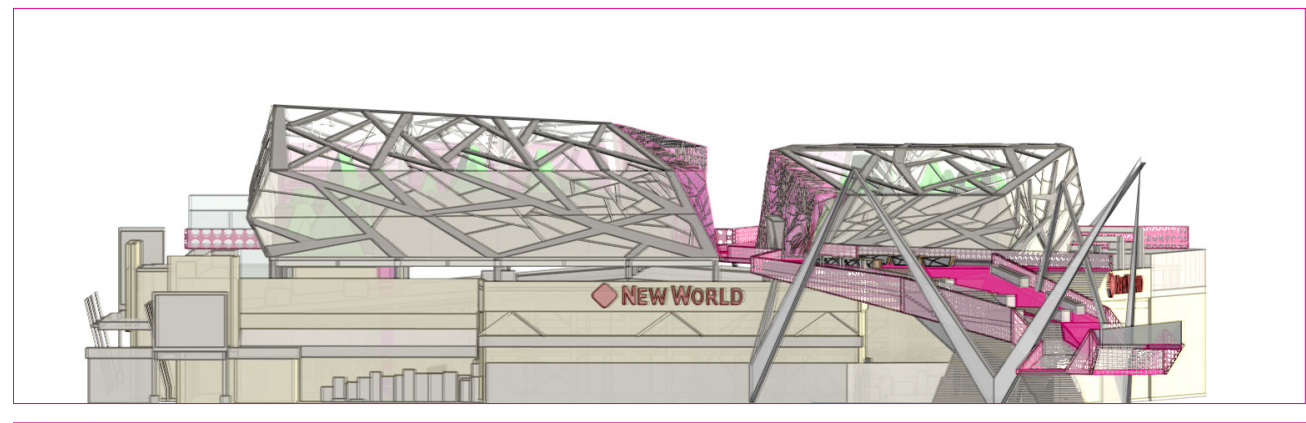

SOUTH

(existing parapet roof shown)

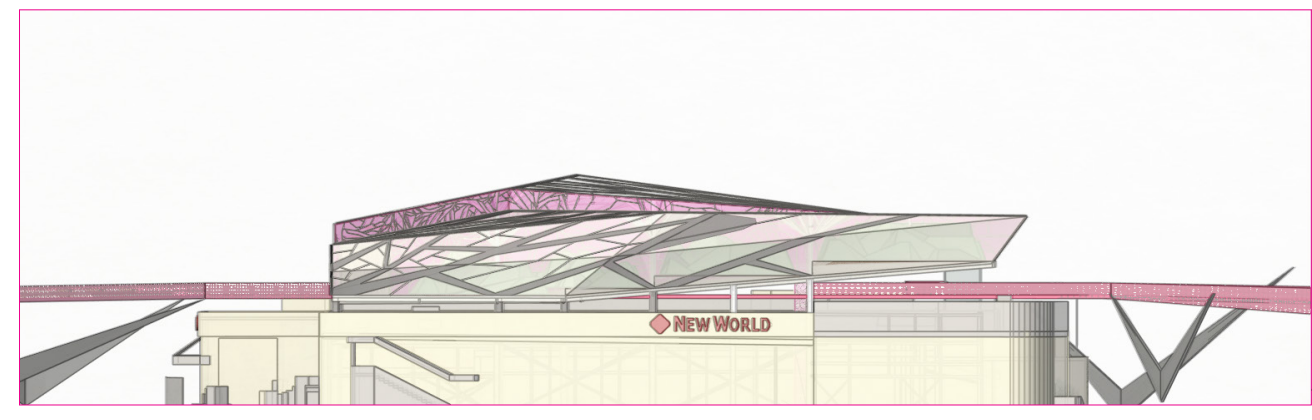

\section{EAST}

view heading towards / from oriental parade

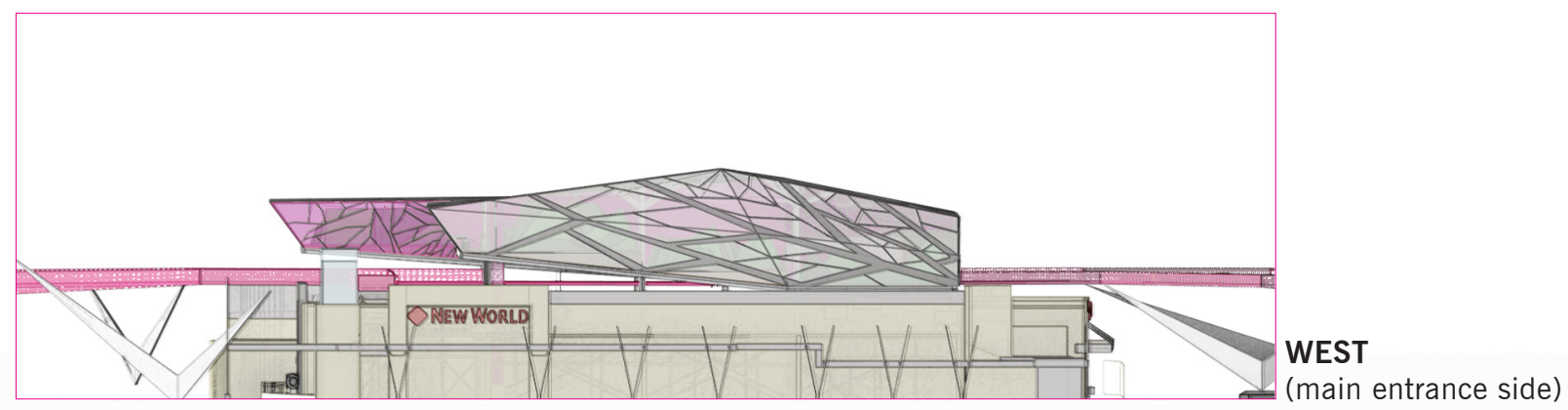

Fig. series 6.3.21 
DEVELOPED

\section{DESIGN}

MATERIAL + STRUCTURE

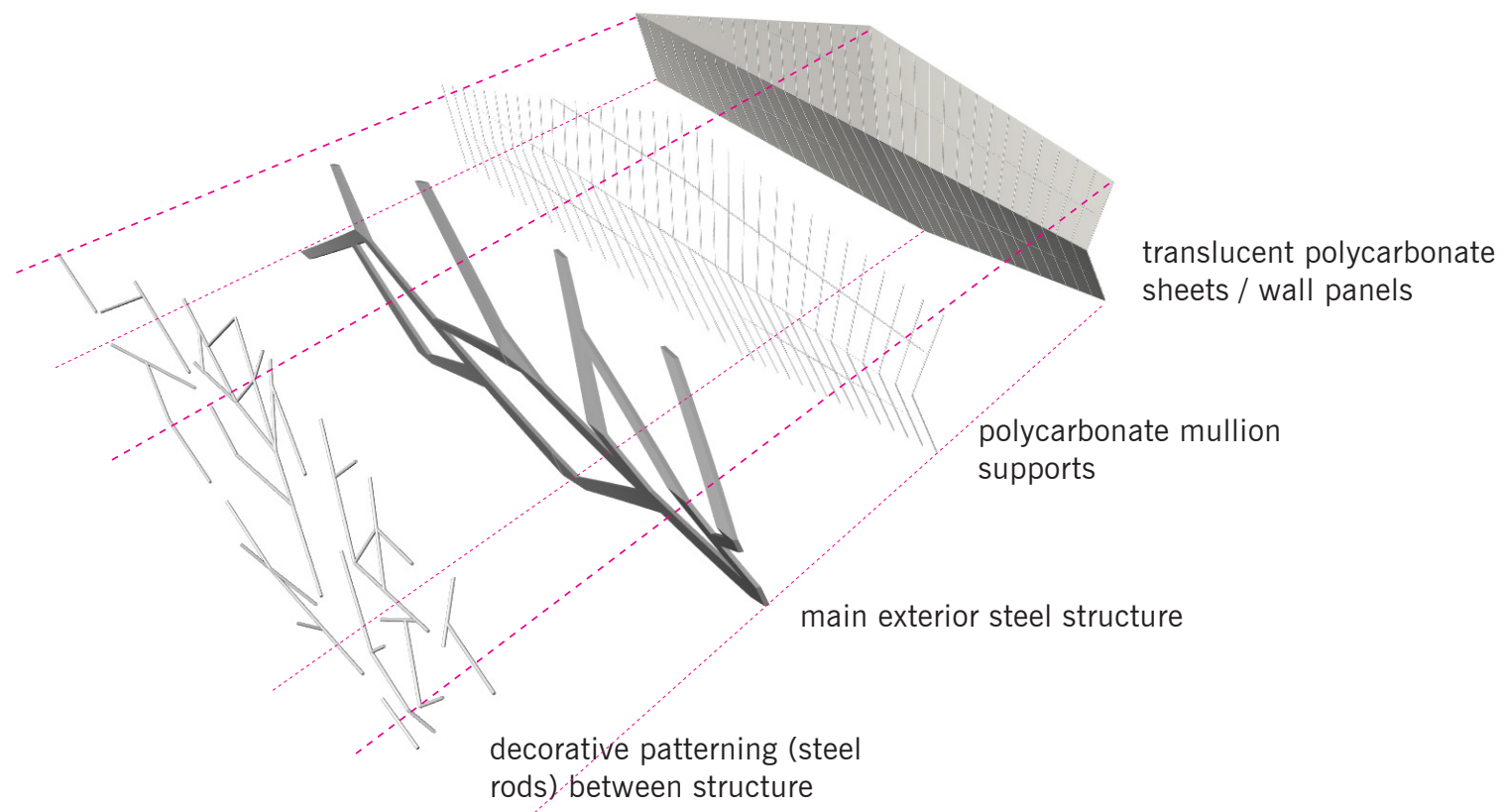

Fig. 6.3.22: Individual elements making up the facades.

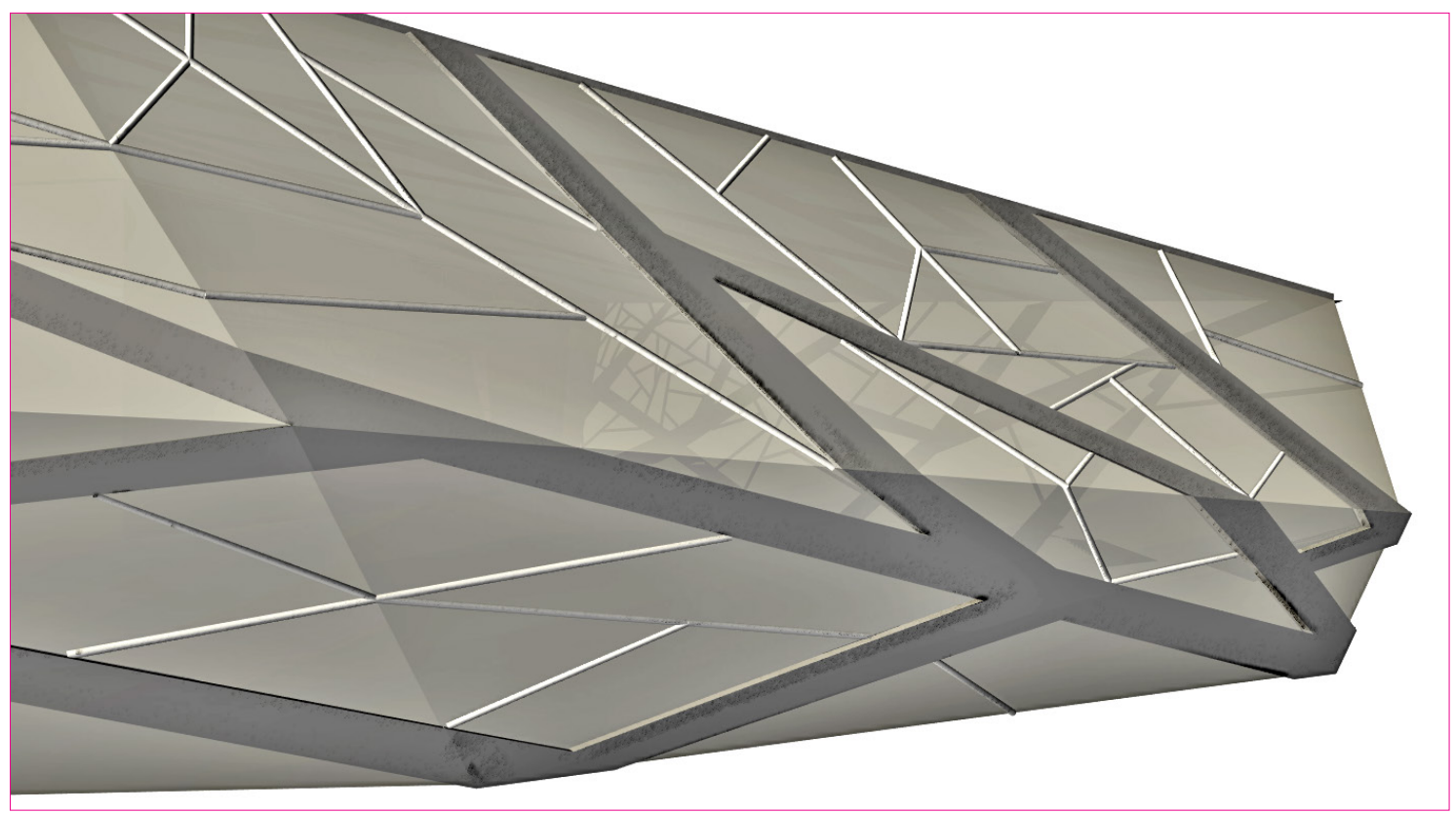

Fig. 6.3.23: Assembled materials - could look great at night with grow lights switched on inside. 


\section{DEVELOPED PLANS}

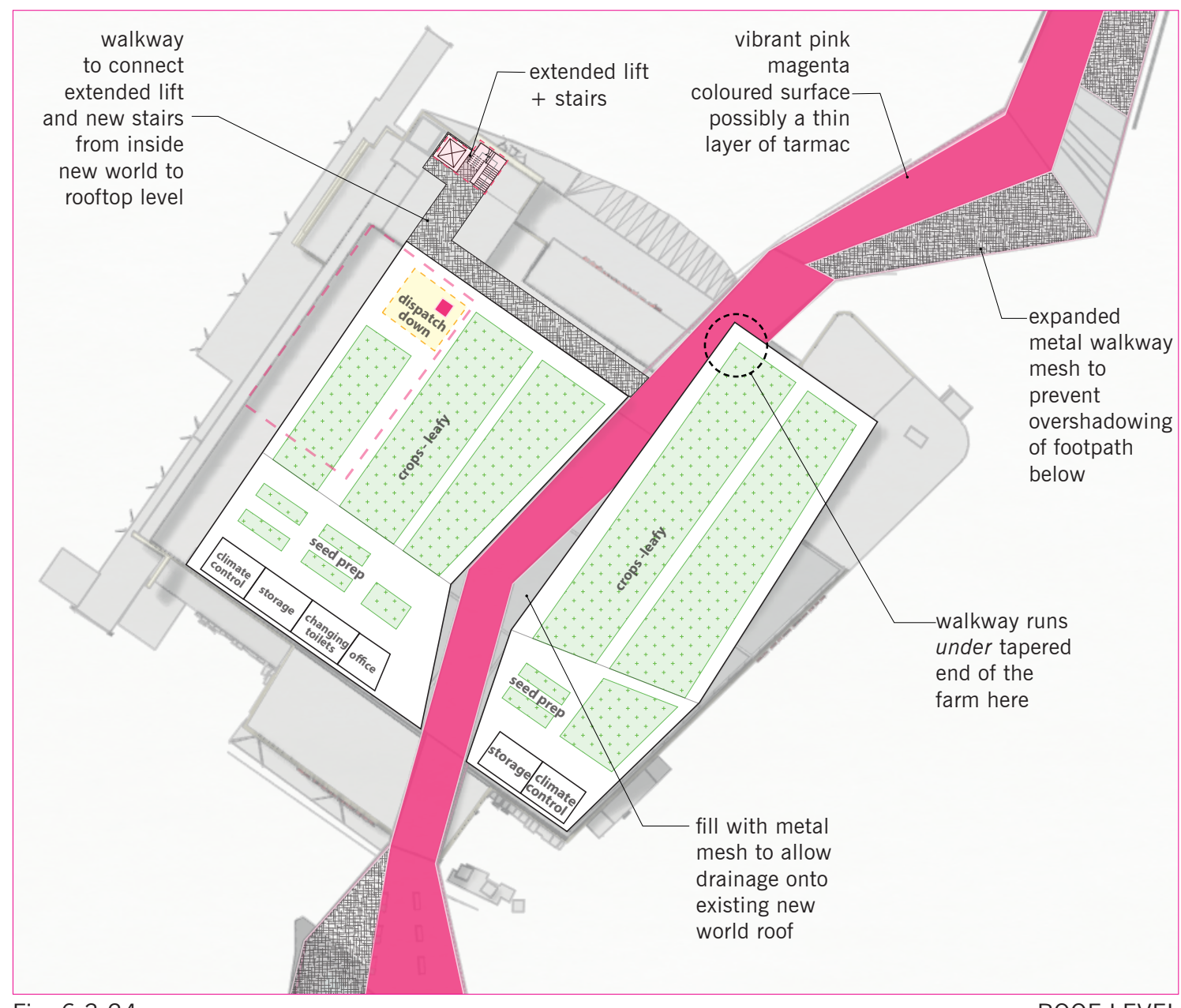

Fig. 6.3.24

FARM \& WALKWAY FLOORPLAN

Fig. 6.3.25 (facing page): Roof view of farm and walkway amongst city context. Pedestrian access routes to walkway shown. 
amp entrance at $\lambda$
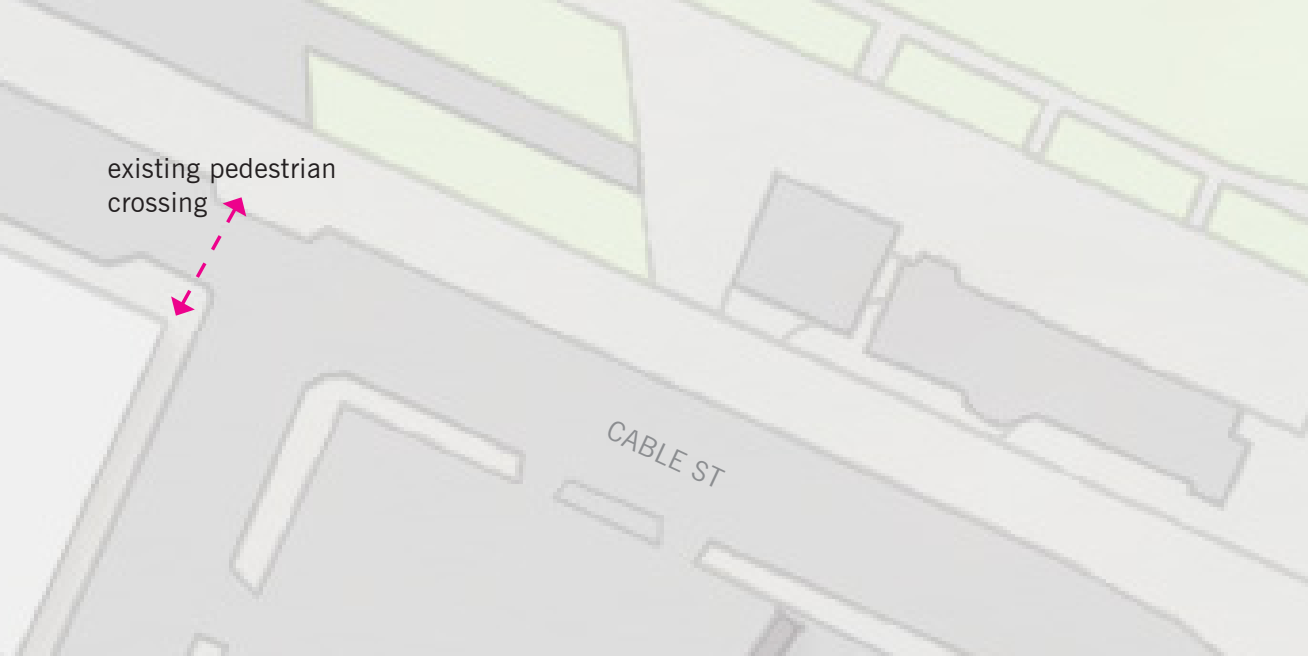

Waitangi Park

(1)

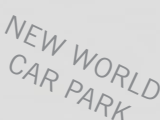

existing pedestrian

crossing 


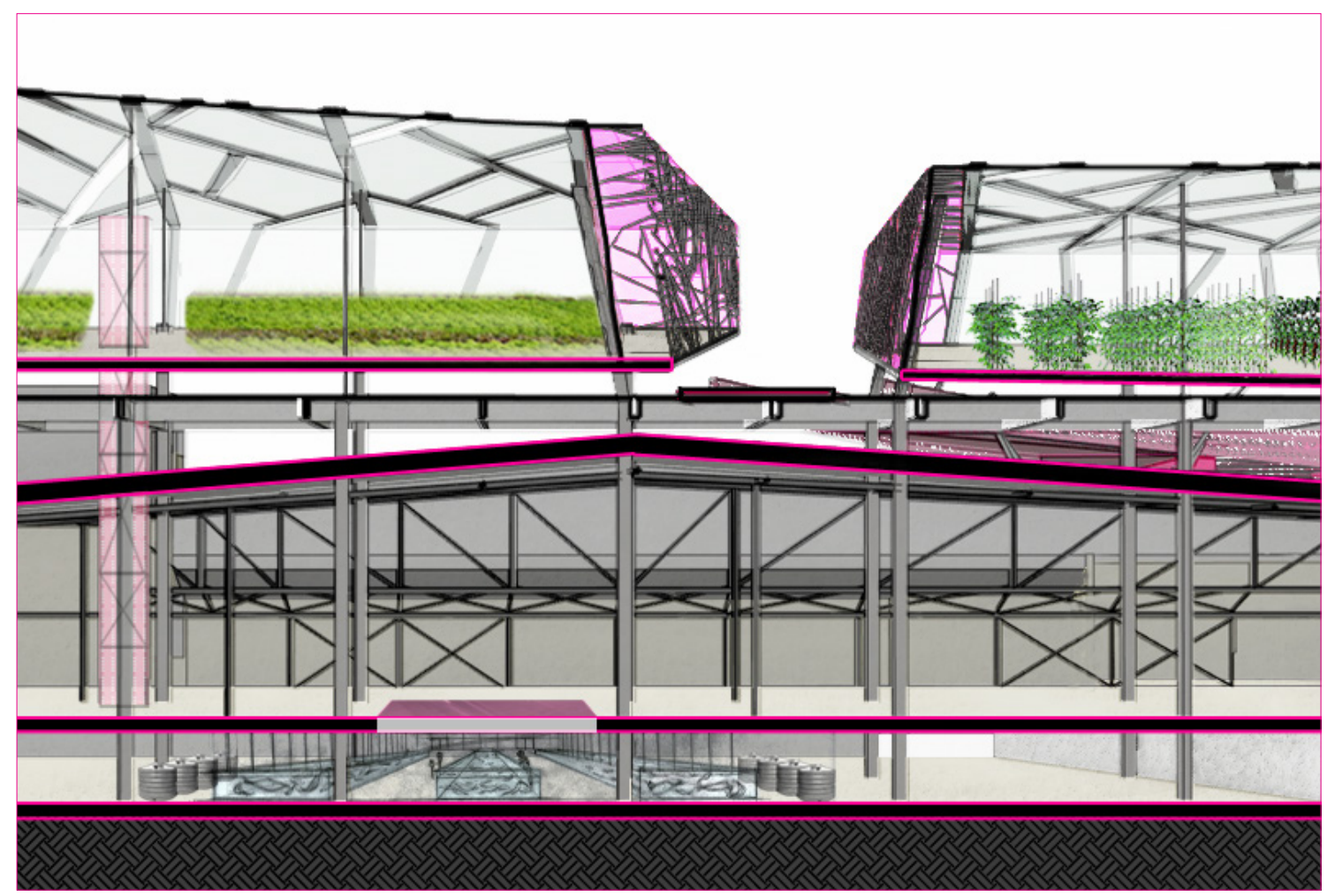

Fig. 6.3.26: Part section showing lift shaft from farm to supermarket to left of image (crop arrangement not final). The fish farm at basement level can be viewed by New World customers through a proposed glass floor window inside the supermarket.

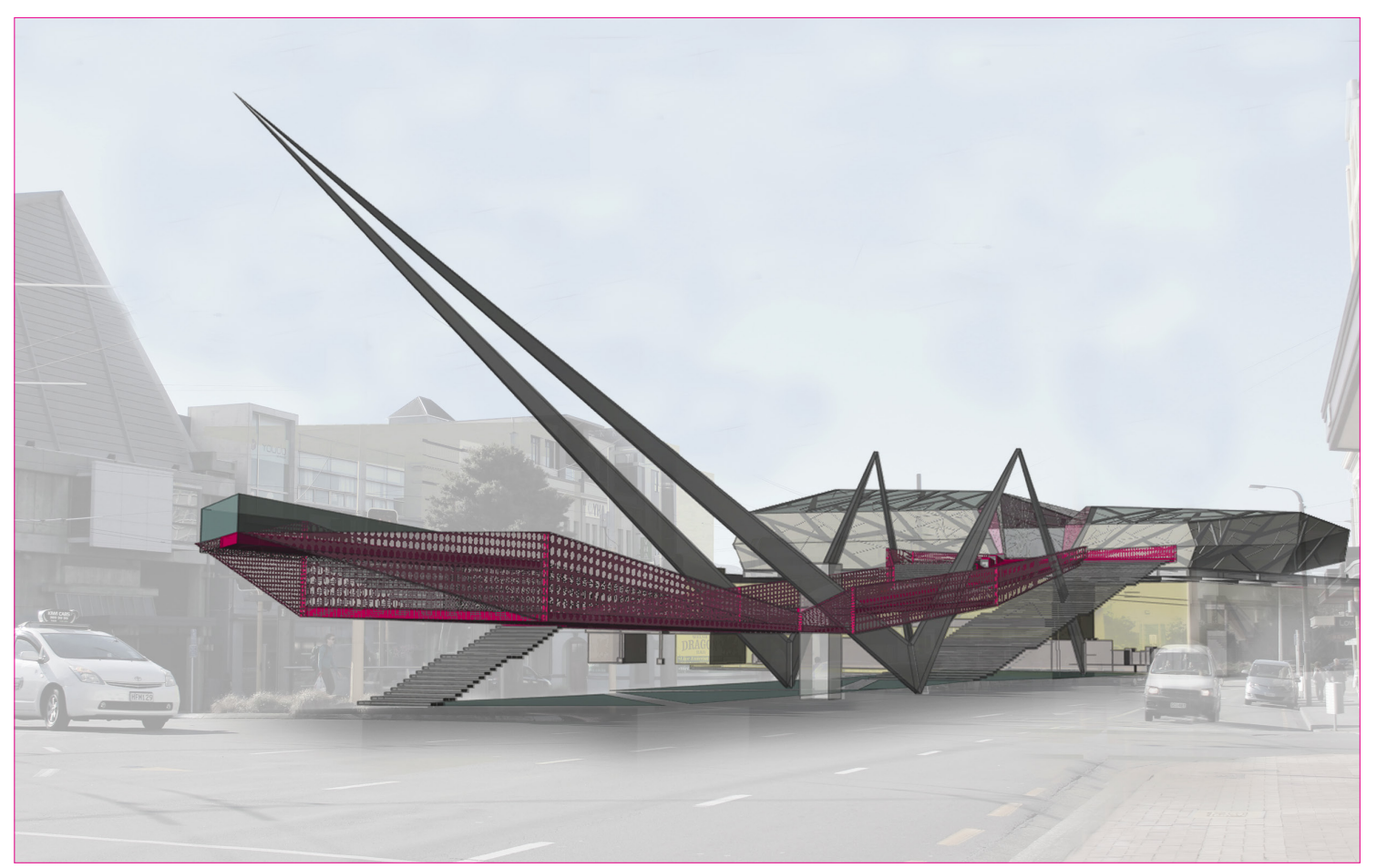

Fig. 6.3.27: View from outside Embassy Theatre on Kent Tce. 
DEVELOPED

DESIGN

PROGRAM
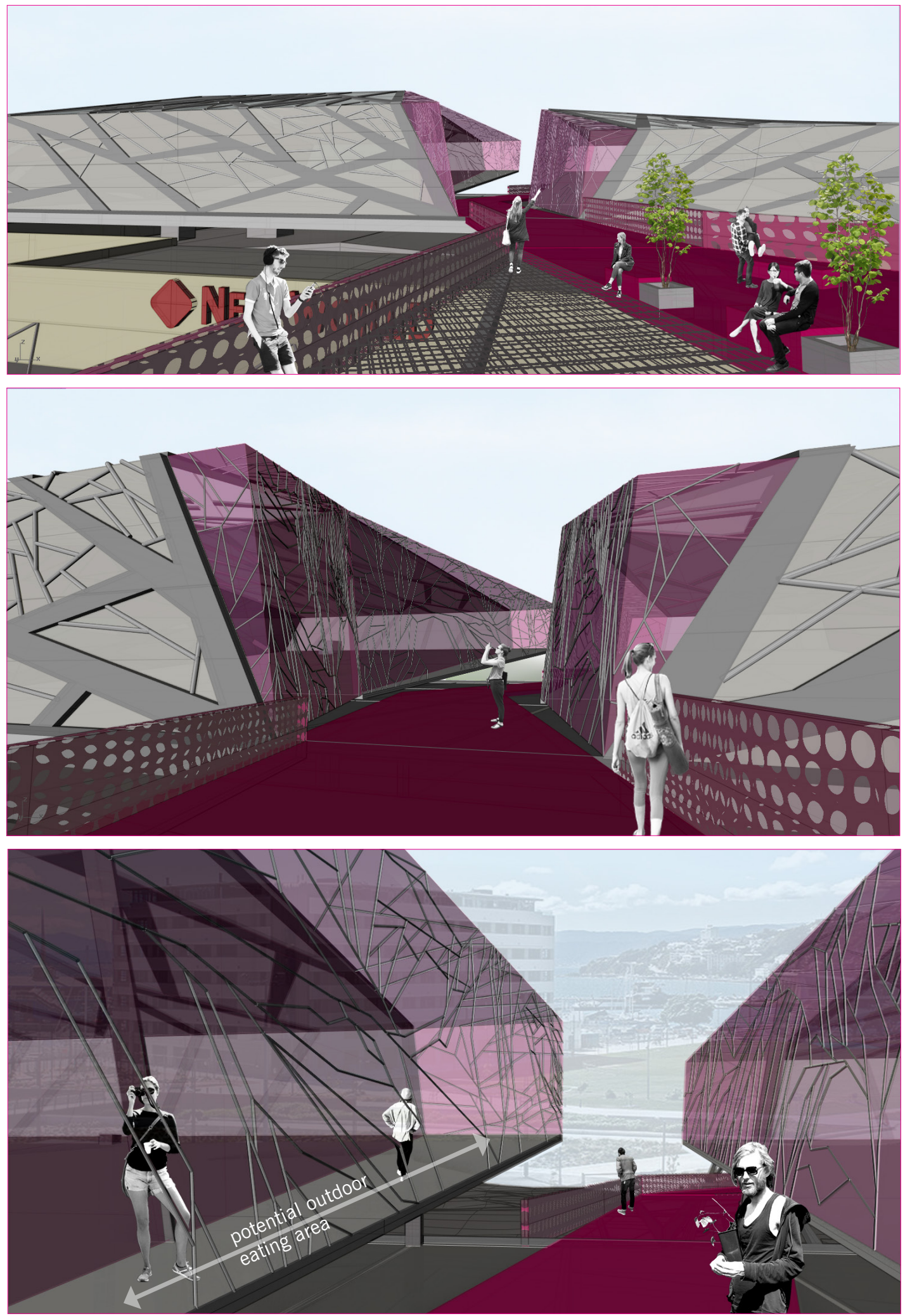

Fig. series 6.3.28: Walkway views while walking towards Waitangi Park from Cambridge/Kent end. Interior layout is yet to be finalized (crops not shown). 


\section{DEVELOPED DESIGN REFLECTION + FURTHER DEVELOPMENT}

Following conclusions from preliminary design, the New World site has been taken forward for development. This phase largely focused on refining the walkway, dealing with matters such as relocating a heritage listed building and proposing what could go under the bridge end of the walkway. The intention of elevating the walkway is to encourage pedestrians to use the new route. However, the space created underneath should not be neglected and requires careful thinking around what activities ought to take place there. The location of the traffic island being between two busy terraces is already unappealing to spend any amount of time at, so the intent is not to make this space more usable at ground level, but rather ensure it does not reflect a neglected urban space despite there being a better alternative above. An option could be to simply beautify the traffic island through the proposed water feature that alludes to the historic channel linking the harbour and Basin Reserve. This proposal ensures the space below the bridge is still kept to a certain urban standard if pedestrians choose to walk through to 'access stairs no.2' (see pg. 103). Admittedly, this is seemingly a 'surface-deep' design response that could do with further exploration.

Another focus during this phase was the integration of a sound structure to further develop its overall form. Following some feedback and self-critique, the design moved from a fairly 'safe' structural solution (pg. 103) to one that was more fitting with the architectural aims of the research (pg. 107). This was completed upon a return to hand rendering which proved useful even during a developed stage and further fed into sculpting the overall building form. Its northern face now reaching towards the water is a result of the tapered/raised ends adding character to both the addition and host building, while placing higher emphasis on the city to water connection.

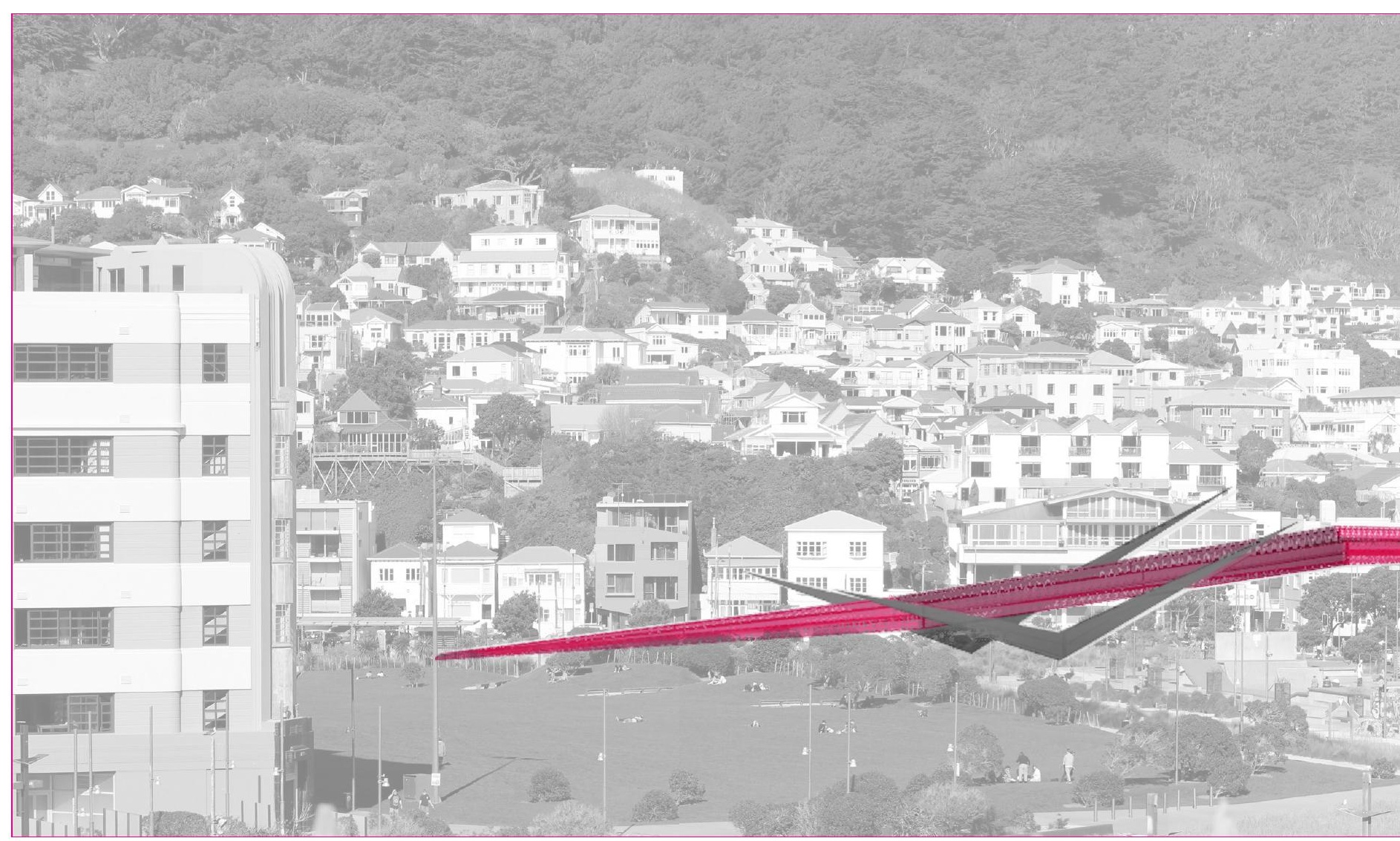

Fig. 6.3.29: View of New World and rooftop farm from Te Papa National Museum. Mount Victoria seen in the background. 
The developed design demonstrated an opportunity in lowering New World's parapet to expose its gable, presenting the rooftop farm as being an intentional addition to the supermarket building, exhibiting dynamism in the way it is positioned (pg. 109). Although it is unlikely that the corporate franchise will allow for alterations in reality (due to keeping with their strict branding guidelines), an exercise in redesigning the supermarket around its rooftop addition would illustrate a local distinctivity so that it is no longer a 'no-place'. This could be an entirely new project altogether.

Heading towards the final design phase, the floor plan is yet to be finalized. Interior crop arrangements will be explored due to it making up a large part of how the farm is viewed from the walkway. A question would be how this could tie in with the design thus far so that it reads a similar architectural language.
Additionally, the lift shaft down to New World's exisitng produce area requires further investigation to see its effect on the supermarket at ground level, not just in plan. The walkway program also requires clarifying, such as designating for sitting/relaxing spaces.

In conclusion, the developed design phase largely finalized the form and structure of the rooftop addition and walkway - the following final design phase works around refining the details of the program.

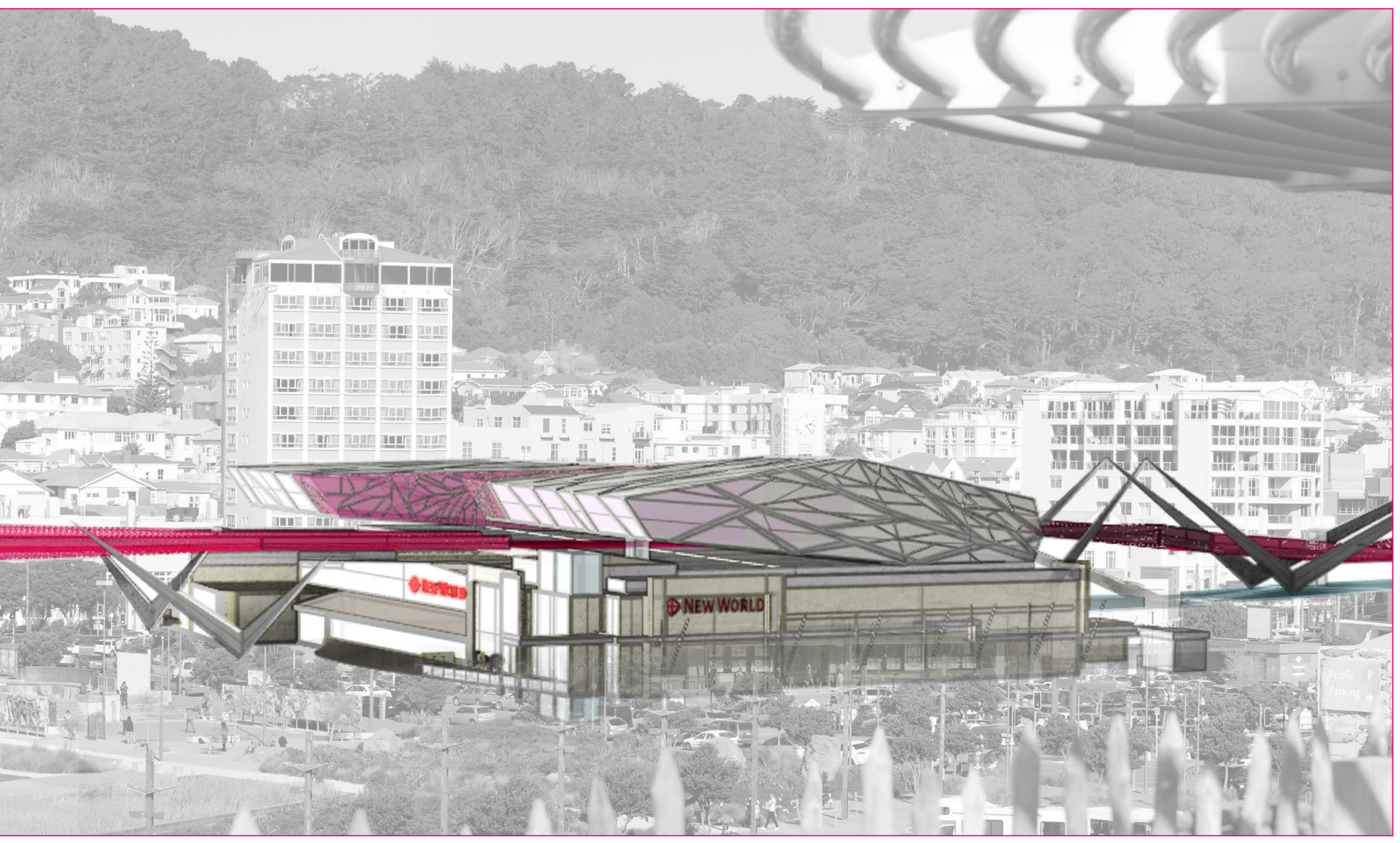




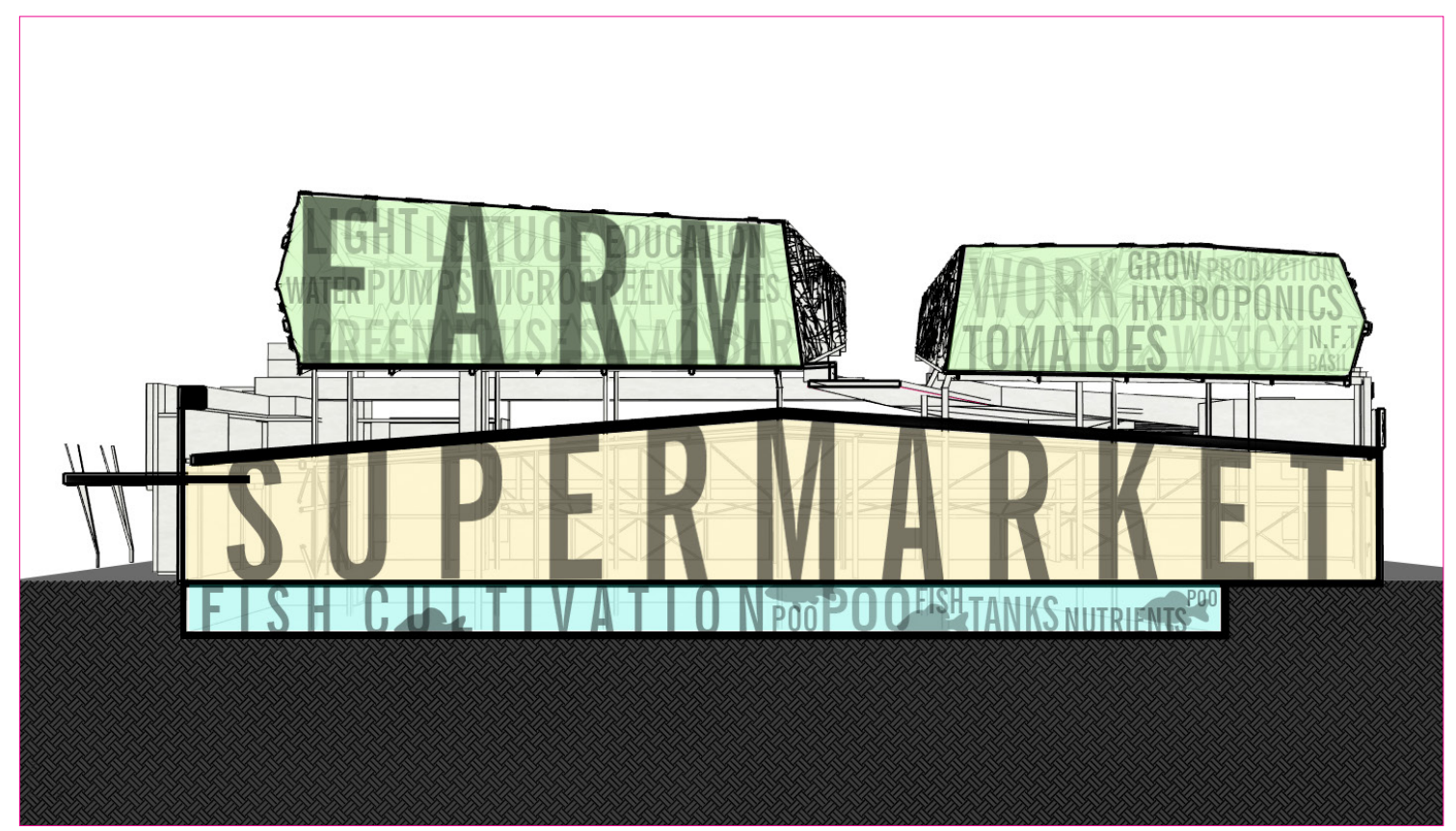

Fig. 6.4.1: Conceptual program section of New World Farm.

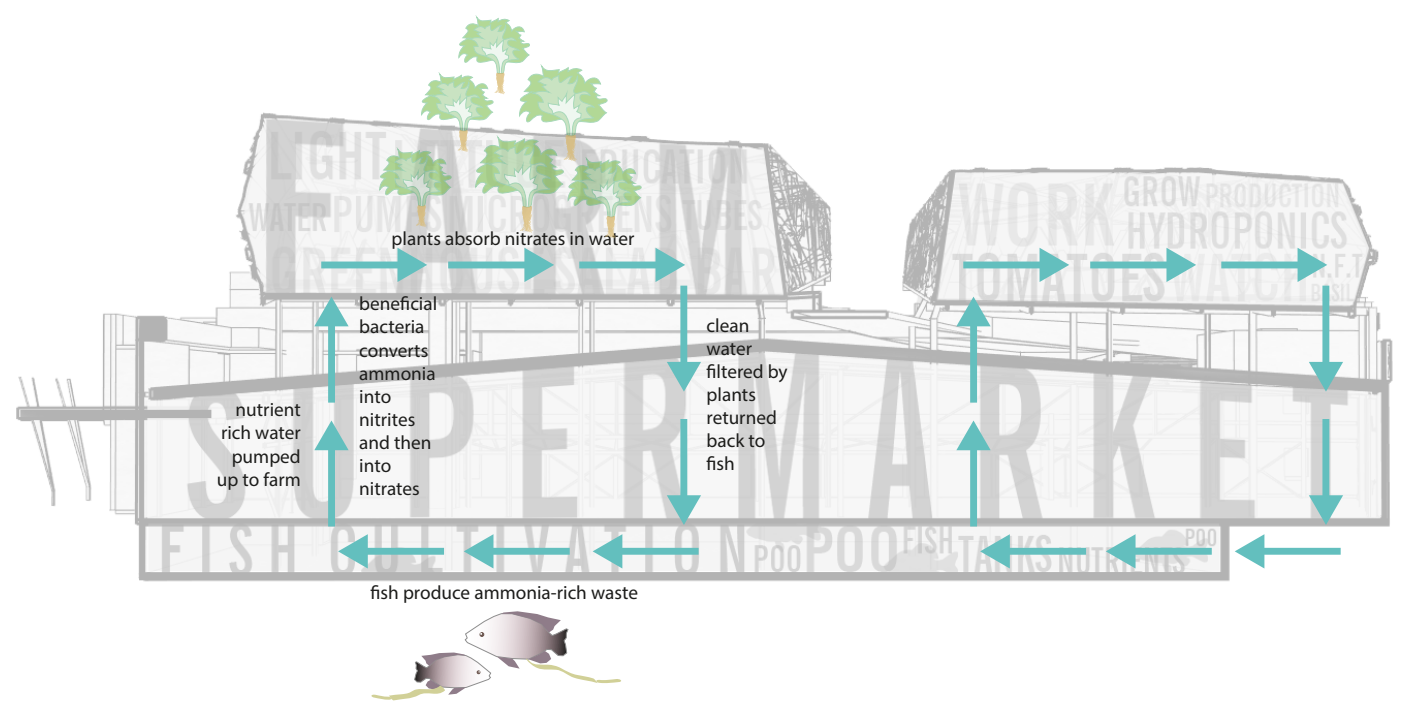

Fig. 6.4.2: Ecological diagram of aquaponic cycle occuring at both wings of the farm. 
FINAL

DESIGN

FORM / STRUCTURE

ITERATIONS
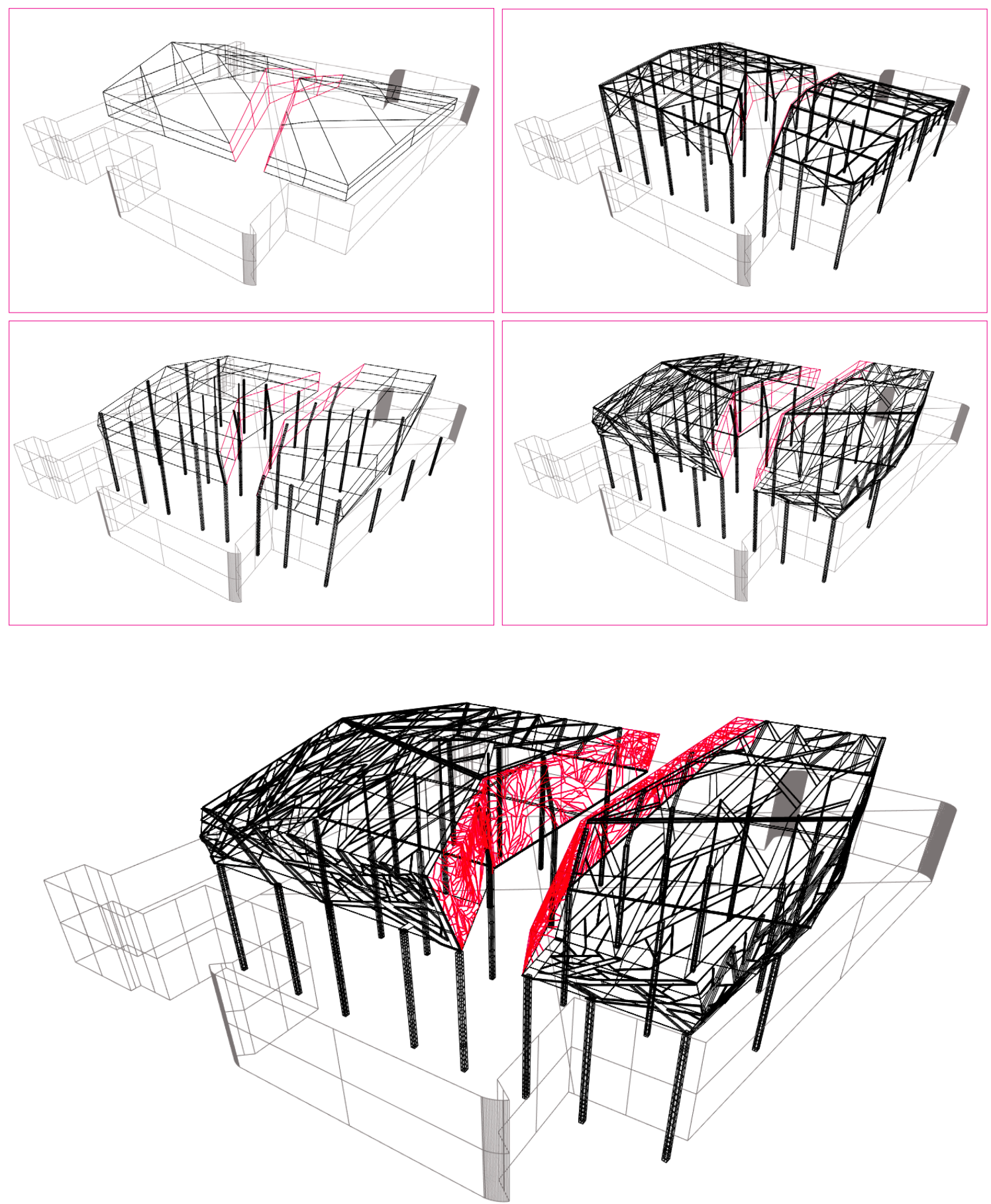

Fig. series 6.4.3: Milestone form and structure iterations from preliminary to final design of rooftop farm. 


\section{CROP ARRANGEMENT OPTIONS - SURFACE AREA COMPARISON}

[a] single-plane row planting

\section{$1647 \mathrm{~m} 2$}
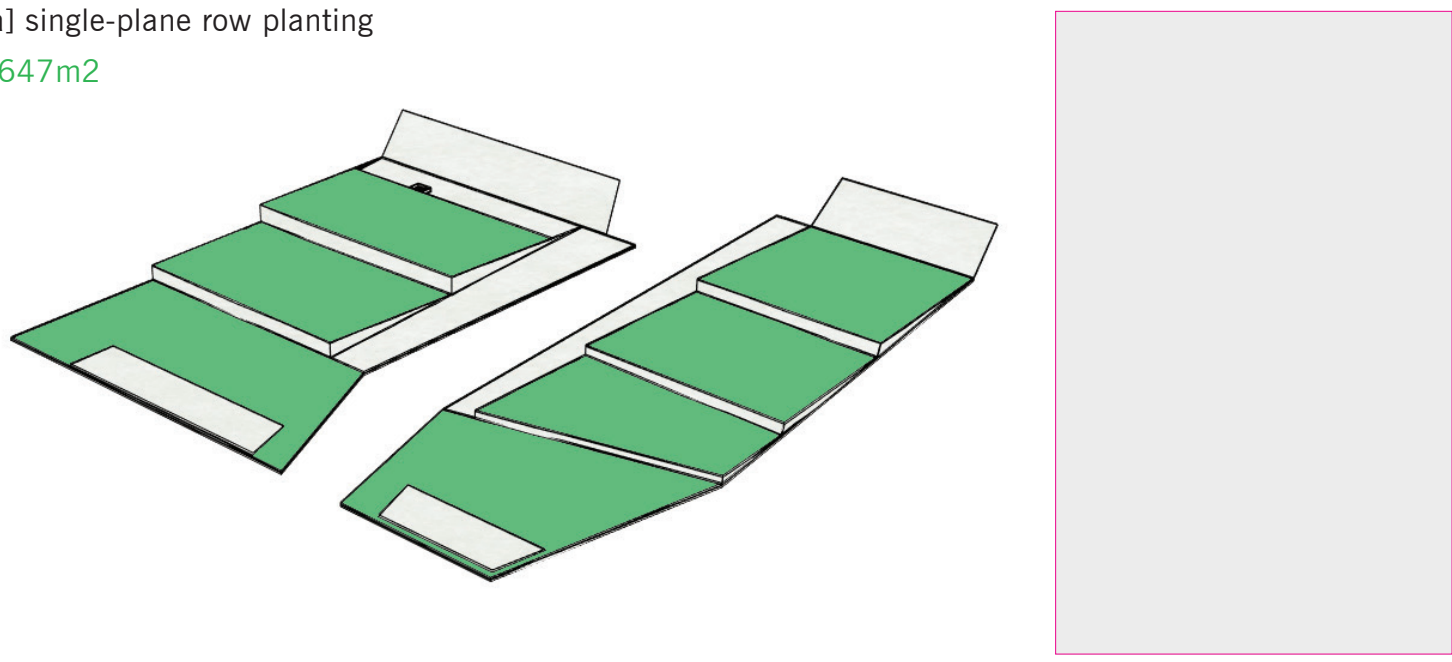

[b] vertical arrangement (rotation technology)

\section{$1812 \mathrm{~m} 2$}
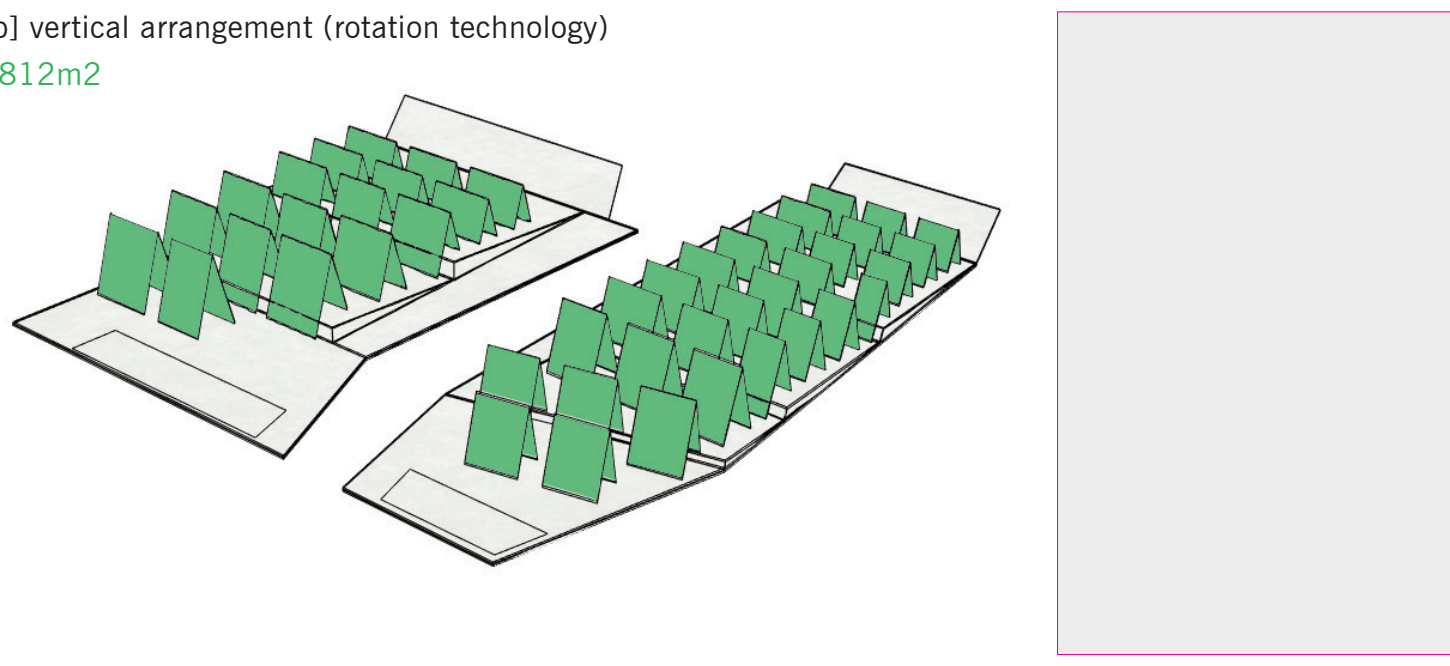

Fig. 6.4.4

Fig. 6.4.5

[c] bespoke arrangment

\section{9m2}
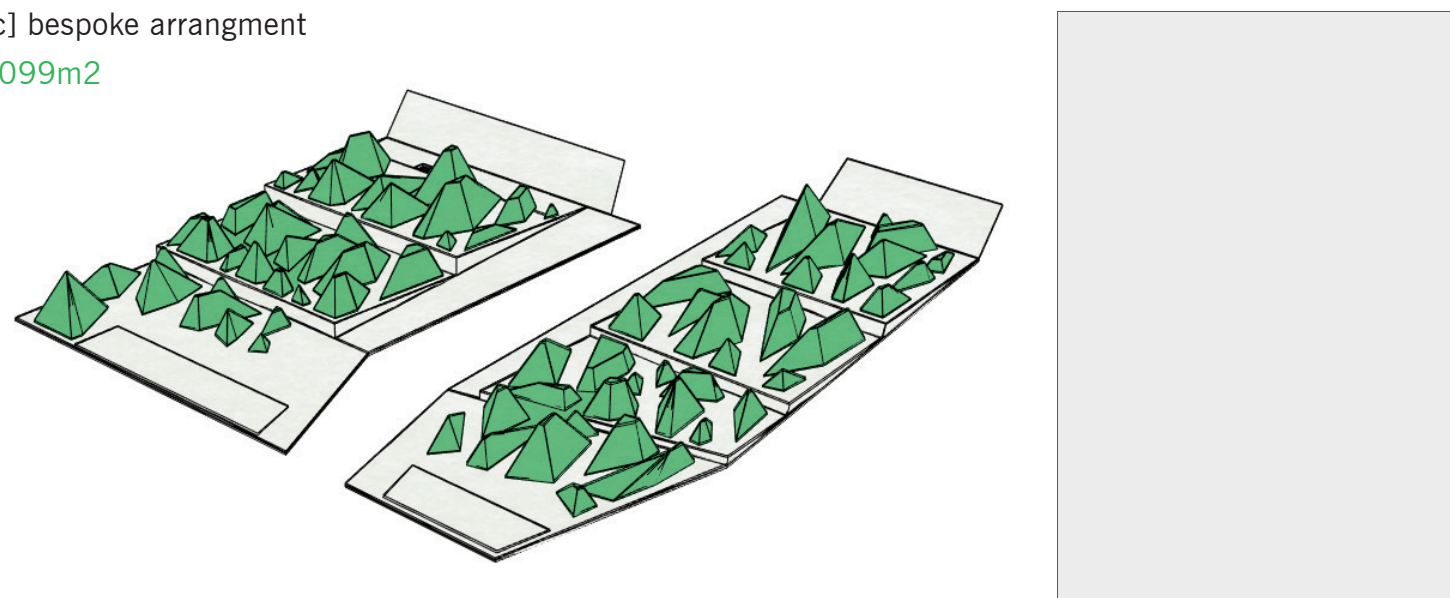

Fig. series 6.4 .3 (above): In analyzing crop arrangements, several factors are taken into account with priority given in the order of: 1) architectural intent/relation; 2) human engagement; 3) growing surface area; 4) lighting; and 5) type of crops. Ultimately the project calls for a type of 'spectacle farm' as established after preliminary reflections. Hence, option [c] will be the selected arrangement due to its more 'designed' nature, notwithstanding further explorations into hydroponic planting would be a useful exercise. It also happens that option [c] offers the highest surface area and can be manipulated further. 
FINAL

\section{DESIGN}

PROPOSED CROP ARRANGEMENT - THE FOOD PYRAMIDS
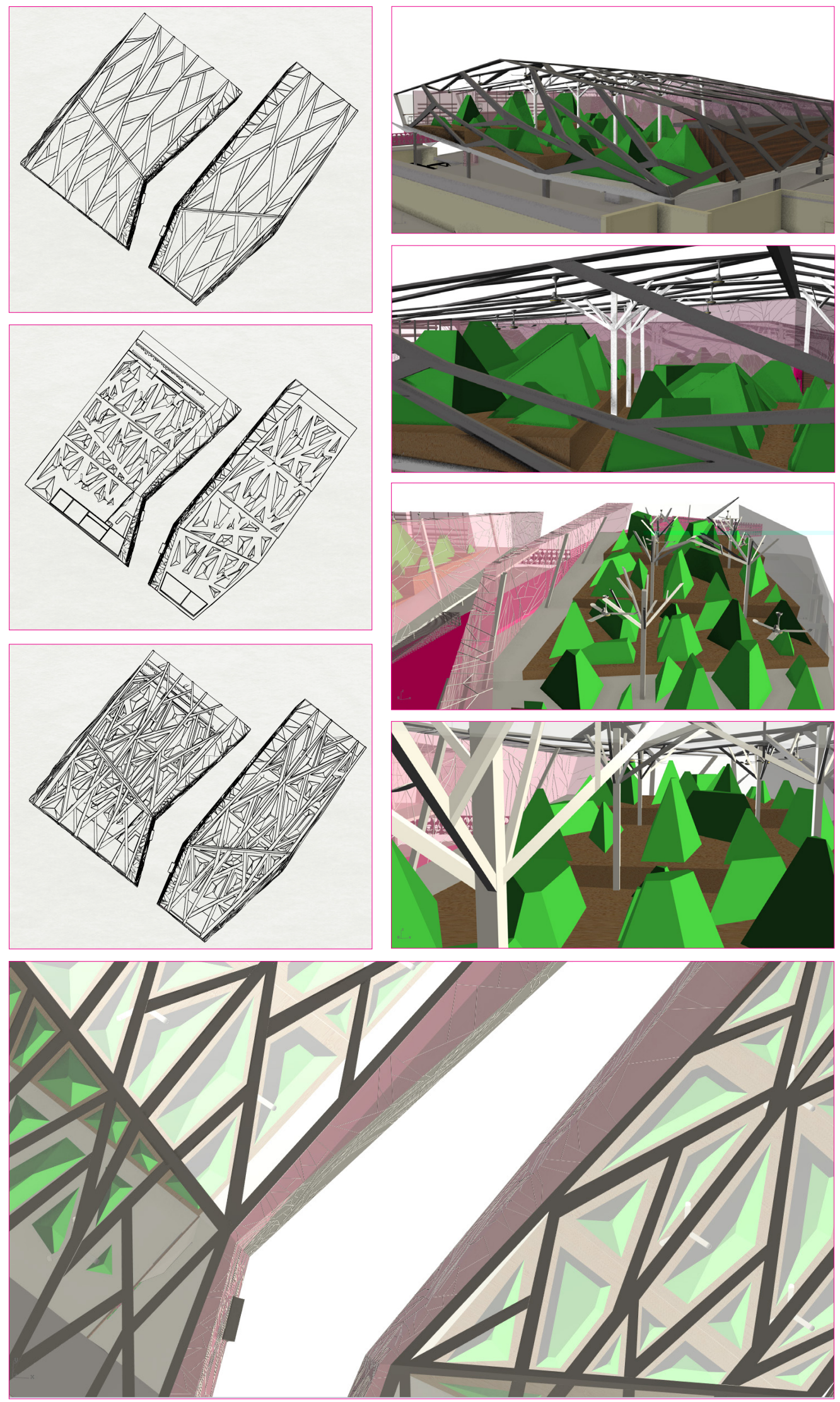

Fig. series 6.4.7: Crop design takes influence from roof structure patterns. Of varying widths and heights, the 'food pyramids' are spatially intriguing. They could even be mobile to ensure adequate lighting throughout the day providing a change of scenery as part of the process spectacle. 
WALKWAY PLAN - BRIDGE END

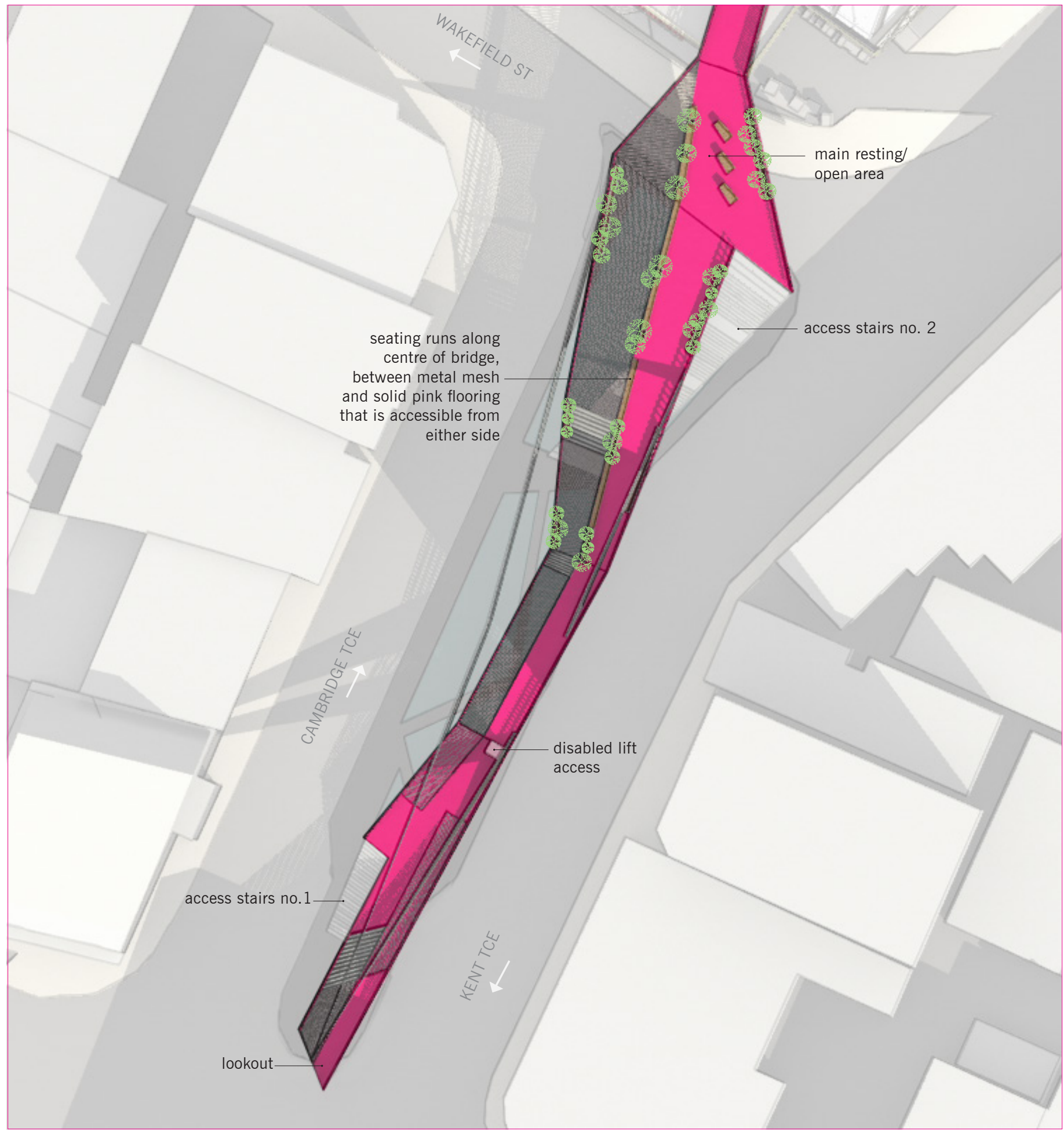

Fig. 6.4.8 
FINAL

DESIGN

PROGRAM

WALKWAY PLAN - RAMP END

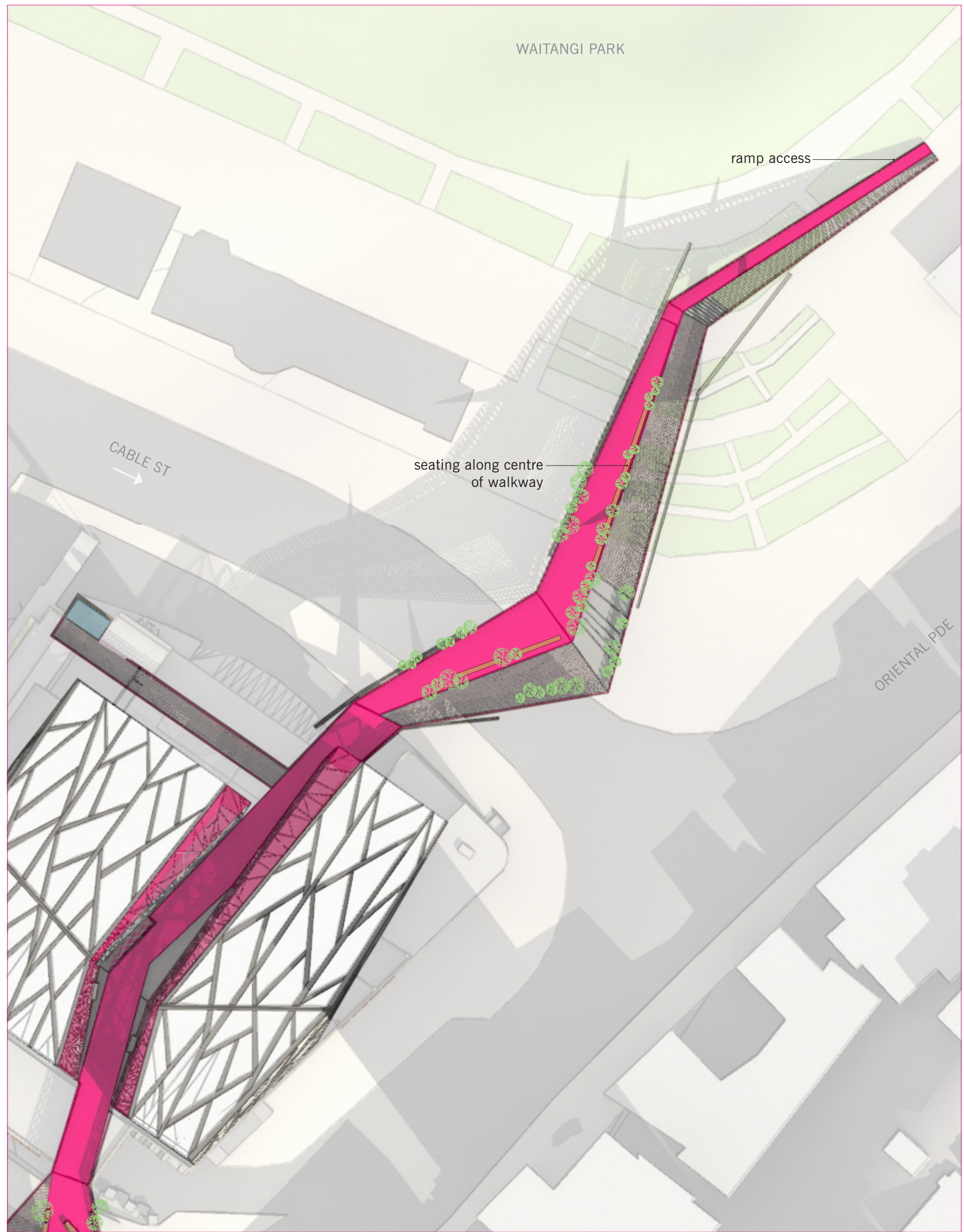

Fig. 6.4.9 


\section{FLOORPLANS}

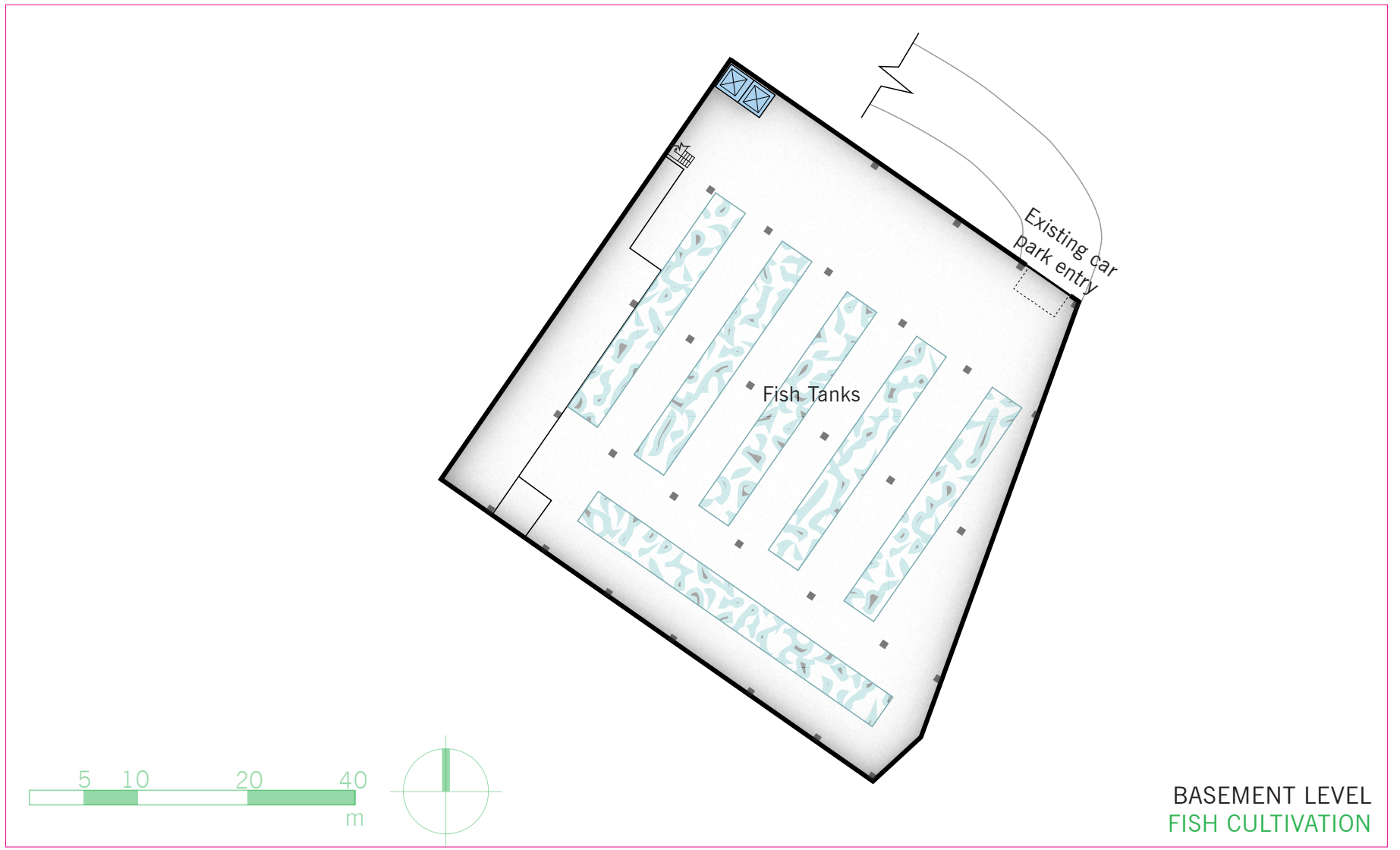

Fig. 6.4.10

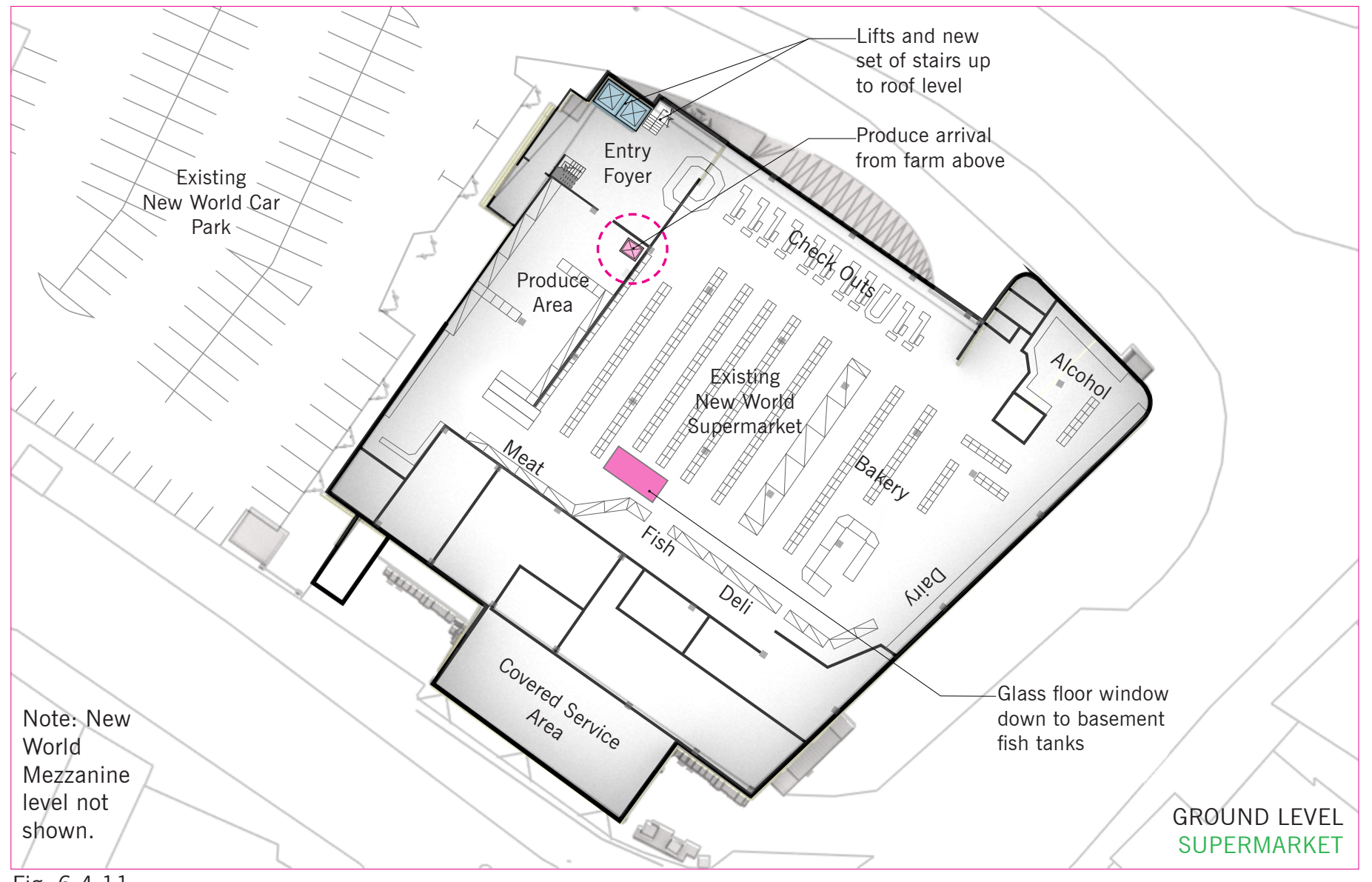

Fig. 6.4.11 
FINAL

\section{DESIGN}

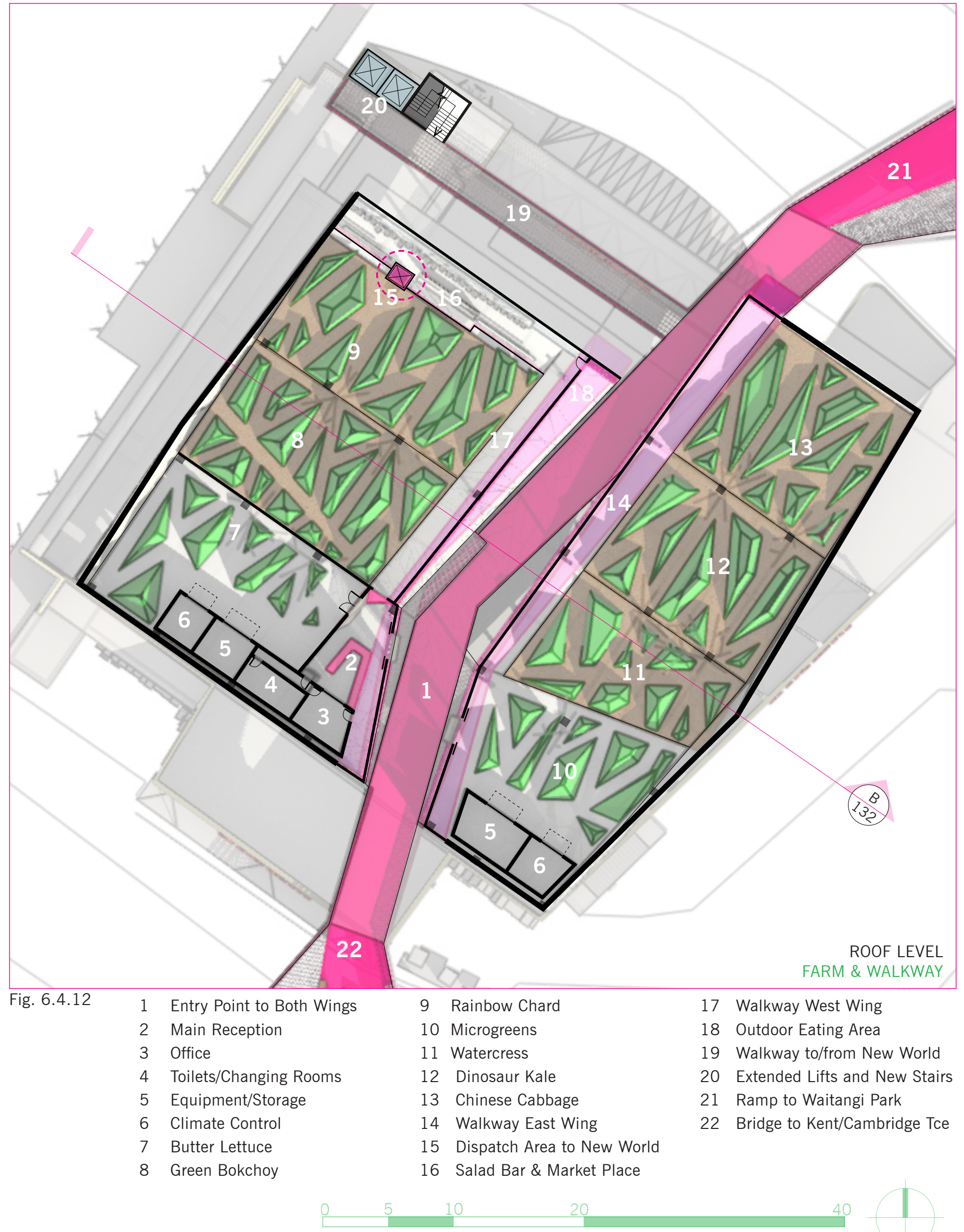




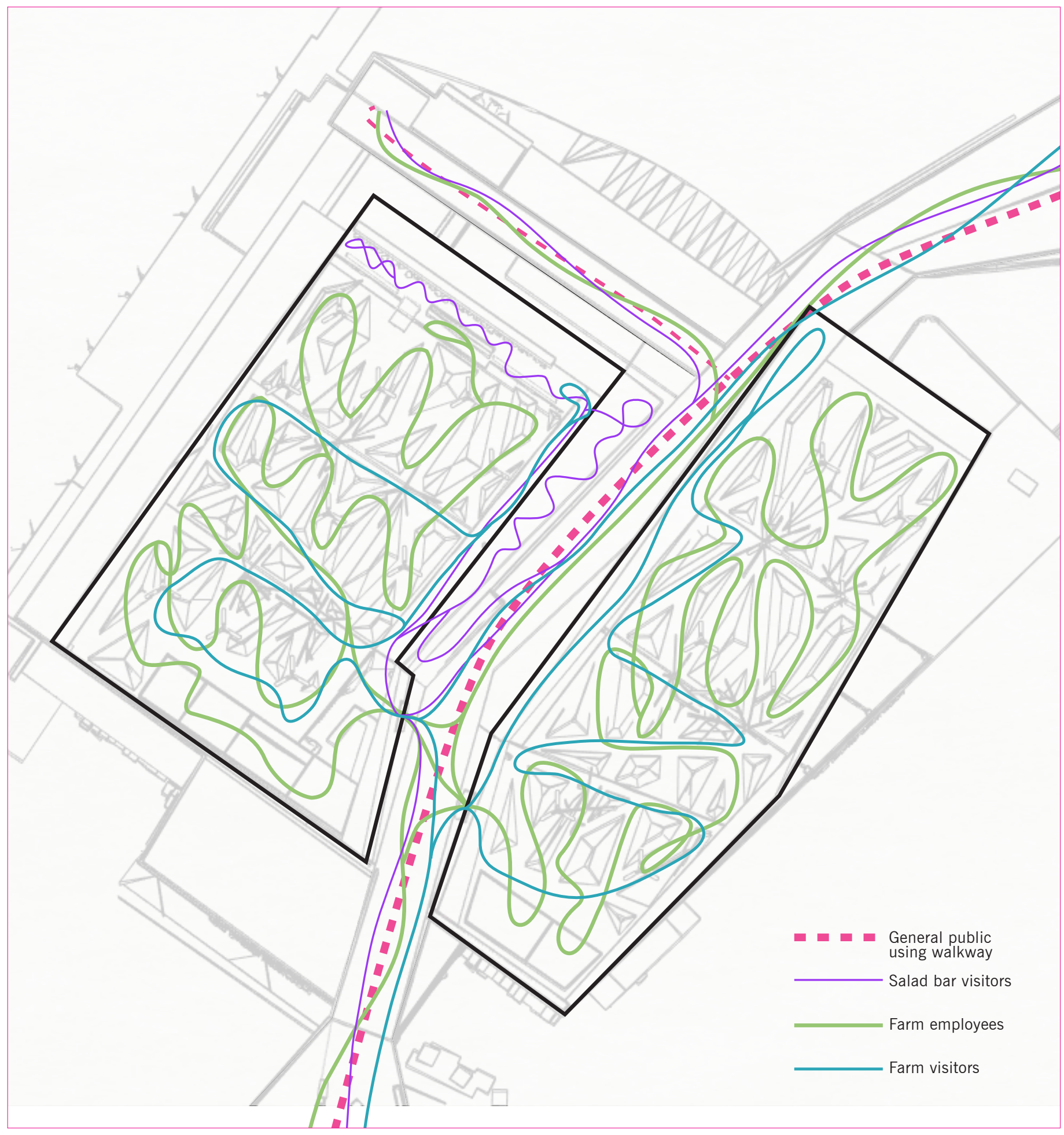

Fig. 6.4.13 
FINAL

DESIGN

VIEWSHAFTS FROM WALKWAY

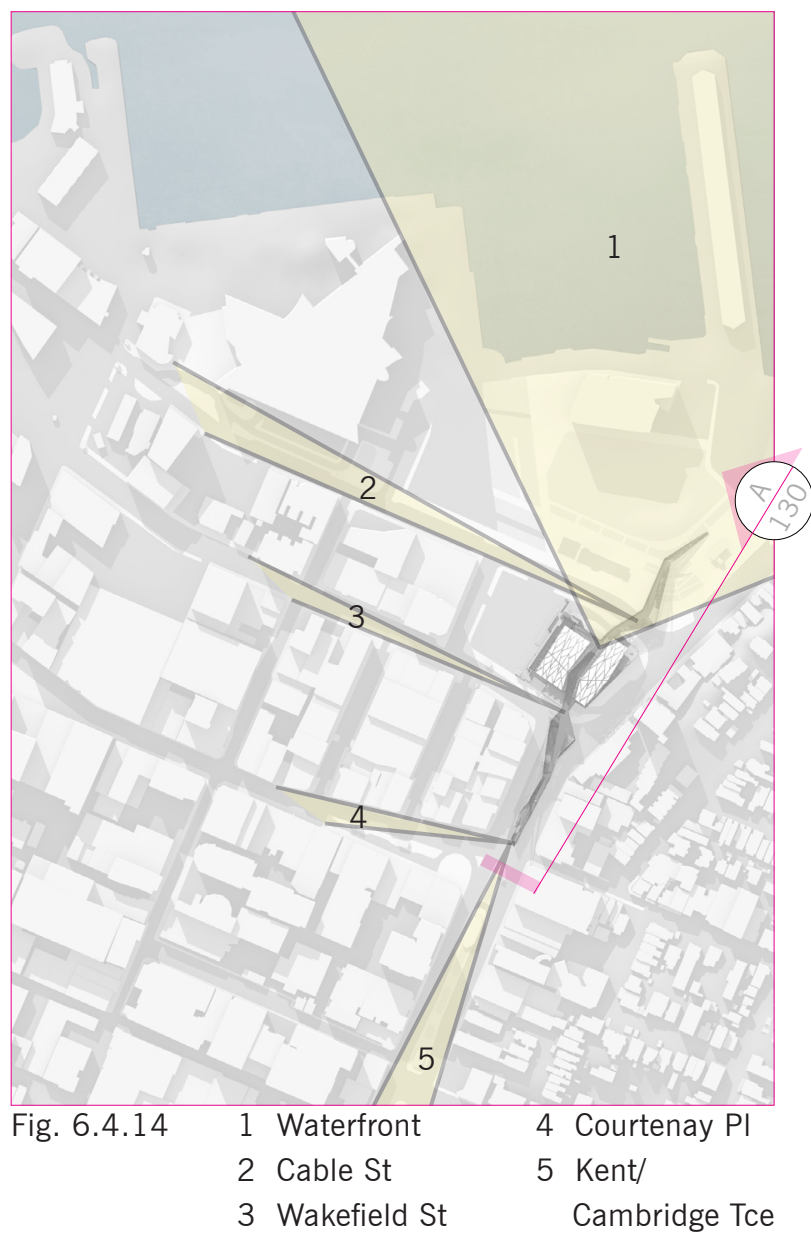

\section{NEW CITY TO SEA PEDESTRIAN ROUTE}

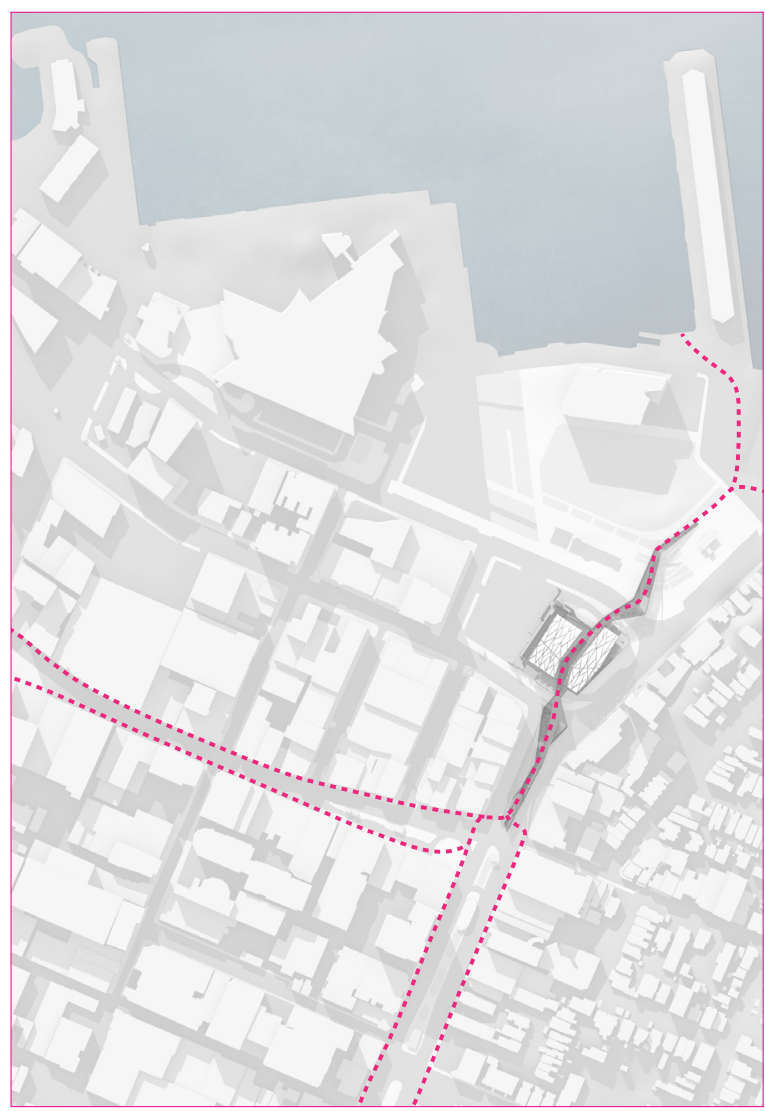

Fig. 6.4.15

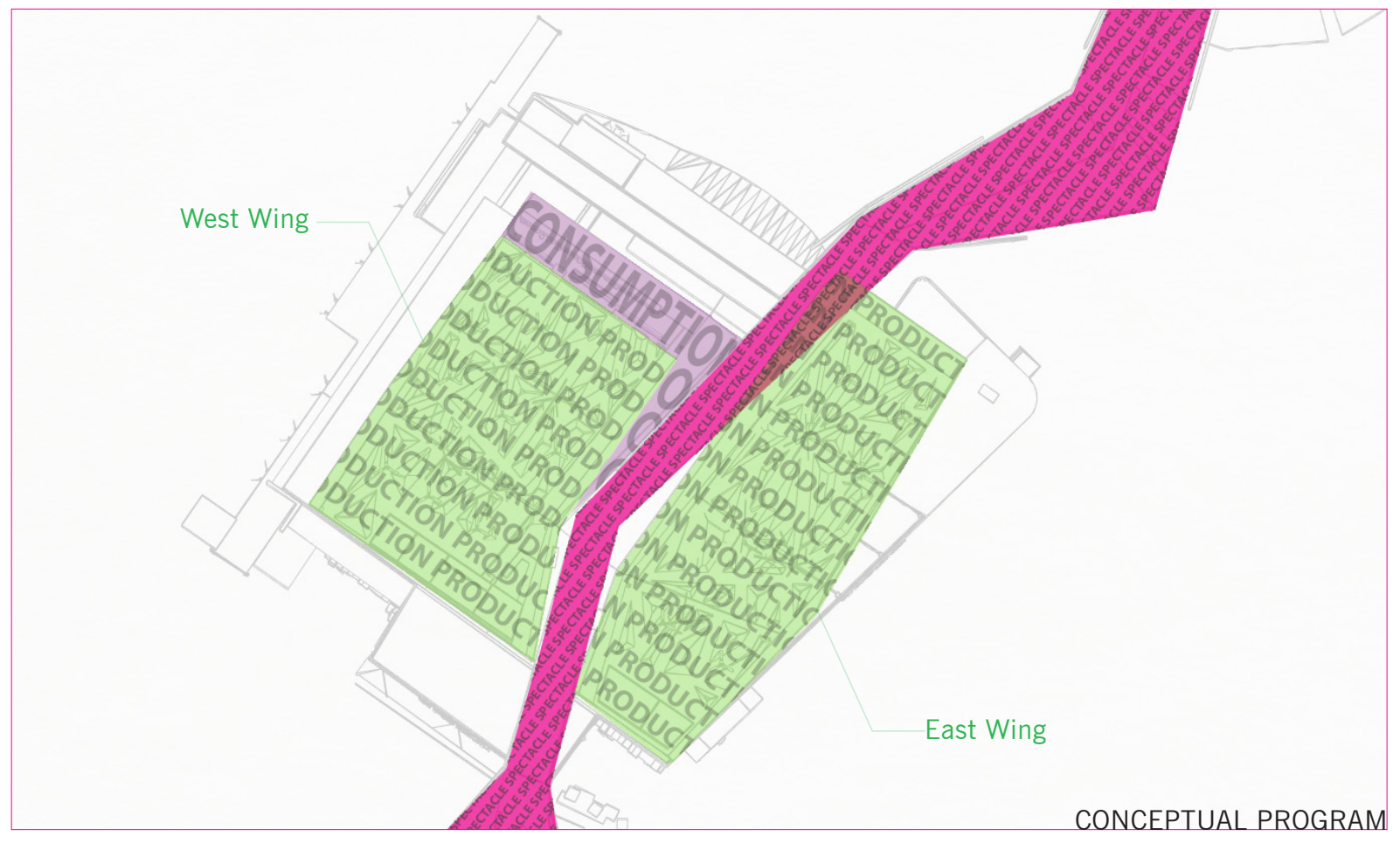

Fig. 6.4.16 

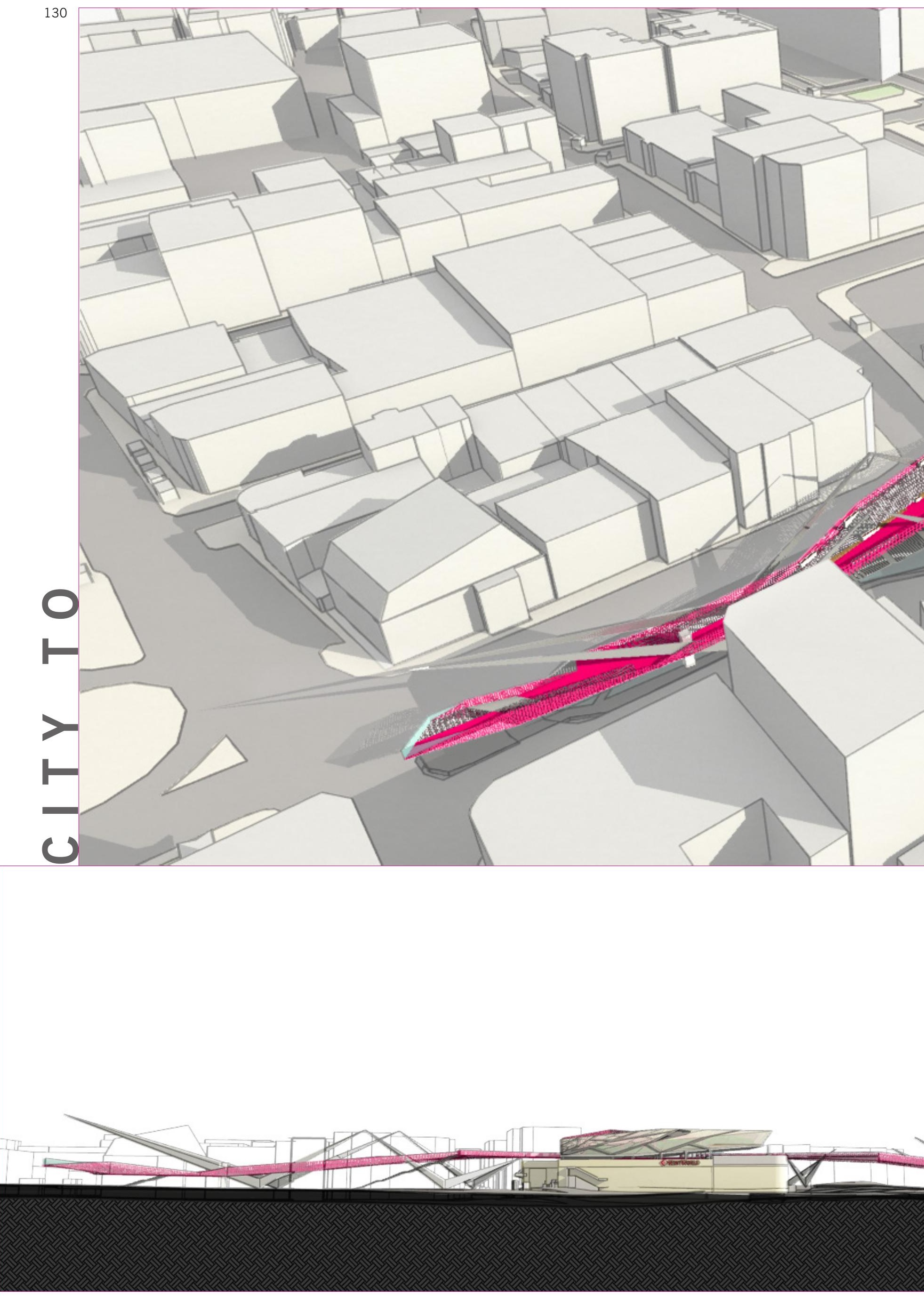
Fig. 6.4.19: The service lift adds to the spectacle of a production to consumption program. Upon entry to the supermarket, customers are able to see fresh

vegetables brought directly down from the rooftop farm.
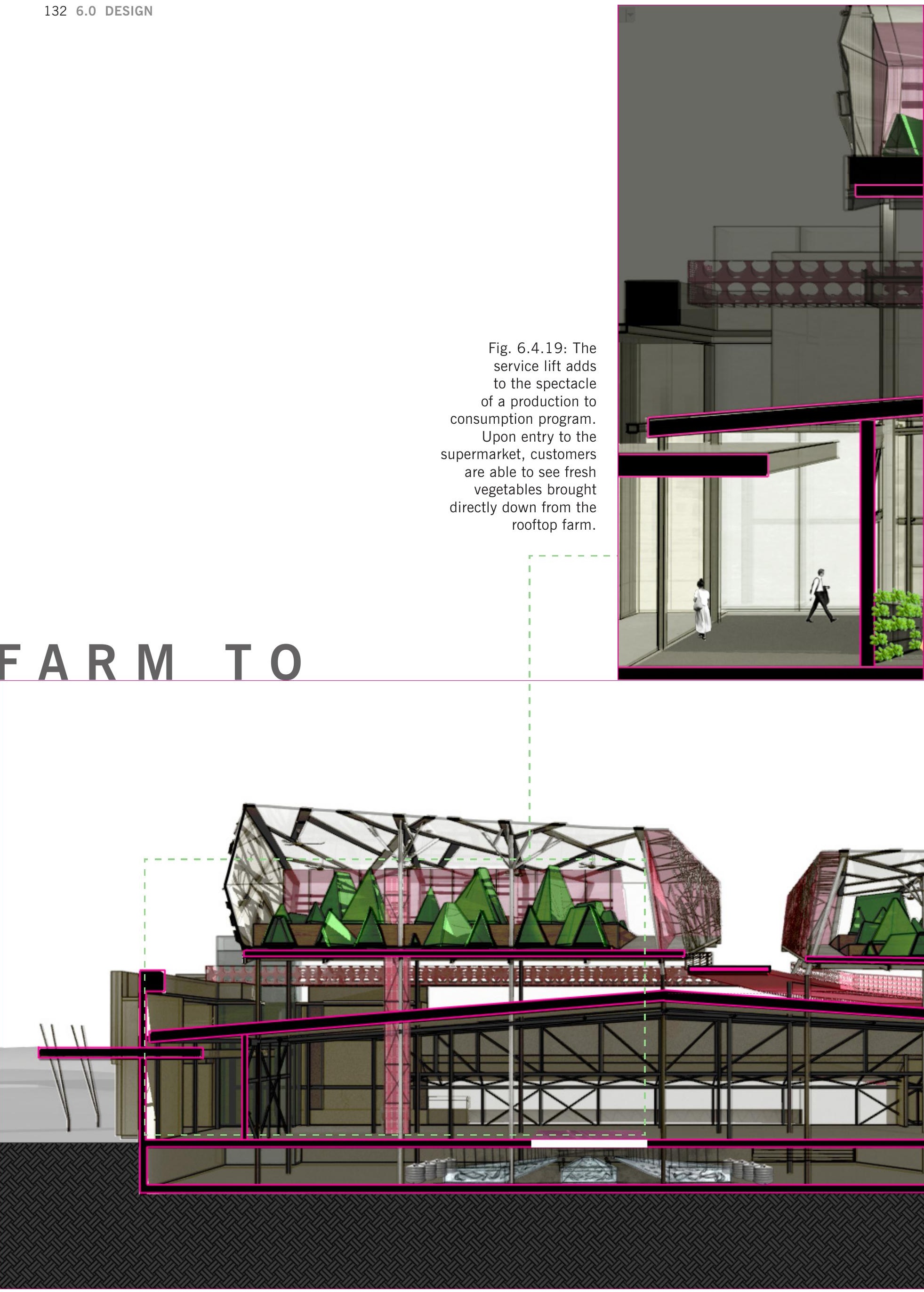

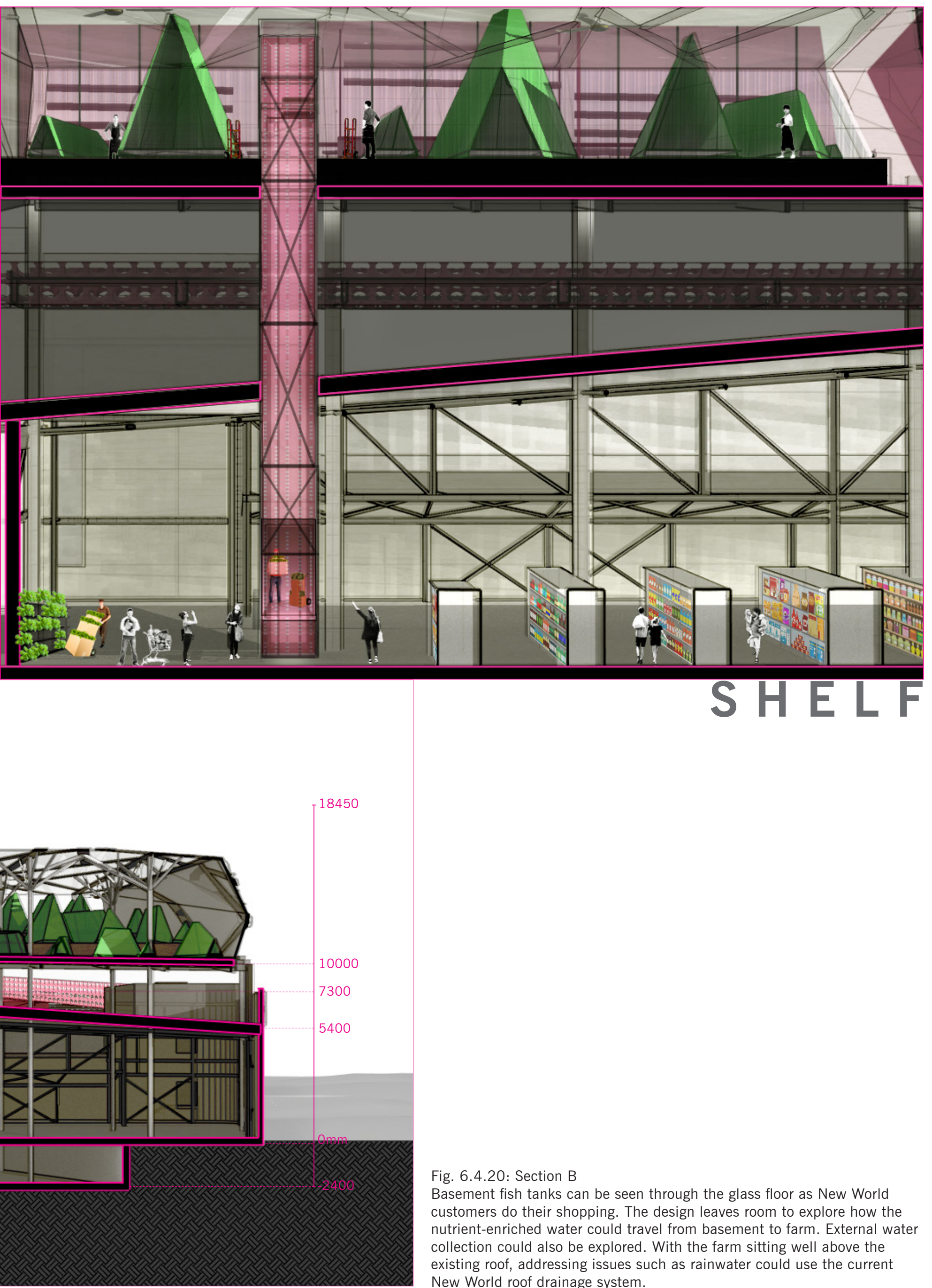

Fig. 6.4.20: Section B

Basement fish tanks can be seen through the glass floor as New World customers do their shopping. The design leaves room to explore how the nutrient-enriched water could travel from basement to farm. External water collection could also be explored. With the farm sitting well above the existing roof, addressing issues such as rainwater could use the current New World roof drainage system. 


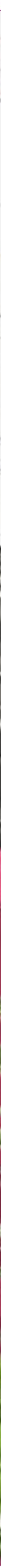

Fig. 6.4.21: The walkway serves many urban functions - including a farm. 
FINAL

DESIGN
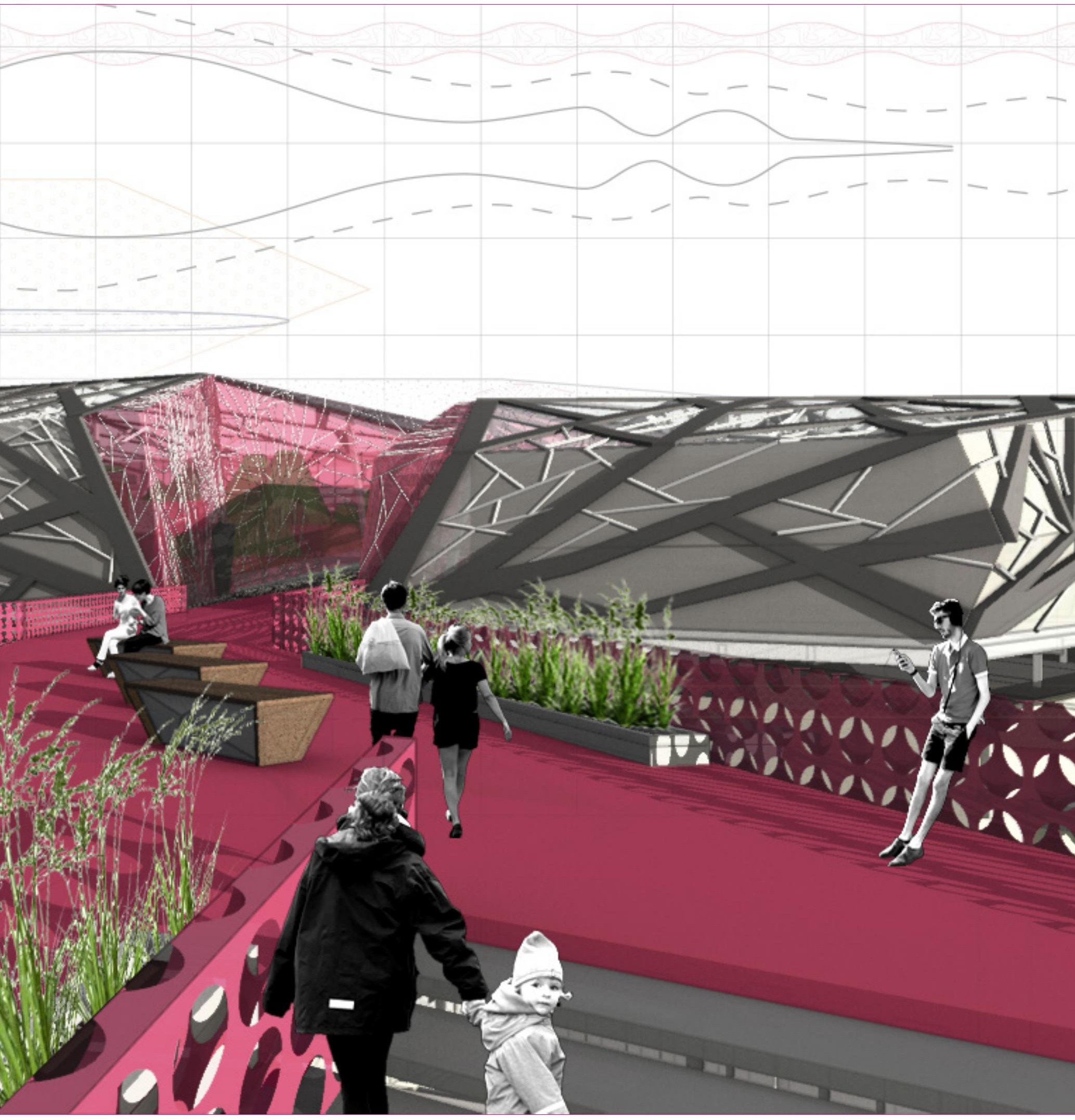


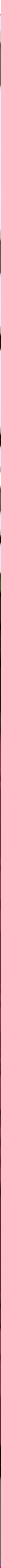


FINAL

DESIGN

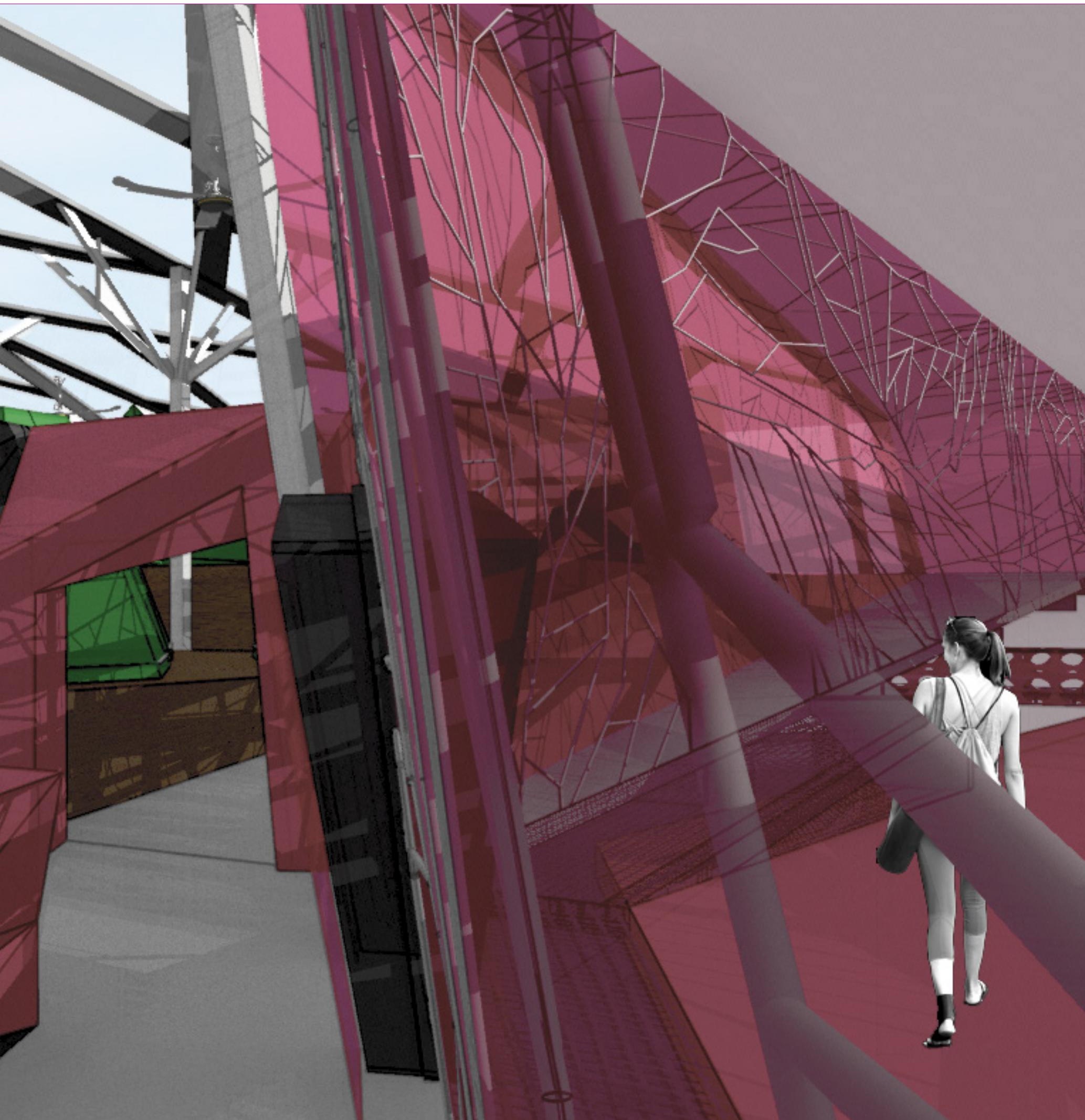




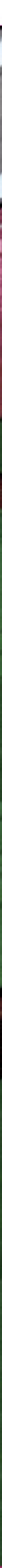


FINAL

DESIGN

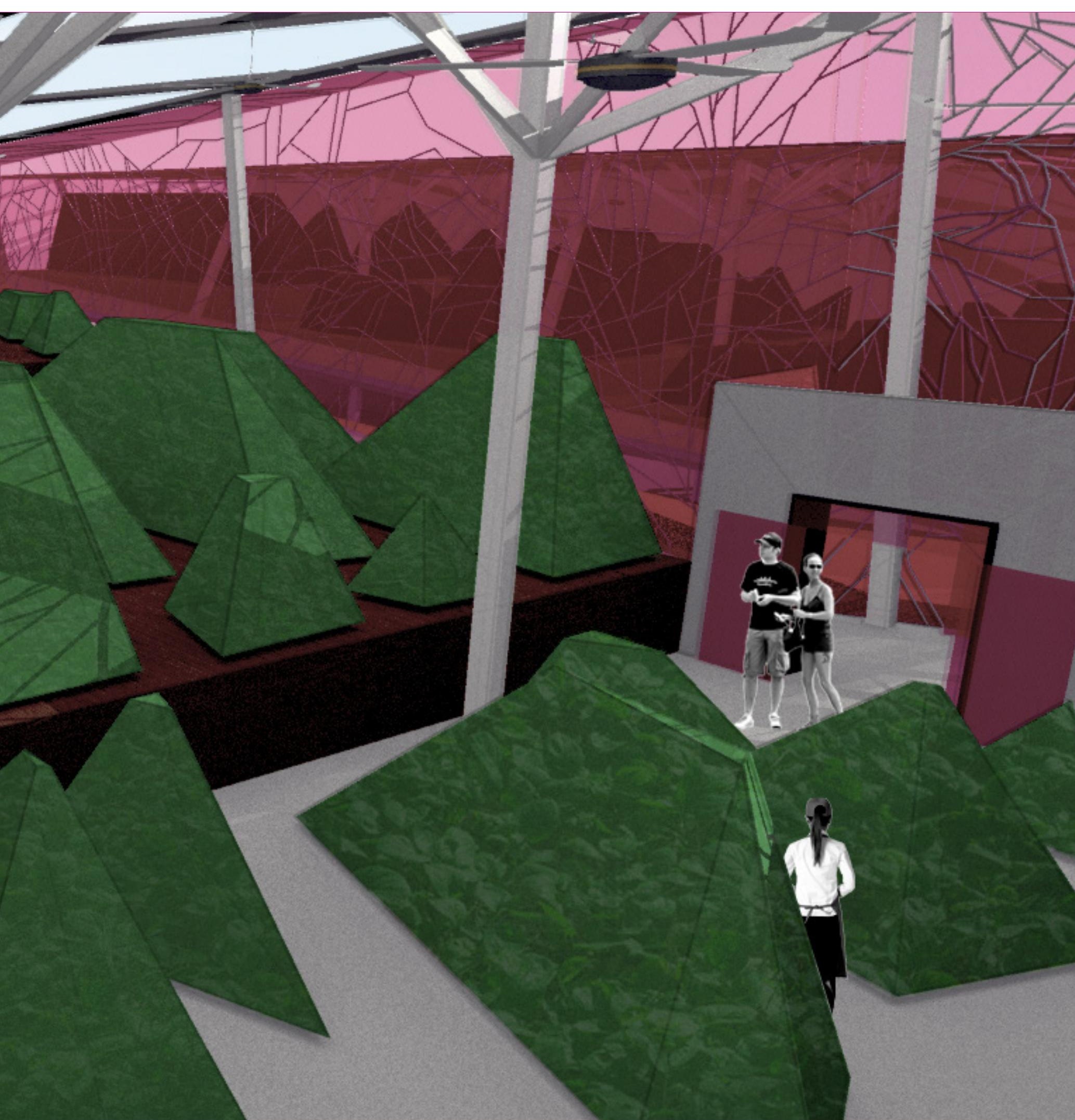



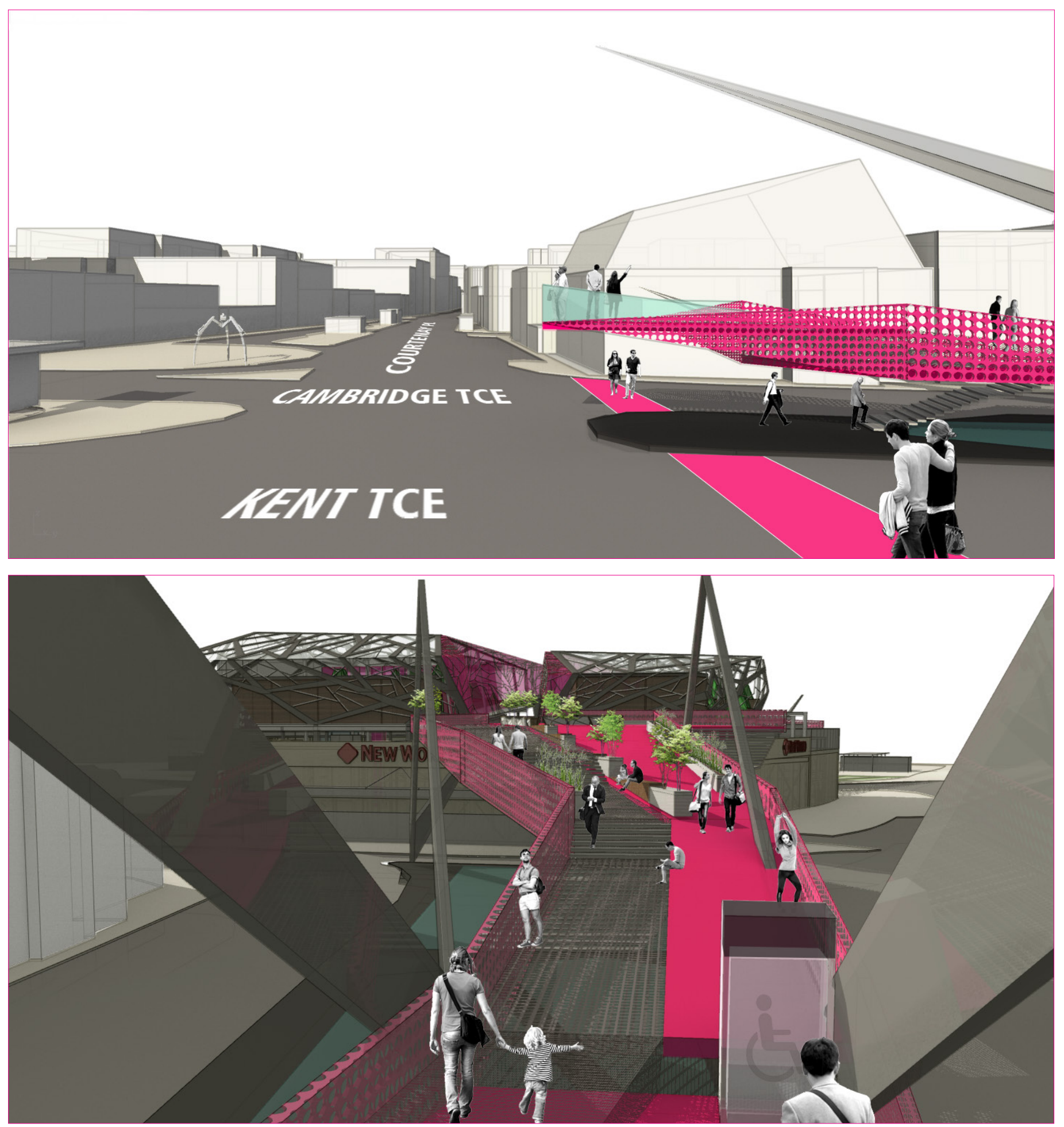

Fig. 6.4.24 (top): Crossing Kent and Cambridge terraces to access walkway entry point via stairs no. 1. Opportunity presented of applying colour to the pedestrian crossings to highlight route. Fig. 6.4.25 (bottom): View of walkway at bridge end. Water feature seen below. 
FINAL

\section{DESIGN}
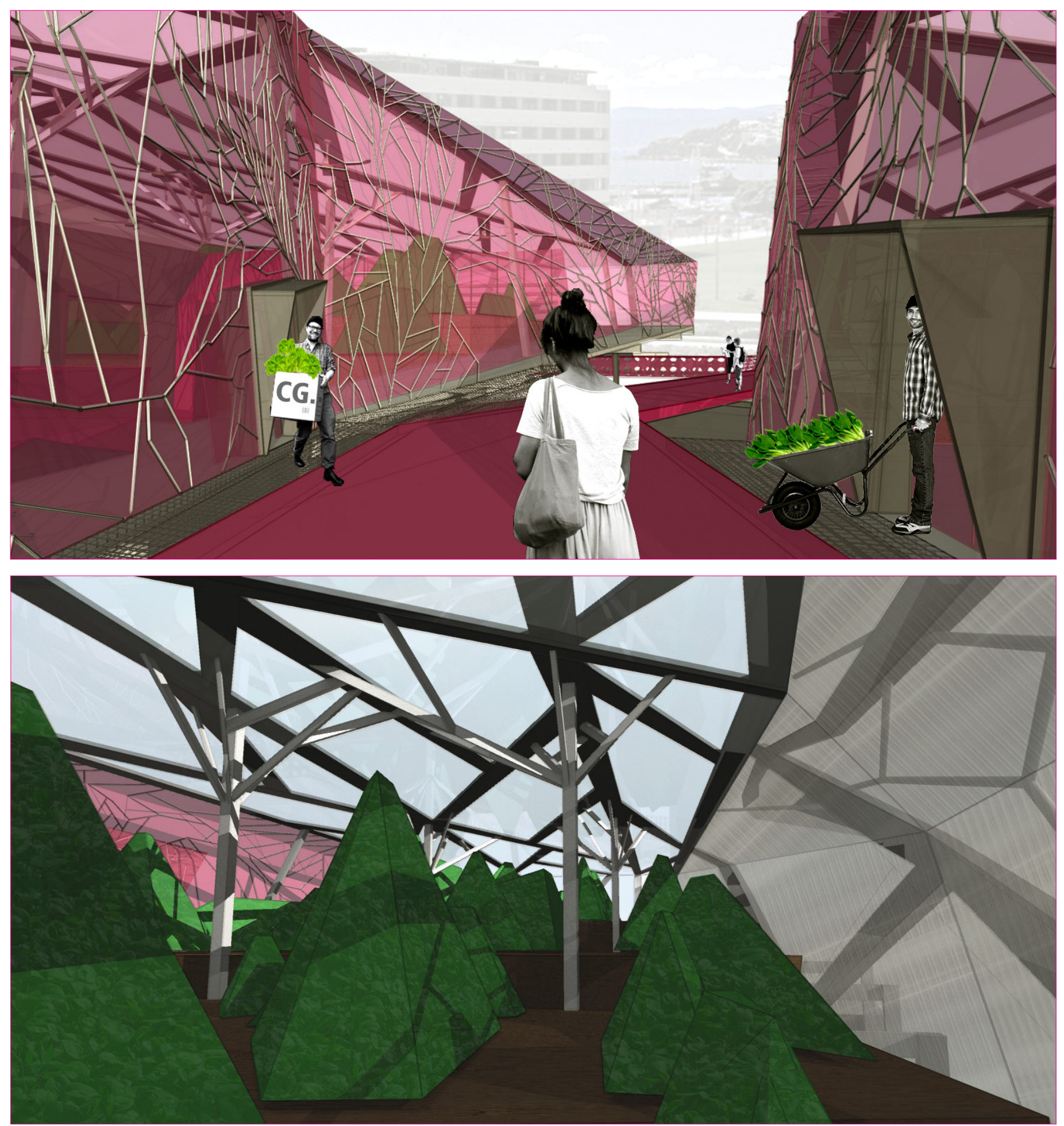

Fig. 6.4.26 (top): Approaching farm entry points. Throughout the day, employees at Capital Greens may move stock between each wing or enter/exit to make deliveries to local business, allowing a highly transparent program for the enjoyment and engagement of the public.

Fig. 6.4.27 (bottom): View inside farm (east wing). 

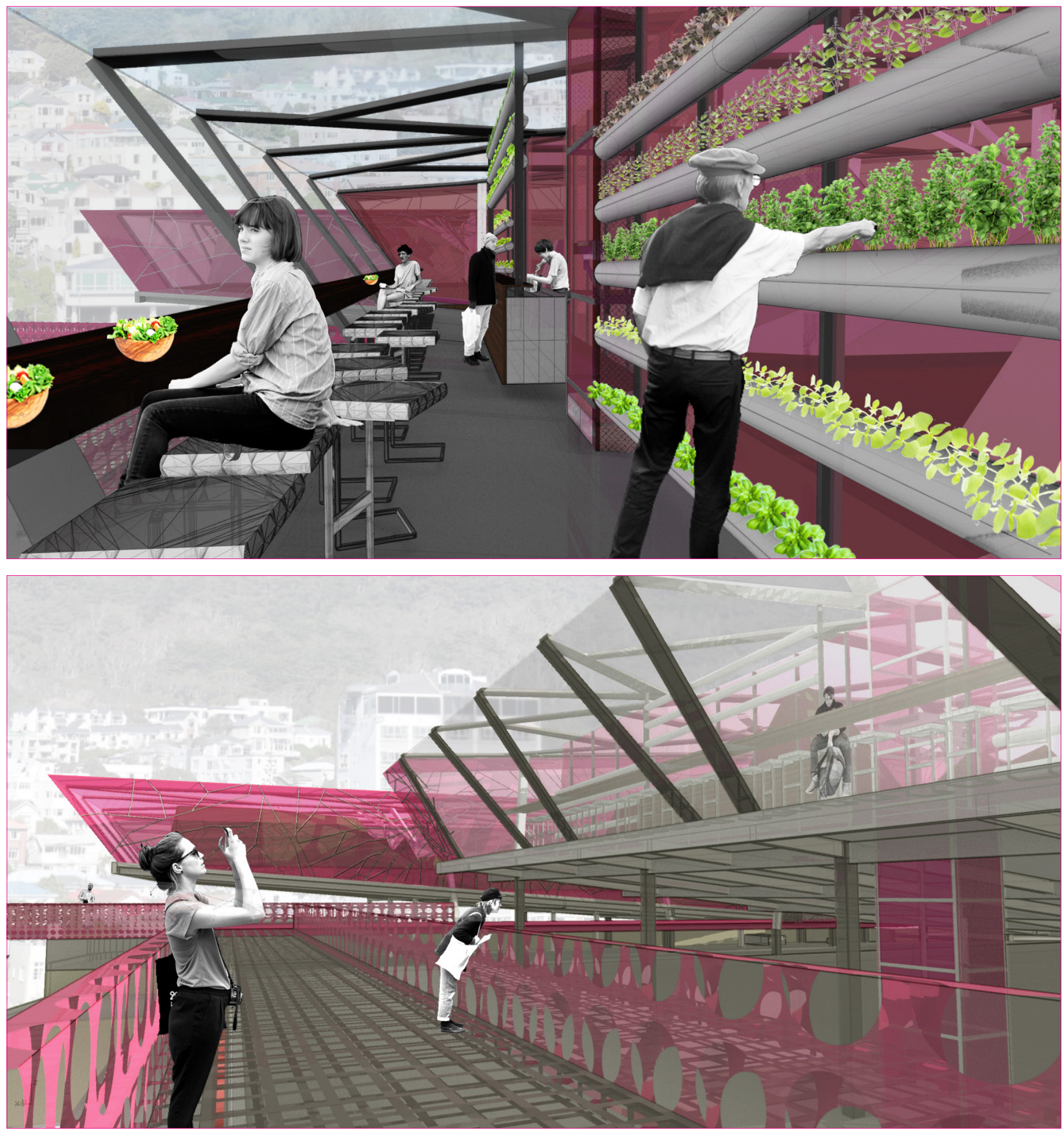

Fig. 6.4.28 (top): Salad Bar and Market Place. Upon purchasing a salad bowl from Capital Greens, customers are able to personalize meals with their favourite herbs. Furthermore they can enjoy views of the waterfront while indulging on green goodness. Mount Victoria is seen in the background.

Fig. 6.4.29 (bottom): The walkway connecting vertical access from New World provides views into the salad bar. This northern tapered end of the farm also allows views of the service lift running between farm to supermarket and structure supporting the rooftop addition. 
FINAL

\section{DESIGN}
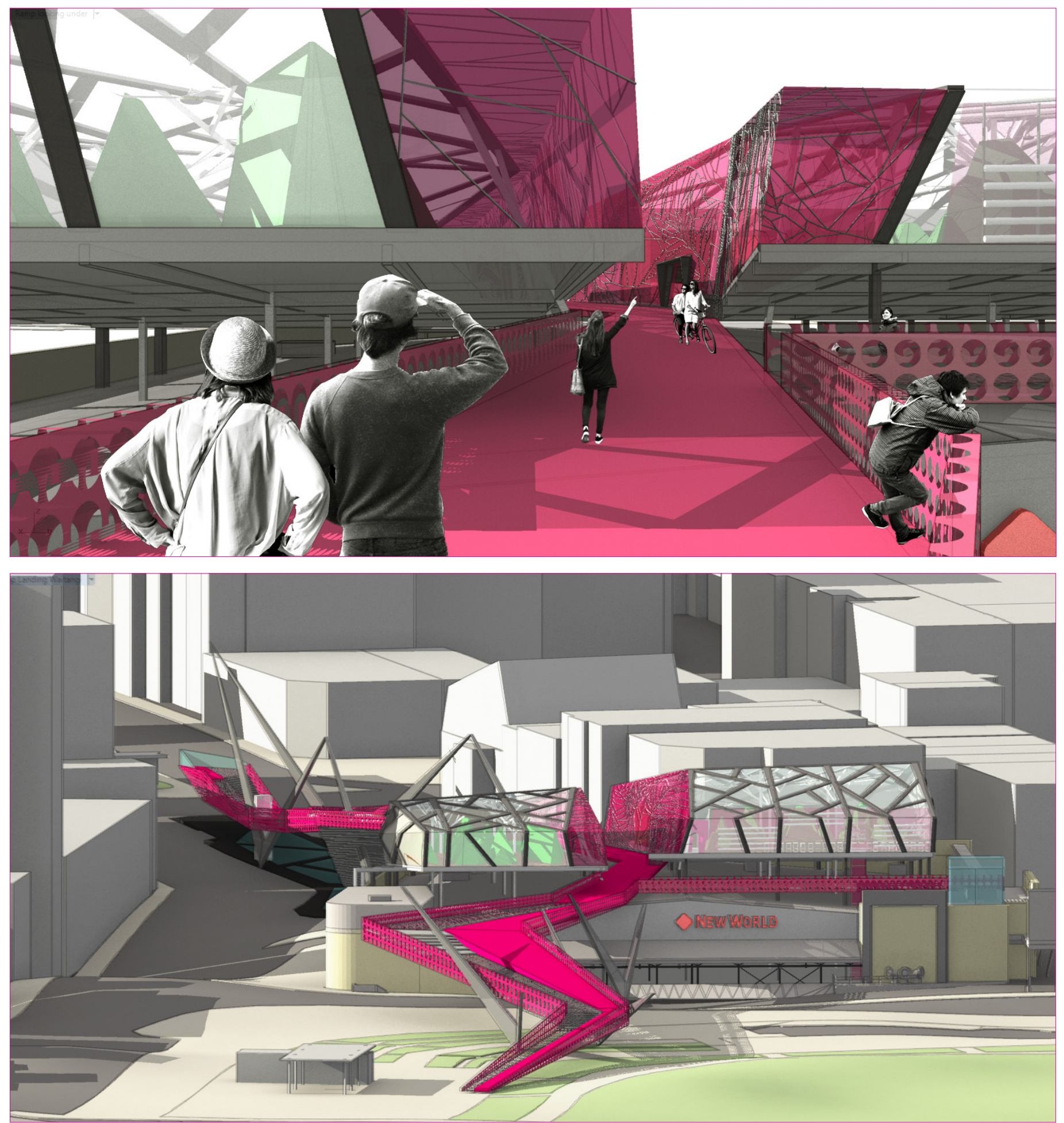

Fig. 6.4.30 (top): Approaching farm from ramp end (Waitangi Park).

Fig. 6.4.31 (bottom): View of New World and Capital Greens from the north where walkway ramp lands at Waitangi Park. This side of the walkway has admittedly received less design investigation in comparison to the bridge end in the overall case study. It will benefit from further study into how it meets the park program, especially with the wetlands. The existing kiosk and toilet block is seen to the left. 


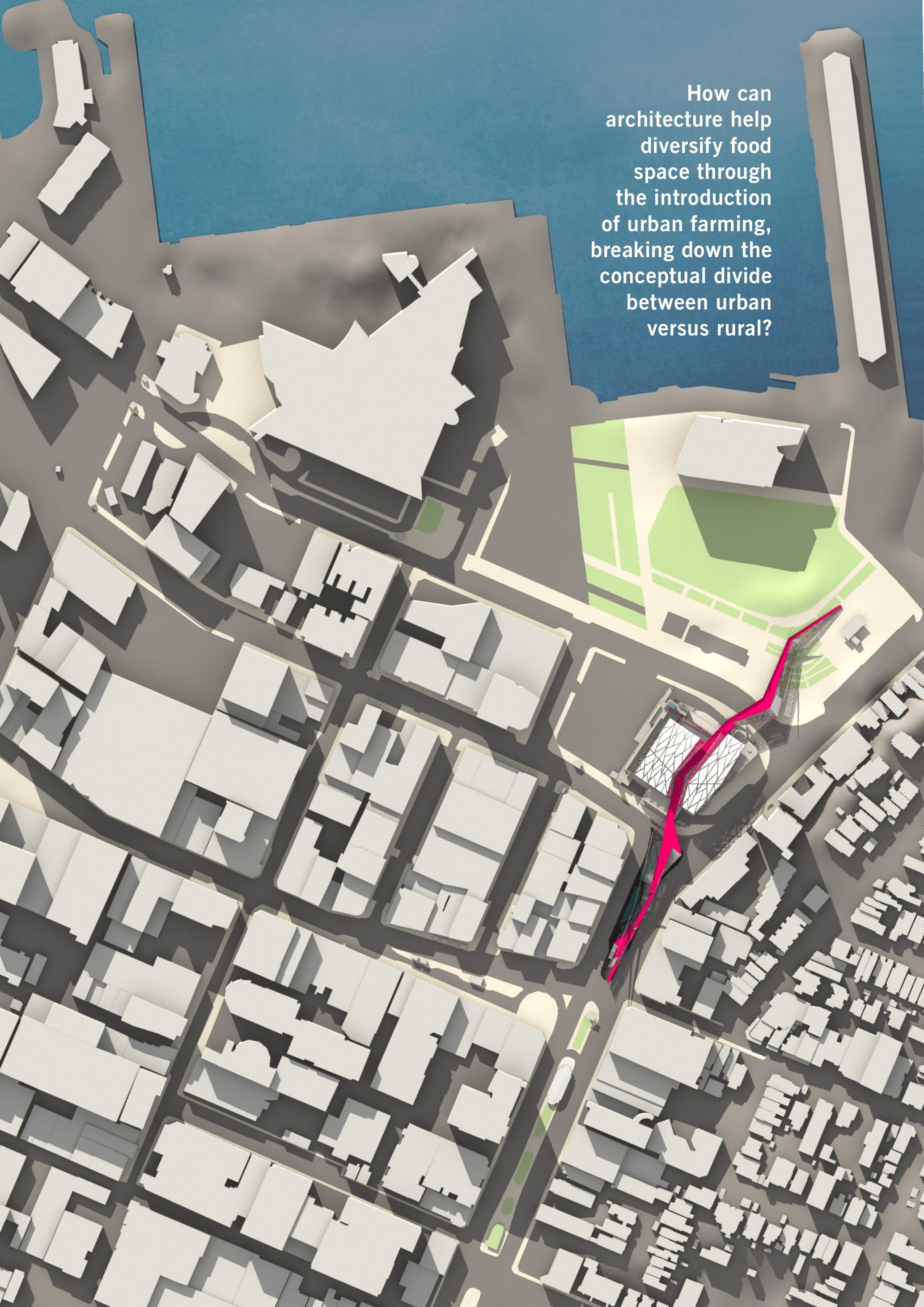




\section{[7.0] \\ CONCLUSION}

\section{EXEGESIS}

\section{Not Just About the Food}

The research through design indicates that urban farming when well-integrated into the complexities of the urban system can have lasting effects on the wider city, not just for those directly involved. The presence of a working farm, strengthened by architectural input illustrates the viability of production in an urban environment. But more importantly, when seen and encountered through the many interconnected activities of urban life, it encourages a new understanding of food and where it can and should be produced. The conceptual divide surrounding what activities ought to be 'urban' versus 'rural' could therefore decrease, as a primary step in changing the meaning of what it means to be 'urban' in the 21 st century. Additionally, it presents invaluable opportunities in developing a city's social, economic and environmental sustainability.

Across the three design scales investigated - the public realm/the building/the program architecture's role enhanced the physical presence of urban farms through a contextual response to site, a distinctive form identity and human engagement. This contributes to overall urban quality that in time could translate to a sense of place and local food identity. This is due to the heightened experience of urban farming where participation does not only include those who practice it, but simply share the same urban spaces. As a result, it has the potential to diversify conversations surrounding food beyond consumption among the wider public, to include awareness of food's production stage as well as consumption. This change in way of thinking diversifies urban food space at the core, meaning it is not just about producing adequate supplies of food, but recognizing the opportunities an urban farm presents for a more holistic outlook in designing cities. Architecture's role can therefore act as an agent towards promoting a dilusion of conceptual boundaries in redefining urban life.
The project initially considered a business focus, where the technicalities of farming operations were to be resolved. However throughout the course of the investigation, it became clear that the topic of food and the city is a much wider issue altogether that cannot solely be resolved with quantitative solutions of supply meets demand. The role of architecture was a valuable reminder that design intentions should not only focus inwardly on farming operations, but how they interrelate with existing urban activities to provide opportunities in making a place - largely depicted in the public realm as seen with the valuable walkway addition. Through this, opportunities of improving urban quality for a much wider audience are presented, while simultaneously promoting a local food identity through production on site. Ultimately, this is a much more valuable contribution to the topic of urban farming. Perhaps this could also indicate that 'demonstration farms' such as the resultant proposal of this thesis should co-exist with solely 'productive farms' throughout city rooftops as an approach to urban farming.

\section{Use of Rooftops}

The project has shown that the siting of a greenhouse as a rooftop addition is viable, given the host building is structurally capable, though certain rooftops present more opportunities for a successful integration into the city than others.

The original rooftop site selections of the Tory St car park along with New World supermarket was a result of their proximity to potential partner businesses, their locations being between city and water and to each other creating a "rooftop food network". But with the aim to have high pedestrian level exposure to an urban farm, it emerged that the New World site presented more urban development opportunities due to factors such as: its lower building height; its function as a popular inner city supermarket; its connective potentials to Waitangi Park/waterfront. The Tory car park being nine storeys high would have less capability in addressing urban issues. 
The implications are that the role of rooftop constructions depend on the pre-existing site conditions. Each new construction carries with it the responsibility of responding to site specific demands, where the role of design is fundamental. This is about the difference that a new program on a rooftop and its related activities could make at its location - about its ability to alter existing conditions for the betterment of the city. Suitably, New World supermarket as an existing urban food space happens to be at an undesirable location. Therefore it has benefited from testing an additional program on-site to improve conditions. The focus on food production on its rooftop as a tool for urban regeneration has been appropriate for this site.

The new urban connection created by crossing the rooftop of the supermarket is a valuable addition to Wellington, a city that already thrives on compactness and walkability. In turn, the enhanced mobility of the pedestrian benefits the farm by being exposed to it.

\section{Cross-Programming}

A large part of the investigation placed emphasis on resolving the farming program to meet with existing functions on/around its location. This included a cross-programming between three major functions on site: farming, supermarket shopping and using the walkway, each coexisting to support the other in its own mini system.

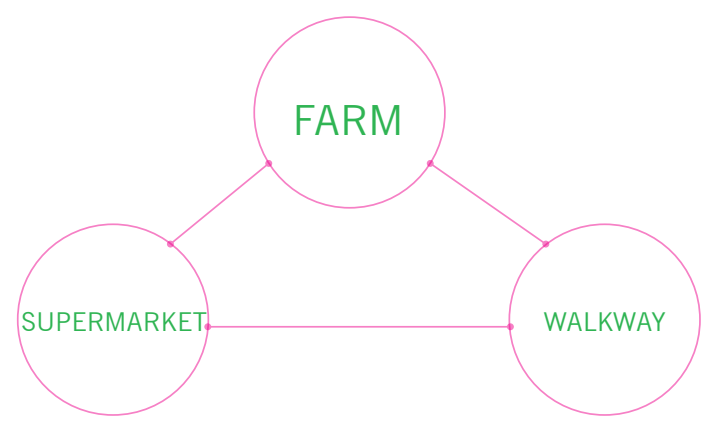

\section{Farm + Supermarket}

The supermarket as the host building offered an opportunity to innovate a connection between the two food spaces of consumption and production. A direct physical link such as the exposed service lift to New World's produce area means farming activities can still reach those consumers who are not actively participating in the farm itself, but rather they receive a degree of food education solely through witnessing the spectacle of their products descend from the farm. The practical logistics of circulation between supermarket and farm had been met with extending existing lifts and inserting a set of stairs in the New World foyer, making it easy for users on site to cross between programs at roof and ground level.

\section{Farm + Walkway}

The cross programming between the farm and walkway is a result of initial interest into the citywaterfront connection, while also addressing rooftop access to New World. Through utilizing the existing traffic island between Kent and Cambridge terraces, the walkway became a major design program in itself as a place that hosts a myriad of urban activities while providing a valuable route. This evidently developed into a significant contribution to the farm's city integration, linking the building's design with public realm considerations. The walkway functions not only as a path from one destination to another but fosters a social and cultural dimension at the site, supporting urban vitality and quality. The farm being almost a "feature" along the way profoundly benefits from this. Furthermore, the noticeably vibrant colour of the walkway (extending to the "cut" of the farm) adds to the identity of the new urban food space.

\section{Design Process}

Designing simultaneously between three different scales - urban (public realm), building (form) and program (human interaction) has been an invaluable approach for this investigation. This 
prevented the research from being entirely linear and allowed for opportunities to be presented that are open for further discussion. A mixed methods approach between intuitive and informed design decision-making worked well. Early stages involved more intuitive exercises through form sculpting/ pattern finding while during further development, digital tools were useful in realizing the details. Further physical modeling of the site and form (of bridge and building) could have affected the project, especially during iterations. This would have added more depth into preliminary investigations if time was invested into it.

\section{FUtURE DEVELOPMENT}

Though the proposal has reached a level of "final design" within the thesis timeframe, it is yet to be fully resolved with the many opportunities that had arisen during its inception. Its current state should instead be perceived as a foundation for further investigations. Some aspects that would benefit from this are the following:

\section{Waitangi Ramp Landing}

A large portion of design research into the walkway focused on the bridge end where access is available from Kent/Cambridge Terraces. The emphasis on designing to site specificity has not been extended to the Waitangi Park landing where there are existing wetlands and a mix of waterfront/park activities. Further development could begin from here.

\section{Kent and Cambridge Terraces}

The development of the terraces can be additionally explored with the introduction of an elevated landscape, especially pertaining to the wide traffic islands that stretch all the way down to the Basin Reserve. Currently they are unattractive, underutilized and underrealized. Extending the bridge south could be an option, though the space created below must also be addressed.
The specific technologies involved and its integration with architecture such as water circulation would be an interesting study, especially if the entire system were to be exposed to increase the spectacular of an aquaponic farm.

\section{Materiality and Structure}

The practical aspects of the project involving construction detailing can reach a higher level of resolution, increasing the project's viability.

\section{The Full Cycle}

Further research could address other stages of the food cycle through an architectural response - e.g. waste, being another major environmental/ sustainable issue. This would complete the main elements of the food cycle - from production to consumption to waste.

\section{FINAL SUMMARY}

In the current day, it is difficult to say if food production will ever be at the forefront of urban agendas, especially at an intensive/commercial scale when there continually exists more immediate demands. Change begins with the individual and their experiences. Architecture as a tool for designing urban farms can have a valuable influence as there is a direct connection with how one experiences a city. But it is only when all scales of design have been acknowledged that this will be effective in revealing a path towards a more sustainable food system. 


\section{LIST OF FIGURES}

All unlisted figures are produced by the author.

Fig. 1.1 Google. Google Maps. 2017. 2016. <www.google.co.nz/maps>.

Fig. 3.0 Lim, CJ. Food City. Abingdon: Routledge, 2014.

Fig. series Dezeen Magazine. Biasol Design Studio adds booths with pitched roofs to Melbourne

3.1

(left to right)

Fig. 3.2

(right)

Fig. 3.3

Fig. 3.4

Fig. 3.5

(left to right)

Fig. 3.6

Fig. 4.0

Fig. 4.1.2 Fig. 4.1.3- Mok, Kimberley. Fresh \& city-grown: Montreal's second rooftop urban farm opens. 16 August
$\begin{aligned} & \text { 4.1.4 2013. April 2016. < http://www.treehugger.com/green-food/second-lufa-farms- }\end{aligned}$ 4.1.4

Fig. 4.1.5

4.1.7

Fig. 4.1.8-

4.1.9

Fig. 4.1 .10

$-4.1 .11$

Fig. 4.1.12

$-4.1 .15$

Fig. series

4.1.19 restaurant. 2016. 01 July 2016. <http://www.dezeen.com/2016/06/25/biasoldesign-studio-kitty-burns-restaurant-interior-melbourne-australia-booths-pitchedroofs/>.

NZ Herald. Restaurant review: Tokyo Bay, Takapuna. 2016. 04 July 2016. <http://www. nzherald.co.nz/food-wine/news/article.cfm?c_id =206\&objectid $=11666125>$.

Home Magazine. A Cuba Street eatery brings new flavours to dining in the capital. 2016. 30 June 2016. <http://www.homestolove.co.nz/inside-homes/news/cuba-street-eaterybrings-new-flavours-dining-capital $>$.

Bhansali, Monisha. A peek at the eco friendly smart city of Paris of the future. 2015. 01 July 2016. <http://luxurylaunches.com/real_estate/a-peek-at-the-eco-friendly-smart-cityof-paris-of-the-future.php>.

Lufa Farms Inc. Lufa Farms. 2014. 22 May 2016. <https://lufa.com/en/>.

Dezeen. "EFFEKT designs ReGen villages that could produce all their own food and energy." 20 May 2016. Dezeen Magazine. 18 June 2016. <http://www.dezeen. com/2016/05/20/effekt-designs-regen-villages-produce-own-food-energy-danishpavilion-venice-architecture-biennale-2016/> .

Greig and Stephenson. Borough Market, London. 2014. 03 July 2016. <http://www.gands. co.uk/projects/3/42/markets/borough-market-london.html>.

Holbrook, Ben. La Boqueria Food Market Barcelona Spain. 2014. 02 July 2016. < http:// www.driftwoodjournals.com/la-boqueria-food-market-barcelona-spain/>.

Montgomery, John. "Making a city: Urbanity, vitality and urban design." Journal of Urban Design 3.1 (1998): 93-116.

Lufa Farms. Yellow Cocktail Tomato Row, Lufa Farms Laval. 13 May 2013. April 2016. <https://www.flickr.com/photos/94385898@N05/8904958812>.

Food Urbanism. Lufa Prototype Farm. 4 July 2011. May 2016. <http://www.foodurbanism. rooftop-urban-farm-opens-laval-quebec-canada.html>.

Rathmell, Lauren. Happy (Happy Happy Happy) New Year! 30 Dec 2016. Jan 2017. $<$ https://montreal.lufa.com/en/blog/articles/happy-happy-happy-happy-new-year>.

Gotham Greens Farms LLC. Our Farms. May 2016. May 2016. <http://gothamgreens.com/ our-farms/gowanus>.

Brooklyn Grange. Farms. April 2016. April 2016. <http://www.brooklyngrangefarm.com/ farms-1/>.

GrowUp Urban Farms Ltd. Aquaculture. 2014. March 2016. <http://growup.org.uk/all-posts/ photos-and-videos/gallery/unit-84/aquaculture/>.

a) Abokezo Supplier. Hydroponic System. 2016. May 2016. <http://www.abokezosupplier. dekorplast.us/product-tag/hydroponic-system.abokezo>.

b) Pegasus Agriculture. Pegasus Agriculture Farms. 2015. May 2016. <http:// pegasusagriculturegroup.com/gallery/>.

c) Upchurch, Deanna. Different Ways to Grow Food: All You Need is Water, Sun and Nutrients. 
14 April 2015. May 2016. <https://greeningforward.org/different-ways-to-growfood-all-you-need-is-water-sun-and-nutrients/>.

d) Beautiful Gardens. What is hydroponic gardening? May 2016. June 2016. < http:// beautiful-gardens.com/what-is-hydroponic-gardening/>.

e) Designboom. selgascano: between air in the spanish pavilion at the venice biennale 2012 . 29 Aug 2012. May 2016. <http://www. designboom.com/architecture/selgascanobetween-air-in-the-spanish-pavilion-at-the-venice-biennale-2012/>.

f) Hirschler, Harriet. Let's Go Outside | Outdoor Educational Spaces for Children. 2014. April 2016. <https://www.countryandtownhouse.co.uk/culture/lets-go-outside-outdooreducational-spaces-for-children/>.

g) Alamy Stock Photo. Stock Photo - Hydroponics Strawberry Farming in Ruskin Florida Tampa Hillsborough County Gulf West Central. 2016. May 2016. <http:// www.alamy.com/stock-photo-hydroponics-strawberry-farming-in-ruskin-florida-tampahillsborough-11668126.html>.

h) Open Source Ecology. Hydroponics. 29 Jan 2016. March 2016. <http:// opensourceecology.org/wikiHydroponics $>$.

i) Designboom. selgascano: between air in the spanish pavilion at the venice biennale 2012 . 29 Aug 2012. May 2016. <http://www.designboom.com/architecture/selgascano between-air-in-the-spanish-pavilion-at-the-venice-biennale-2012/>.

j) Creativities. 20 + Cool Vertical Garden Ideas. 03 May 2016. June 2016. <https:// coolcreativity.com/handcraft/cool-vertical-garden-ideas/3/>.

k) City Farmer News. Time Magazine names Valcent's Vertical Farming Technology one of Top 50 Best Innovations of 2009. 20 Nov 2009. April 2016. <http://www.cityfarmer. info/2009/11/20/time-magazine-names-valcents-vertical-farming-technology-one-of top-50-best-innovations-of-2009/>.

Fig. series Lim, CJ. Food City. Abingdon: Routledge, 2014.

4.1.20

Fig. 4.1.21 Aprilli. Urban Skyfarm. 2014. May 2016. <http://www.aprilli.com/urban-skyfarm/>.

Fig. 4.1.22 Alter, Lloyd. Vertical Farm in Dubai Uses Seawater. 05 March 2009. June 2016. <http:// www.treehugger.com/sustainable-product-design/vertical-farm-in-dubai-usesseawater.html>.

Fig. 4.1.23 Wang, Lucy. Visionary Homefarm combines retirement homes and vertical urban farms. 18 Nov 2015. April 2016. <http://inhabitat.com/visionary-homefarm-combinesretirement-homes-and-vertical-urban-farms/>.

Fig. 4.1.24 Work Architecture Company. Locavore Fantasia. 2008. May 2016. <http://work.ac/locavorefantasia/>.

Fig. 4.1.25 World Landscape Architecture. Urban Food Jungle | AECOM. 2012. June 2016. <http://worldlandscapearchitect.com/urban-food-jungle-aecom/\#. WIQqDbFh0xE>.

Fig. 4.1.26 Designboom. Vincent callebaut architectures: dragonfly vertical farm concept in new york. 18 May 2009. April 2016. <http://www.designboom.com/architecture/vincent callebaut-architectures-dragonfly-vertical-farm-concept-in-nyc/>.

Fig. 4.2.1 Designboom. Herzog \& de meuron's elbphilharmonie moves to completion ahead of 2017 opening. 10 Feb 2016. June 2016. <http://www.designboom.com/architecture/ herzog-de-meuron-elbphilharmonie-hamburg-concert-hall-germany-02-10-2016/> .

Fig. 4.2.2 ArchDaily. Zaha Hadid Architects' Antwerp Port House Photographed by Laurian Ghinitoiu. Sep 2016. Sep 2016. <http://www.archdaily.com/795890/gallery-zaha-hadid- 
architects-antwerp-port-house-photographed-by-laurian-ghinitoiu > .

Fig. 4.2.3 Designboom. Elevated urban hut proposed for the rooftops of athens. 09 Jan 2015. June 2016. <http://www.designboom.com/architecture/deltarchi-panos-dragonas-varvarachristopoulou-detached-urban-hut-athens-01-09-2015/>

Fig. 4.2.4 Designboom. Snøhetta cantilevers metallic steel extension in norwegian art museum. $21 \mathrm{Dec}$ 2016. Dec 2016. <http://www.designboom.com/architecture/snohetta-lillehammerart-museum-extension-norway-12-21-2016/>.

Fig. 4.2.5 Tonkin Liu. Growing House. 2015. May 2016. <http://www.tonkinliu.co.uk/projects/growinghouse $>$.

Fig. 4.2.6 Ong, Rob. DVF Studio by Work Architecture Company. 04 Aug 2008. May 2016. <https:// www.dezeen.com/2008/08/04/dvf-studio-by-work-ac/>.

Fig. 4.2.7 Park Associati. Priceless Milano. May 2016. May 2016. < http://www.parkassociati.com/EN/ Projects/projects/2015/priceless_p2307.aspx>.

Fig. 4.2.8 Renzo Piano Building Workshop. Lingotto Factory Conversion. May 2016. May 2016. < http:// www.rpbw.com/project/62/lingotto-factory-conversion/ > .

Fig. 4.2.9 Coop Himmelb(I)au. Rooftop Remodeling Falkestrasse. 2012. April 2016. <http://www.coophimmelblau.at/architecture/projects/rooftop-remodeling-falkestrasse $>$.

Fig. 4.2.10 Grist, Michael John. Asahi Flame, Asakusa. 30 March 2009. May 2016. <http://www. michaeljohngrist.com/2009/03/asahi-flame-asakusa/>.

Fig. 4.2.11 Detail. A Parasite for Rotterdam. 2002. June 2016. <http://www.detail-online.com/ inspiration/a-parasite-for-rotterdam-106657.html>.

Fig. 4.3.1 Designboom. Section 2 of the high line now open in new york. 09 June 2011. May 2016. <http://www.designboom.com/architecture/section-2-of-the-high-line-now-open/>.

Figs. 4.3.2 Winston, Anna. The High Line is a "pulling-back from architecture" say Diller and Scofidio.

+ 4.3.4 O3 Nov 2014. May 2016. <https://www.dezeen.com/2014/11/03/elizabeth-dillerricardo-scofidio-interview-high-line-new-york/>.

Fig. 4.3.3 Heijn, Dan. The High Line, New York. June 2016. June 2016. <http://www. urbangreenbluegrids.com/projects/the-high-line-new-york/>.

Fig. 4.3.6 Arch Centre. Launch Pad 5: City to Sea bridge. May 2015. June 2016. <http://architecture. org.nz/2015/05/21/launch-pad-5-city-to-sea-bridge/>.

Figs. 4.3.7 Divisare. Mount Fuji Architects Studio. December 2010. July 2016. <https://divisare.com/

- 4.3 .8

Figs. 4.4.2

$-4.4 .3$

Fig. 4.4 .4

Figs. 4.4.5

- 4.4 .6

Figs. 4.4.7 Burch, Unna. Best Ugly Bagels + an interview with Al Brown | Part 1. 01 Aug 2016. Sep

- 4.4.9 2016. <http://www.theforestcantina.com/single-post/2016/08/01/Best-Ugly-Bagelsan-interview-with-Al-Brown-part-1>.

Fig. 5.1 Wellington City Council. Wellington City Council WebMap. June 2016. June 2016. < http:// wellington.govt.nz/webmap/wccmap.html>.

Fig. 5.1.1 a) The Arborist. Rooftop Bar. July 2016. July 2016. <http://www.thearborist.co.nz>.

b) Dirty Little Secret. Functions \& Events. July 2016. July 2016. < http://dirtylittlesecret. co.nz>.

c) Inter-bar. Baseque Rooftop Bar Wellington NZ. July 2016. July 2016. <http://www.interbar.com/listing/basque-rooftop-bar-wellington-nz>.

d) WellingtonNZ. New city watering holes. 16 May 2016. July 2016. <http://www. 
wellingtonnz.com/discover/word-on-the-street/eat-and-drink/new-city-wateringholes/>.

Fig. 5.1.3 National Library. Southern part of Kent and Cambridge Terraces, Wellington. Evening post (Newspaper. 1865-2002) : Photographic negatives and prints of the Evening Post newspaper. Ref: 1/2-090001-G. Alexander Turnbull Library, Wellington, New Zealand. <http://natlib.govt.nz/records/22433150>

Fig. 5.1.4 National Library. Kent Terrace and Oriental Parade, Wellington. Ref: 1/2-116556-F. Alexander Turnbull Library, Wellington, New Zealand. <http://natlib.govt.nz/ records/22838426>

Fig. 5.1.5 Google. Google Maps. 2017. 2016. <www.google.co.nz/maps>.

Fig. 5.3.4 - Wellington City Council. Wellington City Council WebMap. June 2016. June 2016. <http://

5.3.5

Fig. series

6.1 wellington.govt.nz/webmap/wccmap.html>.

b) Winston, Anna. The High Line is a "pulling-back from architecture" say Diller and Scofidio. 03 Nov 2014. May 2016. <https://www.dezeen.com/2014/11/03/elizabeth-dillerricardo-scofidio-interview-high-line-new-york/>.

c) Grist, Michael John. Asahi Flame, Asakusa. 30 March 2009. May 2016. <http://www. michaeljohngrist.com/2009/03/asahi-flame-asakusa/>

d) Divisare. Mount Fuji Architects Studio. December 2010. July 2016. <https://divisare.com/ projects/150159-mount-fuji-architects-studio-secondary-landscape $>$.

e) Rathmell, Lauren. Happy (Happy Happy Happy) New Year! 30 Dec 2016. Jan 2017. <https://montreal.lufa.com/en/blog/articles/happy-happy-happy-happy-new-year>.

f) Greig and Stephenson. Borough Market, London. 2014. 03 July 2016. <http://www.gands. co.uk/projects/3/42/markets/borough-market-london.html>.

Fig. 6.2.2 Google. Google Maps. 2017. 2016. <www.google.co.nz/maps>.

Fig. 6.2.4 Rathmell, Lauren. Happy (Happy Happy Happy) New Year! 30 Dec 2016. Jan 2017. $<$ https://montreal.lufa.com/en/blog/articles/happy-happy-happy-happy-new-year>.

Fig. 6.4.5 Doucleff, Michaeleen. Sky-High Vegetables: Vertical Farming Sprouts In Singapore. 09 Nov 2012. Oct 2016. <http://www.npr.org/blogs/thesalt/2012/11/06/164428031/skyhigh-vegetables-vertical-farming-sprouts-in-singapore?live $=1 \% 3$ Futm source\%3DNPR\&utm_medium =facebook\&utm_campaign $=20121109>$.

Fig. 6.4.6 Beautiful Gardens. What is hydroponic gardening? May 2016. June 2016. <http://beautifulgardens.com/what-is-hydroponic-gardening/ 


\section{BIBLIOGRAPHY}

Arch Centre. Launch Pad 5: City to Sea bridge. May 2015. June 2016. <http://architecture.org. nz/2015/05/21/launch-pad-5-city-to-sea-bridge/>.

Augé, Marc. Non-Places: Introduction to an Anthropology of Supermodernity. London: Verso, 1995.

Bhansali, Monisha. A peek at the eco friendly smart city of Paris of the future. 2015. 01 July 2016. <http:// luxurylaunches.com/real_estate/a-peek-at-the-eco-friendly-smart-city-of-paris-of-the-future.php> .

Castle, Helen. "Editorial." Architectural Design: Food + Architecture 72.6 (2002): 4.

Centre for Active Design. The High Line. 2016. July 2016. <https://centerforactivedesign.org/high-line/>. Clouse, Carey. "Cuba's Urban Farming Revolution: How to Create Self-Sufficient Cities." 17 March 2014. The Architectural Review. 18 June 2016.

—. Farming Cuba: Urban Agriculture from the Ground Up. New York: Princeton Architectural Press, 2014.

Cullen, Gordon. The Concise Townscape. Abingdon: Routledge, 1971.

Dalton, Lon and Rob Smith. Hydroponic Gardening: A practical guide to growing plants without soil. Tauranga: Hydroponic Developments Ltd, 2003.

Despommier, Dickson. The Vertical Farm: Feeding the world in the 21st Century. New York: Thomas Dunne Books, 2010.

Dezeen. Biasol Design Studio adds booths with pitched roofs to Melbourne restaurant. 2016. 01 July 2016. <http://www.dezeen.com/2016/06/25/biasol-design-studio-kitty-burns-restaurant-interiormelbourne-australia-booths-pitched-roofs/>.

—. "EFFEKT designs ReGen villages that could produce all their own food and energy." 20 May 2016. Dezeen. 18 June 2016. <http://www.dezeen.com/2016/05/20/effekt-designs-regen-villagesproduce-own-food-energy-danish-pavilion-venice-architecture-biennale-2016/>.

Divisare. Mount Fuji Architects Studio. December 2010. July 2016. <https://divisare.com/projects/150159mount-fuji-architects-studio-secondary-landscape $>$.

Doron, Gil. “Urban Agriculture: Small, Medium, Large.” Architectural Design: Food + the City (2005): 5259.

Esperdy, Gabrielle. "Edible Urbanism." Architectural Design: Food + Architecture 72.6 (2002): 44-50.

Franck, Karen A. "Food for the City, Food in the City." Architectural Design: Food + the City 75.3 (2005): 35-42.

—. "The City as Dining Room, Market and Farm." Architectural Design: Food + the City 75.3 (2005): 5-10.

—. "The Space of Food." Architectural Design: Food + Architecture 72.6 (2002): 5-13.

George, Evan. "The Urban Agriculture Movement: History and Current Trends." 2015. Michigin State University College of Law. 20 June 2016. <https://www.law.msu.edu/clinics/food/UrbanAgMvmnt. pdf $>$.

Gotham Greens Farms LLC. Gotham Greens. 2016. 20 May 2016. <http://gothamgreens.com/>.

GreenTech. Q and A with Lauren Rathmell, Greenhouse Director \& Founding Member of LUFA farms. March 2016. June 2016. <http://www.greentech.nl/greentech-news/greentech-qa-with-laurenrathmell/>.

Greig and Stephenson. Borough Market, London. 2014. 03 July 2016. <http://www.gands.co.uk/ projects/3/42/markets/borough-market-london.html>.

Harper, Jenny and Aaron Lister. Wellington: A City for Sculpture. Wellington: Victoria University Press, 2007.

Holbrook, Ben. La Boqueria Food Market Barcelona Spain. 2014. 02 July 2016. <http://www. driftwoodjournals.com/la-boqueria-food-market-barcelona-spain/>.

Home Magazine. A Cuba Street eatery brings new flavours to dining in the capital. 2016. 30 June 2016. $<$ http://www.homestolove.co.nz/inside-homes/news/cuba-street-eatery-brings-new-flavoursdining-capital $>$.

Jacobs, Jane. The Death and Life of Great American Cities. New York: Random House, 1961. 
—. The Economy of Cities. New York: Random House, 1969.

Lange, Michiel de. Review: Kevin Lynch - The Image of the City. 08 May 2009. Dec 2016. <http:// themobilecity.nl/2009/05/08/review-kevin-lynch-the-image-of-the-city/>.

Lim, CJ and Ed Liu. Smartcities + Eco-warriors. Abingdon: Routledge, 2010.

Lim, CJ. Food City. Abingdon: Routledge, 2014.

Lufa Farms Inc. Lufa Farms. 2014. 22 May 2016. <https://lufa.com/en/>.

Lynch, Kevin. The Image of the City. London: The MIT Press, 1960.

Melet, Ed and Eric Vreedenburgh. Rooftop Architecture: Building on an Elevated Surface. Rotterdam: NAi Publishers, 2005.

Montgomery, John. "Making a city: Urbanity, vitality and urban design." Journal of Urban Design 3.1 (1998): 93-116.

NZ Herald. Restaurant review: Tokyo Bay, Takapuna. 2016. 04 July 2016. <http://www.nzherald.co.nz/ food-wine/news/article.cfm?c_id=206\&objectid=11666125>.

Oldenburg, Ray. The Great Good Place: Cafés, coffee shops, bookstores, bars, hair salons and other hangouts at the heart of a community. New York: Da Capo Press, 1999.

OMA. Yokohama Masterplan. June 2016. June 2016. <http://oma.eu/projects/yokohama-masterplan>.

Pothukuchi, Kameshwari and Jerome L. Kaufman. "Placing the Food System on the Urban Agenda: The role of municipal institutions in food systems planning." Agriculture and Human Values 16.2 (1999): 213-224.

Rashbrooke, Max. "The truth about Wellington's food markets." FishHead Magazine (2012): 32-34.

Royte, Elizabeth. "Urban farming is booming, but what does it really yield?" 27 April 2015. Ensia. 18 June 2016. <http://ensia.com/features/urban-agriculture-is-booming-but-what-does-it-really-yield/>.

Smith, Rose Hayden. Sowing the Seeds of Victory: American Gardening Programs of World War I. North Carolina: McFarland \& Company, 2014.

Steel, Carolyn. Hungry City: How Food Shapes Our Lives. London: Chatto \& Windus, 2008.

United Nations. Population Division. 2016. 16 June 2016. <https://esa.un.org/unpd/wup/>.

Upstart Business Journal. Lufa Farms practices agriculture for geeks. October 2012. April 2016. <http:// www.bizjournals.com/bizjournals/topic/startups?page $=$ all $>$.

Wigglesworth, Sarah. "Cuisine and Architecture." Architectural Design: Food + Architecture 72.6 (2002): 102-105.

Winston, Anna. The High Line is a "pulling-back from architecture" say Diller and Scofidio. November 2014. June 2016. <https://www.dezeen.com/2014/11/03/elizabeth-diller-ricardo-scofidiointerview-high-line-new-york/>. 


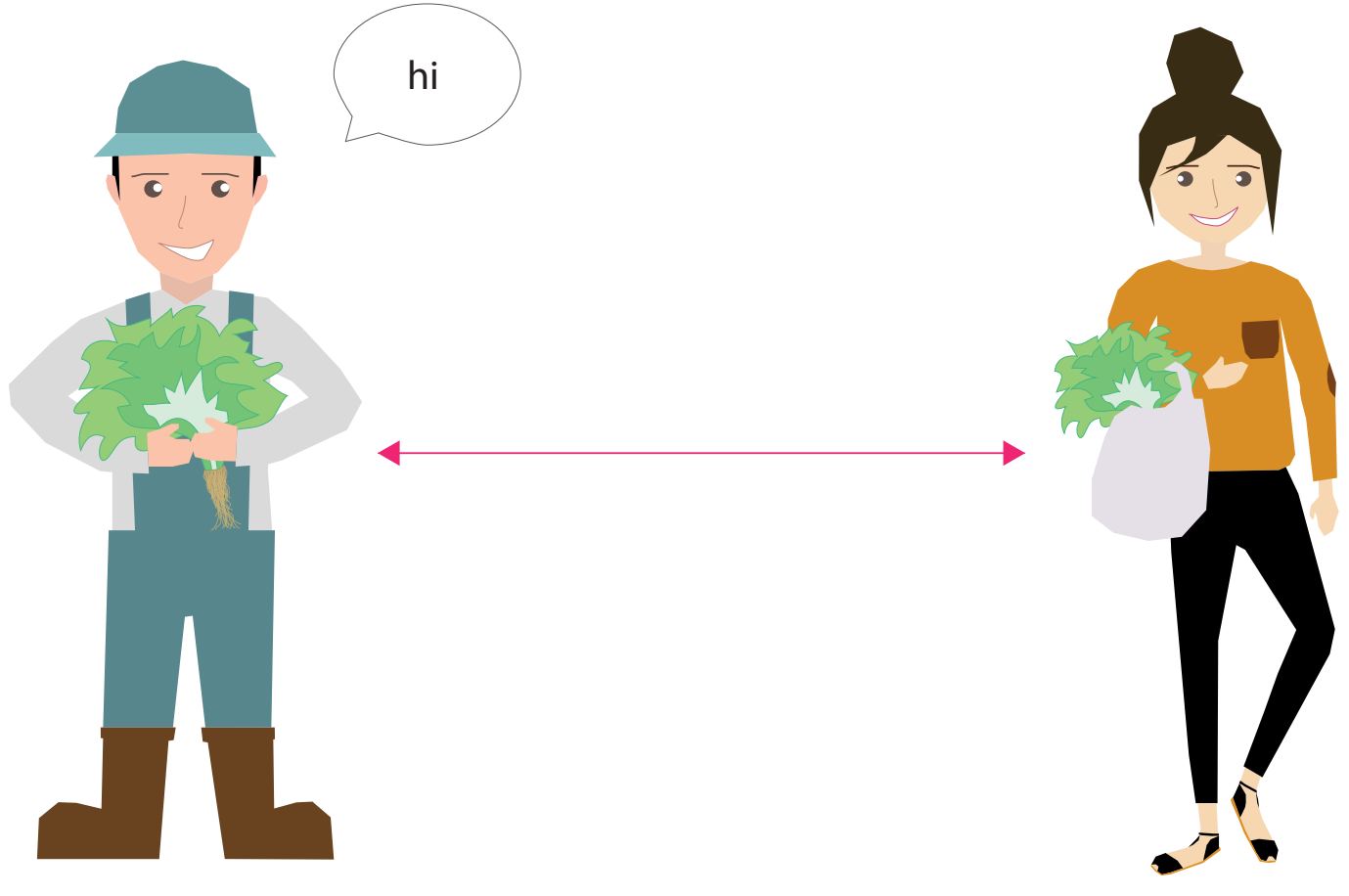

